\title{
DOE/MC/24257--5067
}

\section{INTEGRATED LOW EMISSIONS CLEANUP SYSTEM FOR DIRECT COAL FUELED TURBINES \\ (Moving Bed, Fluid Bed Contactor/Ceramic Filter)}

Twenty-Ninth Quarterly Report
RECEIVED

JAN 301996

O S.T.I

Quarterly Status Report for the Period October - December 1994

\section{By}
R. A. Newby
M. A. Alvin
D. M. Bachovchin
W. C. Yang
E. E. Smeltzer
T. E. Lippert, Project Mgr.

Work Performed under Contract: DE-AC21-87MC24257

For

\author{
U. S. Department of Energy \\ Office of Fossil Energy \\ Morgantown Energy Technology Center \\ Morgantown, West Virginia \\ DOE - COTR: H. McDaniel \\ Prepared by \\ Westinghouse Electric Corporation \\ Science and Technology Center \\ Pittsburgh, Pennsylvania
}




\section{DISCLAIMER}

This report was prepared as an account of work sponsored by an agency of the United States Government. Neither the United States Government nor any agency thereof, nor any of their employees, makes any warranty, express or implied, or assumes any legal liability or responsibility for the accuracy, completeness, or usefulness of any information, apparatus, product, or process disclosed, or represents that its use would not infringe privately owned rights. Reference herein to any specific commercial product, process, or service by trade name, trademark, manufacturer, or otherwise does not necessarily constitute or imply its endorsement, recommendation, or favoring by the United States Government or any agency thereof. The views and opinions of authors expressed herein do not necessarily state or reflect those of the United States Government or any agency thereof.

This report has been reproduced directly from the best available copy.

Available to DOE and DOE contractors from the Office of Scientific and Technical Information, 175 Oak Ridge Turnpike, Oak Ridge, TN 37831; prices available at (615) 576-8401.

Available to the public from the National Technical Information Service, U.S. Department of Commerce, 5285 Port Royal Road, Springfield, VA 22161; phone orders accepted at (703) 487-4650. 


\begin{abstract}
The United States Department of Energy, Morgantown Energy Research Center (DOE/METC), is sponsoring the development of advanced, coal-fueled turbine power plants such as pressurized fluid bed combustion and coal gasification combined cycles. A major technical challenge remaining for the development of the coal-fueled turbine is high-temperature gas cleaning to meet environmental standards for sulfur oxides and particulate emissions, as well as to provide acceptable turbine life.

The Westinghouse Electric Corporation, Science \& Technology Center, is evaluating Integrated Low Emissions Cleanup (ILEC) concepts that have been configured to meet this technical challenge. These ILEC concepts simultaneously control sulfur, particulate, and alkali contaminants in the high-pressure process gases. This document reports the status of a program in the twenty-seventh quarter to develop this ILEC technology.
\end{abstract}




\section{EXECUTIVE SUMMARY}

During the Twenty-Ninth Quarter of the program, the Phase III bench-scale, hightemperature, high-pressure (HTHP) testing of PFBC fly ashes was continued. A Total of two additional tests have been completed to characterize the filter cake pulse cleaning with a high source pressure as a function of temperature. The behavior trends continue to be consistent with field unit observations. A complete summary of the test procedures; tests completed and test results is presented in Appendices A and B. Preparation has been made for upcoming sulfur removal tests. The detailed sulfur removal test matrix is included in this report. 


\section{INTRODUCTION}

Development of coal-fueled turbine power cycles, in the Department of Energy programs, is focused on IGCC and Advanced-PFBC designs that potentially provide high performance, compact and low cost power generation systems. The power generation systems demand high performance from hot-gas cleaning equipment to meet environmental requirements.

To provide emissions control and turbine protection from gas- and solid-phase contaminants in coal-fired turbine systems, contractors are currently testing ceramic barrier filters for particle control and separate stages of cleanup equipment for sulfur, alkali, and other gas-phase contaminant control. Performance and economic concerns make the development of an integrated, low emission, gas cleanup (ILEC) concept desirable.

In this program, two high-temperature Integrated Low Emissions Cleanup concepts are addressed that combine particulate and gas phase contaminant removal in a single, compact filter device that is intended for operation in coal-fueled turbine systems. The program will investigate the key process and design parameters of the concepts, evaluating both a ceramic barrier filter and a fluid bed filter with immersed barrier filters. In both concepts, finely sized sulfur and alkali sorbents are injected into the process gas stream, react with the gas-phase sulfur and alkali species while modifying the nature of the fly ash that is carried over from the gas product. Additives may also be injected to aid the filter performance. Sorbent and ash particles are collected on ceramic barrier filter elements in the contactor vessel. 
The program has been divided into three phases. Phase I of the program deals with critical laboratory testing and conceptual commercial design evaluation. Phase I has been completed and work on the fluid bed filter has been terminated. In Phase II, upgrading of a HTHP bench-scale facility has taken place and a test program has been developed to examine the performance of ILEC sulfur and alkali removal, and the filter cake permeability and pulse cleaning behavior, all under conditions simulating the PFBC environment. Phase III of the program, the HTHP bench-scale testing and engineering assessment, is now in progress. 


\section{WESTINGHOUSE ILEC CONCEPTS}

The Westinghouse ILEC concepts are extrapolations of gas cleaning technologies being developed for similar technical purposes in other applications. These technologies are:

- ceramic barrier filter particulate control (up to $1700^{\circ} \mathrm{F}$ )

- fluidized bed filtration (up to $1200^{\circ} \mathrm{F}$ )

- sulfur sorbent injection into high-temperature gas streams (up to $3000^{\circ} \mathrm{F}$ ), and fluidized bed desulfurization (up to $2000^{\circ} \mathrm{F}$ )

- alkali sorbent injection into high-temperature gas streams (up to $1600^{\circ} \mathrm{F}$ ) These technologies are being developed for applications that require high-pressure gas cleaning at temperatures up to about $1700^{\circ} \mathrm{F}$ (pressurized fluid bed combustion and pressurized coal gasification).

Ceramic barrier filters have the potential to provide extremely high particle removal efficiencies at high gas temperatures. Testing at temperatures up to $1700^{\circ} \mathrm{F}$ has shown that they can exceed the particulate removal needed for both environmental standards and for turbine erosion and deposition protection. One concern for their use is that adhesive particles (slag particles or sticky fly ash particles) might be emitted that may form a filter cake that is difficult to remove from the filter elements by normal pulse cleaning. It is an objective of the IIEC concepts proposed in this program that the process gas containing adhesive particles will interact with added sorbent particles, or inert additive particles, to either remove the adhesive particles before they reach the ceramic barrier filter elements, or to modify the filter cake adhesive nature so that it is removable. This premise is applied in the two ILEC concepts pictured in Figures 2.1 and 2.2. 
In the first concept shown in Figure 2.1, the "baseline" ILEC concept, is a ceramic barrier filter vessel having a design much like that of the ceramic barrier filters vessels being developed for particulate control only. An array of vertical filter elements, candle-type or crossflow type, is supported from a tube sheet, and is housed in a refractory-lined pressure vessel. Filter cake is periodically released from the filter elements by back-pulsing with clean gas. The released filter cake drops into a conical bin at the base of the vessel for removal. The baseline ILEC concept is operated with the injection of sulfur sorbents, alkali sorbents, and possibly selected deposit-modifying additives (e.g., kaolin) that produce a filter cake on the filter elements that is easily removed by pulsed cleaning. The potential success of the baseline $\mathbb{I L C}$ concept is suggested by deposit formation observed in other programs that inject sulfur sorbents into conventional coal-fired furnaces, and programs that have injected deposit additives into coal-fired turbine gases. 4,5,6 The injected sulfur sorbents are -325 mesh calcium-based sorbents, or advanced sulfur sorbents (strontium carbonate, for example), that effectively capture $\mathrm{SO}_{2}$ at the turbine inlet temperatures in the relatively short contact times available. The injected alkali sorbent is -325 mesh emathlite, hectorite, or others, that removes alkali species (sodium and potassium components) from the gas to meet projected turbine alkali limits. The effectiveness of emathlite has been demonstrated at a small-scale at temperatures up to about $1600^{\circ} \mathrm{F}$ in both reducing and oxidizing gases. ${ }^{7}$ Other alkali sorbents such as hectorite and bauxite are also candidates.

The second ILEC concept, in Figure 2.2, is a fluid bed filter concept. In this concept the combustion products are passed through a fluidized bed of either inert particles or sulfur sorbent particles. The adhesive particles agglomerate with the fluid bed media, removing them from the gas. The effectiveness of fluidized bed filters for particle removal by agglomeration phenomena has been demonstrated in other development programs at lower temperatures. Ceramic candle filters are vertically immersed into the 


\section{WESTINGHOUSE ILEC CONCEPT}

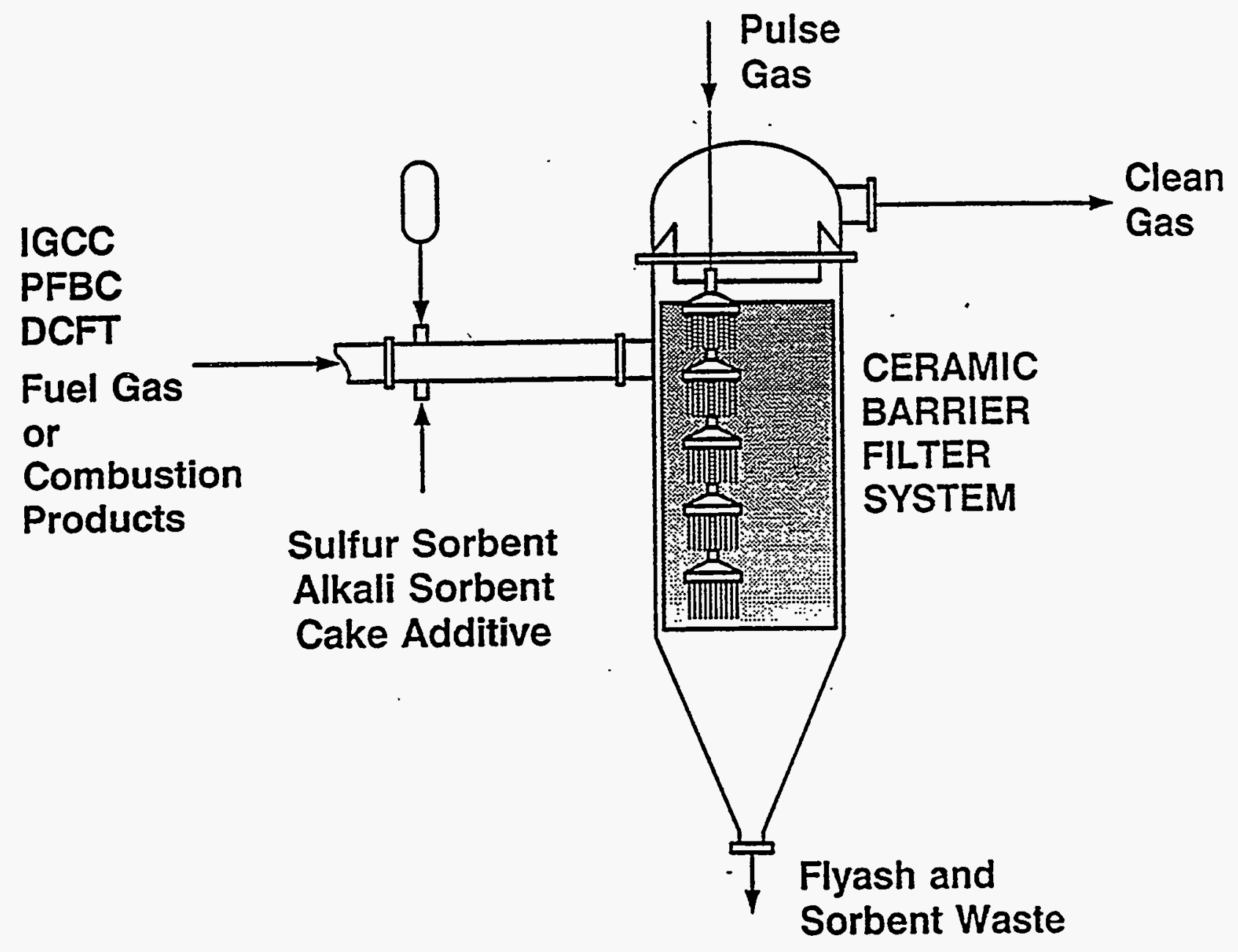

Figure 2.1 - Baseline ILEC Concept 
D.9. 4282893

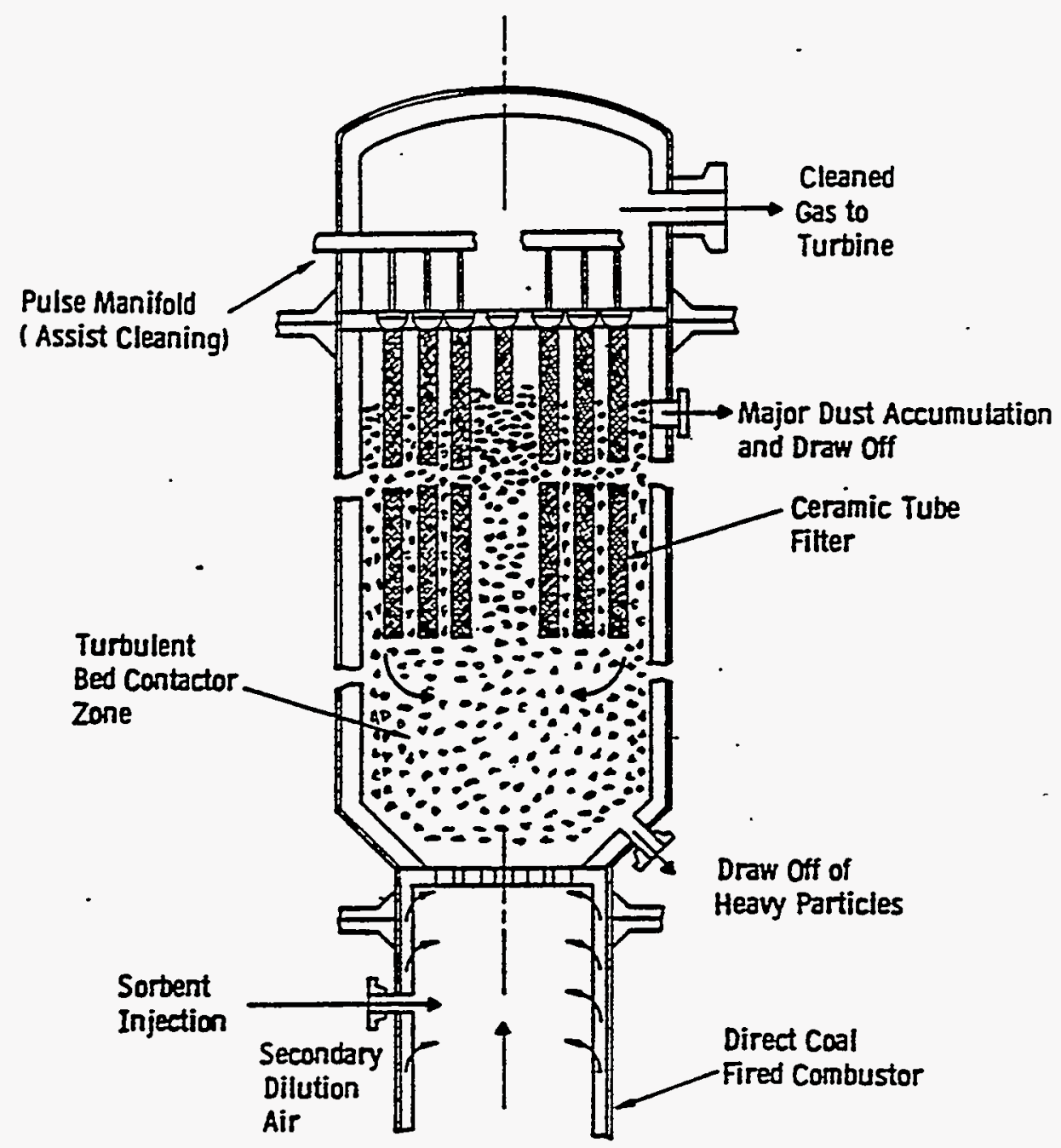

Figure 2.2 - Fluid Bed ILEC Concept 
fluid bed to prevent the elutriation of coarse particles, or the entrainment of fine particles from the fluid bed. In addition, the mixing action of the fluid bed provides cleaning of the filter cake from the ceramic candle filter surfaces, resulting in the potential elimination, or minimization, of the pulsed gas filter cleaning system. A similar fluid bed filter concept, using immersed candle filter elements in the bed, has been previously proposed for use in catalytic reactor systems. ${ }^{8}$

The fluid bed media has a particle size similar to particles used in bubbling PFBC applications. The fluid bed media if inert could be either alumina, sintered dolomite, slag particles generated in the combustor, or fly ash particles generated from the plant solid waste. The most economical material is used. If the fluid bed media is to function as a sulfur sorbent, it would be a cheap, calcium-based material such as dolomite. Sulfur sorbent particles and alkali sorbent particles can also be injected into the gas stream prior to the fluid bed filter.

The gas distributor for the fluid bed requires a design that is free from plugging of the orifice holes. Prior technology development suggests that water cooling, or air cooling, of the distributor plate to some critical temperature, combined with the selection of large orifices having sufficiently high gas velocities will provide protection against deposit formation and plugging. The resulting fluid bed is relatively compact because the immersed ceramic candle filters permit the size of the freeboard region above the fluid bed to be minimized. The captured adhesive particles are removed with a continuous underflow stream of bed media. Fine particles that are not adhesive in nature will tend to segregate to the top of the fluid bed where they can be separately removed from the vessel. 


\section{$\underline{\text { References }}$}

1. Patch, K. D. and W. E. Cole, Fluidized-Bed Waste-Heat Recovery System Development, Final Report, June 1988, DOE/D/12302-9.

2. Bower, J. R., Assessment of Strength Limiting Flaws in Ceramic Heat Exchanger Components, Phase II, Dec. 1987, DOE/ID/12566-2.

3. Coombs, M. G., et al., High-Temperature Ceramic Recuperator and Combustion Air Burner Programs, Annual Report to GRI, April 1982, GRI-82/0015.

4. Logan, R. G., et al., A Study of Techniques for Reducing Ash Deposition in Coal-Fired Gas Turbines, Presented at the 197th ACS National Meeting, Dallas, TX, April 1989.

5. Spiro, C. L., et al., Deposit Remediation in Coal-Fired Gas Turbines Through the Use of Additives, Presented at the 197th ACS National Meeting, Dallas, TX, April 1989.

6. Horner, M. W., et al., GE Gas Turbine Environmental and Deposition Control, Proceedings of the Annual Coal Fuel Heat Engineers and Gas Stream Cleanup Systems Contractors Review Meeting, DOE/METC-88/6094, June 1988.

7. Bachovchin, D. M., et al., A Study of High-Temperature Alkali Removal in a Pressurized Gasification System, Final Report, 1986, DOE/MC/20050-2226.

8. Degnen, W. J., et al., U.S. Patent 2,548,875, Contacting Gases and Solids, April 1951. 


\section{PROGRAM STRUCTURE AND OBJECTIVES}

The program is being conducted in three phases to demonstrate at the bench scale the IIEC concepts. Phase I of the program has been completed. Phase I of the program dealt with laboratory sorbent screening tests, cold flow testing, and commercial system evaluation of the ILEC concepts to support the bench-scale facility design and testing in Phases II and III. In Phase II, upgrading of a HTHP facility was completed along with the design.and procurement of the filter test systems. The bench-scale test program utilizes an existing, high temperature, high pressure (HTHP) facility located at the Westinghouse Science and Technology Center. This facility is being used in Phase III to test the performance of the baseline ILEC system and to verify its engineering design principles. 


\section{SUMMARY OF TWENTY-NINTH QUARTER PROGRAM STATUS}

\section{1 - PHASE I CONTINUATION: SUPPLEMENTAL LAB-SCALE TESTING}

Objectives: Conduct laboratory testing that supports the bench-scale facility design and operation, as well as testing of critical fluid bed ILEC concept issues.

\section{OBJECTIVE I-1 - TEST PLAN DEVELOPMENT}

Identify areas requiring supplemental laboratory testing to support the bench-scale facility modification design and operation. Include critical issues for fluid bed IIEC concept. Define detailed test plan for each supplemental area. The test plan shall be reviewed and approved by the DOE COR.

Status

The test plan development has been completed. 


\section{OBJECTIVE I-5.1 - ENTRAINED SULFUR REMOVAL}

Conduct tests of HTHP sulfur removal in the existing entrained reactor at specific test conditions to optimize sorbent properties and operating conditions for effective sulfur removal, as detailed in the Objective I-1 test plan.

Scope

Conduct tests to measure sulfur removal kinetics with the specific sulfur removal sorbents to be used in bench-scale testing. Preliminary range of test conditions:

- 1850 to $2100^{\circ} \mathrm{F}$

- calcium-based sorbents (limestone, dolomite, hydrated lime)

- 0.1 to 1 second gas residence time

- oxidizing conditions

- sorbent particle size a parameter

Analyze the reaction products and the kinetic data. Confirm the existing entrained sulfur removal model by evaluation of known DCFT test data. Select the sulfur sorbent types, sizes and feed rates to be used in the bench-scale testing.

Status

This testing has been completed, with an option to return to complete some critical testing if needed at a later date. The data collected has been combined with past data, including DCFT tests reported by Solar Turbines, and an evaluation has been completed. Commercial ILEC sulfur removal performance has been projected. The sulfur removal evaluation was presented in the Twelfth Quarterly Report. 


\section{OBJECTIVE I-5.2 - ALKALI REMOVAL}

Modify the entrained reactor and conduct tests, as detailed in the Objective I- 1 test plan, of HTHP alkali removal at specific conditions to optimize sorbent properties and operating conditions for effective alkali removal.

Scope

Design the entrained reactor modification required to test alkali removal kinetics.

Modify the equipment. Conduct tests to measure alkali removal kinetics with the specific alkali removal sorbents to be used in bench-scale testing. Preliminary range.of test conditions:

- 1850 to $2100^{\circ} \mathrm{F}$

- emathlite and hectorite sorbents

- 0.1 to 1 second gas residence time

- oxidizing and reducing conditions

- sorbent particle size a parameter

Analyze the reaction products and the kinetic data, and re-assess the existing entrained alkali removal model. Select the alkali sorbent types, sizes and feed rates to be used in the bench-scale testing.

\section{$\underline{\text { Status }}$}

A total of 22 tests have been conducted in the program, with temperatures of 1850 and $2100^{\circ} \mathrm{F}$, and $\mathrm{NaCl}$ vapor contents ranging from 1.3 to 112 ppmw. Two operating modes of testing were used to assess the relative contributions of the entrained and the cake removal. In all of the tests the gas-particle contact time in the entrained zone was 2 seconds, and in the cake zone the particles resided for 15 minutes. The test results 
have been reported in the 15 th and 16 th Quarterly Reports. Conversions up to 9.24 weight percent of the emathlite reaction product were measured, almost $50 \%$ of the saturation conversion of emathlite. In general, the performance under entrained conditions was better than with a cake only. The results have been correlated and estimates of commercial alkali removal performance in the ILEC have been developed. The complete evaluation will be reported in the task topical report currently in preparation. 


\section{OBJECTIVE I-5.3 - ADDITIVE SELECTION AND PERFORMANCE}

Select deposit additives for the specific operating conditions, coal ash types, alkali and sulfur sorbents to be used in the bench testing. Confirm additive effectiveness in furnace tests.

Scope

Use prior test results and thermodynamic phase diagrams to select economical additives for filter cake modification. Procure these additives. Conduct fumace tests with the mixtures to confirm their performance.

$\underline{\text { Status }}$

This objective has been reduced in scope to a minimum effort of identifying appropriate additives for Phase 3 testing. Some preliminary filter cake additive tests completed in a test unit very similar in design to the bench-scale unit under construction were evaluated and reported in the 21st Quarterly Report. 


\section{OBJECTIVE I-5.4 - FLUID BED CONCEPT CRITICAL ISSUES TESTING}

Design, construct, and operate cold flow hydrodynamic simulation of fluid bed filter based on Phase I commercial conceptual design.

$\underline{\text { Scope }}$

Identify critical issues, including distributor design, ash-bed separation, entrained sorbent mixing in the bed, filter element movement, filter element self-cleaning, element arrangement, etc. Include continuous ash feeding and ash removal capabilities. Eliminate fluidized slugging bed behavior by sizing gas flow to near 1000 actual cubic foot per minute. Prepare detailed design and assemble the facility. Select and procure commercial candle elements. Conduct tests as detailed in the Objective I-1 test plan. Re-assess critical issues and re-evaluate commercial design concept. Develop test plan for HTHP fluid bed testing.

\section{$\underline{\text { Status }}$}

In prior cold model testing effective design and operating conditions have been identified. The major feature remaining to be developed is the removal of the fly ash particles from the fluid bed filter. The fluid bed filter concept appears to be of significant interest to some high-temperature applications:

- applications of relatively small gas flow where the tube sheet required to support the single layer of ceramic candles does not become too large in diameter to be practical;

- applications having primarily "sticky" fly ash particles that will be substantially removed by injection into the fluid bed media. 
The small-scale, industrial DCFT applications such as those of Solar Turbine and Allison Gas Turbine appear to fit this description. The ability to simulate sticky fly ash particle behavior in the cold model, while possible, would be very uncertain, and it seems likely that cold model testing will not be appropriate for the development needed for this process. Hot testing of the concepts is needed under simulated DCFT conditions. 


\section{OBJECTIVE I-6 - TOPICAL REPORTS}

Prepare a Phase I Technical Report detailing the supplemental lab-scale efforts and two topical reports, i.e., High Temperature, High Pressure Deposit Additives; and Sorbents for High Temperature, High Pressure Vaporous Alkali Species Removal.

\section{Status}

Topical reports are scheduled near the completion of the appropriate Objectives. No topical reports have been completed during this quarter. 


\section{2 - PHASE II: BENCH-SCALE FACILITY DESIGN AND FABRICATION}

\section{OBJECTIVE II-1 - TEST PLAN DEVELOPMENT}

Update from Phase I the test plan for the bench-scale facility test program based on the Westinghouse baseline ILEC concept. Include integrated particle, sulfur, and alkali removal performance, deposit additive characteristics of the filter cake, pressure drop, cleaning, and materials.

\section{Scope}

Estimate test conditions to evaluate the performance of simulated coal-fired turbine operation with the Westinghouse baseline IIEC concept. Include integrated

- particle removal performance

- sulfur removal performance

- alkali removal performance

- filter cake modification performance

- filter pressure drop and cleaning performance

- filter material behavior

$\underline{\text { Status }}$

A revised test plan has been developed to focus on a key aspect of ceramic barrier filter technology - the effective pulse cleaning of candles in PFBC applications. This plan was presented in the Twenty-Third Quarterly Report. 


\section{OBJECTIVE II-2 - BENCH-SCALE FACILITY MODIFICATION DESIGN}

Develop detailed design of the facility for the baseline ILEC concept bench-scale testing that meets the test plan requirements. Designs shall be submitted to the DOE COR for review and approval.

\section{Scope}

Utilize an existing HTHP filter test facility modified for

- temperatures up to $2100^{\circ} \mathrm{F}$

- oxidizing environment

- partial coal injection/methane-fired

- sulfur removal with calcium-based sorbents

- alkali sorbent injection

- deposit additives

- cross-flow and candle filters elements

Select:

- appropriate candle material for this duty

- appropriate instrumentation for $\mathrm{SO}_{\mathrm{X}}$, and alkali measurement

- sorbent and additive feeding equipment and feed nozzles

Prepare:

- material and energy balances

- process flow diagrams

- equipment sizes, designs, and specifications

- vessel fabrication drawings

$\underline{\text { Status }}$

The original bench-scale facility design modifications had been completed during the twenty-third quarter of the program. These designs were modified to incorporate the needs of the revised test plan. 


\section{OBJECTIVE II-3 - BENCH-SCALE FACILITY FABRICATION AND ASSEMBLY}

Prepare the facility for testing the baseline ILEC by modifying the existing HTHP test facility as required.

\section{Scope}

Fabricate the facility modifications and required new test vessels. Purchase equipment, candle and cross-flow filters, and instruments. Assemble the facility. Procure and characterize sulfur sorbents, alkali sorbents, deposit additives, coals, and coal ashes.

\section{$\underline{\text { Status }}$}

During the twenty-third quarter, assembly of the test facility equipment was completed, placing the filter unit into a prototypic, state-of-the-art, candle filter configuration applicable to PFBC. The standard Westinghouse candle figure configuration incorporates fail-safe devices. 


\section{OBJECTIVE II-4 - BENCH-SCALE SHAKEDOWN TESTING}

Conduct shakedown testing of the bench-scale facility and instruments to demonstrate the operating capabilities and acceptance to design requirements.

Scope

In support of the Objective II-2 facility modification design, operate the existing facility, prior to modification, to determine its current capabilities for high temperature operation and conduct brief tests to examine the consequences of high temperature operation. Operate the modified facility at maximum and minimum flow test conditions. Operate coal, ash, sorbent and additive feed equipment. Confirm accuracy of instrumentation.

$\underline{\text { Status }}$

Shakedown testing of the major components and of the integrated facility were completed the twenty-third quarter. 


\section{OBJECTIVE II-6 - TOPICAL REPORTS}

Prepare the required Phase II Technical Report

$\underline{\text { Status }}$

A Phase II Topical Report was completed the previous quarter and was submitted to DOE for review, and was approved during the twenty-fourth quarter.

\section{OBJECTTVE II-7 - PROGRAM MANAGEMENT}

Provide overall project management for meeting research objectives and for cost and schedule control.

\section{Status}

Program restructuring has occurred to a significant extent in the program, ensuring that the testing reflects the major technical issues facing ceramic barrier filter development as it relates to the Westinghouse ILEC. Approval to proceed with the Phase III test program was received during the twenty-fourth quarter. 


\section{3 - PHASE III: BENCH-SCALE TESTING}

OBJECTIVE III-1 - PROCUREMENT

Procure the materials required for the Phase III test program.

Scope

Procurement of the following materials is required:

- Ceramic candles

- Fly ashes

- Additives

- Sulfur and alkali sorbents

$\underline{\text { Status }}$

All procurement activities have been completed.

$\begin{array}{llll}\text { Candles } & \text { Fly Ashes } & \text { Additives } & \text { Sorbents } \\ \text { Schumacher } & \text { Tidd } & \text { Dolomite } & \text { Dolomite } \\ \text { Coors } & \text { Tidd Cyclone Catch } & \text { Kaolin } & \text { Lime } \\ \text { Refractron } & \text { Grimethorpe } & \text { Neutralite } & \text { Emathlite } \\ & \text { Karhula } & & \\ & \text { Foster Wheeler } & & \end{array}$

In addition, 20 bottles of premixed $\mathrm{SO}_{2}$ have been procured for sulfur removal testing. 


\section{OBJECTIVE III-2 - BENCH-SCALE TESTING}

Conduct testing of the HTHP candle filter facility to develop improved pulse cleaning phenomena understanding and performance, and to demonstrate the feasibility of in-filter sulfur removal and alkali removal, under PFBC conditions.

Scope

The scope of the testing, as defined in the Phase III test plan (presented in the TwentyThird Quarterly Report), includes the following parameters for the candle cleaning tests:

- Fly ash type

- Candle type

- Temperature

- Pulse cleaning intensity

- Additive type and amount

For the sulfur and alkali removal tests, the scope includes the sulfur and alkali sorbent type and amount. These parameters are to be tested in 6 Test Sets:

1. Cake Permeability tests,

2. Cake Pulse Removal tests,

3. Additive Tests,

4. Pulse Intensity tests,

5. Continuous Operation tests,

6. Sulfur/Alkali Removal tests. 
$\underline{\text { Status }}$

Testing was initiated during October, 1993, on the Test Set 1, Cake Permeability tests. A total of 15 Cake Permeability tests have been conducted. Five tests from Test Set 3, Additives have also been conducted. Two test sequences focused on cake pulse removal, Test Sets 2 and 4, have been completed. One test relating to alkali removal, Test Set 6 , has been completed.

Appendix A summarizes the test procedures used and lists the tests conducted through this quarter.

During the next quarter, testing of sulfur removal will be initiated. In preparation for the sulfur removal testing, 20 pre-mixed bottles of $\mathrm{SO}_{2}$-air have been received, gas distribution piping has been prepared, and a safety and environmental review for the facility has been completed. Pulverized dolomite will be used in the testing. The test matrix is outlined below:

WILEC $\mathrm{SO}_{2}$ REMOVAL TEST PLAN (TEST SERIES 5)

TEST NUMBER - DESCRIPTION

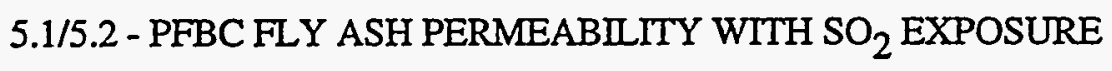

- Build filter cake $\left(30^{\prime \prime} \Delta \mathrm{P}\right.$ ) at $1500^{\circ} \mathrm{F}, 100 \mathrm{psig}, 7 \mathrm{ft} / \mathrm{min}$, no $\mathrm{SO}_{2}$

- Hold for about 2 hours

- Expose to about $200 \mathrm{ppmv} \mathrm{SO}_{2}$ for about $1 \mathrm{hr}$ (about 1 bottle?)

- Record usual data (gas flows, ash wt fed, temps and $\Delta \mathrm{P}$ )

- Measure $\mathrm{SO}_{2}$ inlet and outlet concentrations during test

- Parameters: Tidd fine ash; Karhula ash (enough material?)

\section{3 - DOLOMITE FIL TER CAKE PERMEABLITY WTTH/WITHOUT $\mathrm{SO}_{2}$}

- Build filter cake $\left(30^{\prime \prime} \Delta \mathrm{P}\right)$ at $1500^{\circ} \mathrm{F}, 100 \mathrm{psig}, 7 \mathrm{ft} / \mathrm{min}$, no $\mathrm{SO}_{2}$

- Hold for about 2 hours 


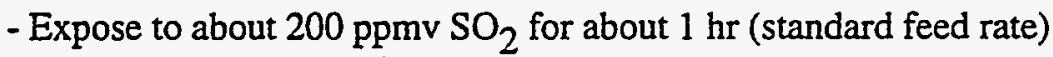

- Record usual data (gas flows, ash wt fed, temps and $\Delta \mathrm{P}$ )

- Measure $\mathrm{SO}_{2}$ inlet and outlet concentrations during test

\section{4/5.5 - DOLOMTTE + FLY ASH FLLTER CAKE PERMEABILITY WITH $\mathrm{SO}_{2}$}

- Mix dolomite and fly ash $50 / 50$ by wt

- Build filter cake ( $\left.30^{\prime \prime} \Delta \mathrm{P}\right)$ at $1500^{\circ} \mathrm{F}, 100 \mathrm{psig}, 7 \mathrm{ft} / \mathrm{min}$, no $\mathrm{SO}_{2}$

- Expose to about $200 \mathrm{ppmv} \mathrm{SO}_{2}$ for about $1 \mathrm{hr}$

- Record usual data (gas flows, ash wt fed, temps and $\triangle P$ )

- Measure $\mathrm{SO}_{2}$ inlet and outlet concentrations during test .

- parameters: Tidd fine ash; Karhula ash

\section{6 - DOLOMITE FILTER $\mathrm{SO}_{2}$ REMOVAL DURING FEEDING/PULSING}

- Heat up filter to $1500^{\circ} \mathrm{F}, 100 \mathrm{psig}, 7 \mathrm{ft} / \mathrm{min}$, no $\mathrm{SO}_{2}$

- Start $\mathrm{SO}_{2}$ flow (200 ppmv in outlet)

- Start dolomite feed $(\mathrm{Ca} / \mathrm{S}$ ratio about 2-3 $=2.2-3.3 \mathrm{lb} / \mathrm{hr})$

- Record usual data (gas flows, ash wt fed, temps and $\Delta \mathrm{P}$ )

- Measure $\mathrm{SO}_{2}$ inlet and outlet during test with pulse cleaning

\section{7 - LONG-TERM COMBINED FLY ASH PLUS DOLOMITE $\mathrm{SO}_{2}$ REMOVAL}

- Mix dolomite and fly ash about $50 / 50$ by wt (which fly ash?)

- Heat up filter to $1500^{\circ} \mathrm{F}, 100 \mathrm{psig}, 7 \mathrm{ft} / \mathrm{min}$, no $\mathrm{SO}_{2}$

- Start $\mathrm{SO}_{2}$ flow (200 ppmv in outlet)

- Start fly ash + dolomite feed $(\mathrm{Ca} / \mathrm{S}$ ratio about 2-3 = 2.2-3.3 lb/hr; total solids flow about 4.4-6.6 lb/hr)

- Measure $\mathrm{SO}_{2}$ inlet and outlet during test with pulse cleaning; at least several days operation

- Open vessel and inspect filter elements 
- After each test, pulse clean the candles and record the pressure drop change so we can assess if a hard deposit might have been formed.

- If the unit is opened, note the appearance/photos of the filter cake.

- Need to have an alkali probe available for the alkali measuring part of the program (Test Series 6). 


\section{OBJECTIVE III-3 - DATA EVALUATION}

Analyze and evaluate the experimental results produced in the bench-scale testing.

Scope

Raw test data will be converted into basic engineering quantities and correlations that can be used for design applications. The significance of the test results will be determined and interpreted in terms of full-scale filter system design, operation and performance.

\section{Status}

This objective was initiated in November 1993 and continued into this quarter. Data from the 15 Cake Permeability tests completed have been compiled and evaluated, extracting "mass" permeabilities for the filter cake, and gross permeabilities for the candle filter element and residue layer. In most tests, a minimum permeability occurred as a function of temperature at about $1550-1650^{\circ} \mathrm{F}$. The minimum appears to correspond to the point where equilibrium conditions change from $\mathrm{CaCO}_{3}$ being stable to $\mathrm{CaO}$ being stable. Further evaluation was performed using subsequent gas $\mathrm{CO}_{2}$ measurements collected during some of the tests.

- Comparisons are being made with field test data from the Tidd, PFBC plant Advanced Particle Filter, the Karhula circulating-PFBC pilot plant filter, and the Foster Wheeler, Livingston, NJ, circulating-PFBC test facility.

Evaluation of the Test Set 3, Additives, test has shown mixed results with some additives being beneficial, some harmful, and others neutral. The two test series completed in the Test Sets 2 and 4 have been evaluated and show a clear influence of higher temperature on high pulse intensities required to pulse clean effectively. One test of the filter cake properties of emathlite powder showed acceptable permeability results.

Appendix B reviews the data evaluation and summarizes conclusions reached in the program. 


\section{OBJECTIVE III-4 - PROGRAM MANAGEMENT AND REPORTING}

Provide overall project management for meeting research objectives and for cost and schedule control. Produce monthly, quarterly, and final reports for the program.

$\underline{\text { Status }}$

The program is making technical progress consistent with the program cost plan. 
APPENDIX A

TEST PROCEDURES AND TEST RECORD

A-1 
This Appendix contains a summary of the testing objectives and procedures that have been applied. listings of the tests completed and their conditions are also presented.

1. Test Objectives and Procedures

\subsection{Filter Cake Permeability Test, (Series 1)}

Objective: Determine the influence of temperature, and other key parameters, such as pressure and face velocity, on the permeability of various $\mathrm{PFBC}$ filter cakes.

Fixed Conditions:

- Face velocity $7 \mathrm{ft} / \mathrm{min}$ (variation to $12 \mathrm{ft} / \mathrm{min}$ )

- Pressure 100 psig (variation to 150 and 50 psig)

- 4 candles (with fail-safe/regenerators installed)

Parameters :

- Fly ash: Tidd fine, Karhula, Grimethorpe, FWDC, others

- Temperature: $1300^{\circ} \mathrm{F}$ to $1650^{\circ} \mathrm{F}$

Measurements:

- gas mass flow

- gas pressure and temperature

- filter pressure drop

- mass of fly ash fed

- gas $\mathrm{CO}_{2}$ content

Calculations:

- mass permeability of cake

- clean system and "residue" pressure drop 
Procedure:

Test Initiation: Raise gas inlet temperature to $1300^{\circ} \mathrm{F}$ following normal heatup procedure.

Step 1: Build filter cake on new candles until cake pressure drop (tubesheet minus baseline) of prescribed value (20 to 50 " $\mathrm{H}_{2} \mathrm{O}$ ) is reached -- fly ash flow is discontinued at this point.

Step 2: Raise filter cake temperature in increments $(100$ to $\left.200^{\circ} \mathrm{F}\right)$, holding at each temperature level long enough ( $1 / 2$ to 1 hour) to determine if a stable cake permeability has been -reached.

Step 3: Continue until temperature reaches the maximum facility capability (about $1700^{\circ} \mathrm{F}$ )

Step 4: Cool the vessel slowly to $1300^{\circ} \mathrm{F}$, in similar temperature increments, continuing to record the tubesheet pressure drop for comparison with the heatup record.

Step 5: Pulse clean the candles with several vigorous pulses.

Parametrics: Repeat steps for each test point.

Final: Cool down without pulse cleaning, remove the candles and observe the appearance of the filter cake (photograph, measure thickness and morphology, sample bulk density) 


\subsection{Pulse Cleaning Test (Series 2 and 4)}

Objective: Observe the performance of pulse cleaning over a range of key PFBC fly ash parameters to understand their relative importance and their relations.

Fixed Conditions:

- Face velocity $7 \mathrm{ft} / \mathrm{min}$

- Pressure 100 psig (potential variation to 50 psig)

- 4 identical candles (without fail-safe/regenerators installed)

Parameters :

- Fly ash: Tidd fine, Karhula, others

- Temperature: $1300^{\circ} \mathrm{F}, 1450^{\circ} \mathrm{F}, 1550^{\circ} \mathrm{F}$

- Initial cake mass

- Pulse conditions (pulse tank pressure, valve open time)

Measurements:

- gas mass flow

- gas pressure and temperature

- filter pressure drop

- mass of fly ash fed at each sequence

- pulse tank pressure before and during pulse event

- plenum pressure before and during pulse event

- pulse valve settings

Calculations

- mass of pulse gas delivered from tank

- mass of pulse gas received by candles 
Procedure:

Instrument check and calibration

Background data: 4 new candles installed; no conditioning; measure filter DP vs gas flow, temperature, and pressure

Pulse test (Typical)

1. Heat system to $1300^{\circ} \mathrm{F}$ at pressure of $100 \mathrm{psig}$ and face velocity $7 \mathrm{ft} / \mathrm{min}$

Feed predetermined mass of fly ash and hold 15 minutes Pulse at maximum tank pressure and normal valve open time; hold for 15 minutes

2.. Feed same mass of fly ash, hold 15 minutes

- Pulse at $3 / 4 \times$ (max tank-system pressure), hold $15 \mathrm{~min}$ Pulse at max tank pressure

3. Feed same mass of fly ash, hold 15 minutes Pulse at $1 / 2 \times$ (max tank-system pressure), hold $15 \mathrm{~min}$ Pulse at max tank pressure

4. Feed same mass of fly ash, hold 15 minutes Pulse at $1 / 3 \times$ (max tank-system pressure), hold $15 \mathrm{~min}$ Pulse at max tank pressure

5. Feed same mass of fly ash, hold 15 minutes Pulse at $1 / 4 \times$ (max tank-system pressure), hold $15 \mathrm{~min}$ Pulse at max tank pressure

Increase temperature to $1450^{\circ} \mathrm{F}$ at $100 \mathrm{psig}$ and $7 \mathrm{ft} / \mathrm{min}$ Repeat sequence of pulse cleanings (steps 6-10)

Increase temperature to $1550^{\circ} \mathrm{F}$ at $100 \mathrm{psig}$ at $7 \mathrm{ft} / \mathrm{min}$ Repeat sequence of pulse cleanings (steps 11-15)

Double the initial filter cake mass and repeat the entire sequence above (steps 1-15) 
Objective: Determine the influence of adaitives on the filter cake permeability and the filter cake pulse cleaning performance.

Procedures: The procedures followed are those outlined for the Cake Permeability Tests, and the Pulse Cleaning Tests. The additives may be premixed with the PFBC fly ash, injected separately into the gas, or applied as a precoat to the filter elements. Additives beneficial to to cake permeability will first be identified and then subjected to pulse cleaning tests to determine their influence on pulse performance. 
2. Record of Tests Completed

The test numbers, test date, and test parameters for tests completed are listed in Tables A1, A2, and A3, for the Cake Permeability Tests, the Additive Tests and the Pulse Cleaning Tests, respectively. Where no value appears in the tables, the last value reported above in the column applies. 
Table Al - Filter Cake Permeability Test Record (Series 1)

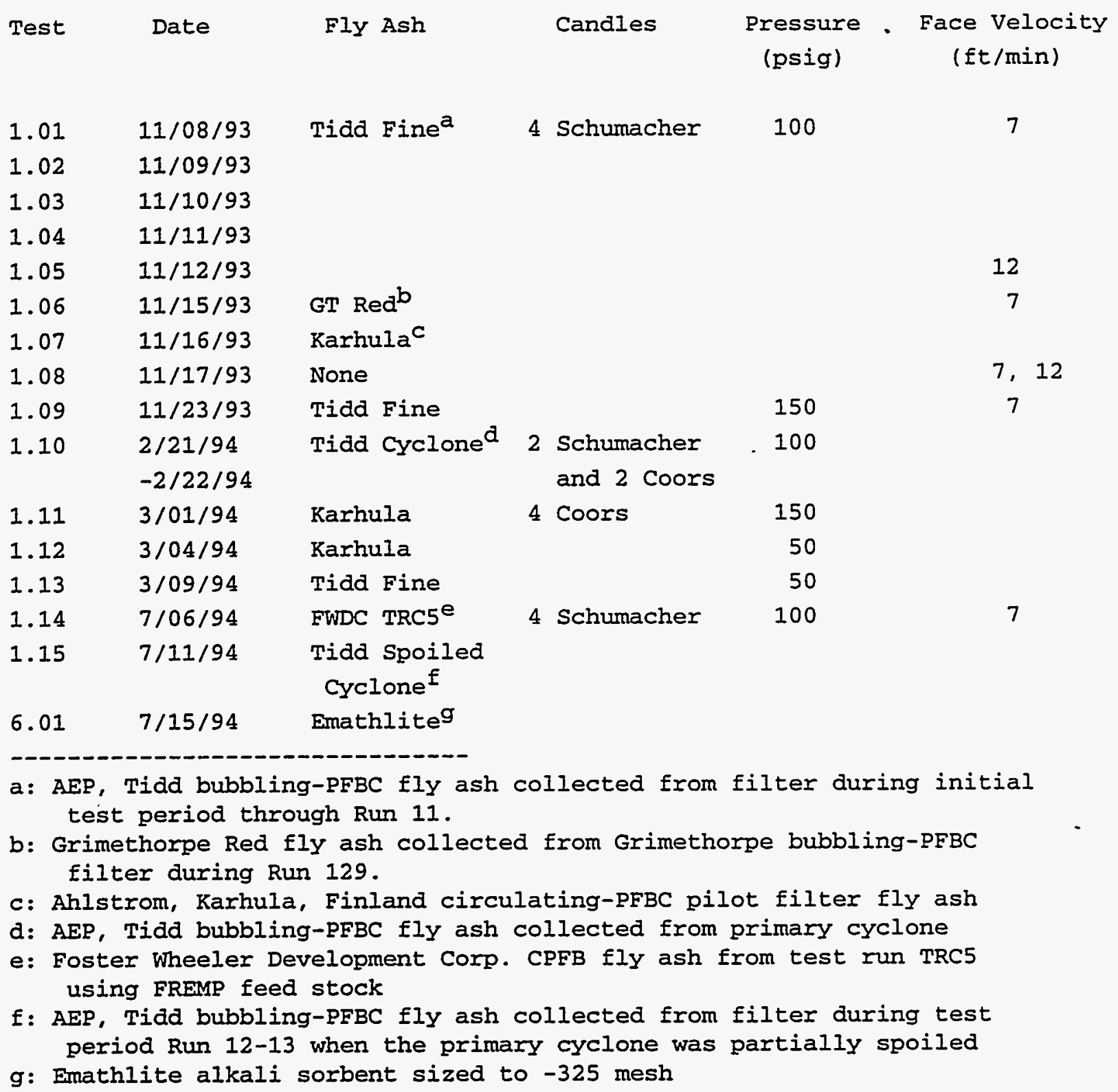


Table A2 - Filter Cake Additives Test Record (Series 3)

Fixed Conditions: Face Velocity $7 \mathrm{ft} / \mathrm{min}$; Pressure $100 \mathrm{psig}$

\begin{tabular}{|c|c|c|c|c|}
\hline Test & Date & Fly Ash & Additive & Candles \\
\hline 3.01 & $11 / 24 / 93$ & Tidd Fine & 10 wto Dolomite & 4 Schumacher \\
\hline 3.02 & $\begin{array}{l}1 / 24 / 94 \\
-2 / 02 / 94\end{array}$ & None & $\begin{array}{l}\text { Neutralite } \\
\text { Precoat }\end{array}$ & \\
\hline 3.03 & $2 / 03 / 94$ & GT Red & On to Precoat & \\
\hline 3.04 & $\begin{array}{l}2 / 04 / 94 \\
-2 / 07 / 94\end{array}$ & GT Red & 5 wto Neutralite & \\
\hline 3.05 & $2 / 16 / 94$ & GT Red & 10 wt? Kaolin & $\begin{array}{l}2 \text { Schumacher and } \\
2 \text { Coors }\end{array}$ \\
\hline
\end{tabular}


Table A3 - Filter Cake Pulse Cleaning Test Record (series 2 \& 4)

\begin{tabular}{|c|c|c|c|c|c|}
\hline Test & Date & Fly Ash & $\begin{array}{c}\text { Temperature } \\
(\cdot F)\end{array}$ & $\begin{array}{c}\text { Pressure } \\
\text { (psig) }\end{array}$ & $\begin{array}{c}\text { Face Velocity } \\
(\mathrm{ft} / \mathrm{min})\end{array}$ \\
\hline 2.011 & $\begin{array}{l}5 / 23 / 94 \\
-5 / 25 / 94\end{array}$ & Tidd Fine & 1300 & 100 & 7 \\
\hline 2.012 & $\begin{array}{l}5 / 27 / 94 \\
-6 / 02 / 94\end{array}$ & & 1450 & & \\
\hline 2.013 & $6 / 08 / 94$ & & 1550 & & \\
\hline 2.021 & $\begin{array}{l}6 / 14 / 94 \\
-6 / 17 / 94\end{array}$ & Karhula & 1300 & & \\
\hline 2.022 & $\begin{array}{l}6 / 21 / 94 \\
-6 / 23 / 94\end{array}$ & & 1450 & & \\
\hline 2.023 & $\begin{array}{l}6 / 24 / 94 \\
-6 / 29 / 94\end{array}$ & & 1550 & & \\
\hline 2.031 & $11 / 2 / 94$ & Tidd Fine & 1300 & 100 & 7 \\
\hline 2.032 & $11 / 2 / 94$ & & 1450 & & \\
\hline 2.033 & $11 / 3 / 94$ & & 1550 & & \\
\hline 2.041 & $11 / 7 / 94$ & Karhula & 1300 & 100 & 7 \\
\hline 2.042 & $11 / 8 / 94$ & & 1450 & & \\
\hline 2.043 & $11 / 9 / 94$ & & 1550 & & \\
\hline
\end{tabular}

Maximum relative pulse tank pressure

2.01 and 2.02 : 26 atm

2.03 and 2.04 : 61 atm 
APPENDIX B

TEST EVALUATION SUMMARY

$B-1$ 
This Appendix contains a summary of the evaluation results and conclusions drawn from the tests performed.

\section{Filter Cake Permeability Tests (Series 1)}

Three figures are presented for each of the 13 tests conducted, Tests 1.01 through 1.13. The first displays the time history of the test, showing the temperature, face velocity, mass of fly ash fed per unit of filter surface area, and the tubesheet pressure drop (total for element, residue, cake, fail-safe, and other losses). It is assumed that all of the fly ash fed deposits on the candle filter surfaces, although it is clear that only a portion actually reaches the filtering surface (about $70 \%$ based on weights measured on the filter elements at the end of some of the testing).

The second figure for each test shows the time history of the distribution of the tubesheet pressure drop between the cake, residue and the clean system (filter element plus fail-safe plus other losses):

$\Delta \mathrm{P}=\Delta \mathrm{P}_{\mathrm{f}}$ (element) $+\Delta \mathrm{P}_{\mathrm{r}}$ (residue) $+\Delta \mathrm{P}_{\mathrm{c}}$ (cake) $+\Delta \mathrm{P}_{\mathrm{p}}$ (others)

The clean system pressure drop is a calculated value based on a correlation of the clean system pressure drop as a function of the gas flow, gas density, and viscosity:

$\mathrm{DP}$ (clean system) $=\Delta \mathrm{P}_{\mathrm{f}}$ (element) $+\Delta \mathrm{P}_{\mathrm{p}}$ (others)

$$
=A \mu U+B \rho U^{2}
$$

The correlation values $A$ and $B$ were developed from initial flow testing of the clean system over a range of flows, temperatures and pressures, and this correlation testing was repeated each time the elements were changed. The residue pressure drop was estimated from the difference between the system pressure drop and the clean system pressure drop at the start of the test prior to feeding fly ash. The cake pressure drop was then. calculated as the difference between the measured tubesheet pressure drop and the sum of the clean system and residue pressure drops. 
The third figure for each test displays the temperature history and the calculated mass permeability of the filter cake. The mass permeability, $k_{m}$, is defined by the following equation:

$$
\Delta \mathrm{P}_{\mathrm{C}}=\mu \mathrm{UM} / \mathrm{k}_{\mathrm{m}}
$$

where $\Delta \mathrm{P}_{\mathrm{C}}$ is the cake pressure drop, $\mu$ is the gas viscosity, $U$ is the face velocity, and $M$ is the mass of filter cake per unit area.

In three cases, Tests 1.10, 1.11, and 1.13, plots are included for the $\mathrm{CO}_{2}$-pressure in the gas against the temperature, and these plots are characteristic of all of the tests performed. The plots appear to have a "historesis" shape, the higher $\mathrm{CO}_{2}$ values occurring as the temperature is increased, and the lower values as the temperature is subsequently decreased.

Thirteen Cake Permeability tests were performed, with the first 4 tests being replications and procedure optimization tests. The same general behavior trends were observed in each test. The filter cake permeability falls as the temperature is initially increased above $1300^{\circ} \mathrm{F}$, and it reaches a minimum value at the temperature where the calcium in the filter cake calcines from $\mathrm{CaCO}_{3}$ to $\mathrm{CaO}$. As the temperature is reduced from the maximum, the filter cake permeability increases slightly, but does not return to its original value because irreversible structural changes in the filter cake have occurred. One test, test 1.08 , was performed without feeding fly ash to observe the behavior of the residue material. The residue shows a similar behavior to the filter cakes, but with lower temperature sensitivity.

The overall testing results are listed in Table B1. The table lists the major test parameters (the fly ash type, pressure and face velocity) and the test results (the initial cake permeability at $1300^{\circ} \mathrm{F}$, the minimum permeability achieved, and.the temperature at which the minimum permeability occurred). Higher pressures resulted in lower minimum permeabilities, and higher face velocity also appears to reduce the cake permeability slightly.

The major aspects of this behavior appear to result primarily from calcium-based sorbent material sintering phenomena. It is known from prior evidence leg., studies of calcium sorbent surface area on injection into hot gas streams, and calcium-based deposits on boiler heat transfer surfaces) that sintering is a fast process at these temperatures. The rate and extent of calcium sintering increases with: 
- increased temperature

- reduced particle size

- increased $\mathrm{CO}_{2}$ and $\mathrm{H}_{2} \mathrm{O}$ in gas

- increased content of $\mathrm{Na}$ and $\mathrm{K}$ in the cake

- increased content of $\mathrm{CaCO}_{3}$ and $\mathrm{CaSO}_{4}$ vs $\mathrm{CaO}$ and $\mathrm{MgO}$

- occurrence of sulfation and carbonation reactions

The characteristic "sintering" temperatures (Tammann bulk diffusion) of calcium constituents in the fly ash are:

$\begin{array}{lr}\text { - } \mathrm{CaO} & 2139^{\circ} \mathrm{F} \\ \text { - } \mathrm{MgO} & 2306 \\ \text { - } \mathrm{CaCO}_{3} & 991 \\ \text { - } \mathrm{CaSO}_{4} & 1091\end{array}$

The results are consistent with field test trends, and direct comparison of the laboratory test and field test permeabilities are shown in Table B2. In the field tests, the mass permeability is extracted from the plant data using the equation

$$
\Delta \mathrm{P}_{\mathrm{c}}=\mu \mathrm{U}^{2} \rho \mathrm{I} \mathrm{T}_{\mathrm{p}} / \mathrm{k}_{\mathrm{m}}
$$

where $\Delta \mathrm{P}$ is taken as the difference between the trigger and the baseline system pressure drops, $I$ is the dust loading in the gas (mass ratio particulate to gas), $\rho$ is the gas density, and $\mathrm{T}_{\mathrm{p}}$ is the time duration between pulses. There are significant uncertainties in the values inserted into this equation. The baseline system pressure drop in a filter vessel containing multiple plenums is never actually recorded because of the significant time delay in completing the pulse cleaning of all of the plenums. The dust loading is generally an estimate based on the mass of material periodically removed from the filter vessel, or based on limited particle sampling measurements. Again, it is assumed that all of the fly ash in the gas is deposited onto the active filtering surfaces. It is also assumed that the pulse cleaning is effective, with all of the fly ash deposited being removed by the pulse. The laboratory permeabilities are generally greater than the field test permeabilities, and this may be because the $\mathrm{CO}_{2}$ and $\mathrm{SO}_{2}$ partial pressures are lower in the laboratory tests than in the field tests. The uncertainties in the values used to calculate the mass permeabilities might also result in differences between the two sets of 
values. Figure $\mathrm{B} 1$ plots the $\mathrm{CO}_{2}$ partial pressure and filter operating temperature for Tidd PFBC filter tests, for Karhula CPFB filter tests, for FWDC filter tests, and for the laboratory filter cake permeability tests. The equilibrium Iine for $\mathrm{CaCO}_{3}-\mathrm{CaO}$ stability is also plotted in the figure.

The Cake Permeability conclusions reached are:

- Laboratory filter cake trends are consistent with field unit data trends;

- PFBC filter cake permeability and sintering is largely controlled by limestone constituents in the fly ash;

- Filter cake sintering is induced by $\mathrm{CO}_{2}$ and $\mathrm{SO}_{2}$ in the gas;

- Increased sintering results from:

- higher $\mathrm{CO}_{2}$ and $\mathrm{SO}_{2}$ pressures,

- higher temperatures,

- finer fly ash particles,

- calcitic limestone vs dolomitic limestone;

- Control of cake permeability and bridging might be realized by:

- limiting the PFBC temperature (especially in AdvancedPFBC)

- limiting primary cyclone performance,

- PFBC sorbent selection,

- use of additives. 
Table B1 - Filter Cake Permeability Test Results

\begin{tabular}{|c|c|c|c|c|c|}
\hline $\begin{array}{l}\text { Fly Ash } \\
\text { Source }\end{array}$ & $\begin{array}{l}\text { Pressure } \\
\text { (psig) }\end{array}$ & $\begin{array}{c}\text { Face } \\
\text { Velocity } \\
\text { (ft/min) }\end{array}$ & $\begin{array}{c}\text { Cake Permeability } \\
\text { at } 1300^{\circ} \mathrm{F} \\
\left(10^{-10} \mathrm{lb} / \mathrm{ft}\right)\end{array}$ & $\begin{array}{l}\text { Minimum } \\
\text { Permeability } \\
\left(10^{-10} \text { Ib/ft }\right)\end{array}$ & $\begin{array}{c}\text { Temperature } \\
\text { at Minimum } \\
\left({ }^{\circ} \mathrm{F}\right)\end{array}$ \\
\hline Tidd Fine & 100 & 7 & 3.0 & 1.8 & 1550 \\
\hline Tidd Fine & 150 & 7 & 3.3 & 1.6 & 1550 \\
\hline Tidd Fine & 50 & 7 & 3.3 & 2.1 & 1500 \\
\hline Tidd Fine & 100 & 12 & 2.4 & 1.6 & 1550 \\
\hline $\begin{array}{l}\text { Tidd Primary } \\
\text { Cyclone }\end{array}$ & 100 & 7 & 5.0 & 4.3 & 1535 \\
\hline $\begin{array}{l}\text { Tidd Spoiled } \\
\text { Cyclone }\end{array}$ & 100 & 7 & 3.8 & 3.2 & 1550 \\
\hline $\begin{array}{l}\text { Grimethorpe } \\
\text { Red }\end{array}$ & 100 & 7 & 1.3 & 1.0 & 1550 \\
\hline Karhula & 100 & 7 & 9.3 & 8.2 & 1600 \\
\hline Karhula & 150 & 7 & 7.3 & 7.5 & 1550 \\
\hline Karhula & 50 & 7 & 8.2 & 8.2 & 1400 \\
\hline FWDC TRC5 & 100 & 7 & 9.0 & 8.5 & 1600 \\
\hline
\end{tabular}


Table B2 - Comparison of Laboratory and Field Permeabilities

$$
\begin{aligned}
& \text { Laboratory } \\
& \text { Permeability } \\
& \left(10^{-10} \mathrm{lb} / \mathrm{ft}\right)
\end{aligned}
$$

\author{
Field \\ Permeability \\ $\left(10^{-10} 1 \mathrm{~b} / \mathrm{ft}\right)$
}

Tidd Fly Ash

$\begin{array}{lll}\text { Fine }^{\mathrm{a}} \text { : } & 1.6 & 0.2-0.6 \\ \text { Spoiled Cyclone }^{\mathrm{b}}: & 3.2 & 1-2 \\ \text { Primary Cyclone }^{\mathrm{a}} & 4-5 & 5-6\end{array}$

Karhulad:

$7.5-8$

$2-6$

Grimethorpe Red ${ }^{e}$ :

1.0

FWDC (TRC5) $f$

8.5

$2-5$

a: AEP, Tidd bubbling-PFBC fly ash collected from filter during initial test period through Run 11

b: AEP, Tidd bubbling-PFBC fly ash collected from filter following testing with partially-spoiled primary cyclone

c: AEP, Tidd bubbling-PFBC fly ash collected from primary cyclone

d: Ahlstrom, Karhula, Finland circulating-PFBC pilot filter fly ash

e: Grimethorpe Red fly ash collected from Grimethorpe bubbling-PFBC filter during Run 129

f: Foster Wheeler Development Corp. circulation-PFBC fly ash collected from the filter vessel during Test TRC5 run using FREMP feed stocks 
The additive tests performed to date have focused on the influence of additives on the cake permeability and have been of two types: additive premixed with PFBC fly ash, and additive applied as a precoat to the filter elements. The five additive tests reviewed in Table $B 3$ were performed. The additive characteristics are listed in Table B4.

The test history and results are plotted in the attached figures for Tests 3.01 through 3.05. The 3 figures for Test 3.01 show the test history (temperature, face velocity, filter total pressure drop, and mass of cake deposited per unit area plotted against the time-of-day), the pressure drop distribution (cake, clean system, and residue), and the cake mass permeability. The results show that the use of pulverized dolomite benefitted the Tidd Fine fly ash permeability significantly even though only 10 wt $\%$, or about 5 volumeq, additive was used. It is not known if such a great benefit would result if the gas contained $\mathrm{SO}_{2}$, but this will be clarified during the sulfur removal testing phase of the program.

Test 3.02 (3.020 through 3.025) precoated the candle elements with Neutralite. Neutralite was fed for 4 days to obtain a standard filter cake pressure drop of about $40{ }^{\prime \prime} \mathrm{H}_{2} \mathrm{O}$ and figures showing the run history for each of those days are attached. A cake having relatively high permeability resulted, and temperature variations were performed on two days (Tests 3.024 and 3.025). Figures showing run history, pressure drop distribution, and mass permeability plots for those two days are attached. The reduction in the filter cake permeability as the temperature increased was very great on the first day. The Neutralite filter cake permeability was measured to be slightly lower on the second day, but was still a relatively high value.

The next test, Test 3.03 , built a cake of fly ash, Grimethorpe Red, on the Neutralite precoat to see if a measurable impact on the cake permeability resulted. The plotted results show that the cake permeability was slightly lower than it had been in earlier tests having no precoat. Following this test, the vessel was opened for inspection and it was found that the Neutralite precoat was very thick (about 5/8") and was a hard, stable layer that needed to be cut out in sections. The mass permeability calculations performed to yield the plotted results in the figure were corrected for this thick coating since it changes the 
actual face velocity through the fly ash cake. A thinner precoat should be used, and the stable layer could provide some protection to the candle if no detrimental reactions occurred with the candle materials, and the precoat might provide an aid to pulse cleaning. Further considerations of the precoat concept will be conducted.

The next test, Test 3.041, built a cake of Grimethorpe Red fly ash mixed with 5 wto Neutralite, and resulted in a cake permeability much lower than previously measured with Grimethorpe Red. Neutralite would not appear to be a useful cake permeability aid. A further series of continuous pulse cleanings and cake buildups (Test 3.042) showed a significant deterioration in the baseline pressure drop, further exposing the poor performance of Neutralite as a direct additive.

The final additive test performed to date, Test 3.05, used a mixture of 10 wto Kaolin with Grimethorpe Red fly ash. Again, the test history, pressure drop distribution, and cake mass permeability is shown in 3 attached figures. The results showed little influence of the Kaolin on the Grimethorpe Red cake permeability compared to prior tests without the additive. 


\begin{tabular}{|c|c|c|c|}
\hline Test & Fly Ash & Additive & Results \\
\hline 3.01 & Tidd Fine & $\begin{array}{l}10 \text { wto pulverized } \\
\text { dolomite }\end{array}$ & $\begin{array}{l}\text { Permeability increased } 508 \\
\text { by the additive }\end{array}$ \\
\hline 3.02 & None & $\begin{array}{l}\text { Neutralite } \\
\text { precoat }\end{array}$ & High permeability precoat \\
\hline 3.03 & $\begin{array}{l}\text { Grimethorpe } \\
\text { Red }\end{array}$ & $\begin{array}{l}\text { On Neutralite } \\
\text { precoat }\end{array}$ & $\begin{array}{l}\text { Results uncertain; } 1 / 2-5 / 8 " \\
\text { thick, hard precoat found }\end{array}$ \\
\hline 3.04 & $\begin{array}{l}\text { Grimethorpe } \\
\text { Red }\end{array}$ & 5 wto Neutralite & $\begin{array}{l}\text { Additive reduced the cake } \\
\text { permeability significantly }\end{array}$ \\
\hline 3.05 & $\begin{array}{l}\text { Grimethorpe } \\
\text { Red }\end{array}$ & 10 wto kaolin & $\begin{array}{l}\text { Permeability increased slightly } \\
\text { by the additive }\end{array}$ \\
\hline
\end{tabular}


Table B4 - Additive Characteristics

Additive

Dolomite

Neutralite

Kaolin
Supplier

Espoma garden

lime

BHA commercial

bag house aid

Thiele Kaolin

co.
Composition

21 wt? $\mathrm{Ca}$

12 wto $\mathrm{Mg}$

aluminum silicate

(proprietary)

hydrous aluminum

silicate
$928-325$ mesh

$99.98-200$ mesh

Very fine

$1008-325$ mesh

$56 \%<2 \mu \mathrm{m}$ 
3. Pulse Cleaning Tests (Series 2 and 4)

The first set of pulse cleaning tests, with Tidd Fine fly ash, have been evaluated. Test histories; temperature, face velocity, and total filter pressure arop, are plotted against the time-of-day for Tests $2.011\left(1300^{\circ} \mathrm{F}\right), 2.012\left(1450^{\circ} \mathrm{F}\right)$, and $2.013\left(1550^{\circ} \mathrm{F}\right)$. Each figure also indicates the pulse gas tank pressure applied during the pulses performed. Each pulse was conducted with a pulse valve open-time of 0.4 seconds. Test 2.011 ran for 3 days, Test 2.012 for 4 days, and Test 2.013 for 3 days.

The pulse intensity measured in all of the tests $(2.011-2.013)$ is plotted in Figure $B 2$ against the relative tank pressure. The pulse intensity is. defined as the maximum pressure reached in the filter plenum during the pulse minus the background pressure (100 psig). The relative tank pressure is defined as the pulse gas tank pressure applied at the start of the pulse minus the background pressure $(100 \mathrm{psig})$. The pulse intensity rises almost linearly as the relative tank pressure increases, but it also appears that the intensity is slightly higher as the temperature is increased. This probably results because the filter cake and residue pressure drops have increased as the temperature was increased.

Figure B3 plots the pulse gas received by the candle elements against the pulse gas released from the pulse tank for tests 2.011 2.013. The quantity of pulse gas released from the pulse tank is a measured quantity based on the tank pressure before and after the pulse event. The quantity of pulse gas received by the filter elements is a calculated, approximate quantity based on the filter element pressure drop before the pulse and the pulse intensity measured during the pulse. The received pulse gas is significantly less than the released pulse gas, with the ratio of received to released gas quantity increasing as the released pulse gas quantity increases.

In Figure 34 , the pulse intensity and the baseline minus the clean system pressure drop are plotted against the cumulative, hot operating hours in the tests $(2.011-2.013)$. The three sets of data at $1300^{\circ} \mathrm{F}, 1450^{\circ} \mathrm{F}$, and $15550^{\circ} \mathrm{F}$ are shown. The "baseline pressure drop" is the tubesheet pressure drop following the pulse cleaning event. The quantity plotted, "baseline minus clean DP" is equal to the sum of the filter cake pressure drop and the residue pressure drop. A lower value of this quantity means a more effective pulse cleaning was performed. At each temperature, as the pulse intensity was decreased a clear increase in the baseline minus clean DP quantity resulted. As the temperature increased, the baseline minus clean DP quantity was higher at the same pulse intensity. For example, at $1300^{\circ} \mathrm{F}$ a pulse intensity 


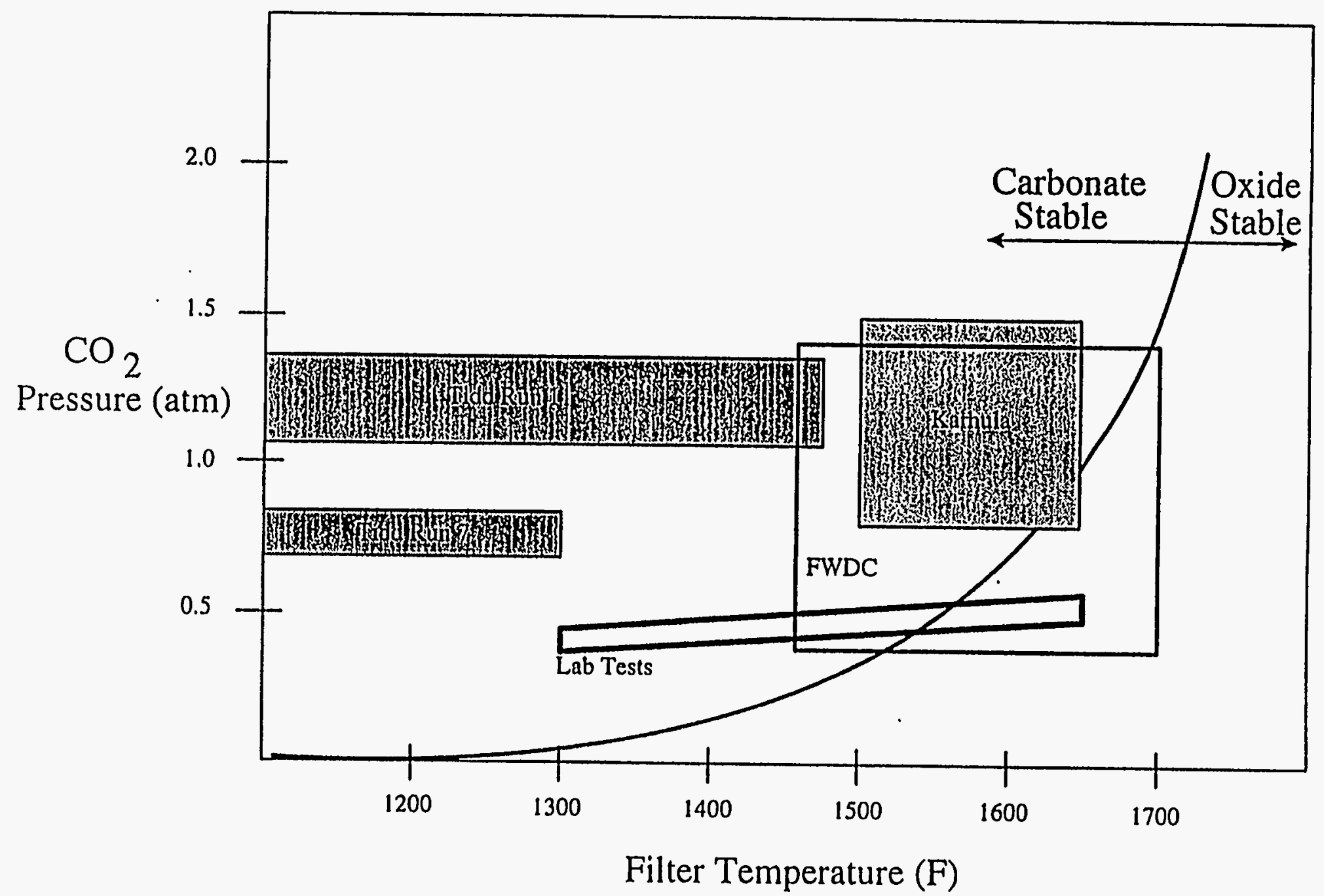

Figure B1 - Comparison of Field and Lab Test Conditions 


\section{PULSE CLEANING TESTS Tests $2.011-2.013$}

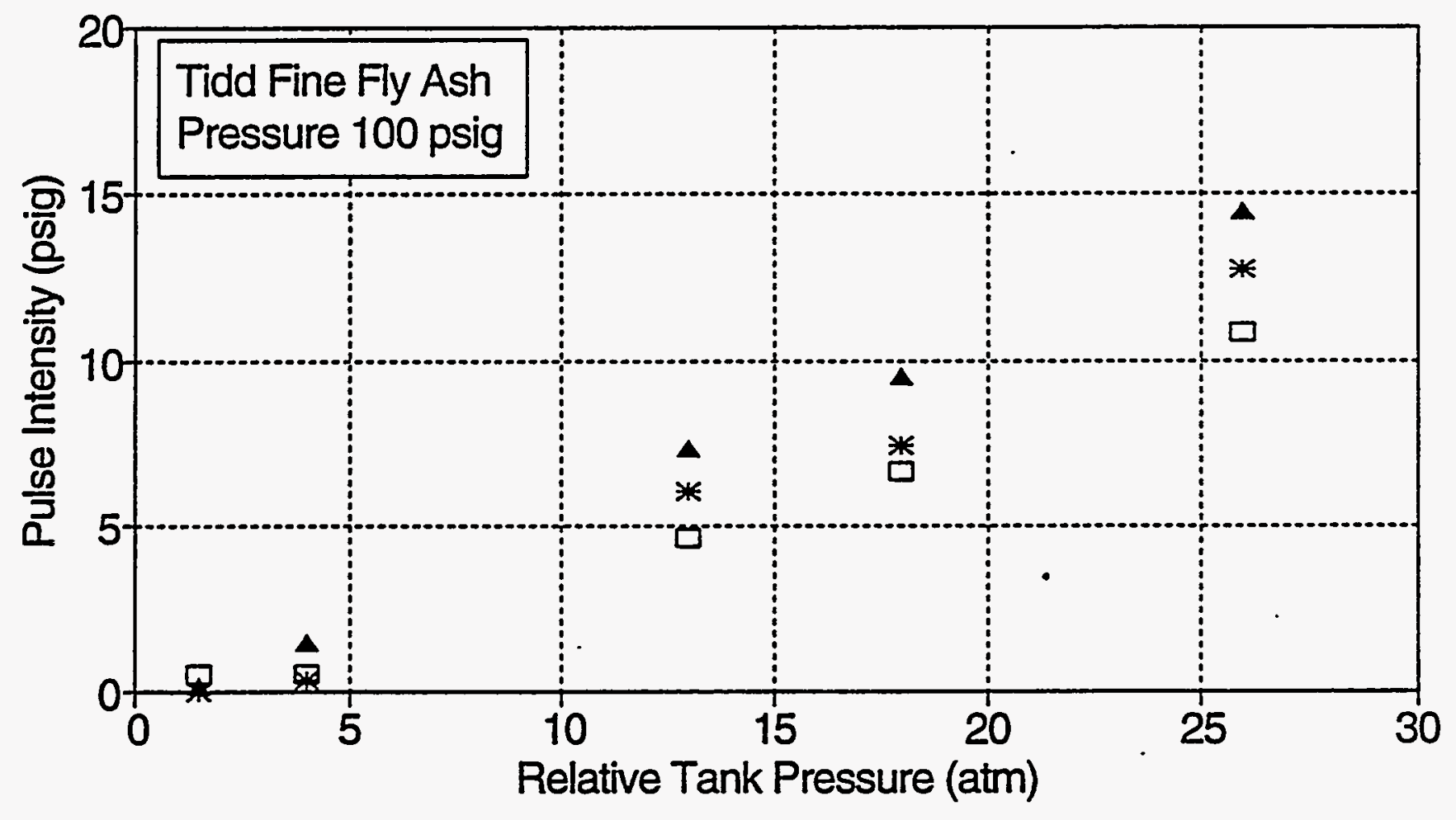

Figure B2 


\section{PULSE CLEANING TESTS Tests $2.011-2.013$}

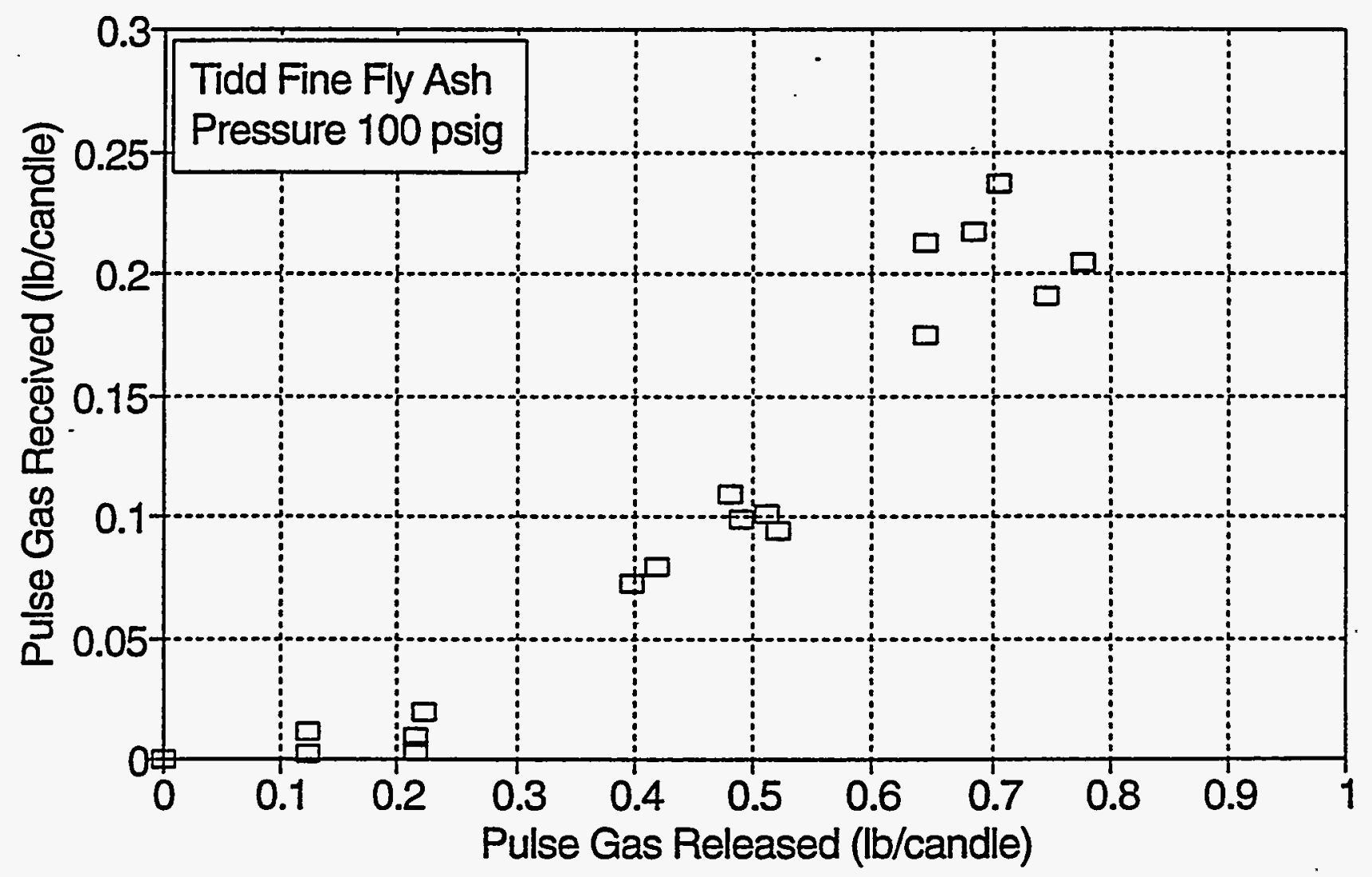

Figure B3 


\section{PULSE CLEANING TESTS Tests $2.011-2.013$}

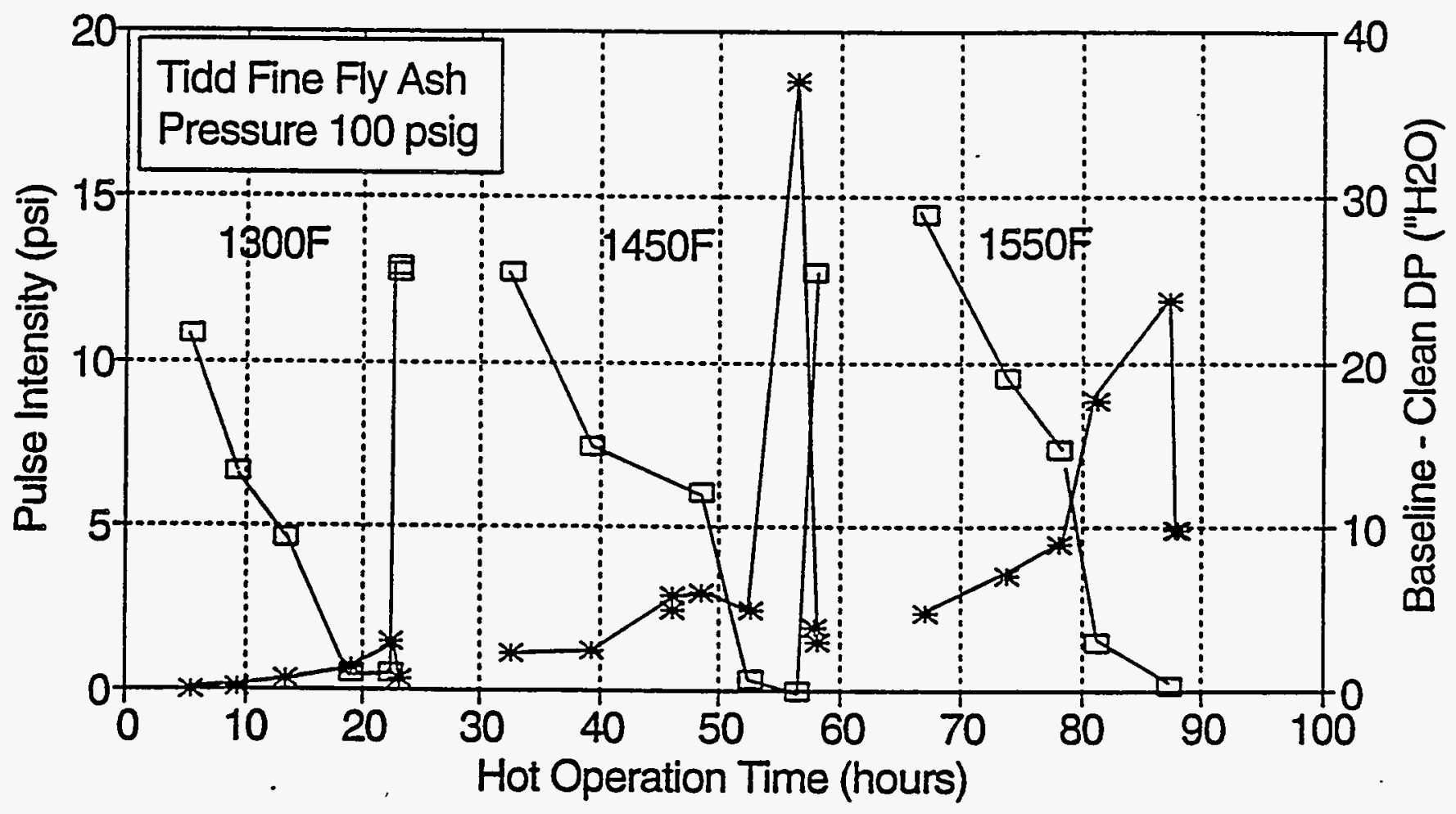

Figure B 4 
of 5 psi resulted in a baseline minus clean DF quantity of about 0.5 " $\mathrm{H}_{2} \mathrm{O}$, while at $1450^{\circ} \mathrm{F}$ the same $5 \mathrm{psi}$ pulse intensity resulted in a baseline minus clean DP quantity of about 3 psi, and at $1550^{\circ} \mathrm{F}$ the same 5 psi pulse intensity resulted in a baseline minus clean DP quantity of about 7 psi.

Similar findings were made for the pulse cleaning tests conducted with Karhula fly ash (Figures B5, B6 and B7). Even though the Karhula fly ash has a significantly higher permeability than the Tidd fine fly ash, with also much less sensitivity to temperature, a significant influence of temperature and time on the pulse cleaning effectiveness was observed.

There are two factors that have contributed simultaneously to these results. First, higher temperature results in lower cake permeability and greater residue accumulation, so that a lower pulse gas quantity yields the same measured pulse intensity. Secondly, the tests were performed in the order of ascending temperatures, so that as the temperatures increase the cumlative test time also increased. This second factor resulted in more opportunity for residue accumulation on the candles as time, and temperature progressed. In any case, the result imply that, with both the Tidd Fine fly ash and the Karhula fly ash, a steady accumulation of residue might occur that cannot be effectively cleaned even at the highest pulse intensity conditions used in these tests.

Tests 2.03 and 2.04 were conducted to observe the benefits of a higher pulse source pressure of the candle cleaning. The Tidd fine ash was used in Test 2.03, and the Karhula ash in Test 2.04. Both tests use a tank relative pressure of $61 \mathrm{~atm}$, and both resulted in a pulse intensity of $35 \mathrm{psi}$. Figures $B 8$ and $B 9$ imply that with the fine Tidd ash a buildup of residue occurred on the candles that increased as the temperature increased, while this temperature sensitivity was not shown for the Karhula ash. A significant residue resistance remains on the candles even with the high pulse intensity used. 


\section{PULSE TEST - 2.021-2.023 Karhula Fly Ash}

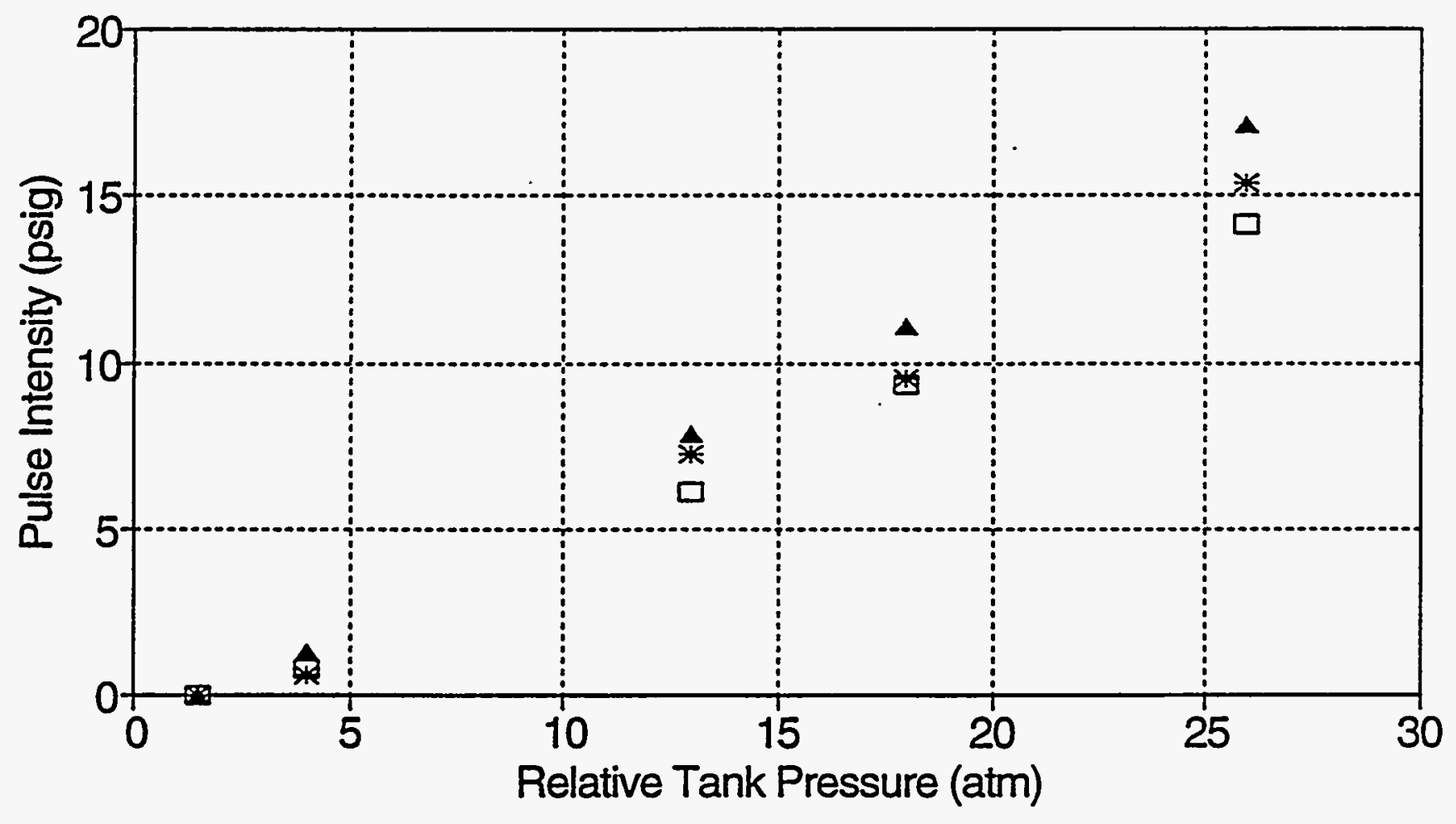

Figure B5 


\section{PULSE TEST - 2.021-2.023 Karhula Fly Ash}

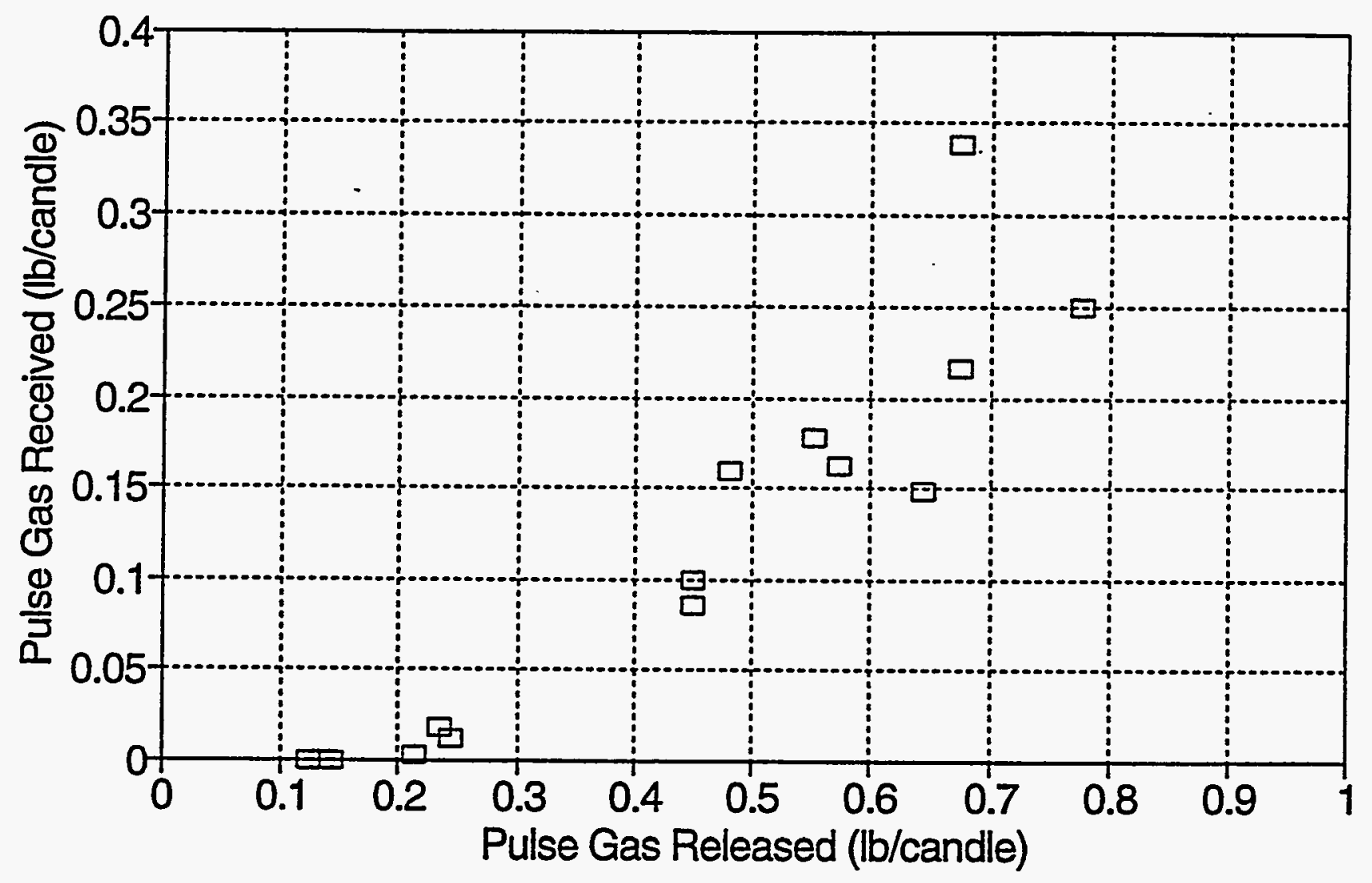

Figure B6 


\section{PULSE TEST - 2.021-2.023 Karhula Fly Ash}

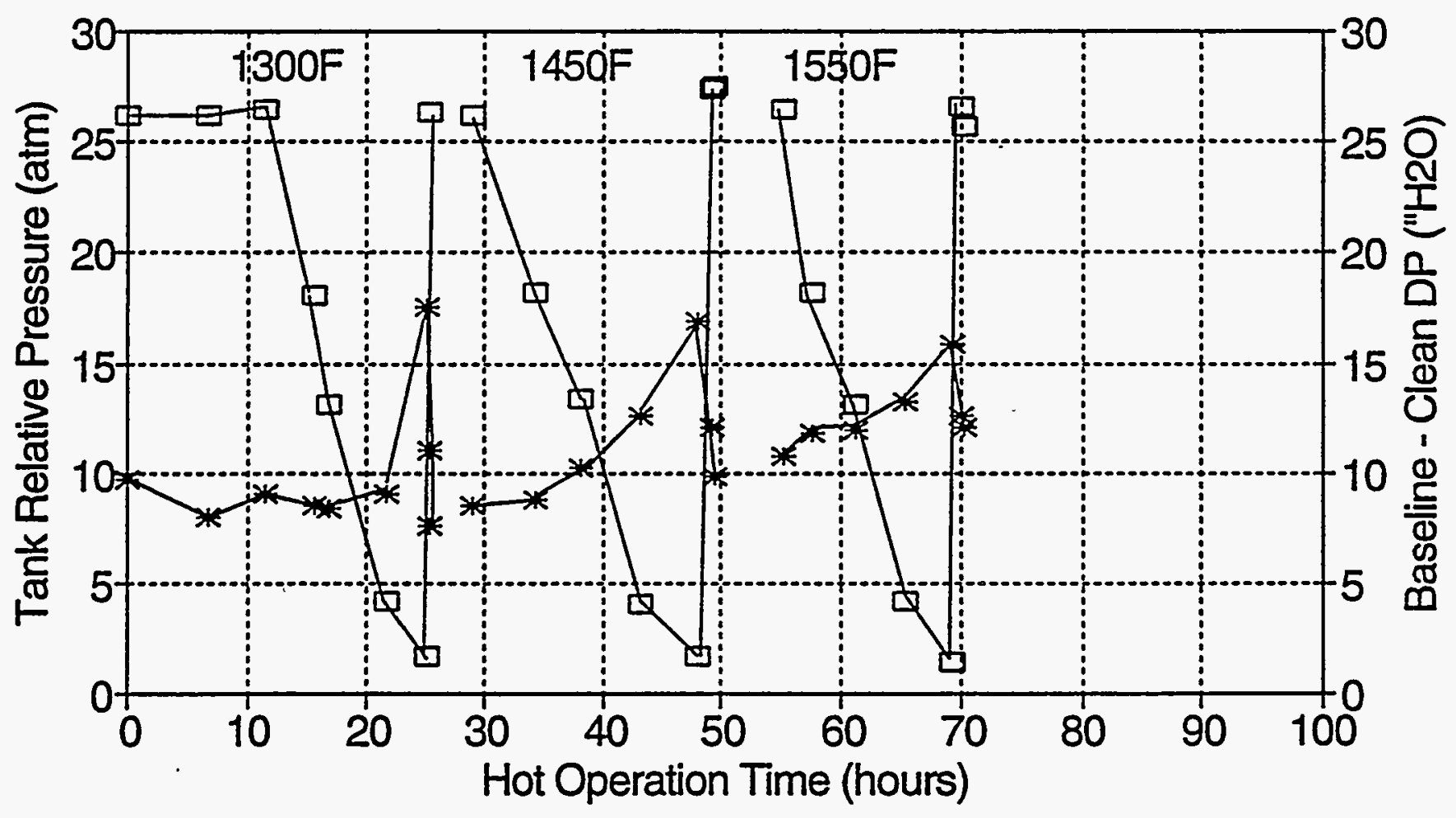

Figure B7 


\section{PULSE TEST - 2.031-2.032 Tidd Fine Fly Ash}

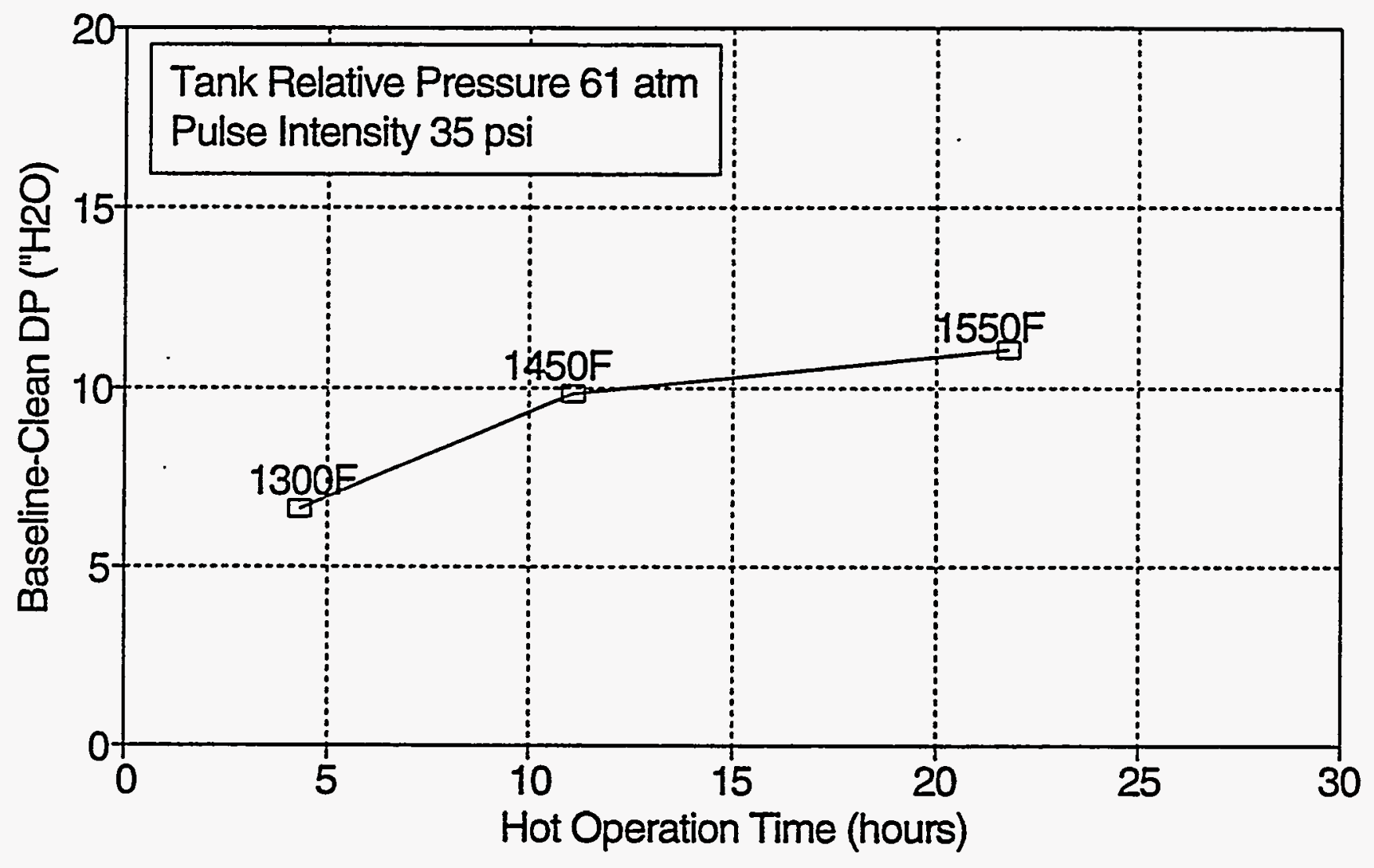

Figure B8 


\section{PULSE TEST - 2.041-2.043 Karhula Fly Ash}

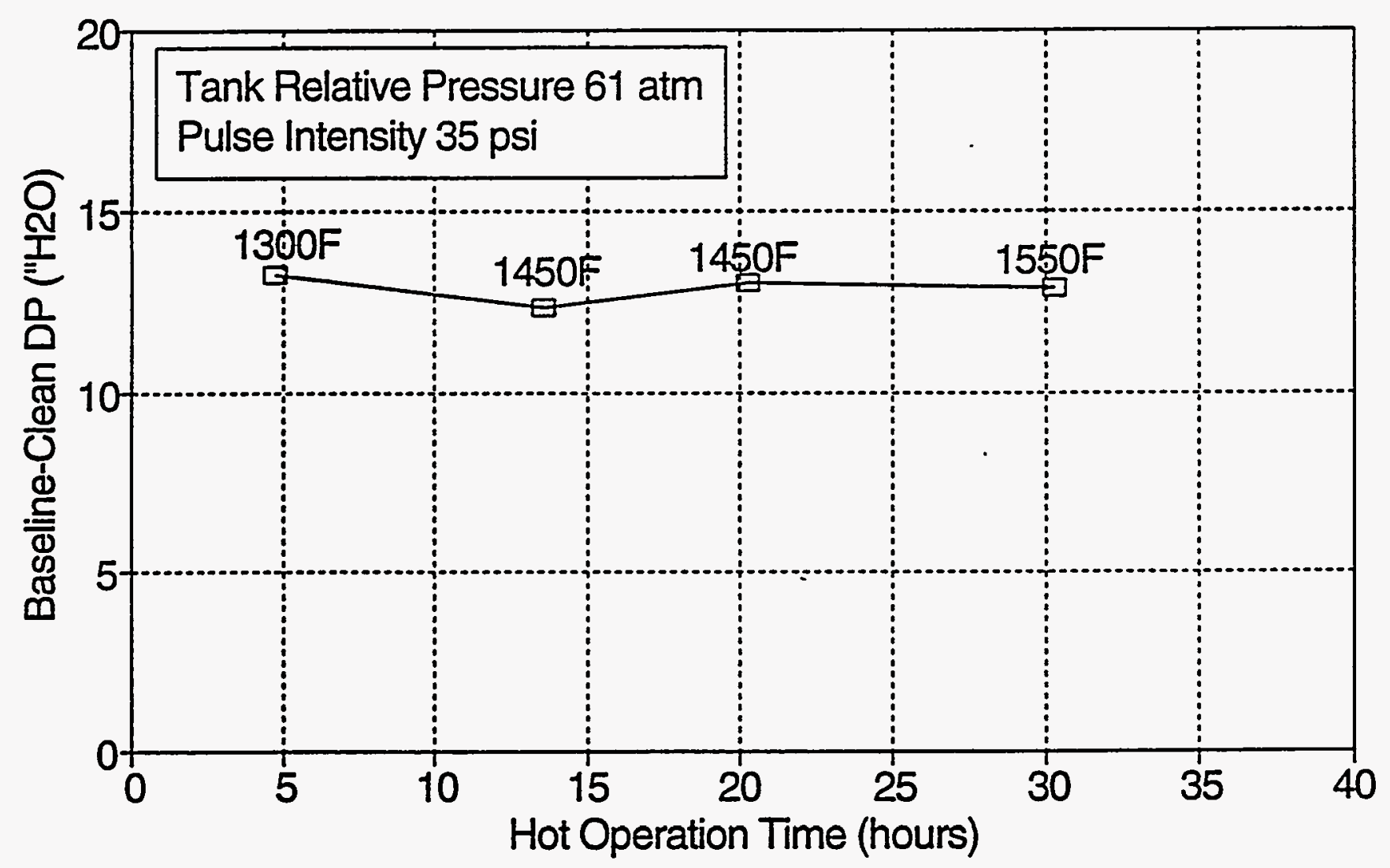

Figure B9 
APPENDIX C

TEST DATA

$c-1$ 


\section{Test 1.01 - 11/08/93}

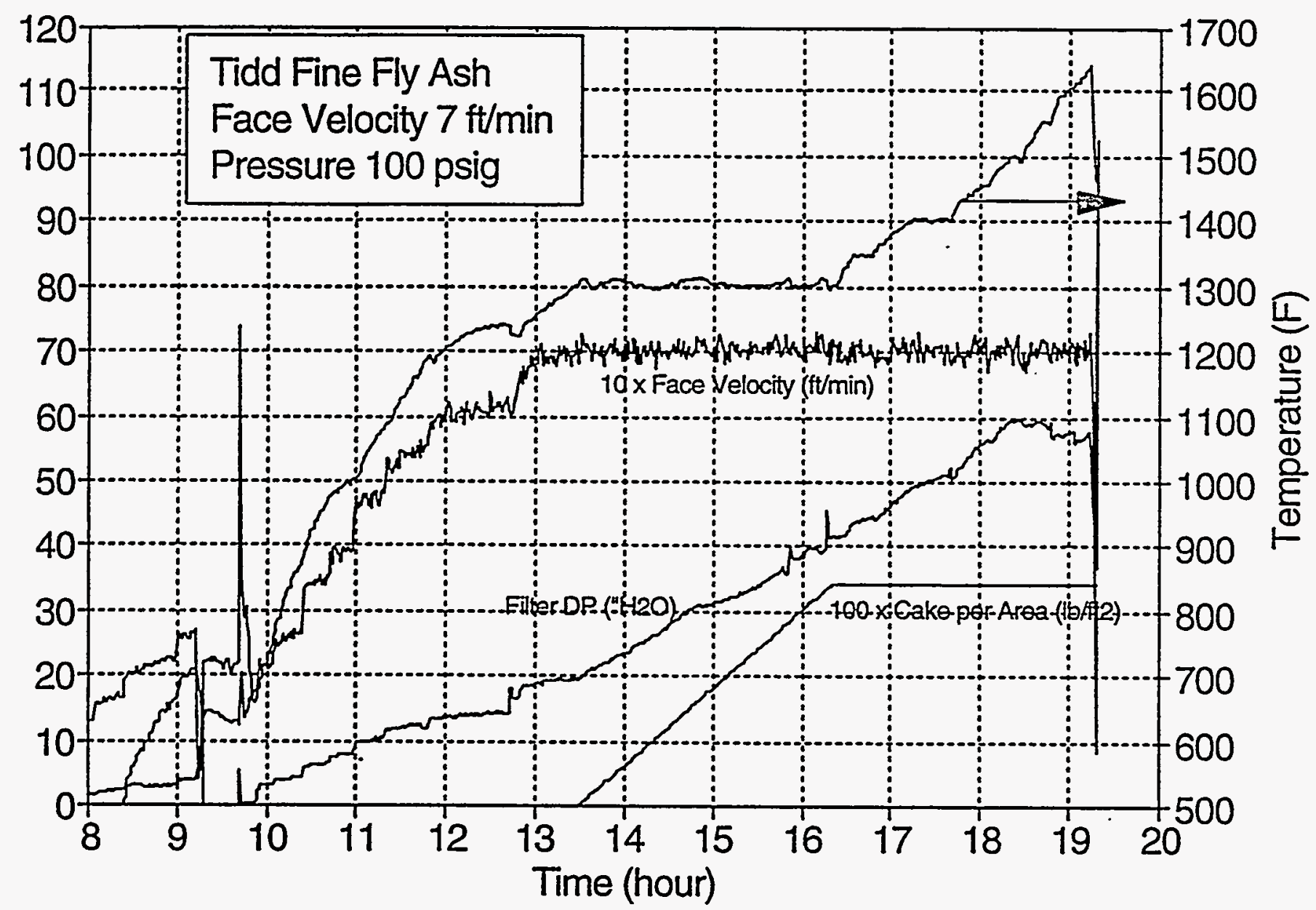




\section{Test $1.01-11 / 08 / 93$}

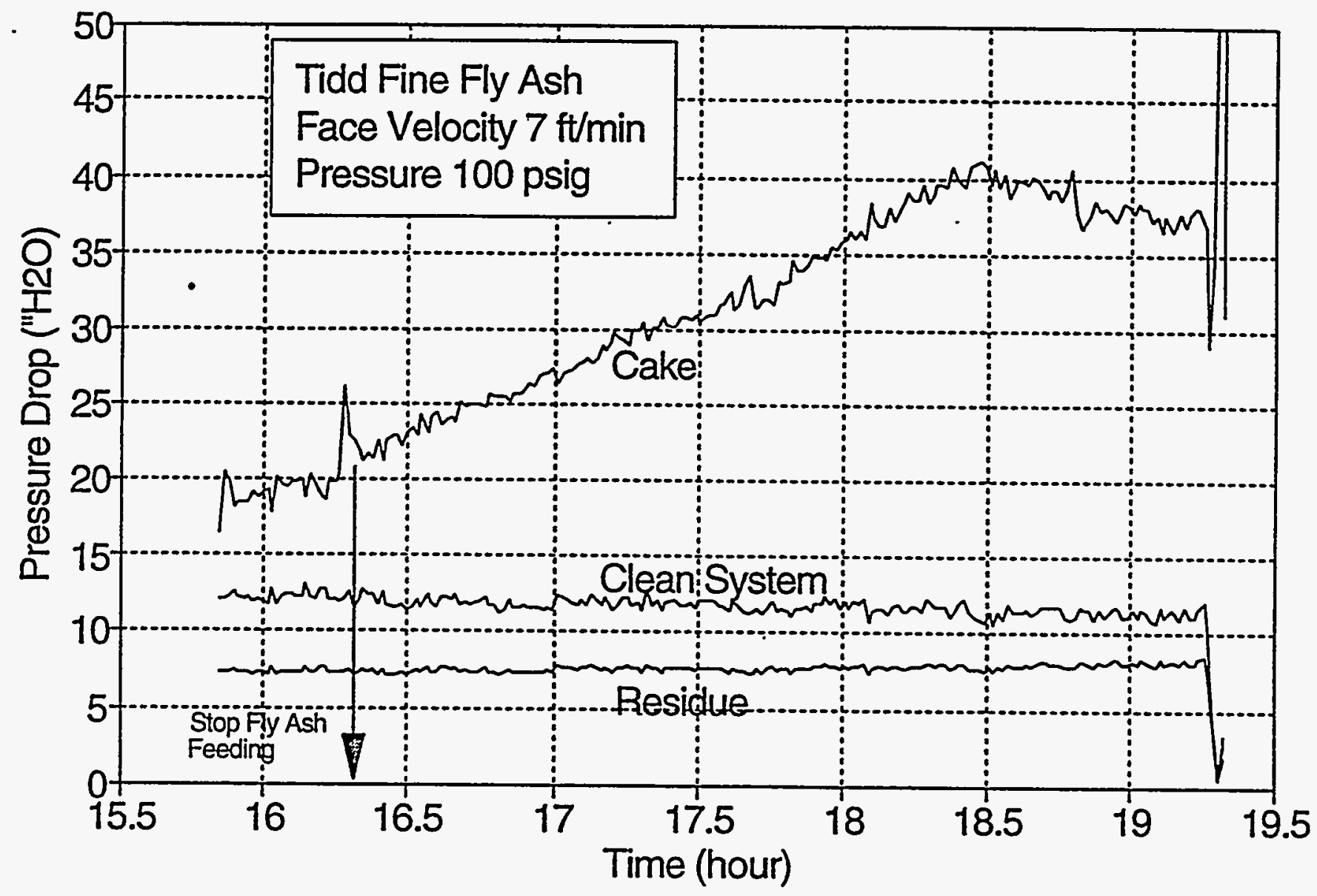




\section{Test $1.01-11 / 08 / 93$}

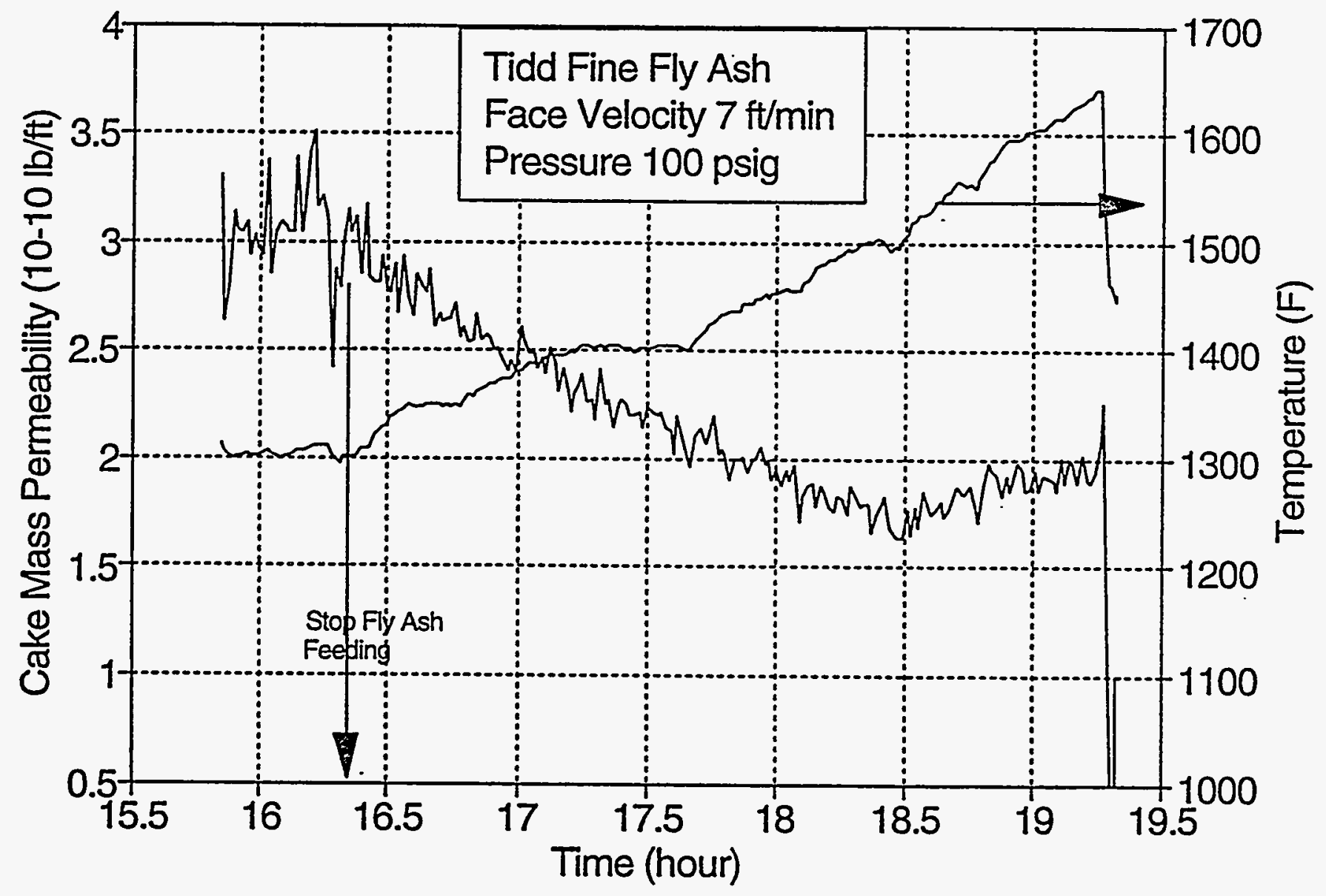




\section{Test 1.02 - 11/09/93}

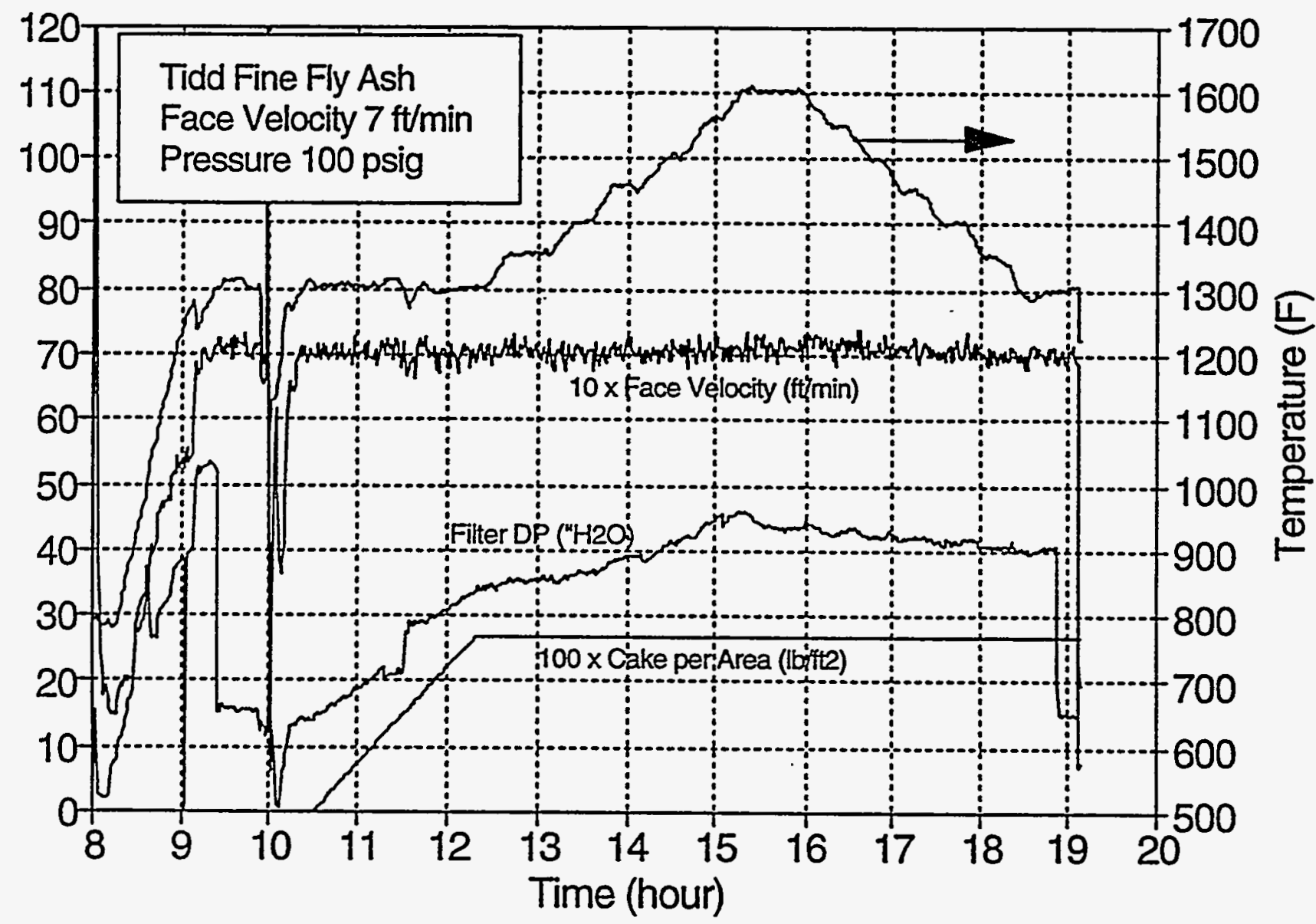




\section{Test 1.02 - 11/09/93}

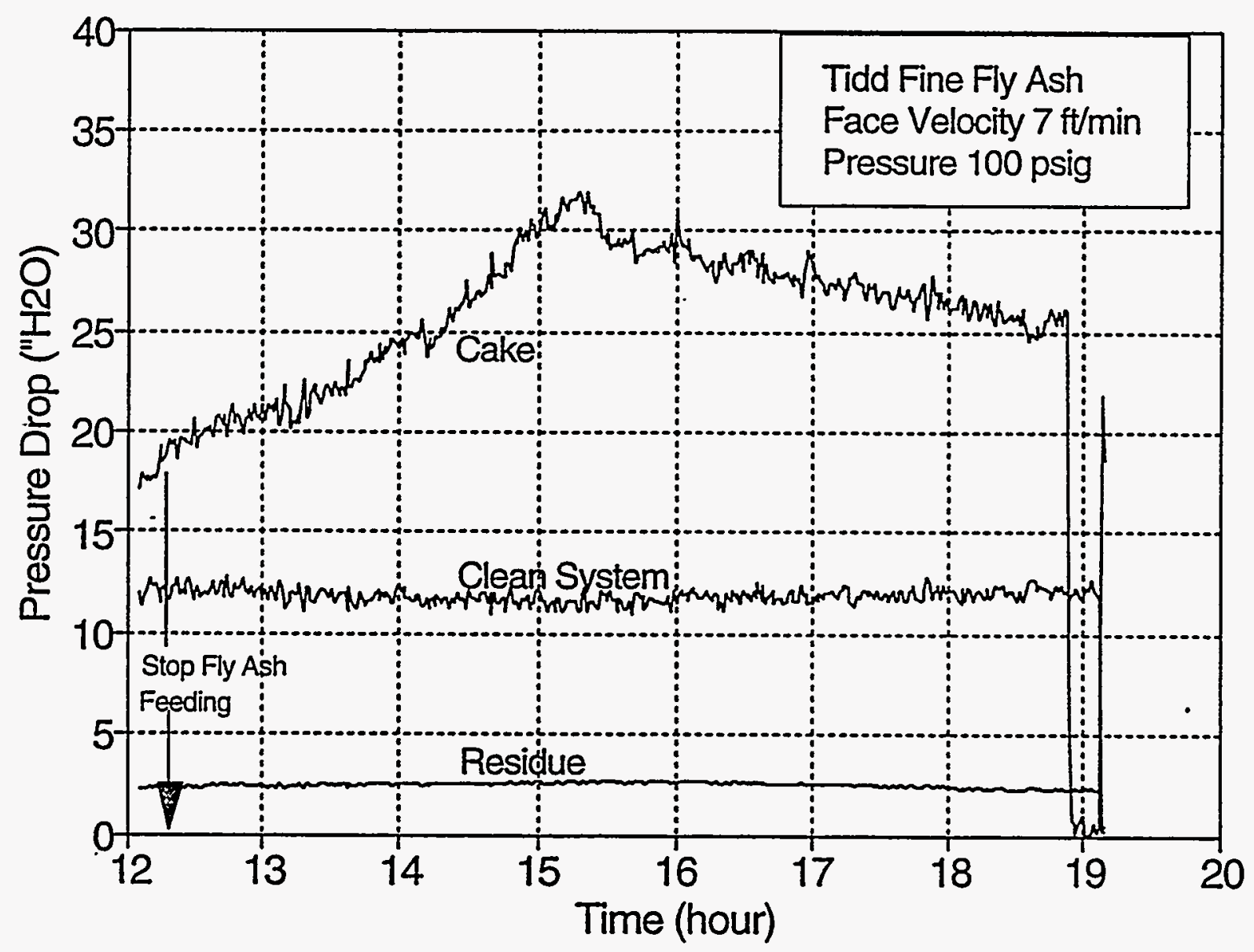




\section{Test 1.02 - 11/09/93}

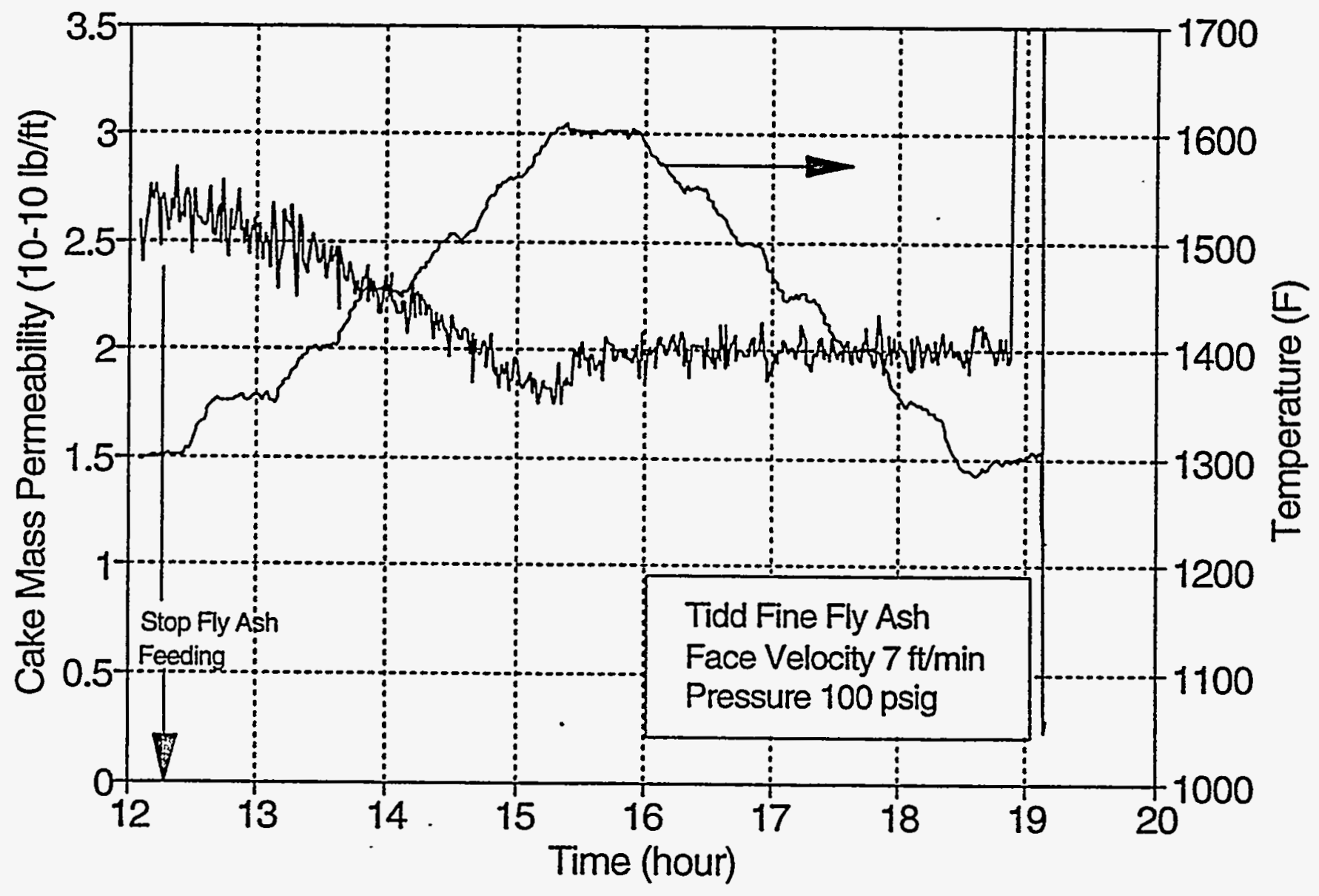




\section{Test 1.03 - 11/10/93}

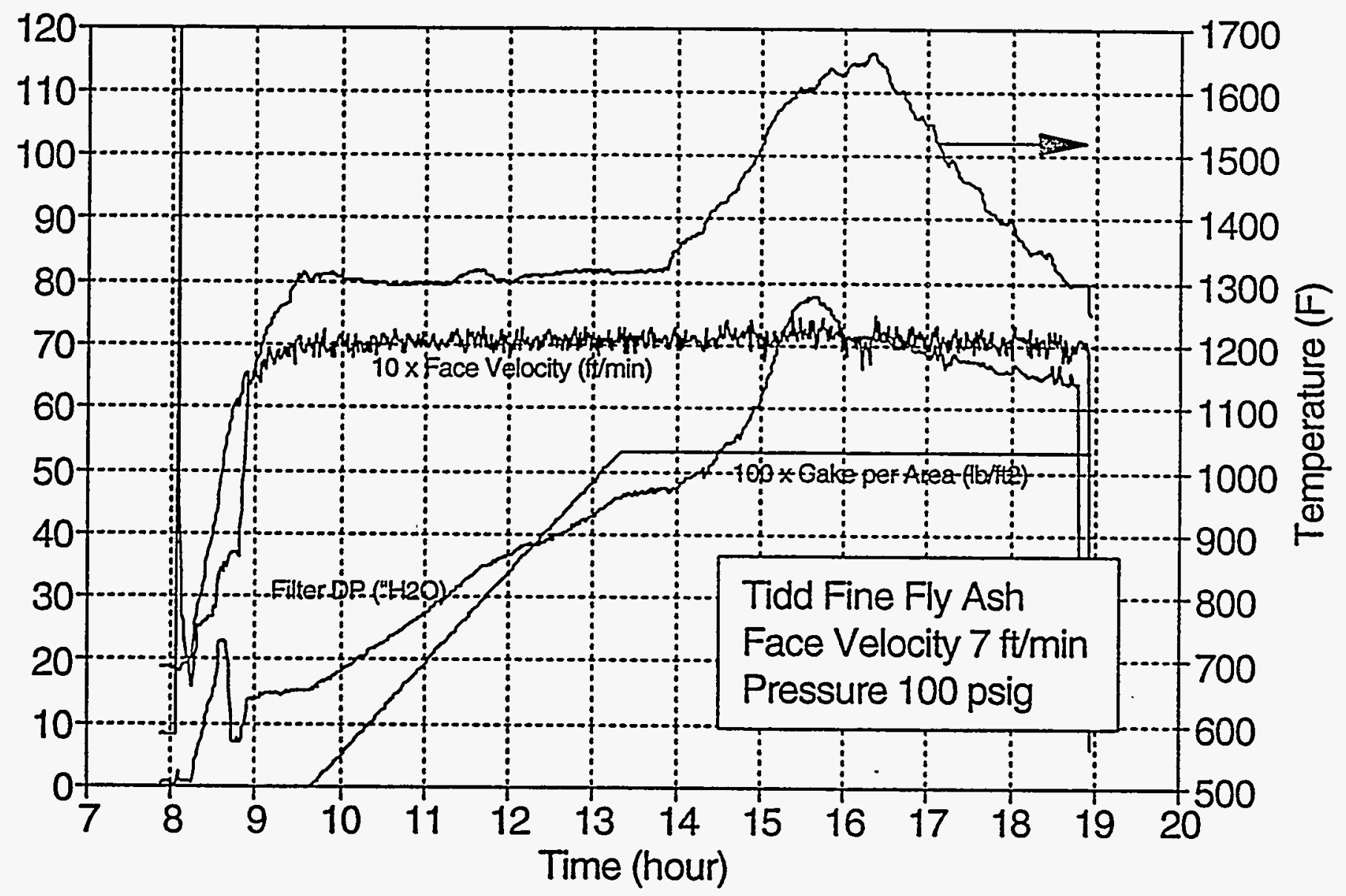




\section{Test $1.03-11 / 10 / 93$}

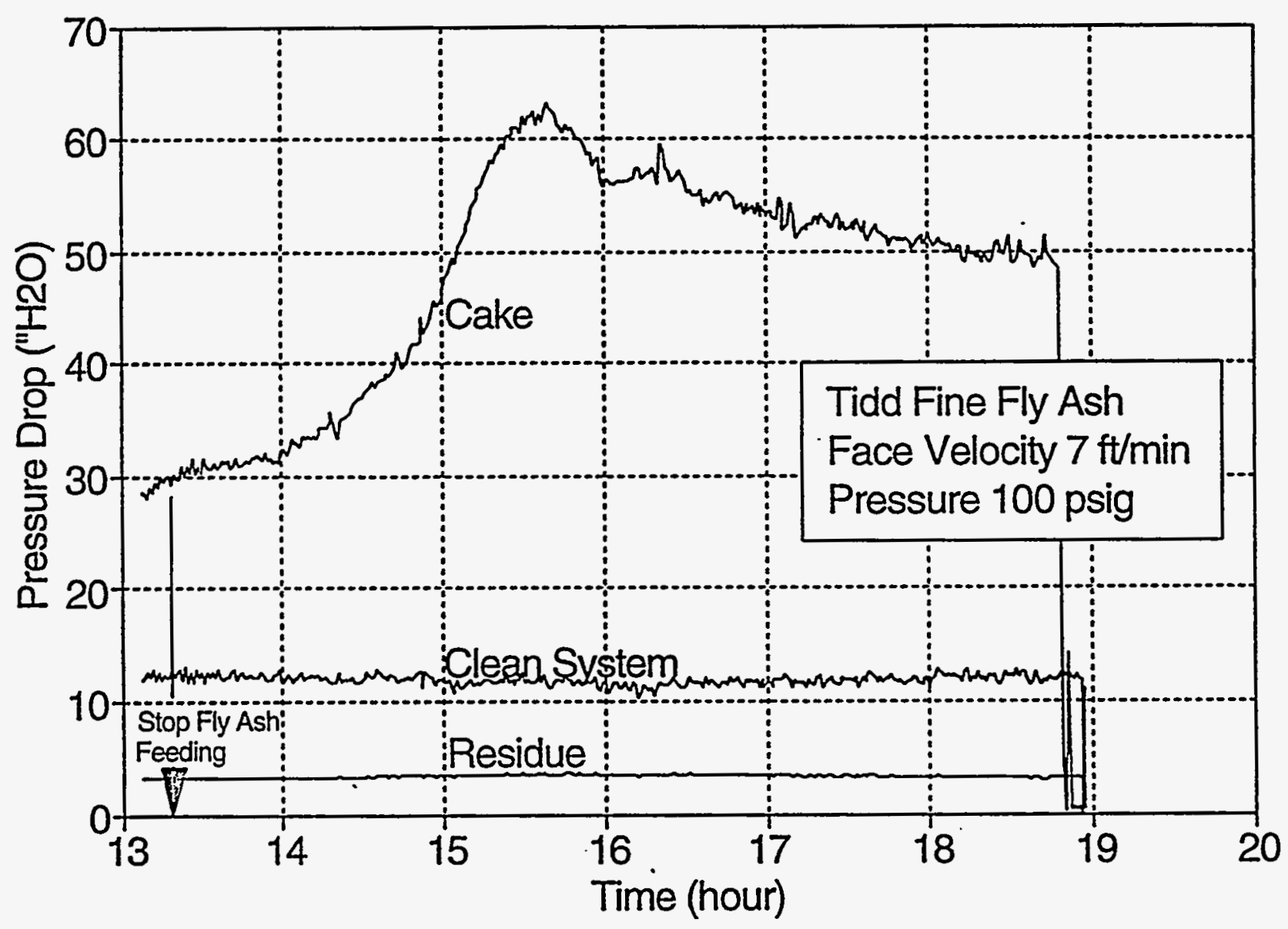




\section{Test $1.03-11 / 10 / 93$}

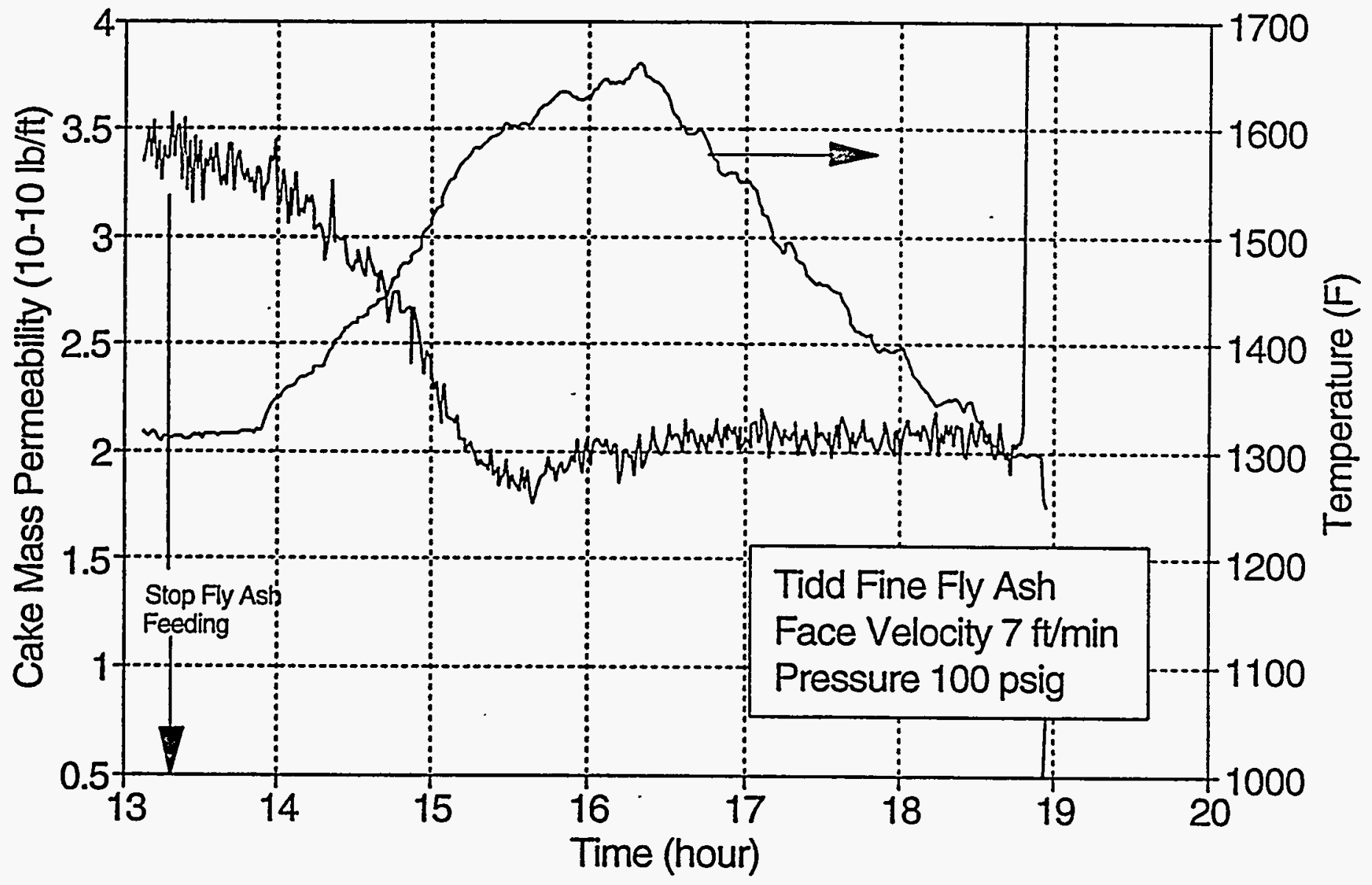




\section{Test $1.04-11 / 11 / 93$}

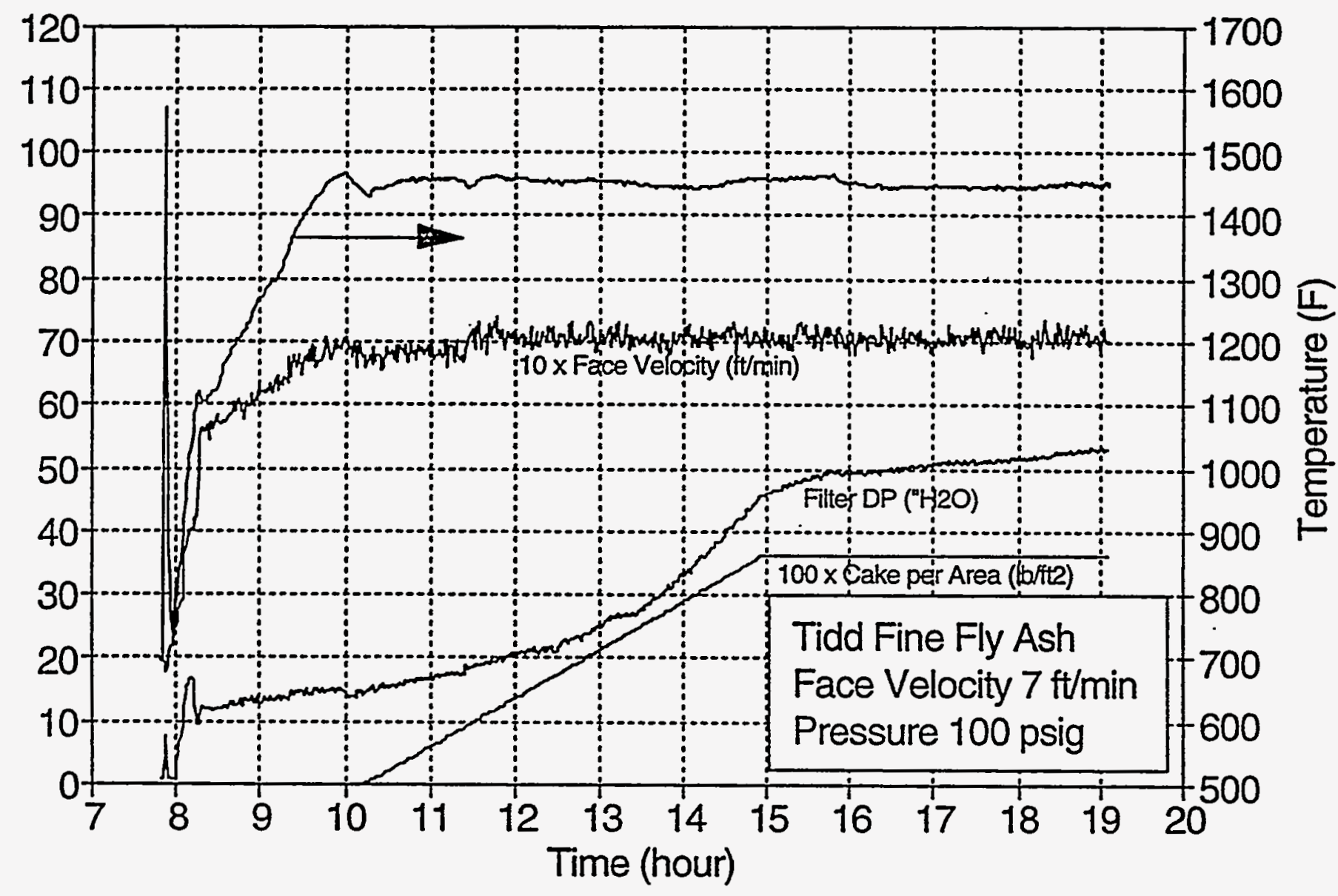




\section{Test $1.04-11 / 11 / 93$}

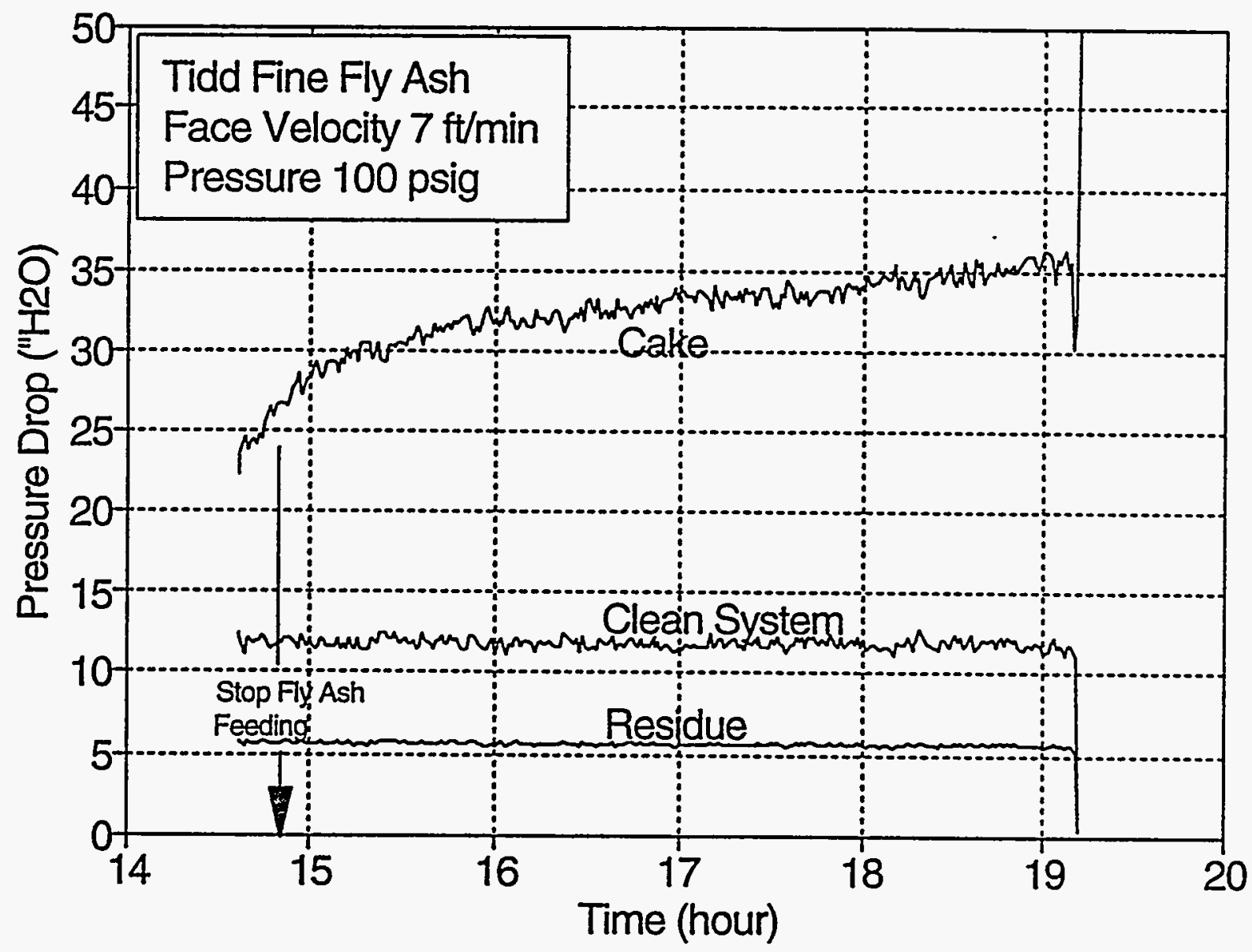


Test $1.04-11 / 11 / 93$

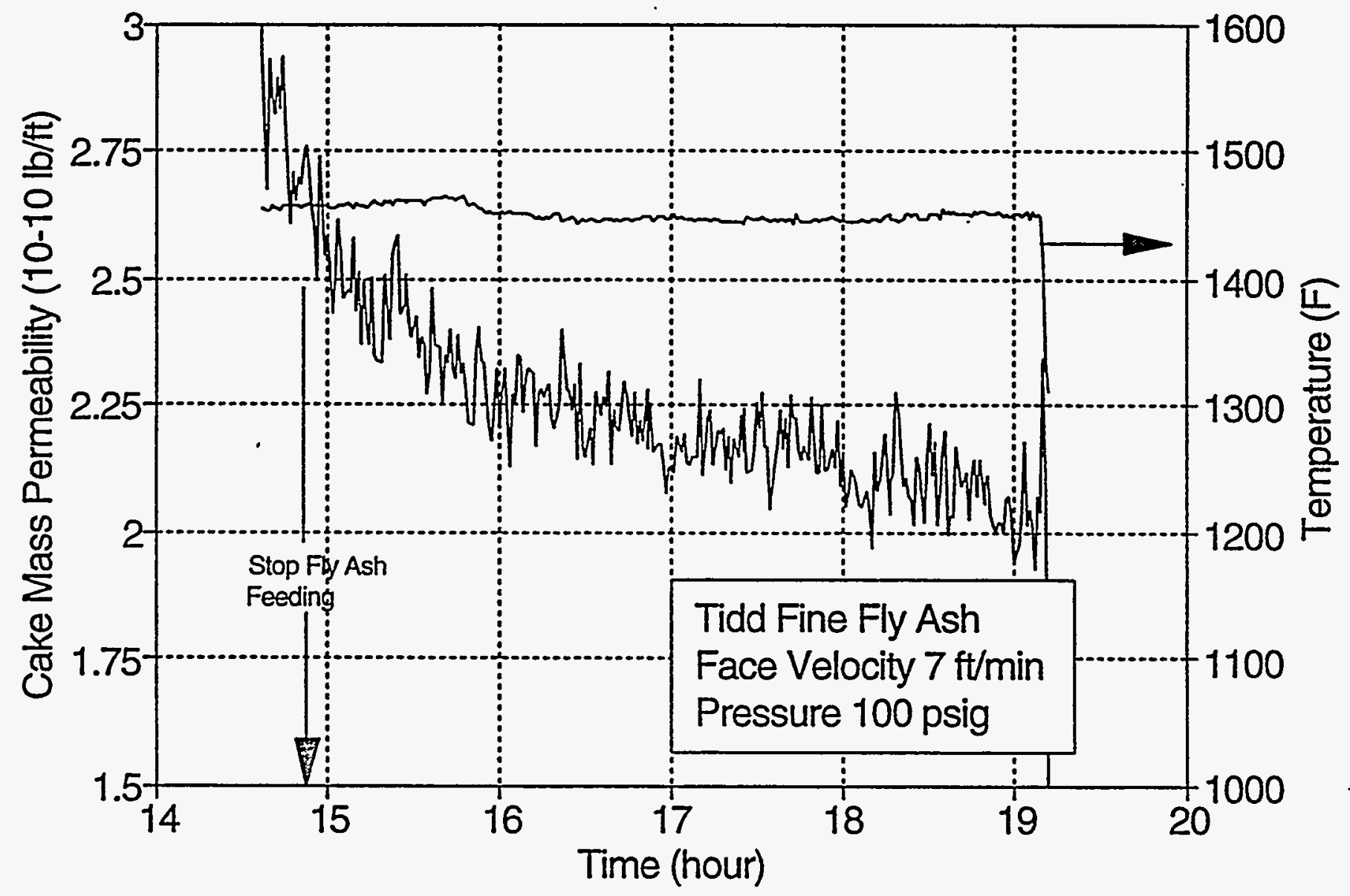




\section{Test 1.05 - 11/12/93}

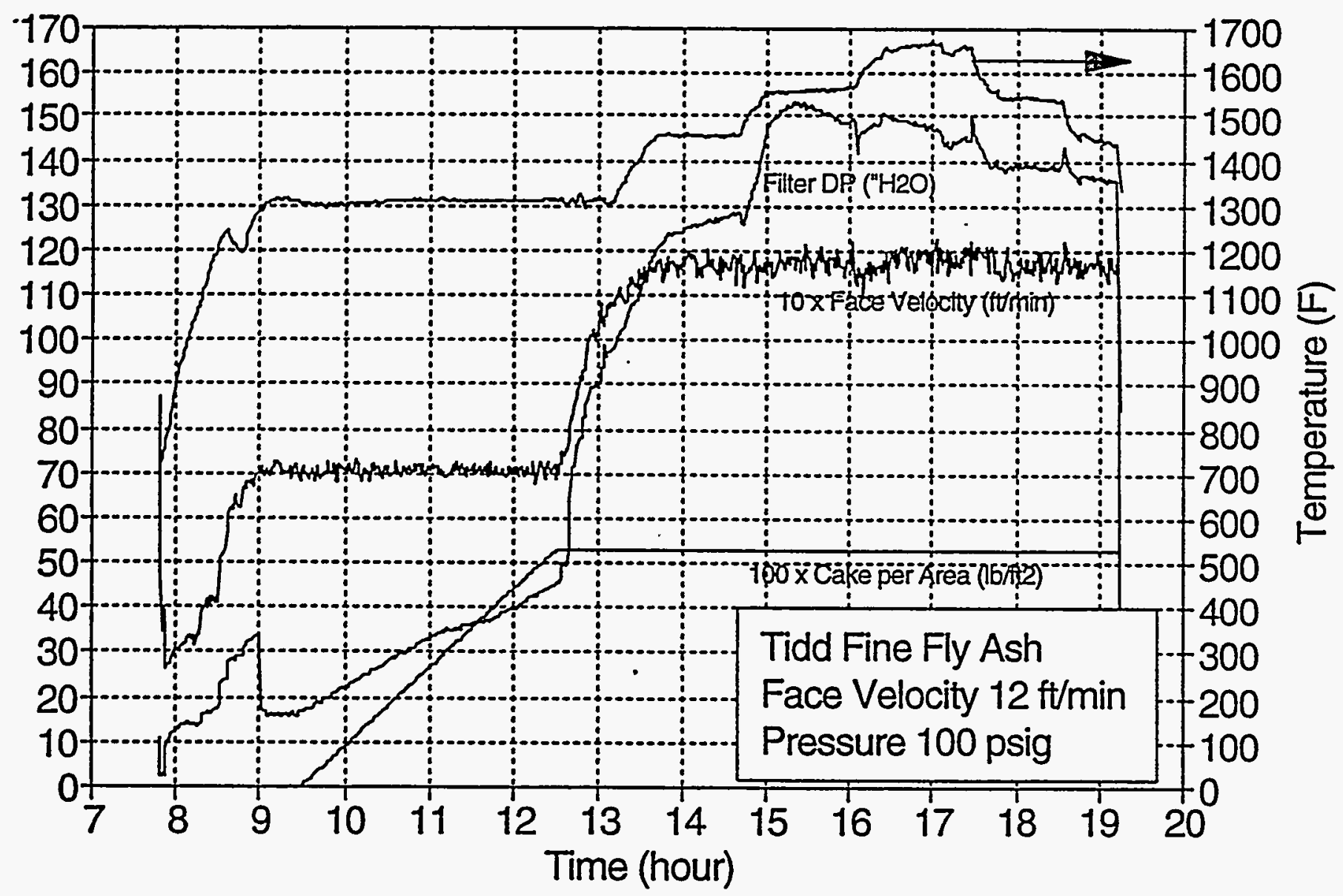




\section{Test 1.05 - 11/12/93}

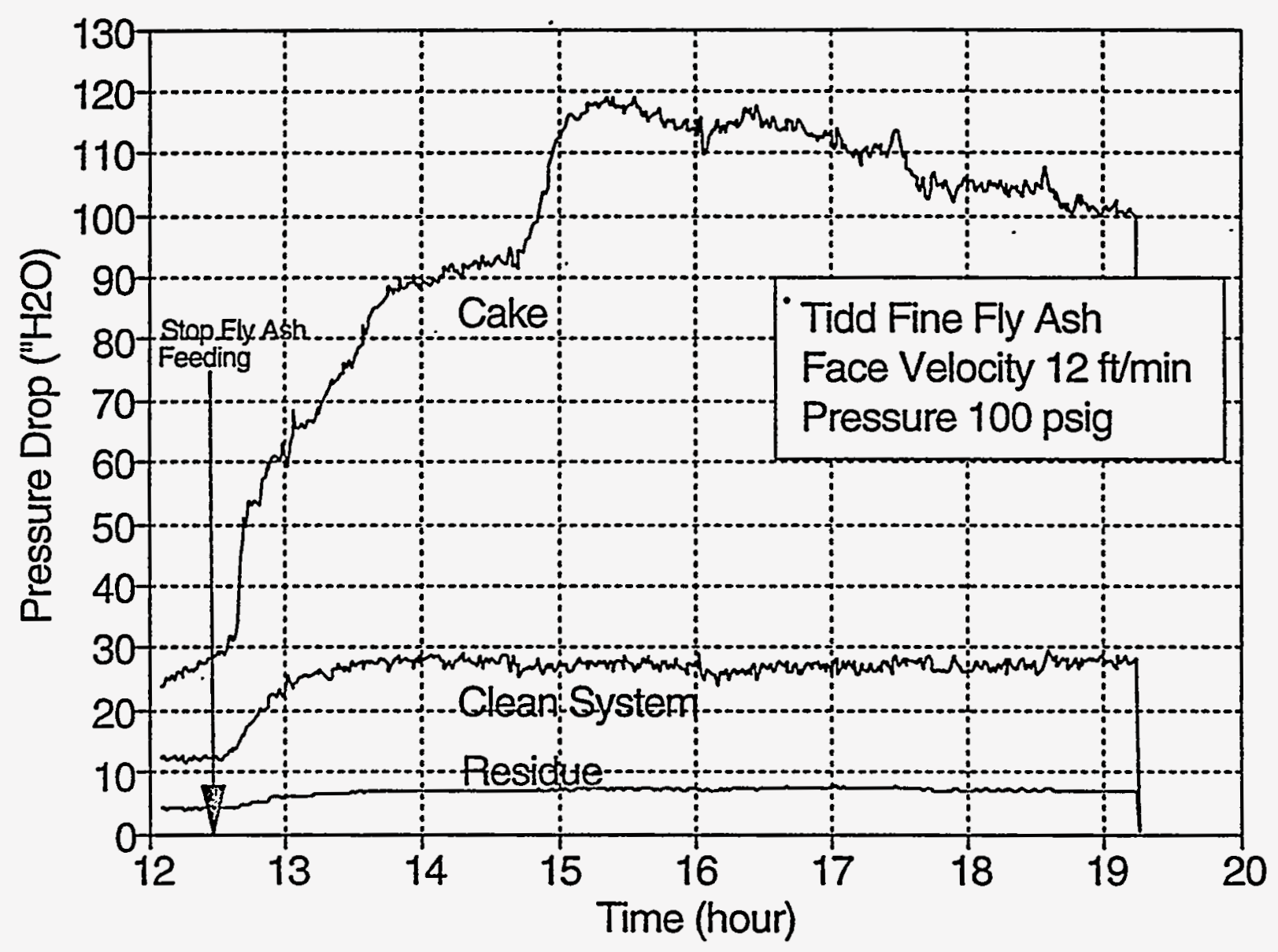




\section{Test $1.05-11 / 12 / 93$}

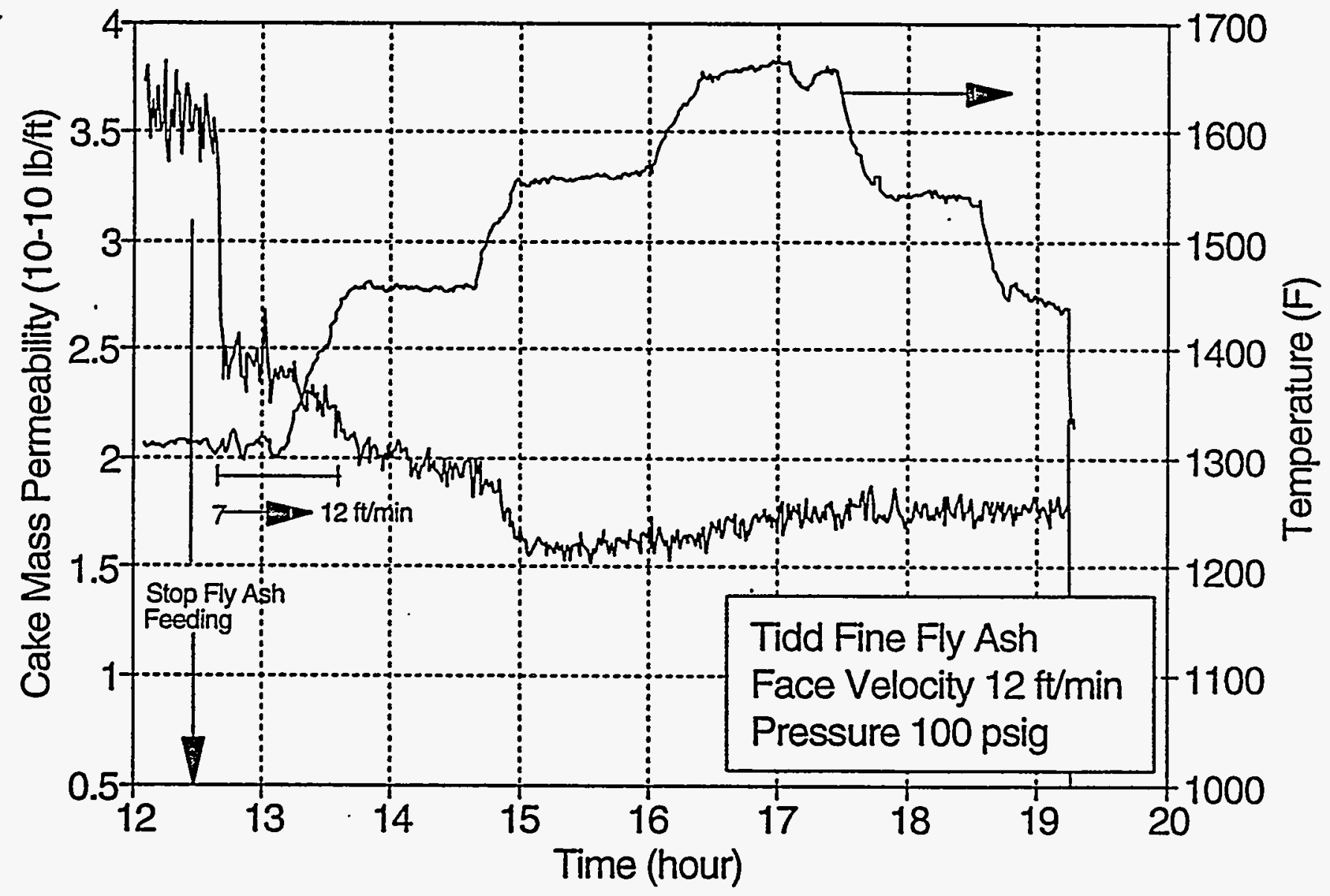


Test $1.06-11 / 15 / 93$

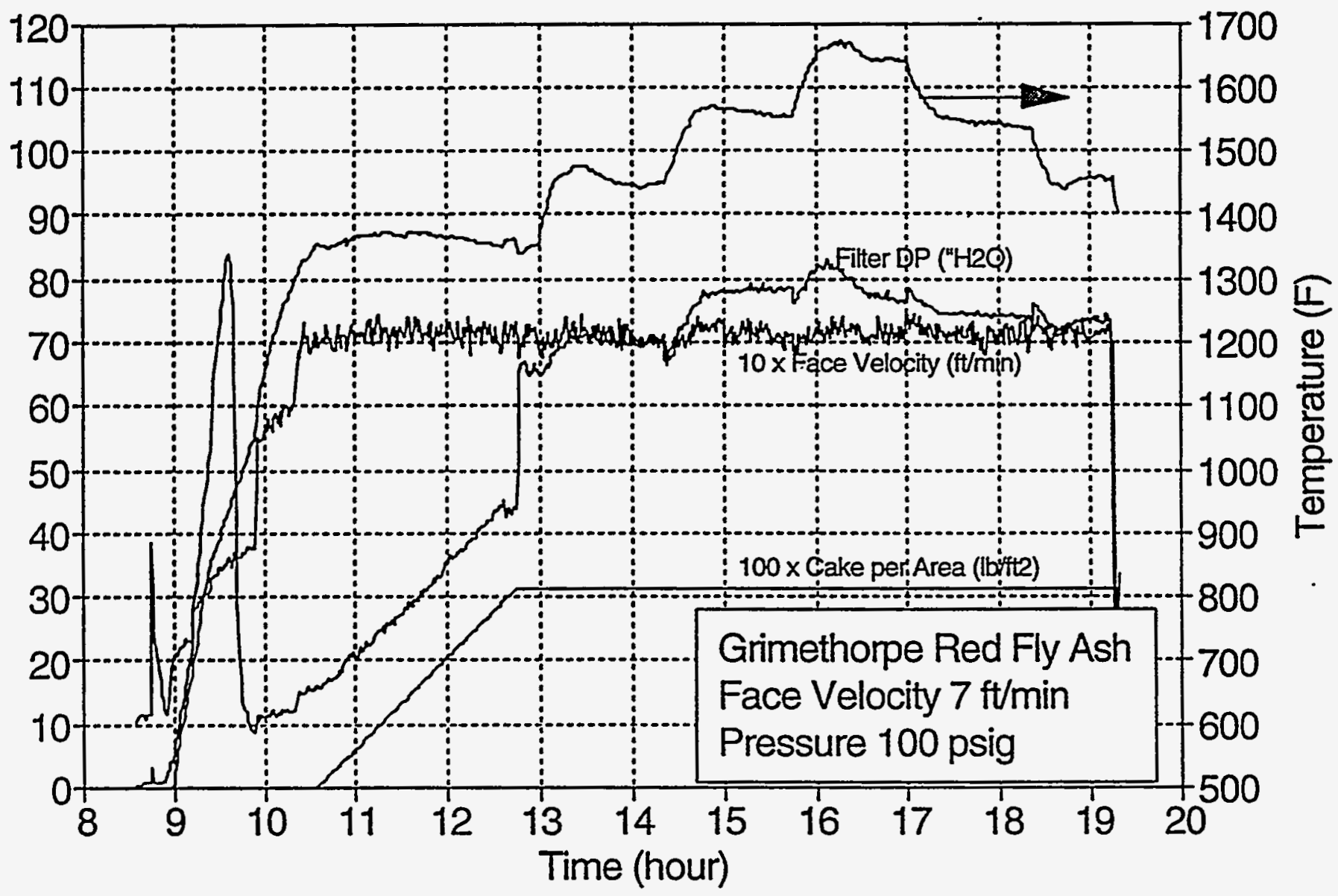




\section{Test $1.06-11 / 15 / 93$}

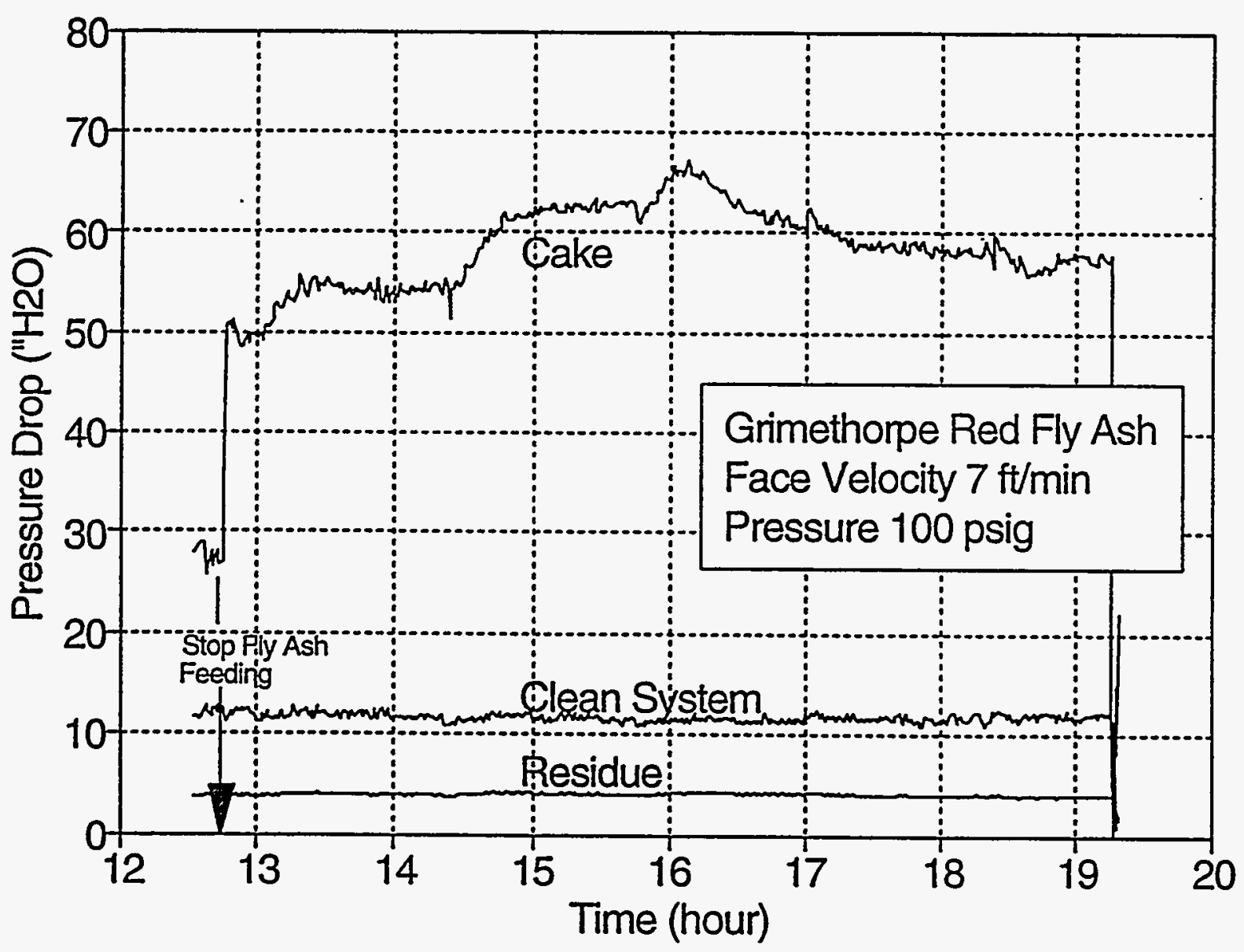




\section{Test 1.06 - 11/15/93}

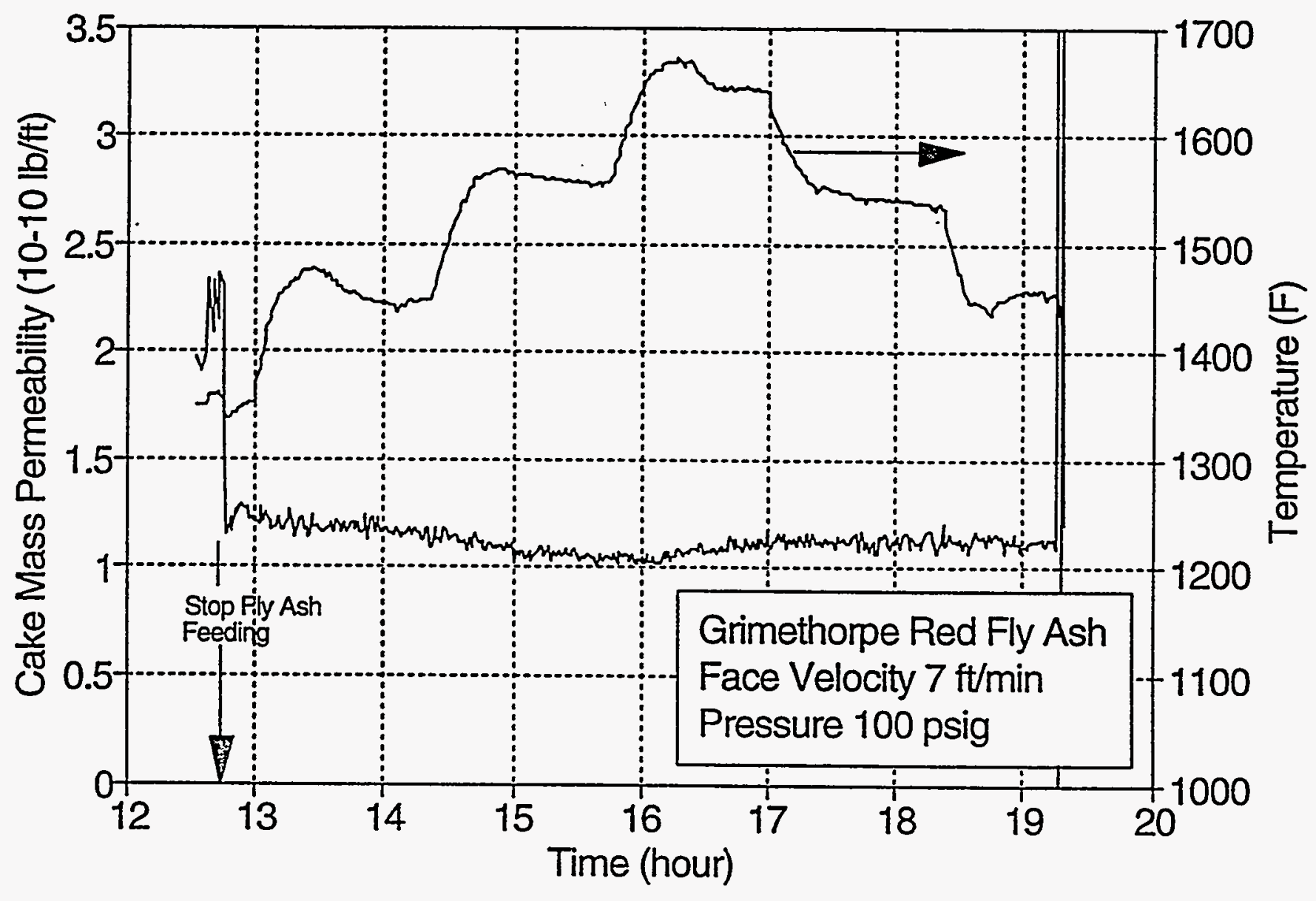




\section{Test $1.07-11 / 16 / 93$}

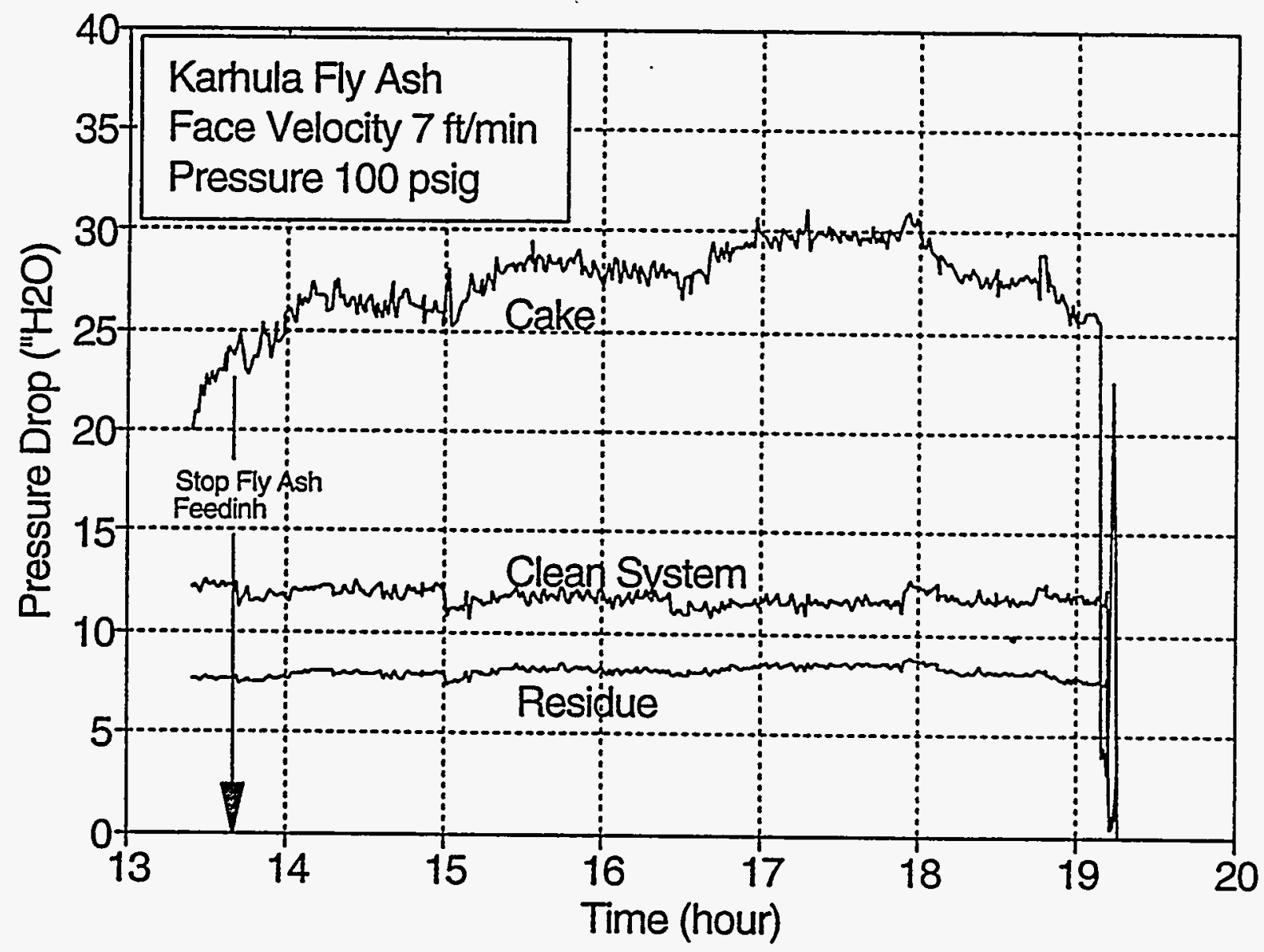




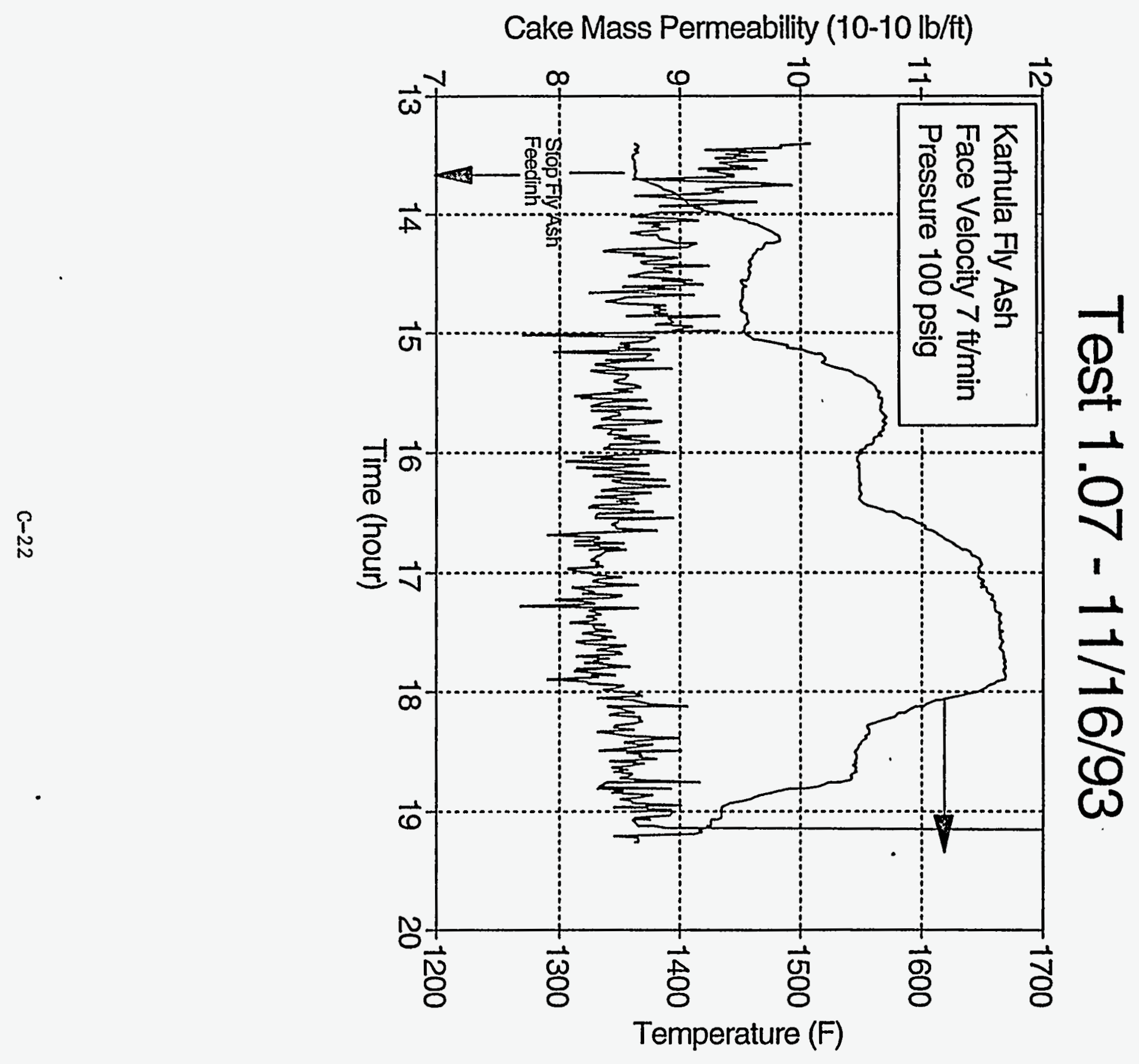




\section{Test $1.08-11 / 17 / 93$}

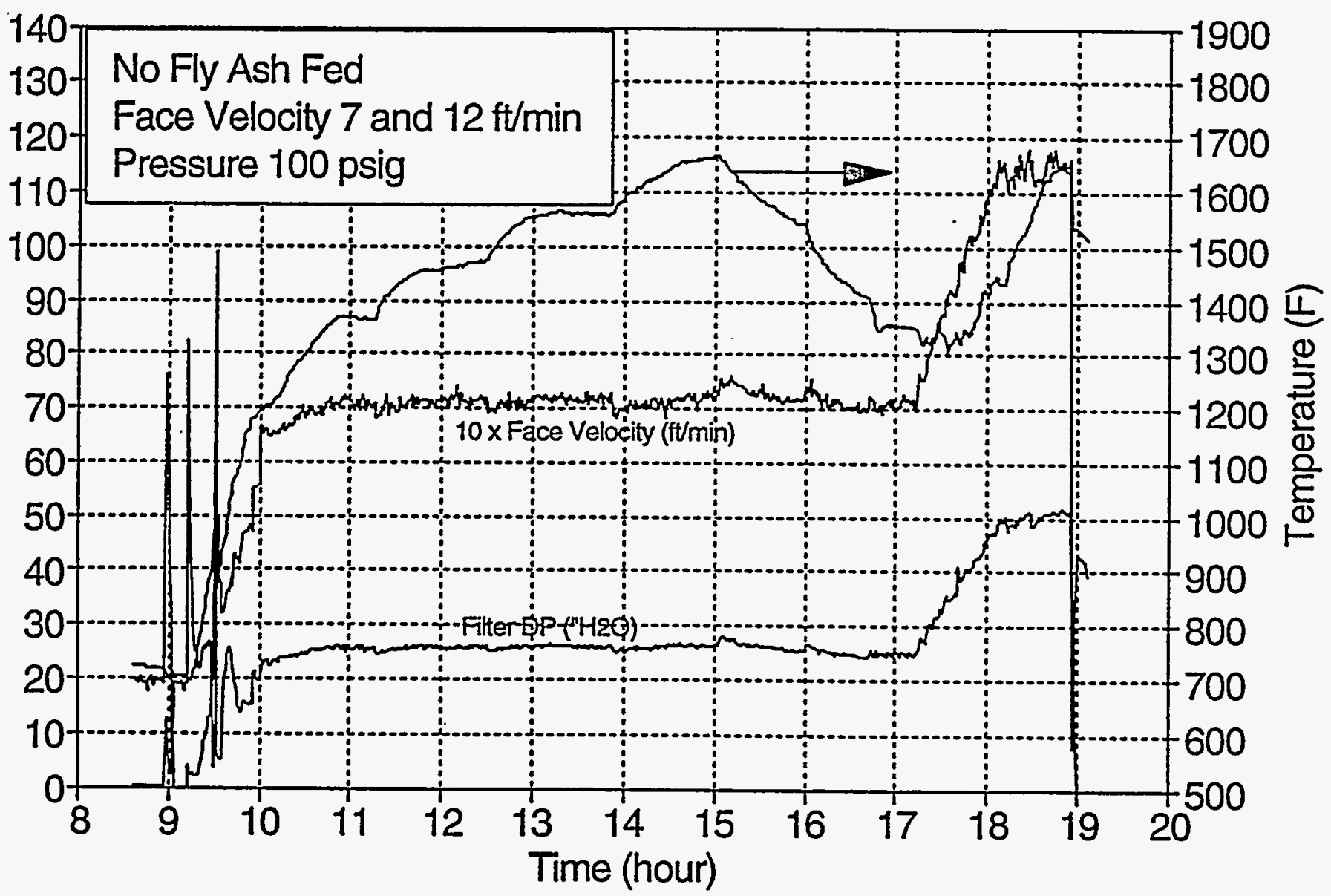




\section{Test $1.08-11 / 17 / 93$}

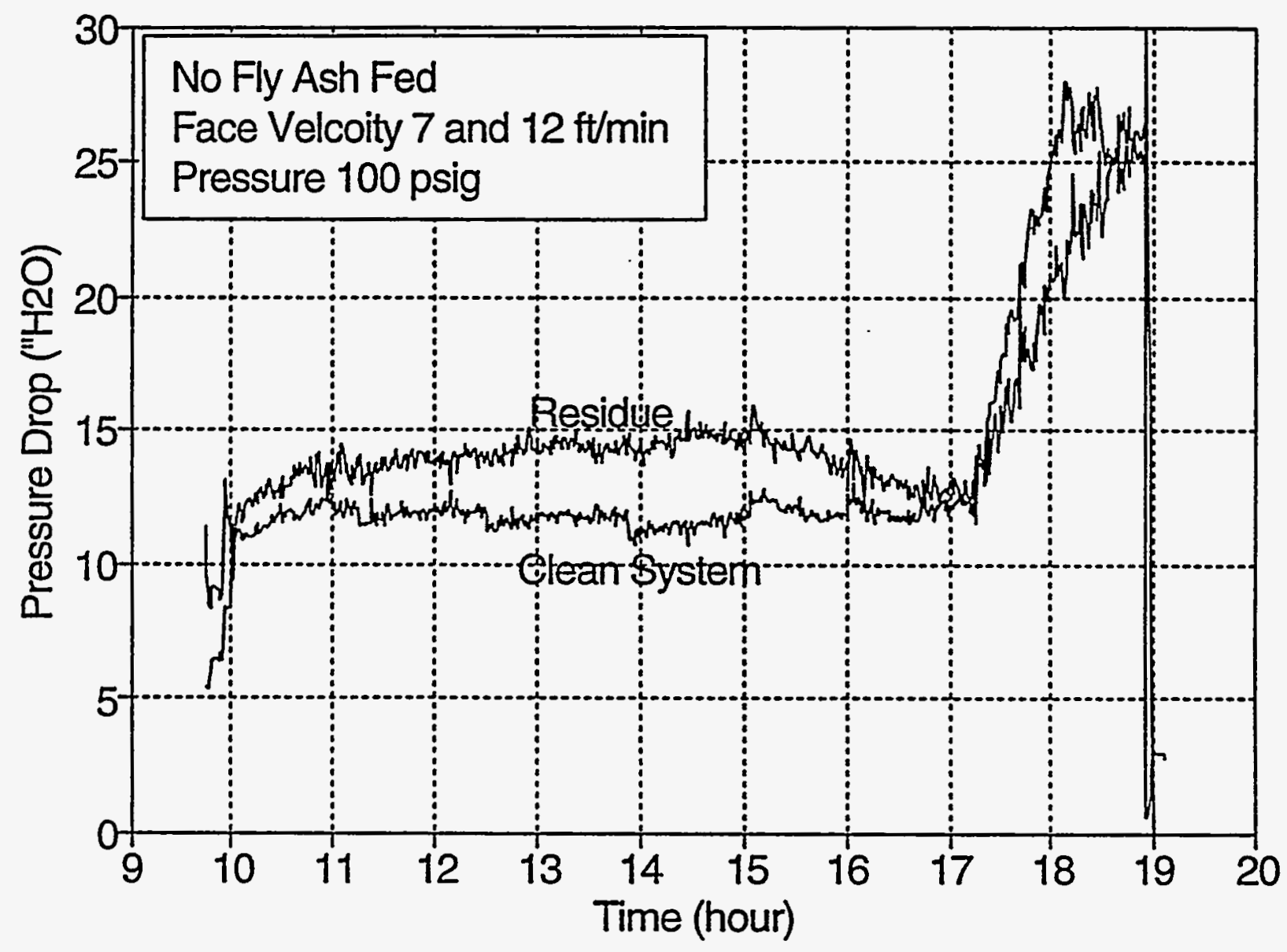




\section{Test 1.08 - 11/17/93}

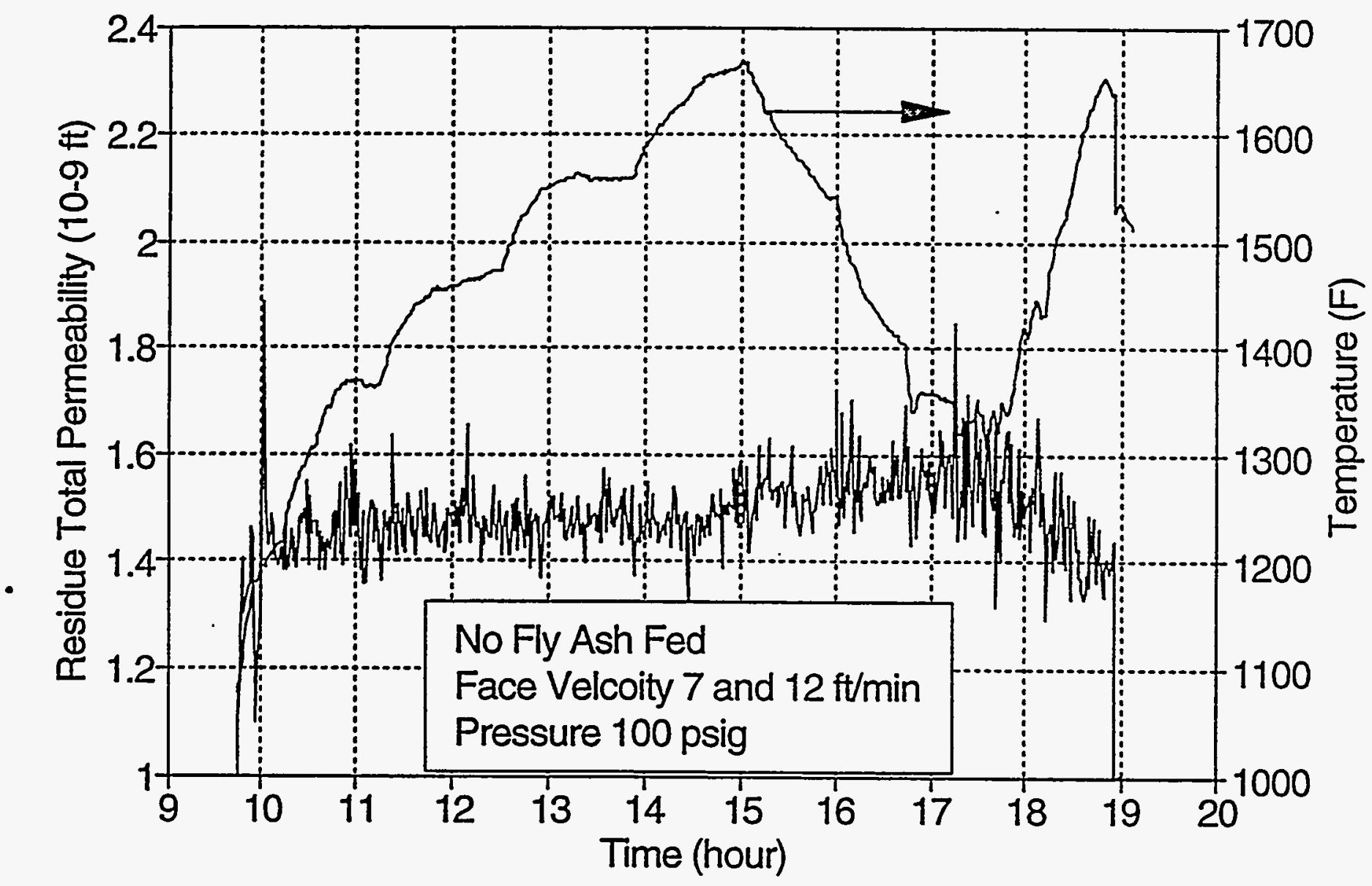




\section{Test 1.09 - 11/23/93}

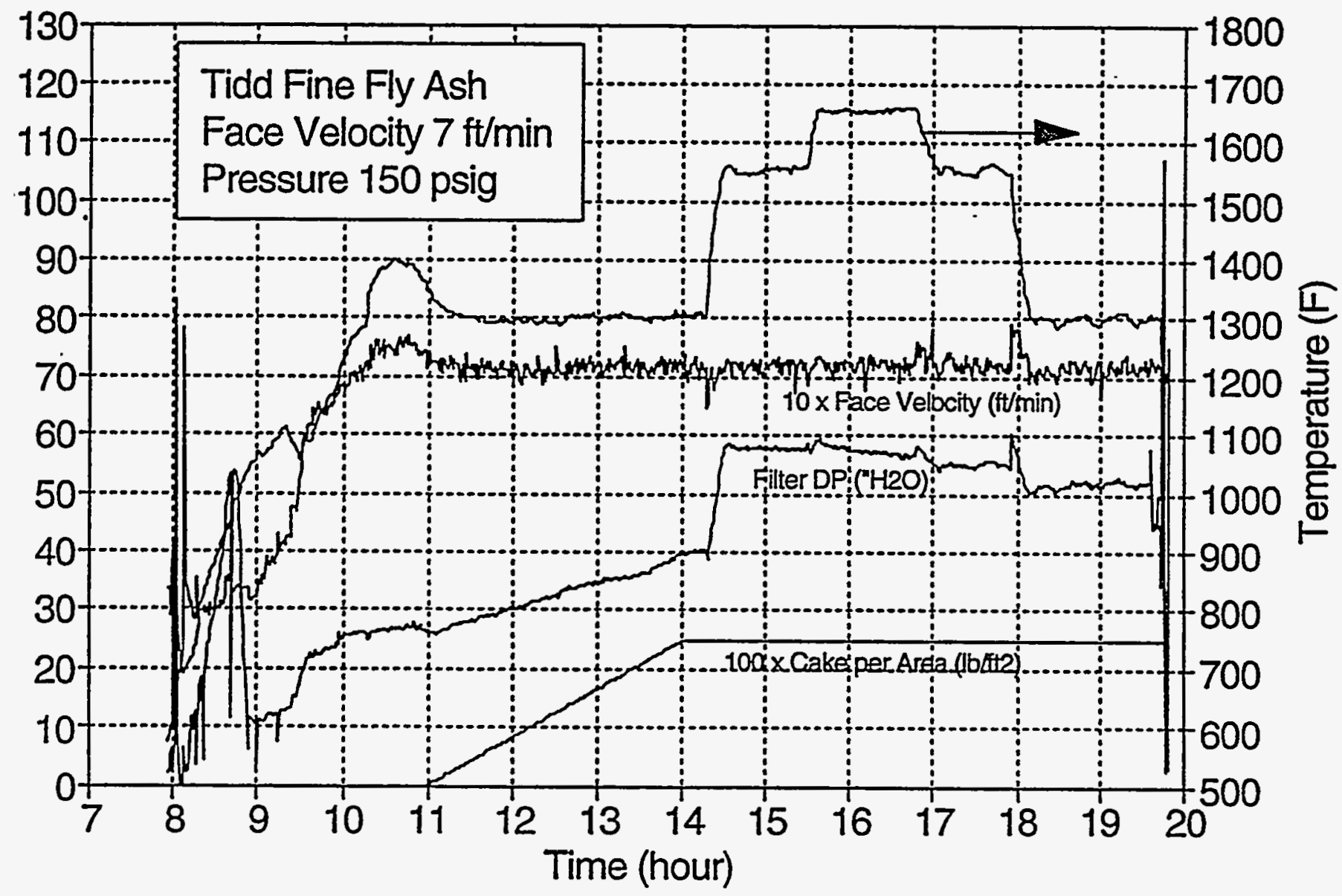




\section{Test 1.09 - 11/23/93}

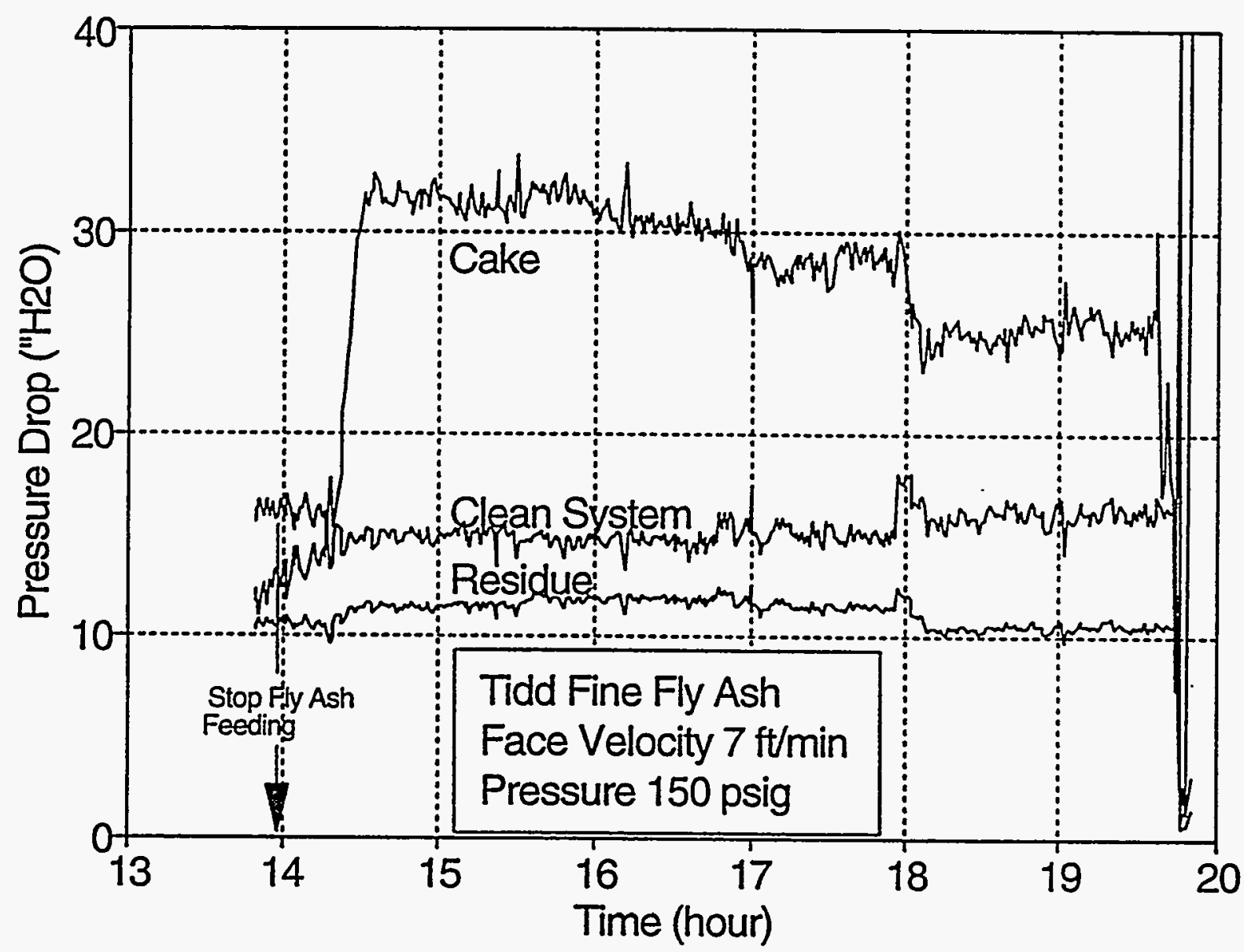




\section{Test $1.09-11 / 23 / 93$}

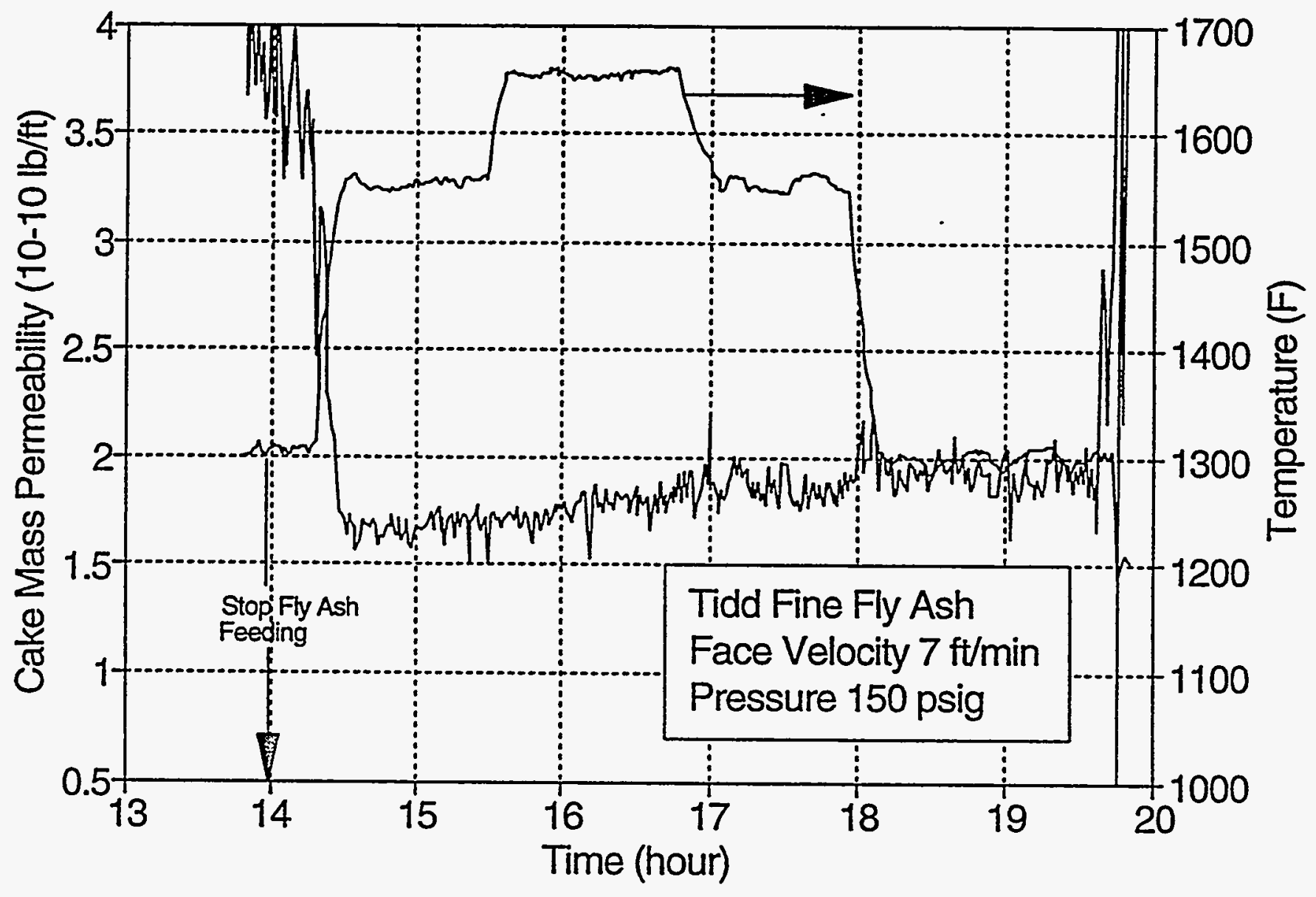




\section{Test 1.10 - 2/21/94}

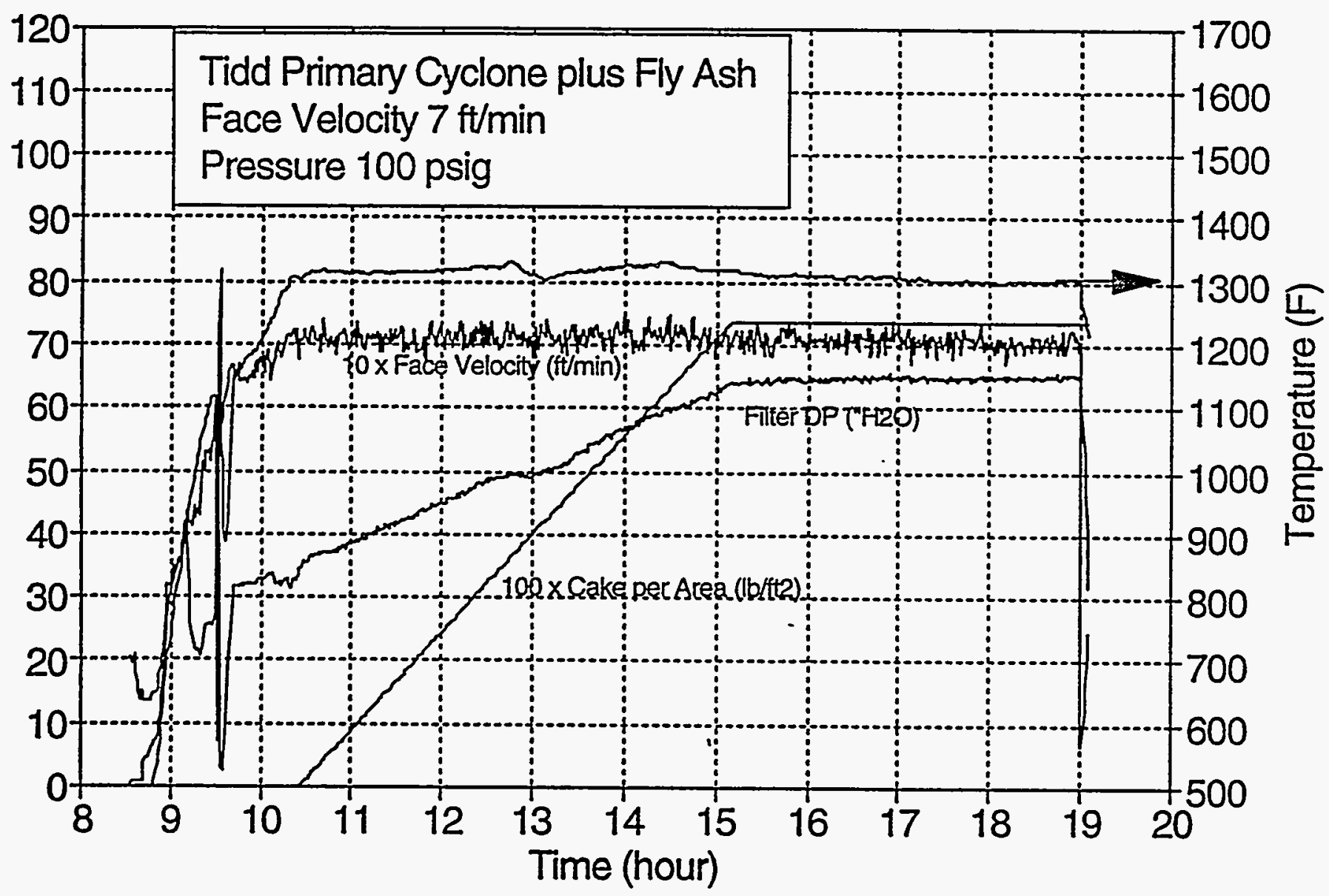


Test 1.10 - 2/21/94

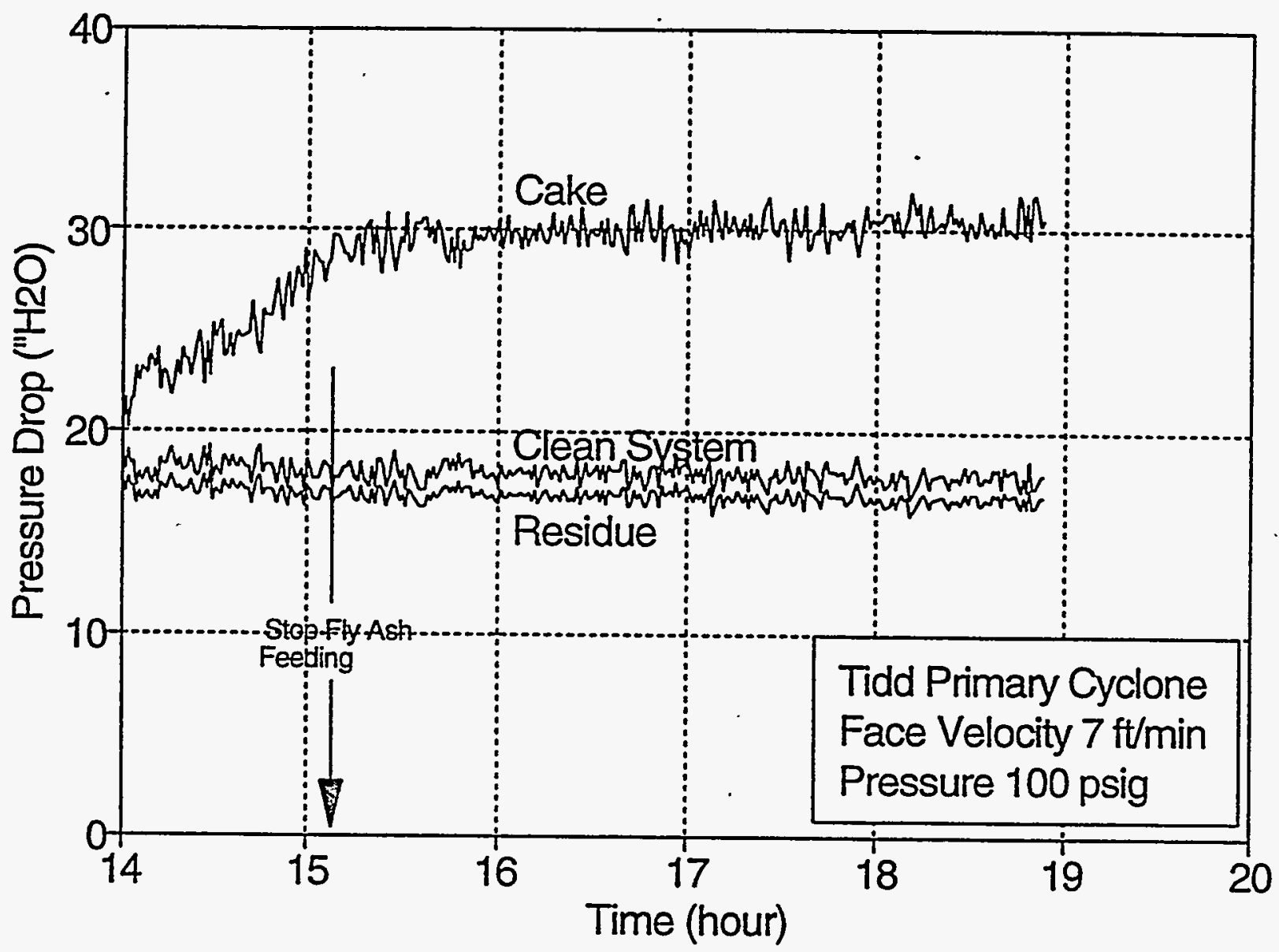




\section{Test $1.10-2 / 21 / 94$}

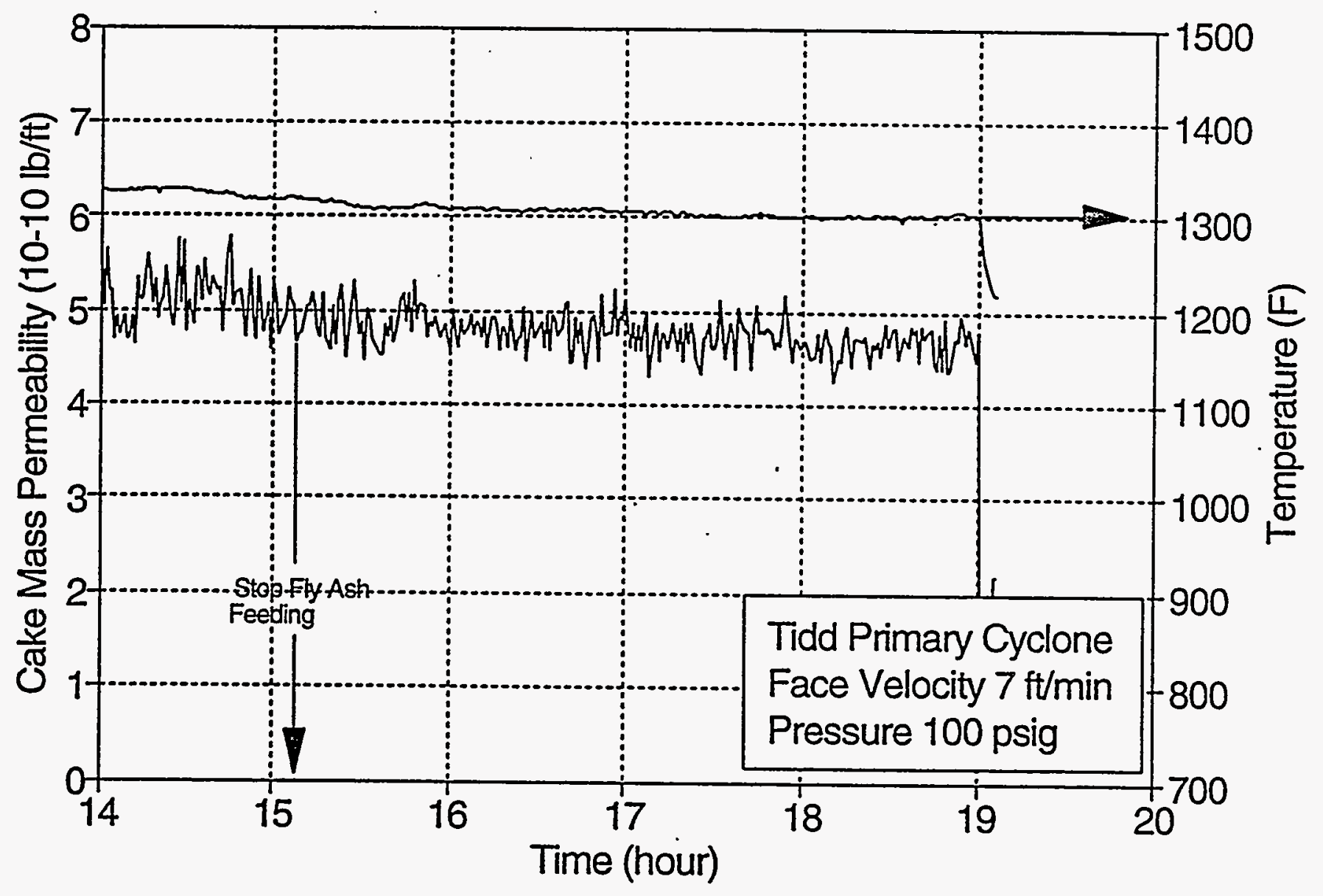




\section{Test 1.10 - 2/22/94}

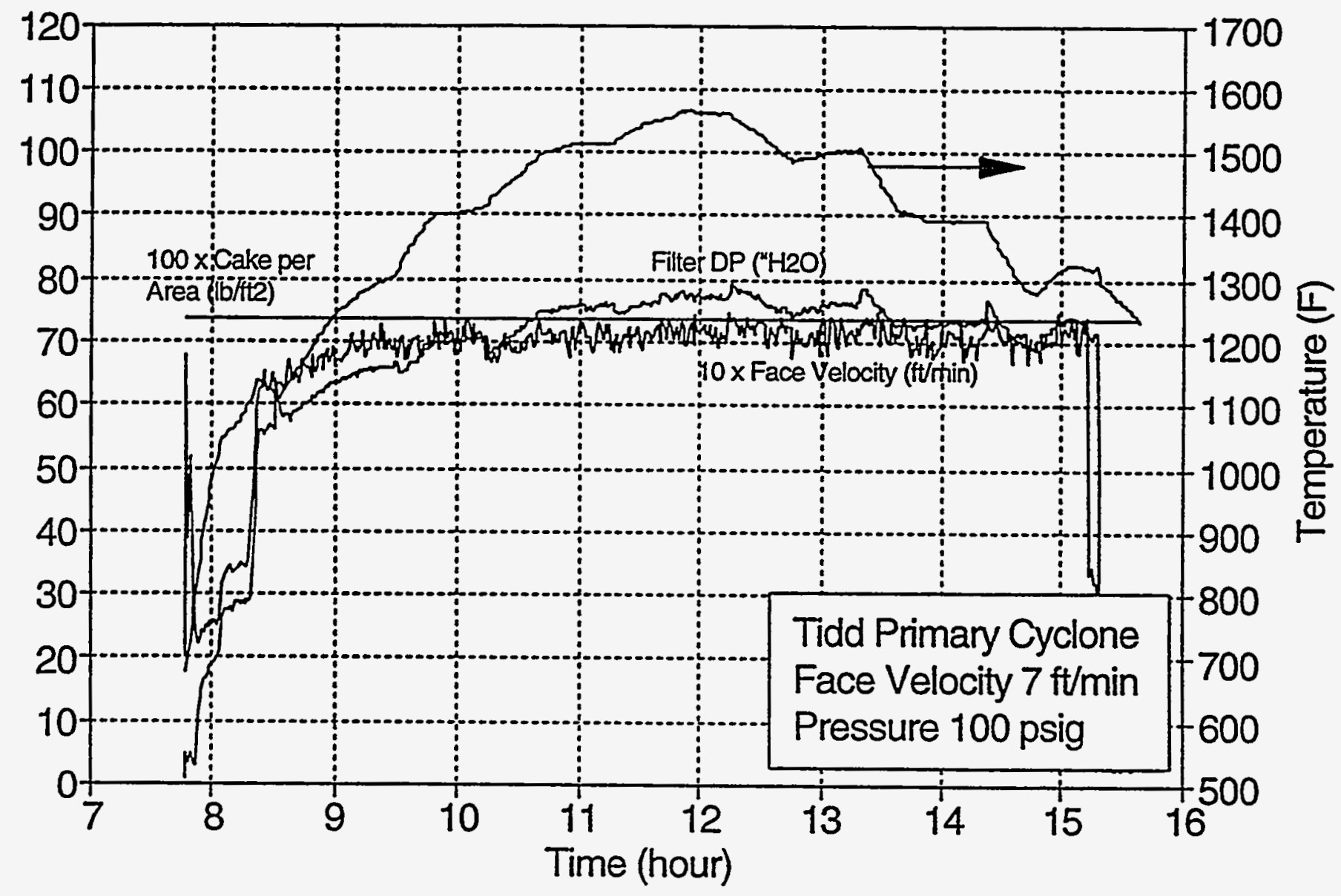




\section{Test 1.10 - 2/22/94}

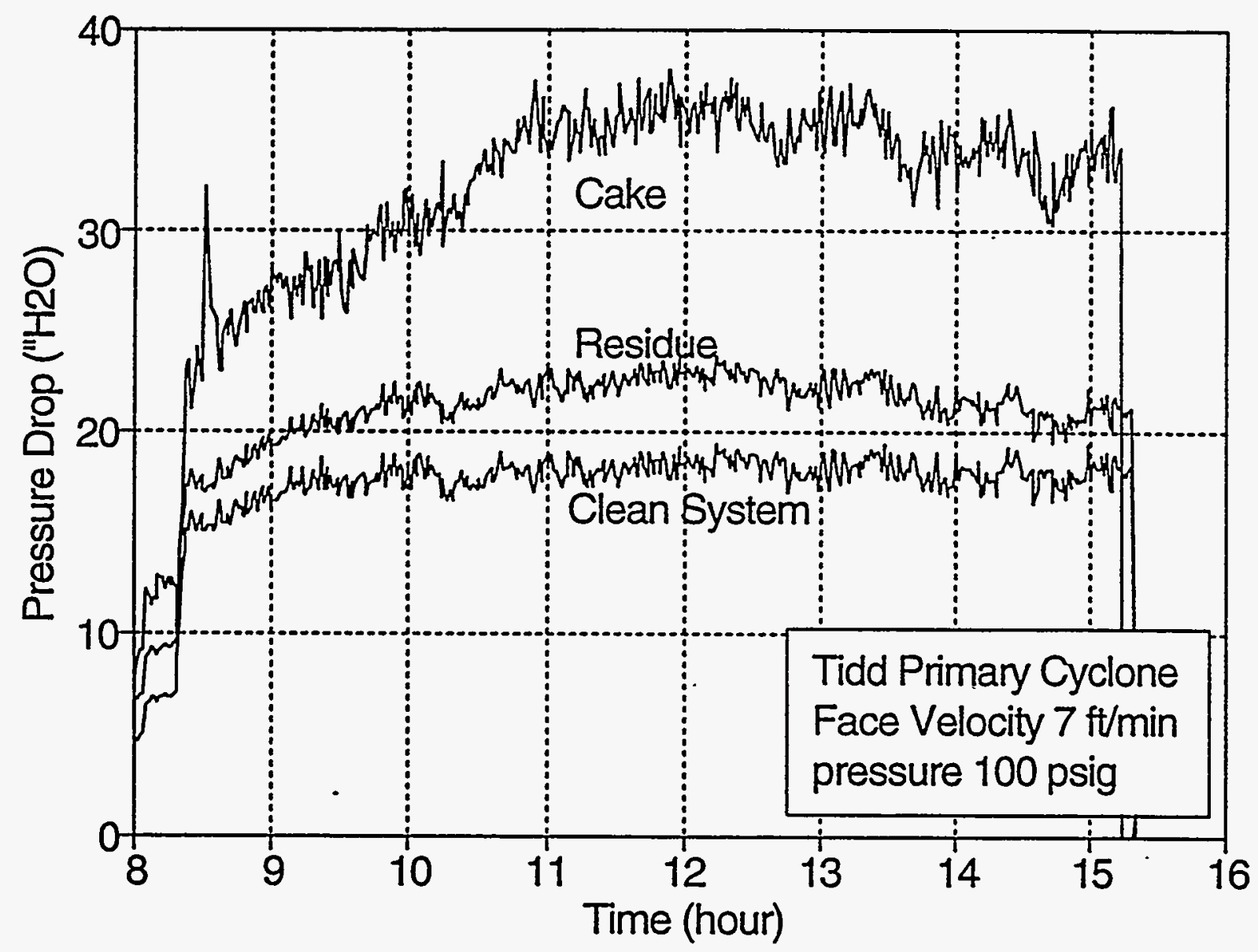




\section{Test 1.10 - 2/22/94}

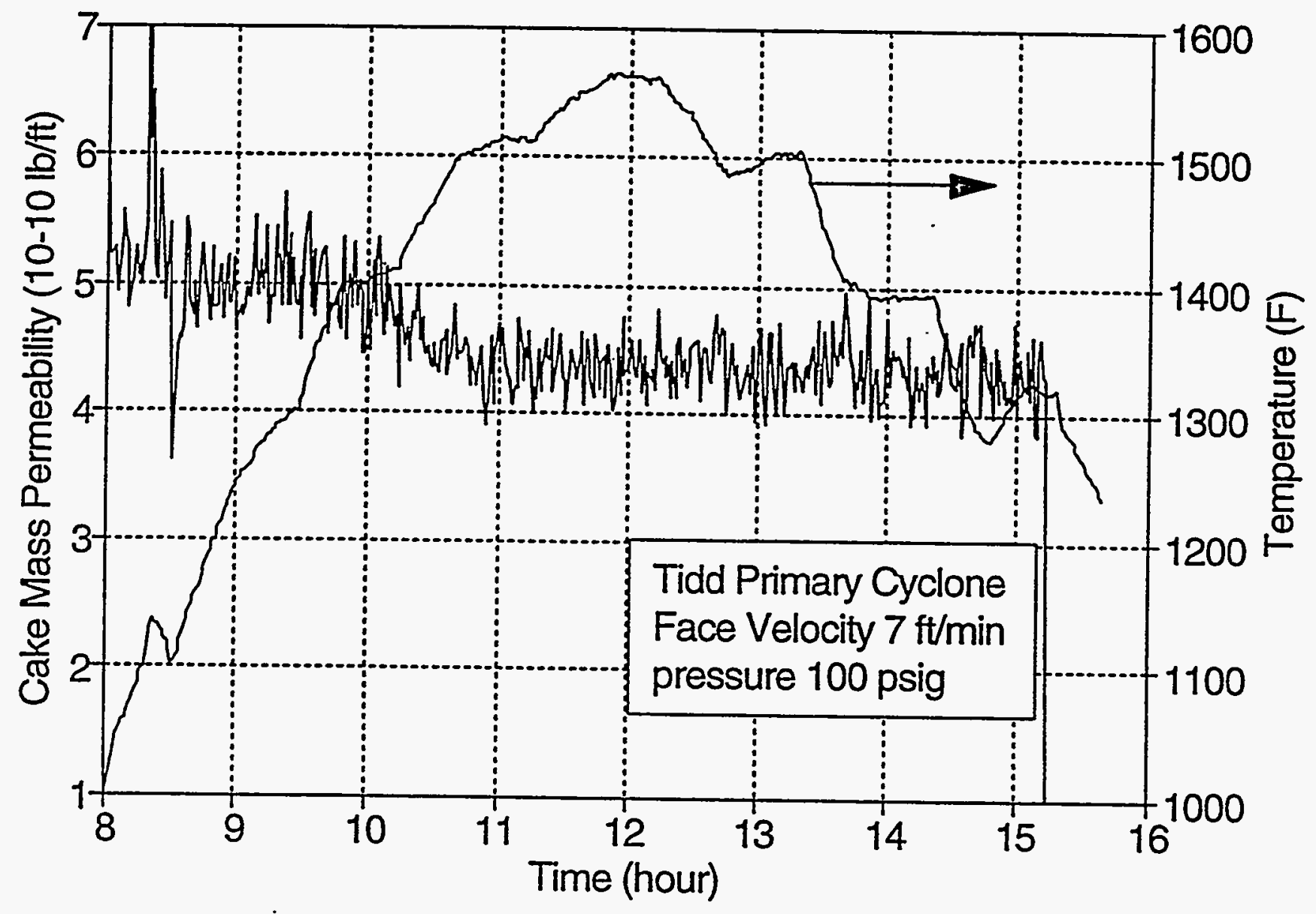




\section{Test $1.10-2 / 22 / 94$ Pressure $100 \mathrm{psig}$}

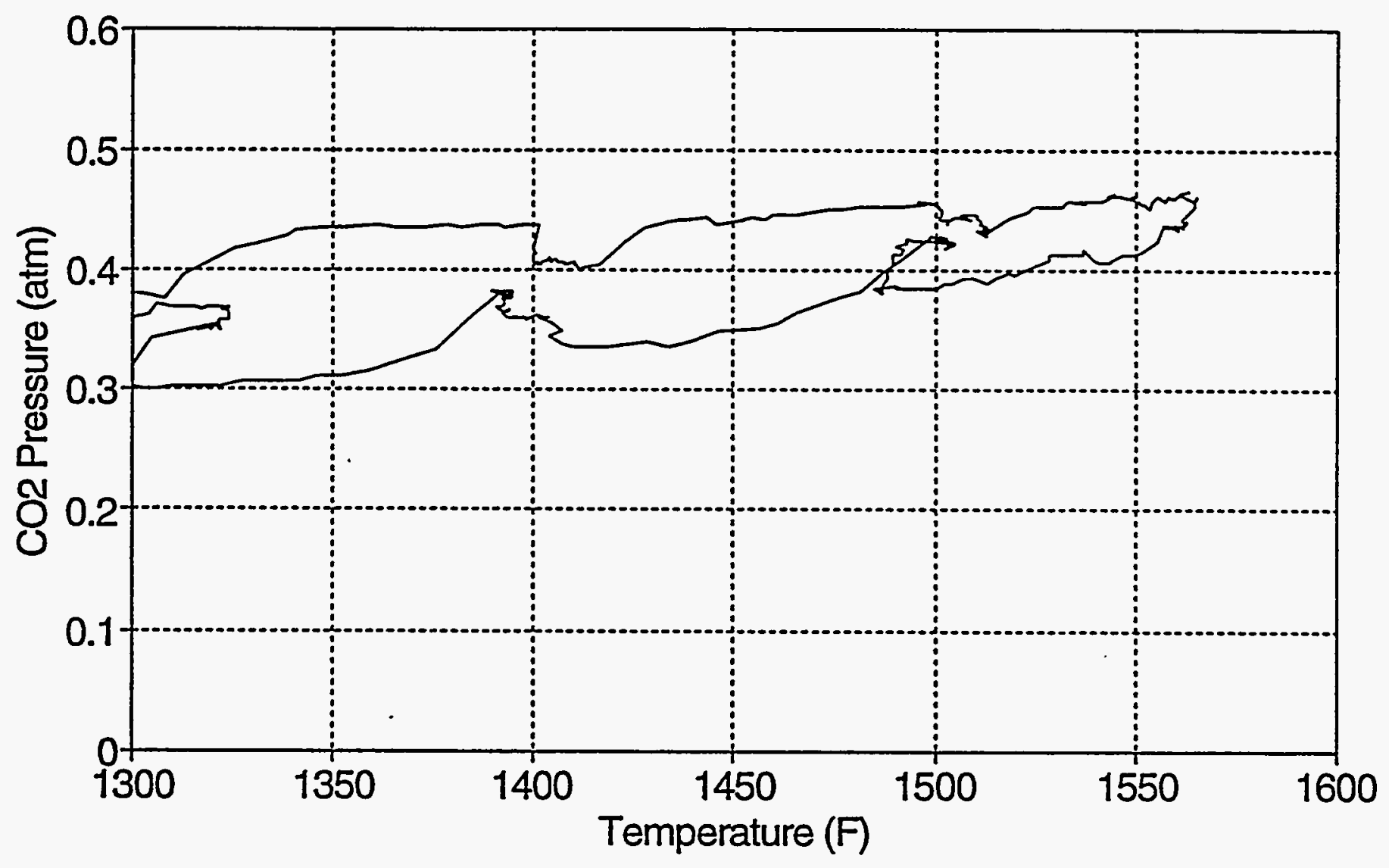




\section{Test $1.11-3 / 1 / 94$}

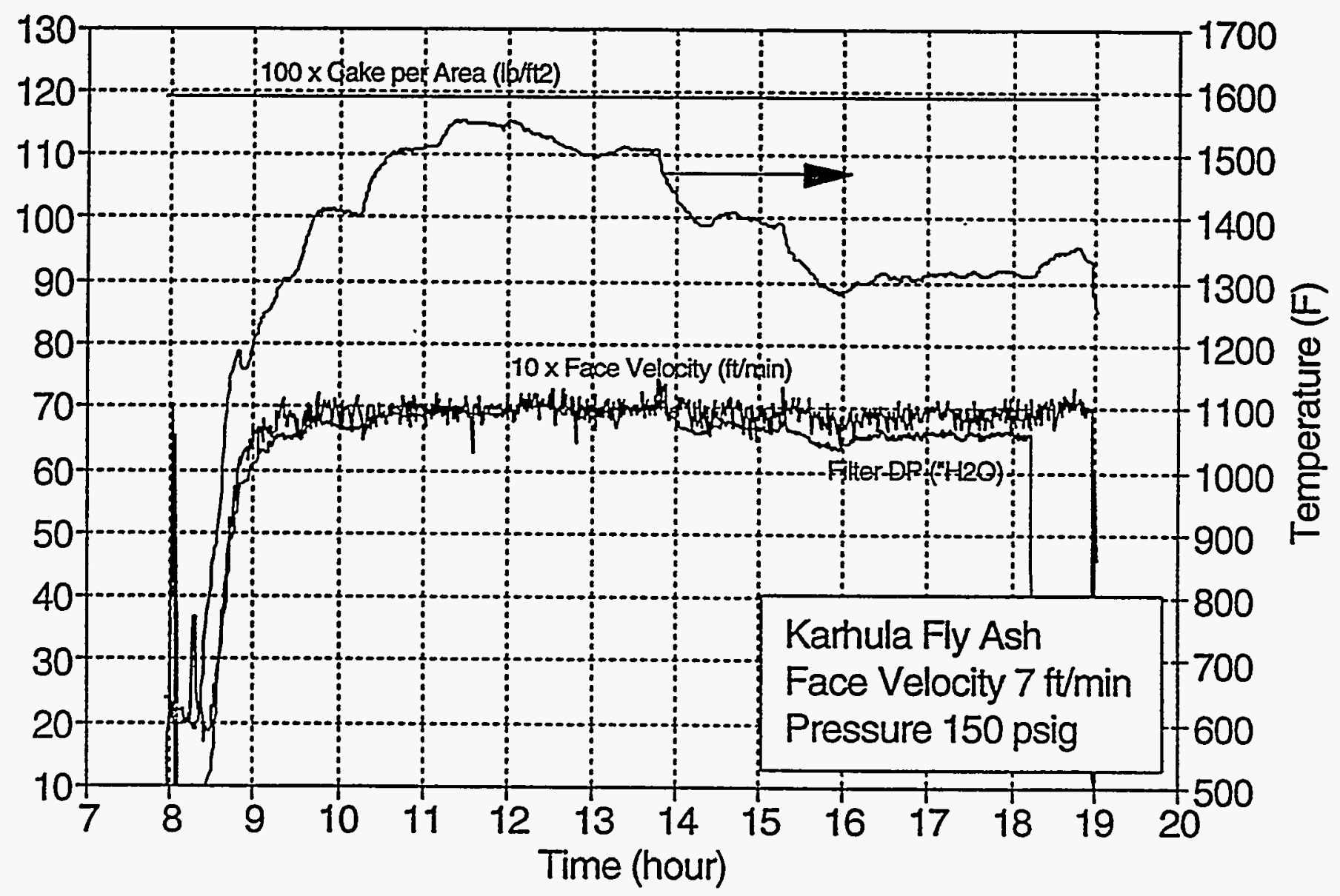




\section{Test 1.11 - 3/1/94}

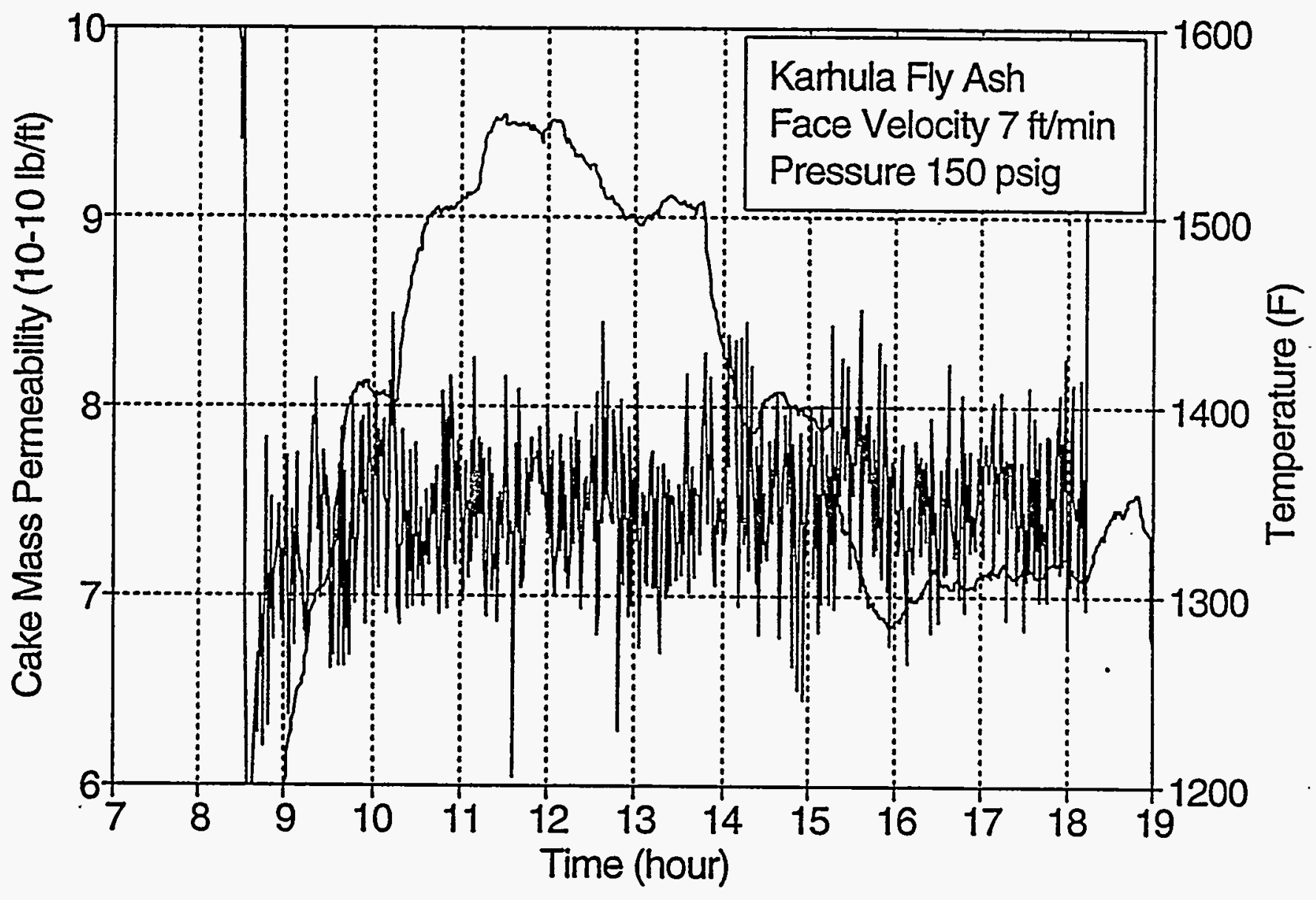




\section{Test 1.11 - 3/1/94 \\ Pressure $150 \mathrm{psig}$}

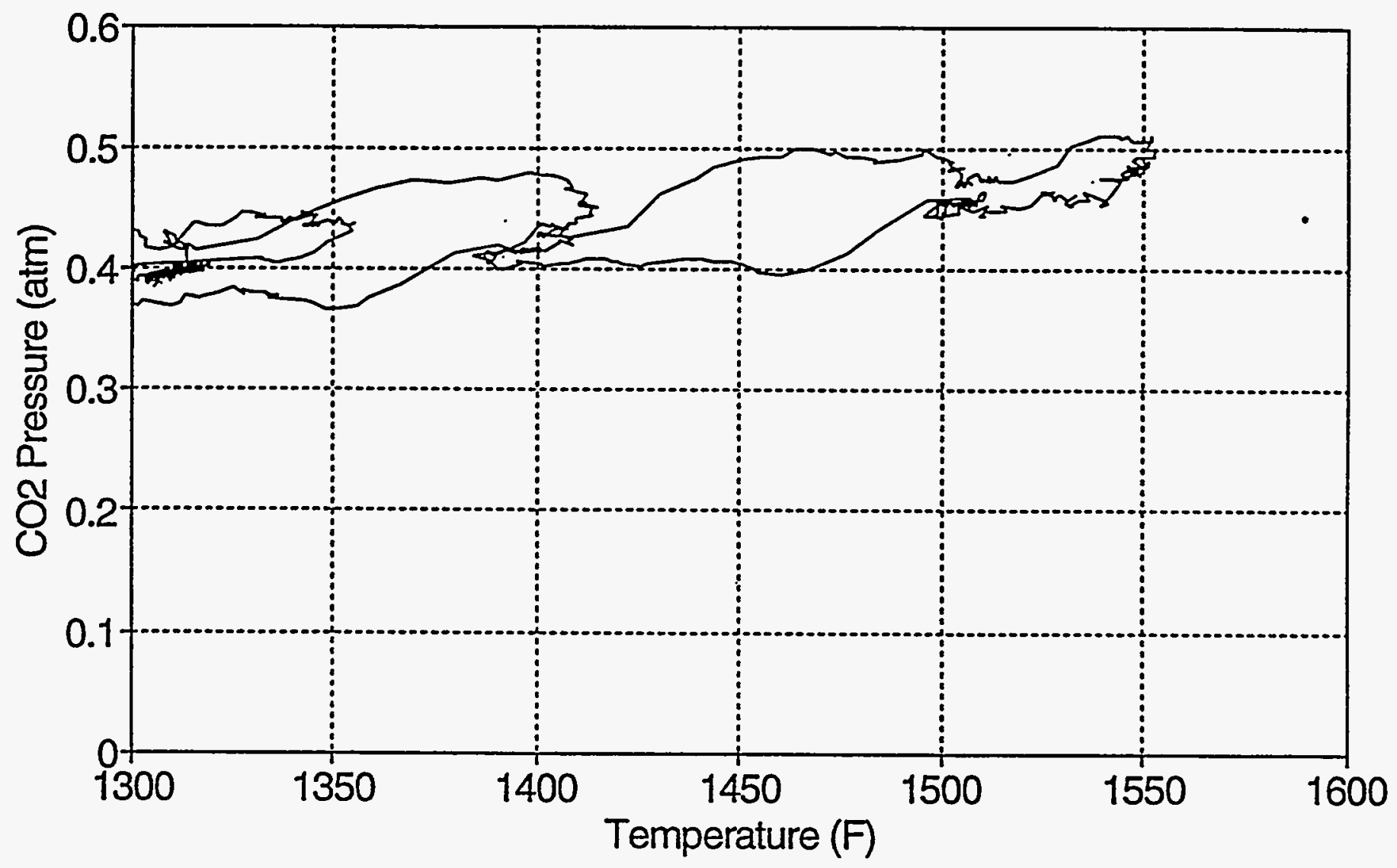




\section{Test 1.12 - 3/4/94}

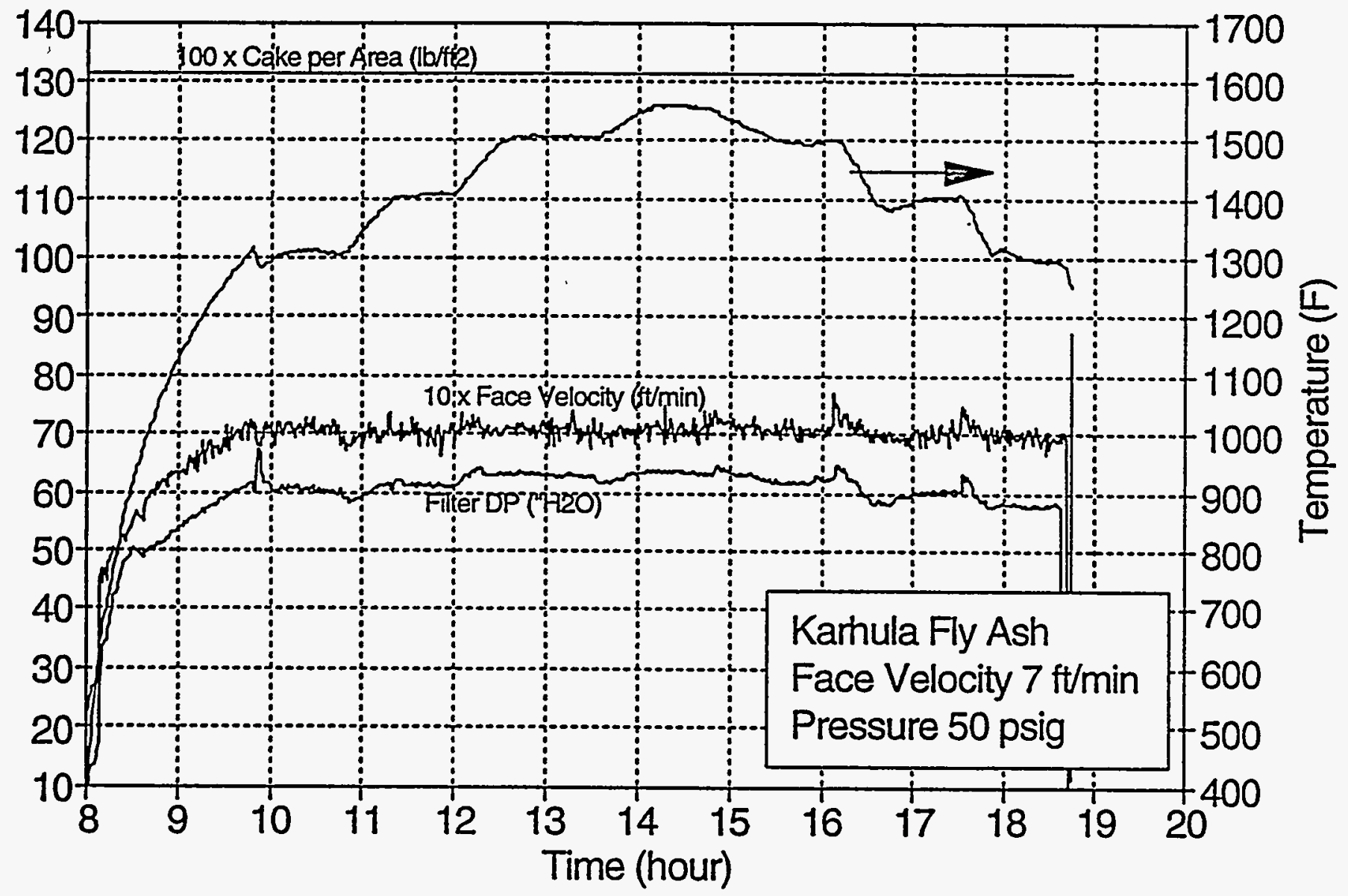




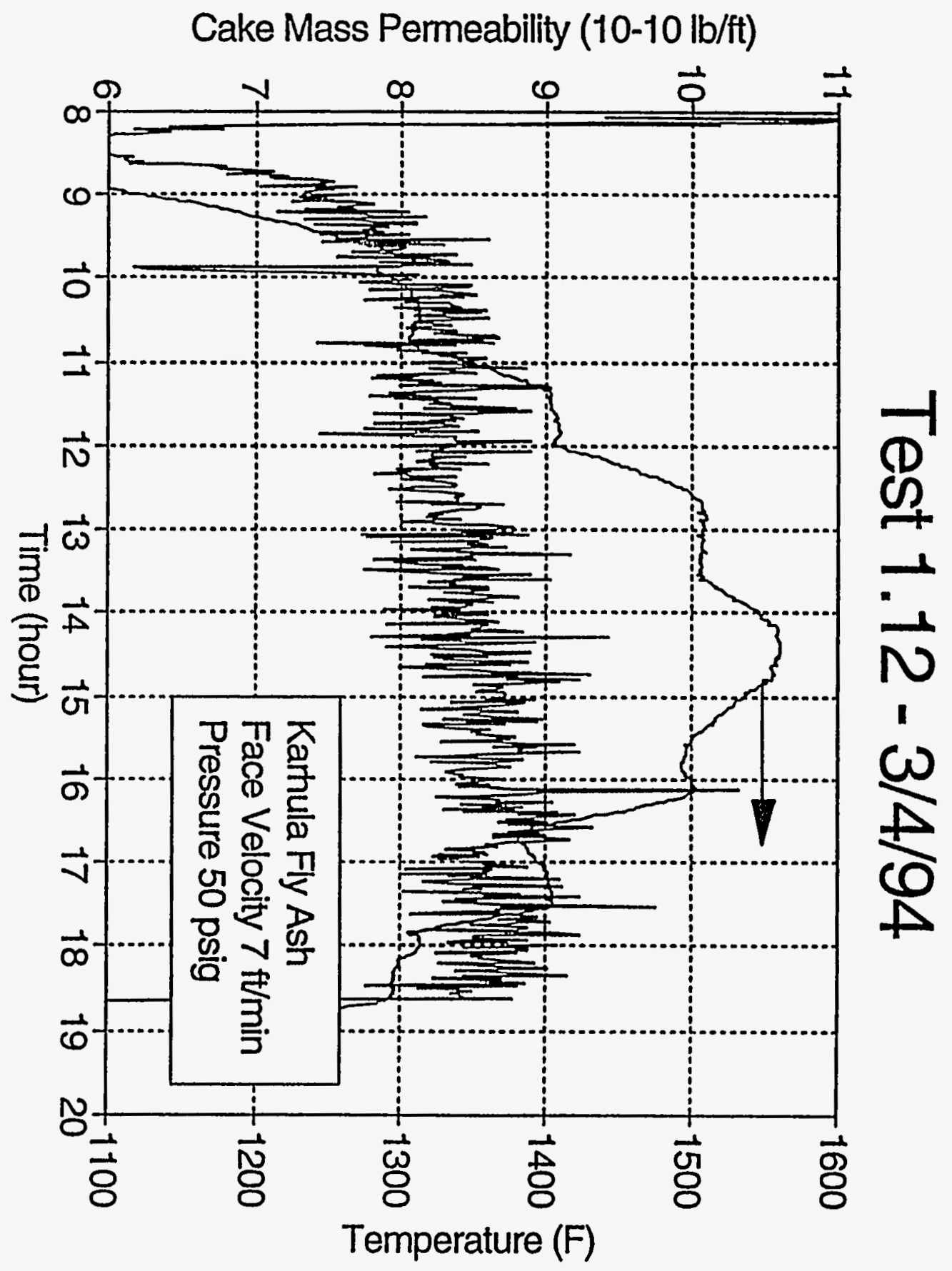




\section{Test 1.13 - 3/9/94}

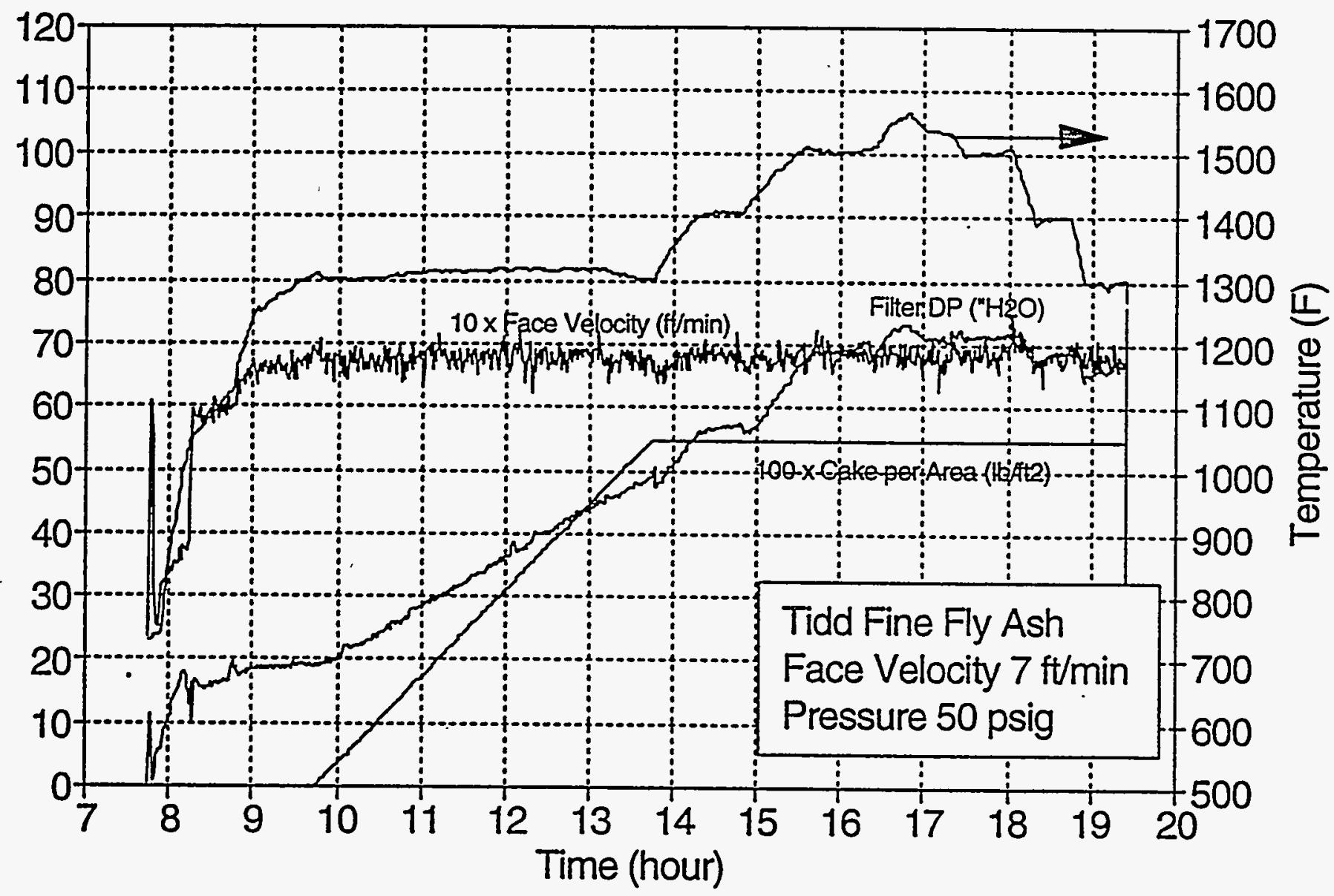




\section{Test 1.13 - 3/9/94}

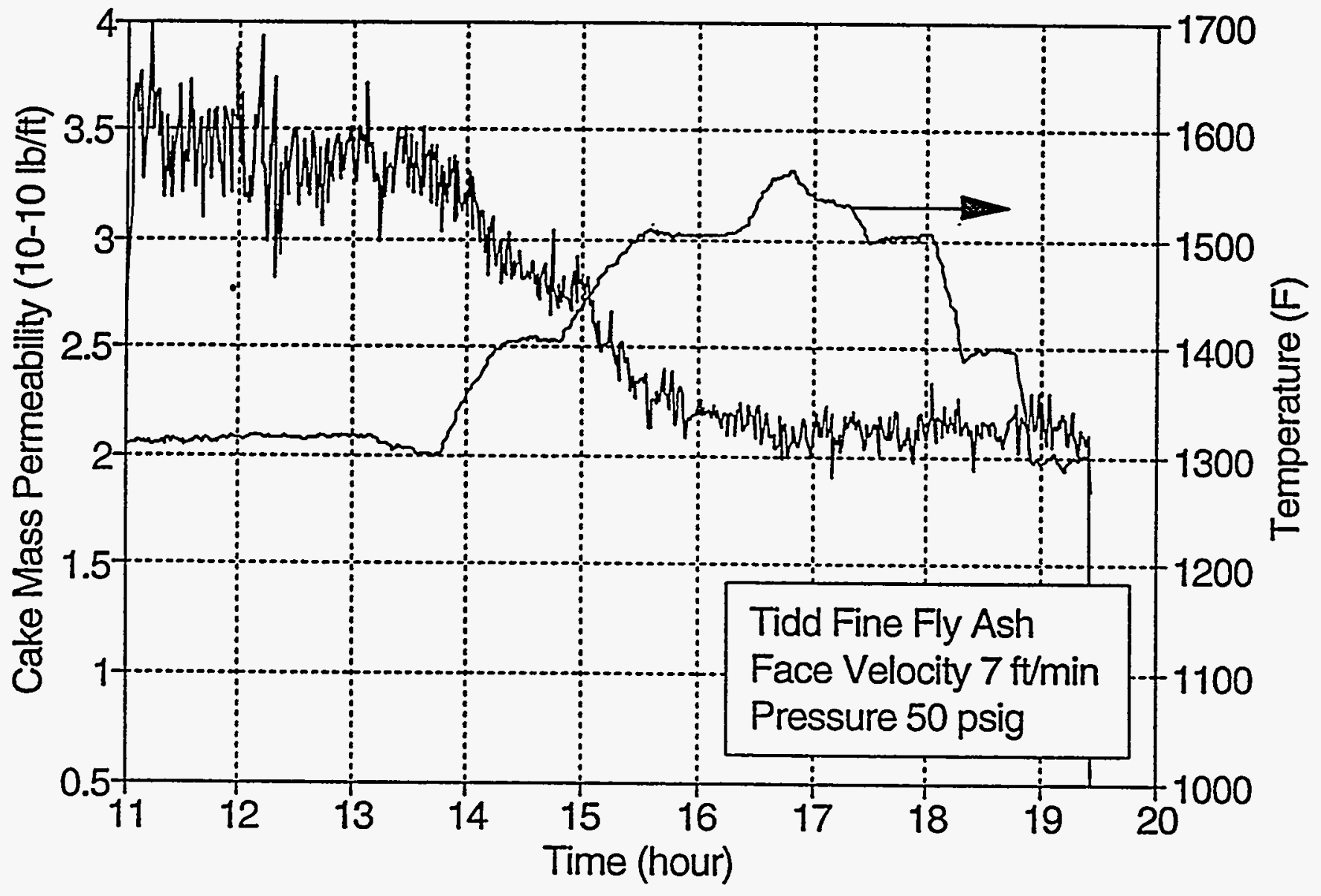




\section{Test 1.13 - 3/9/94 \\ Pressure $50 \mathrm{psig}$}

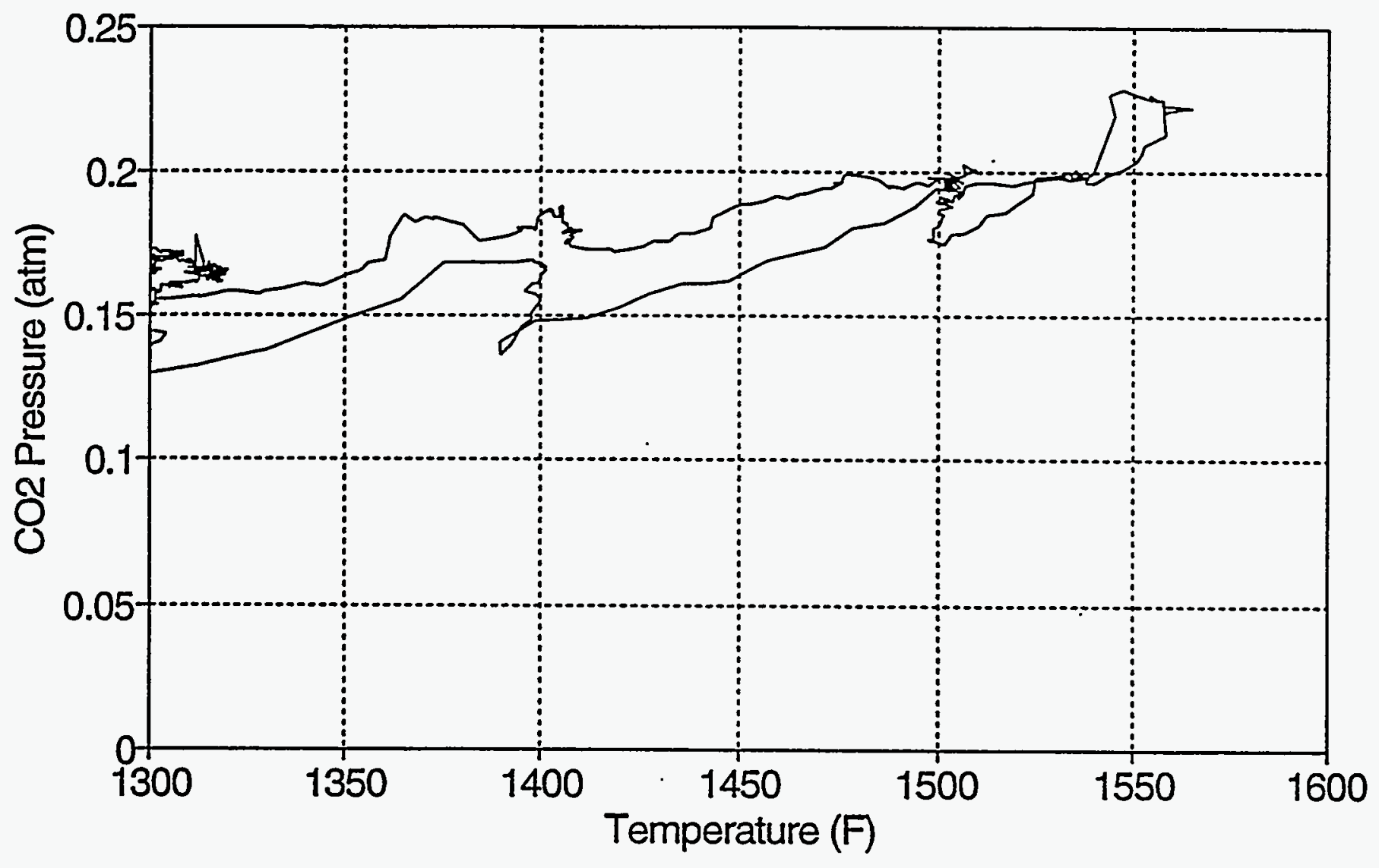




\section{Test 1.14 - 7/6/1994}

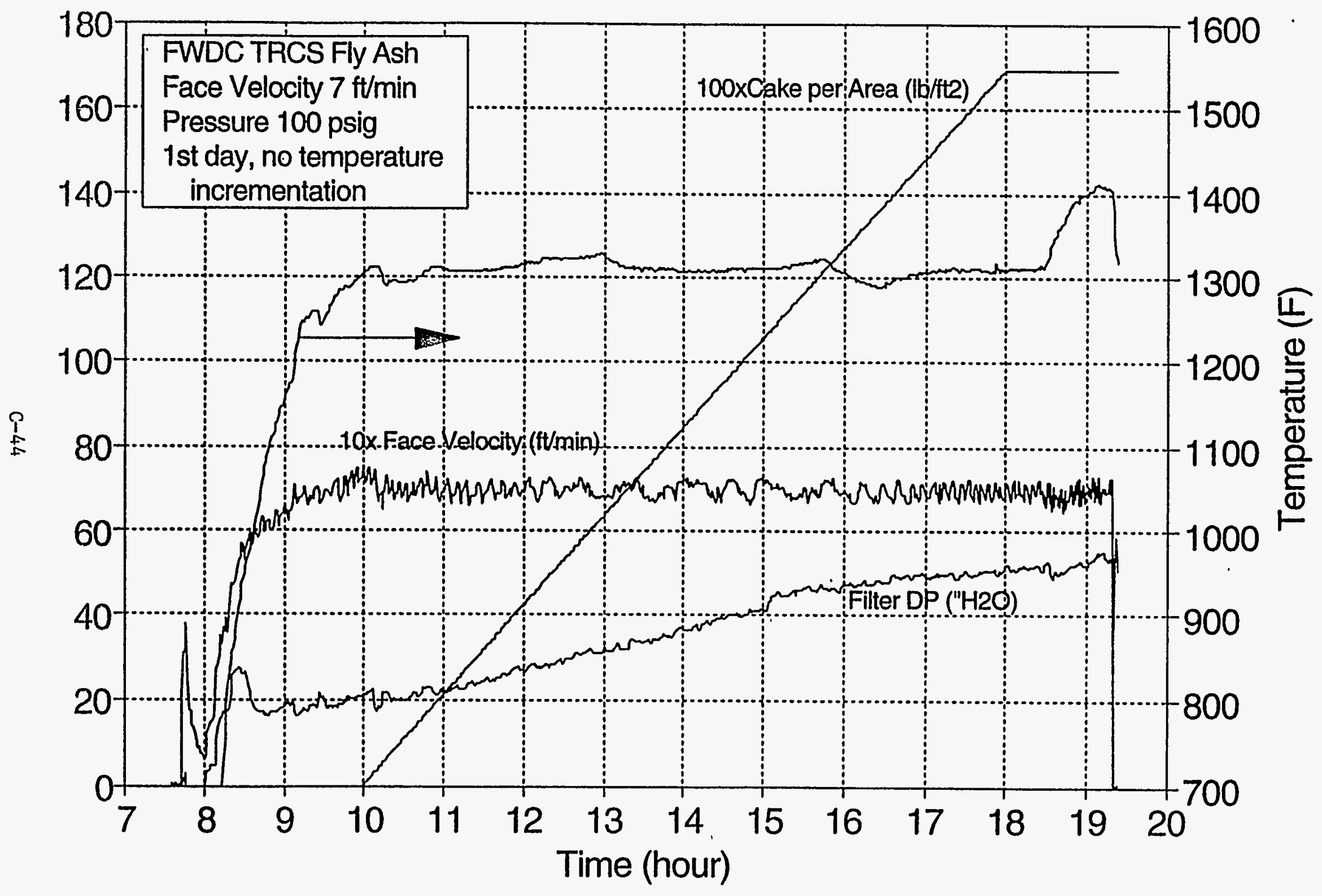




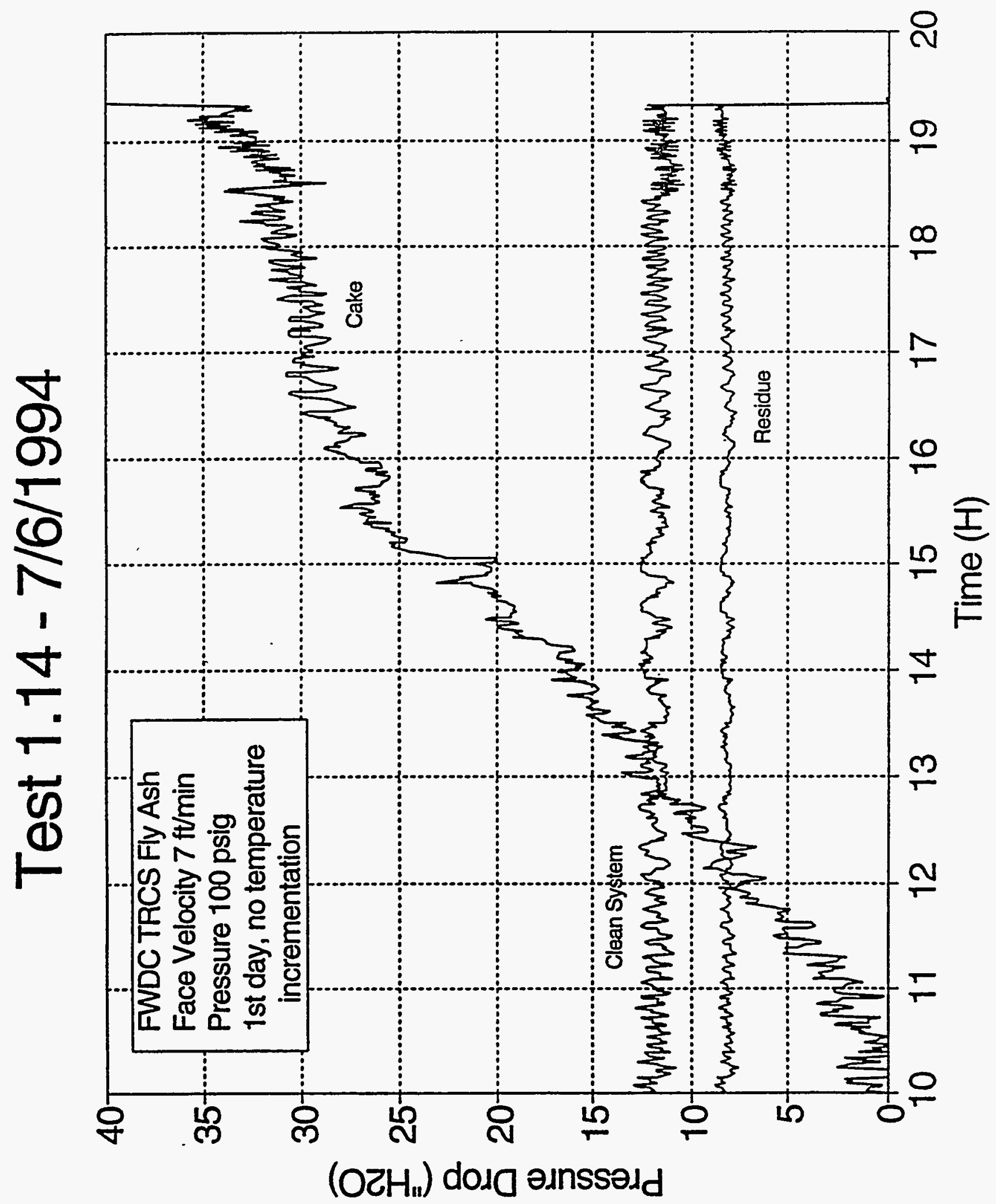


() əגnłeגəduə $\perp$

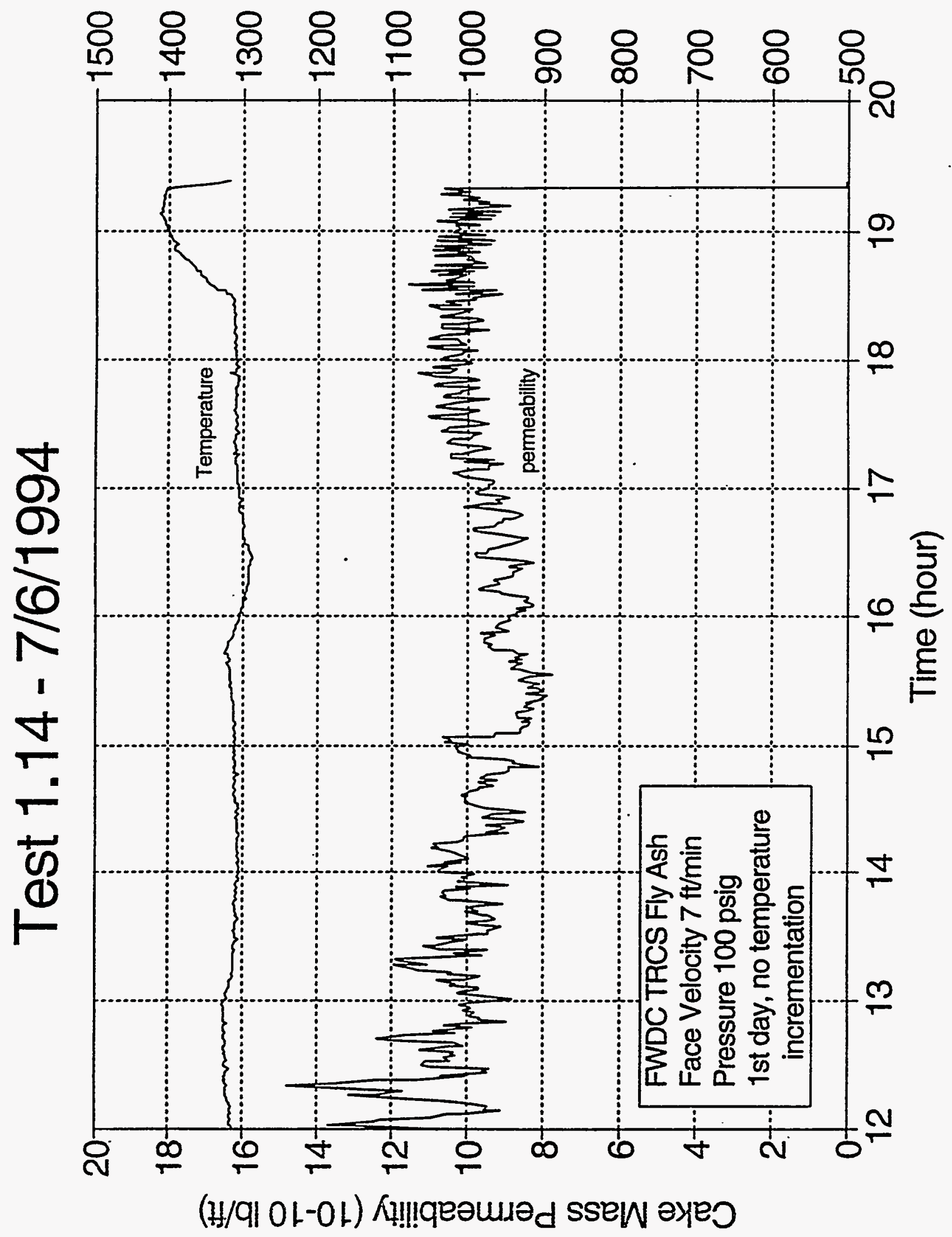




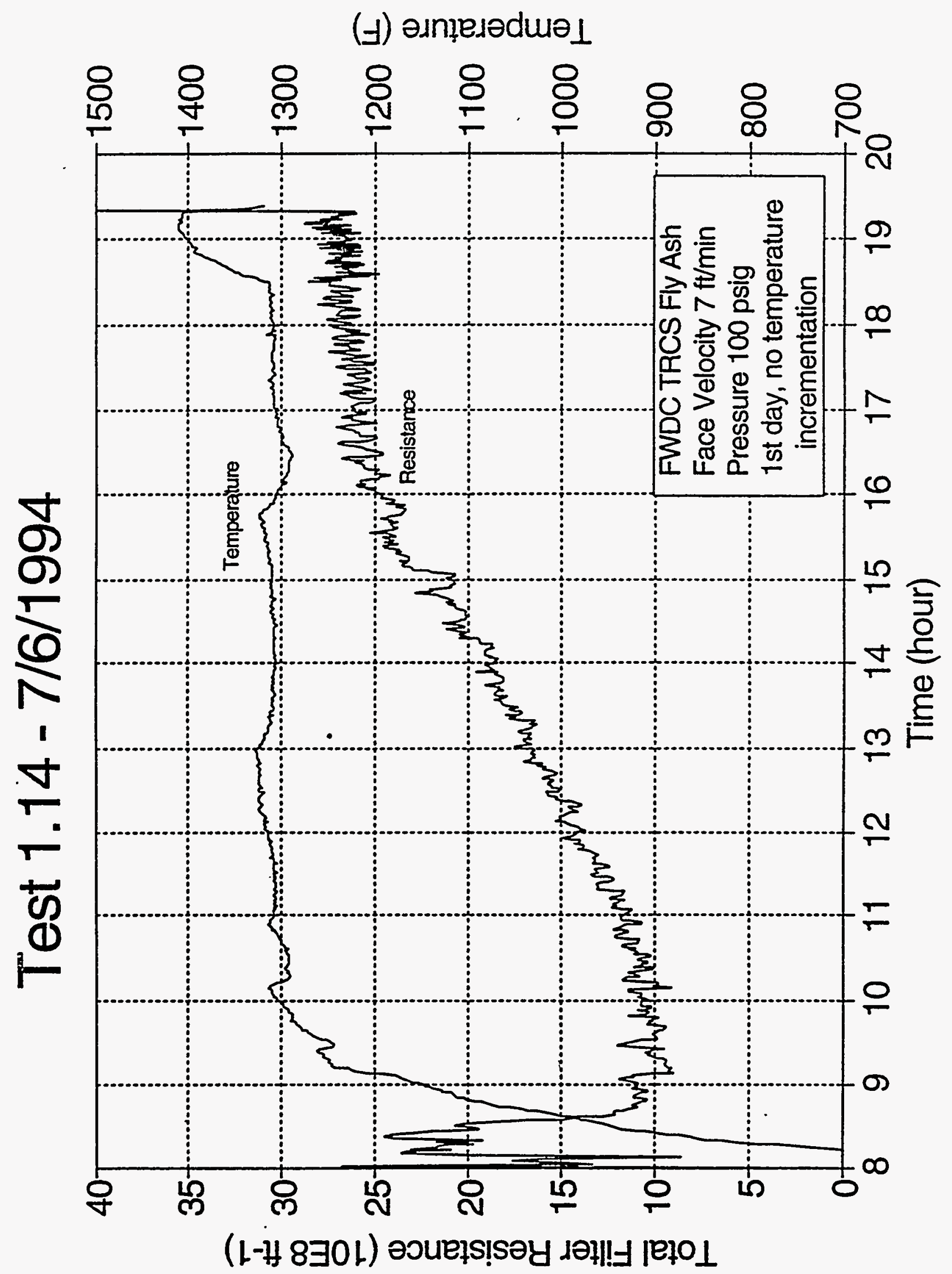




\section{Test 1.14 - 7/7/1994}

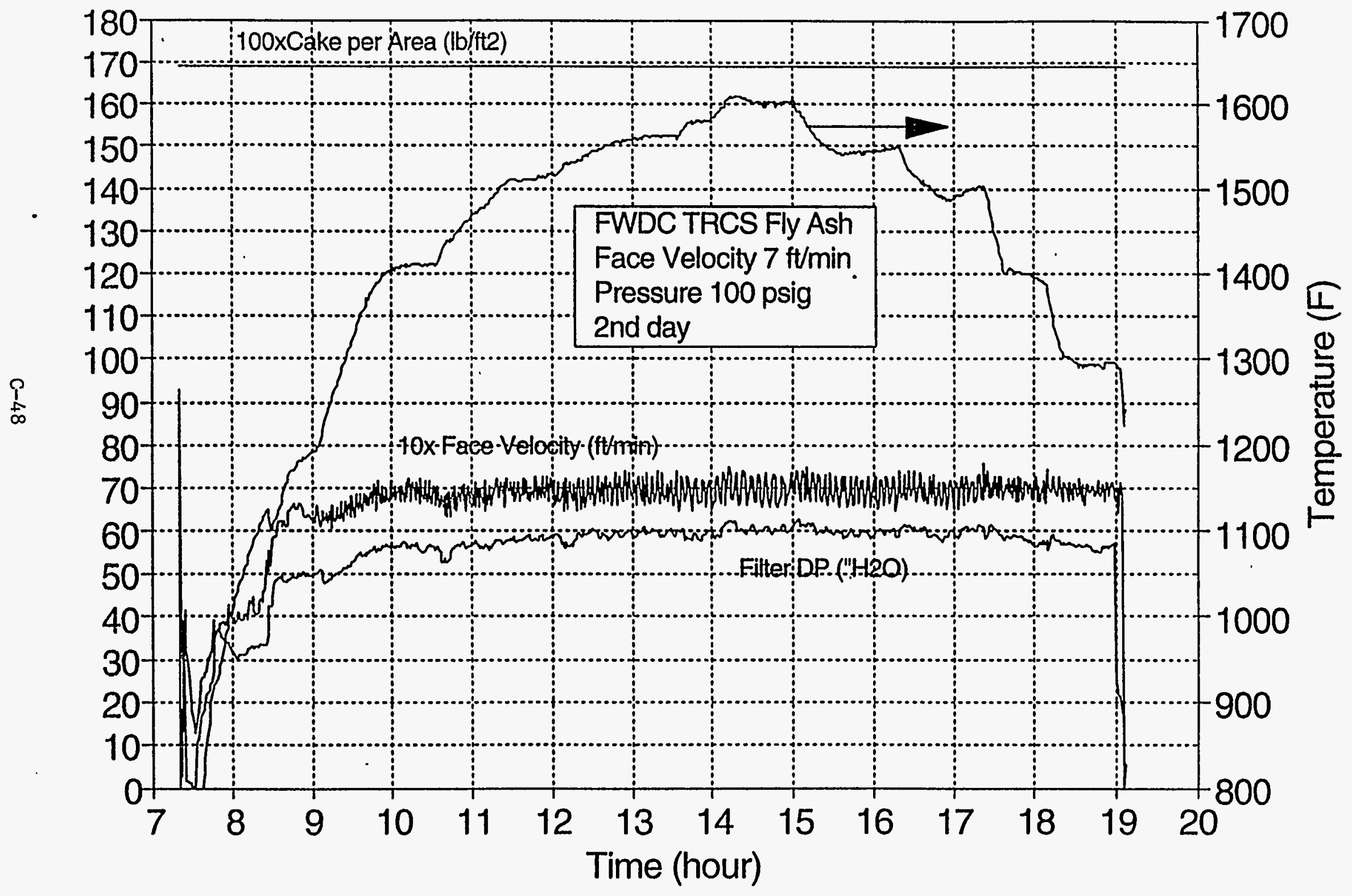




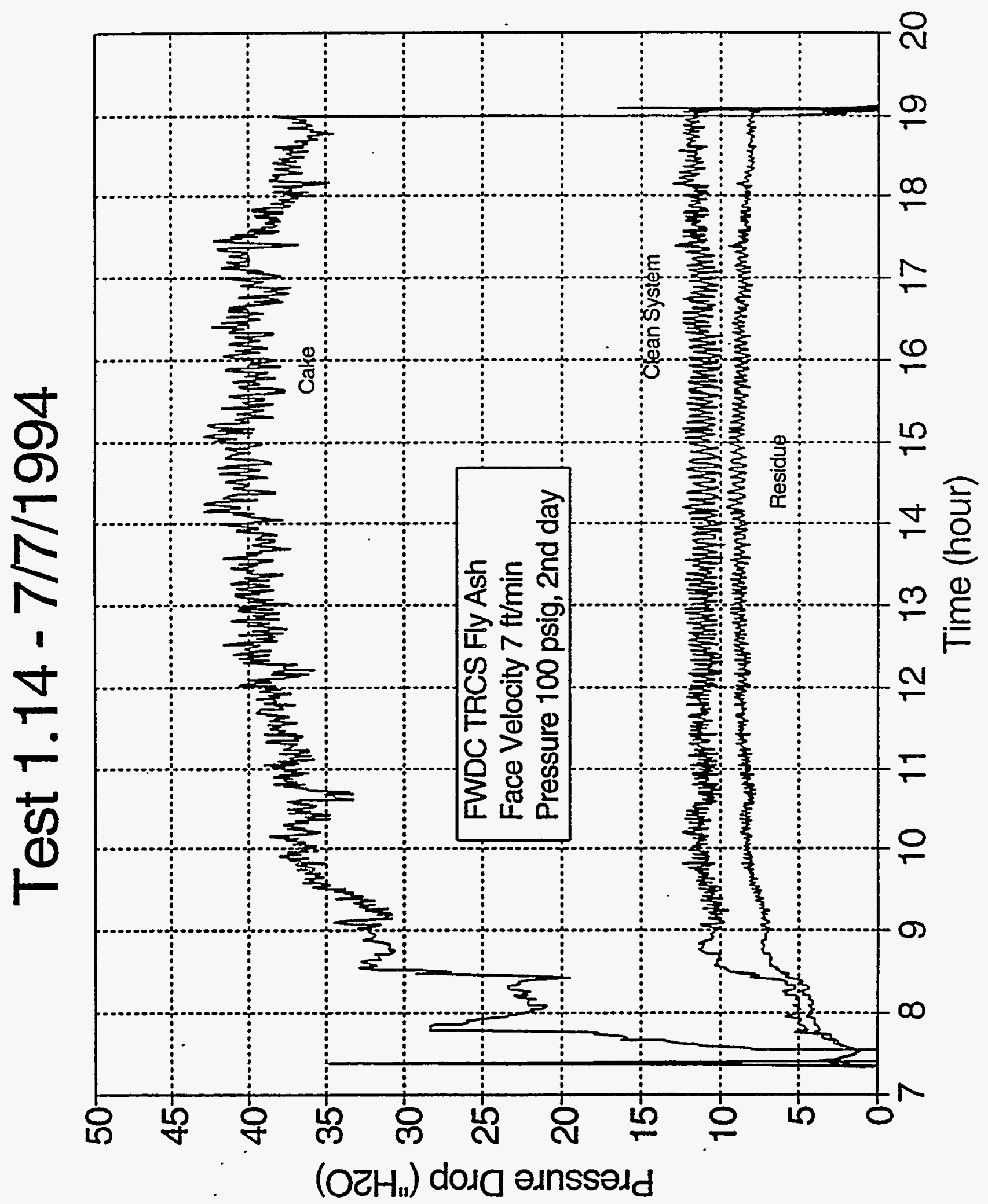




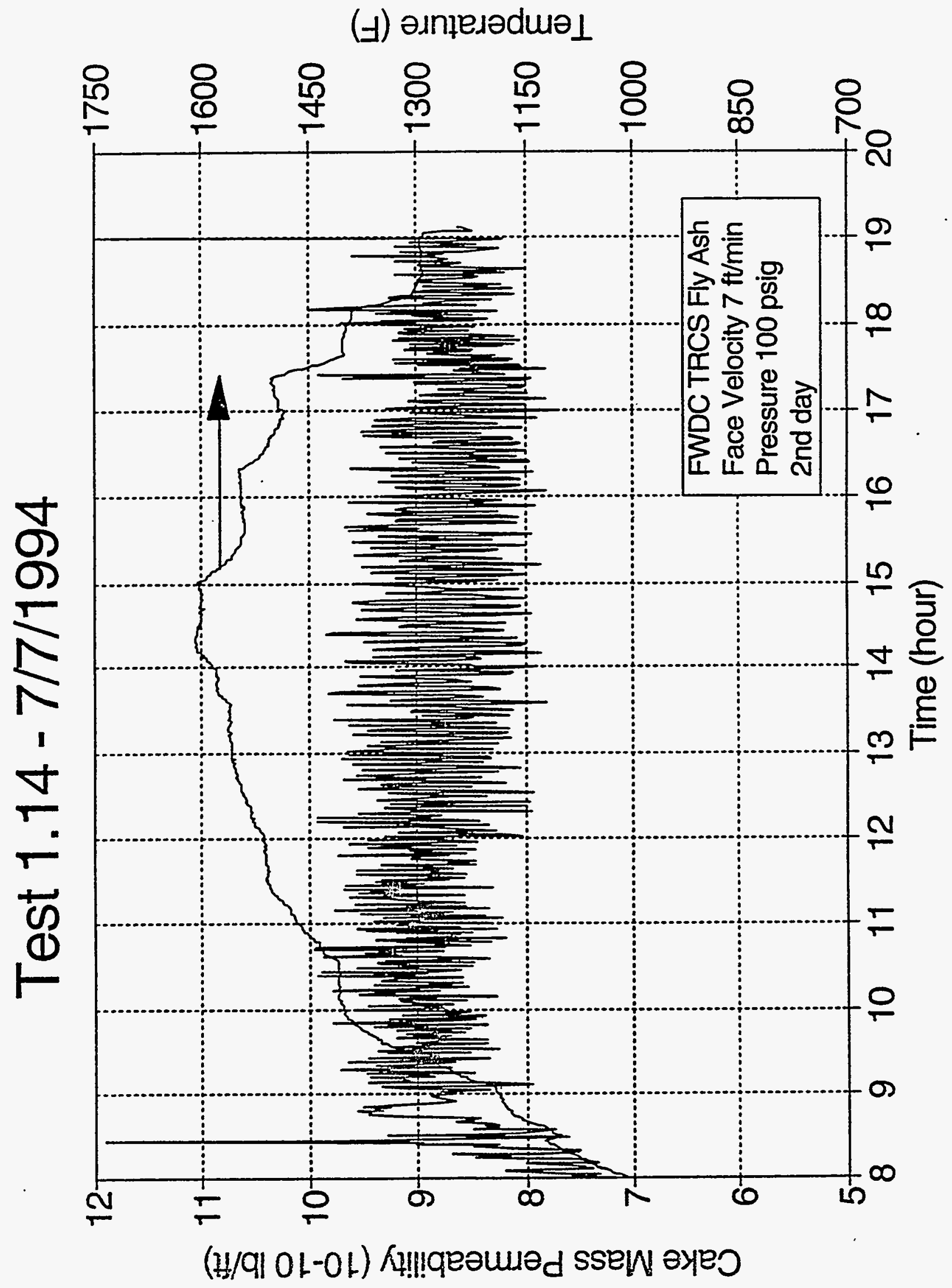




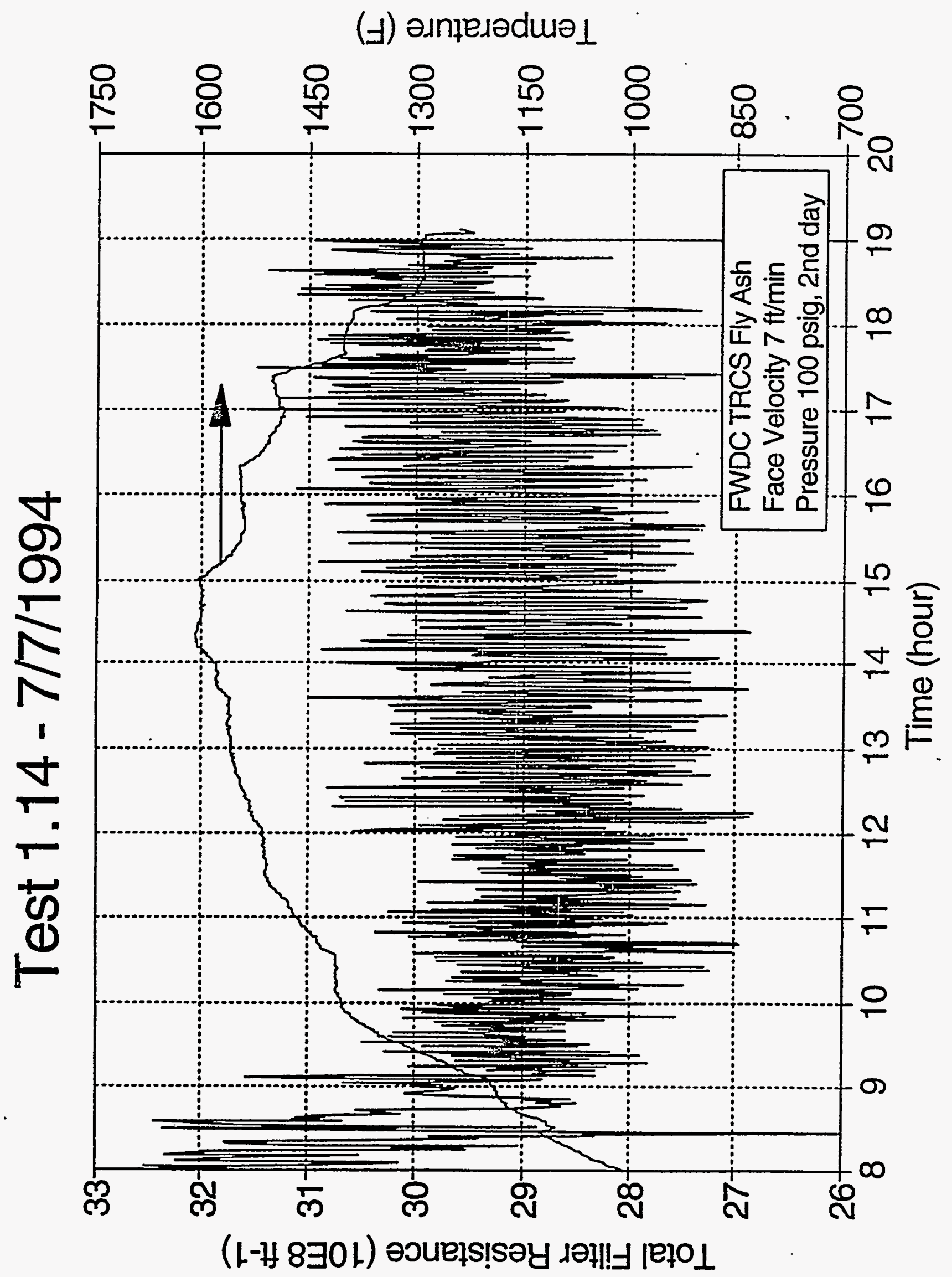




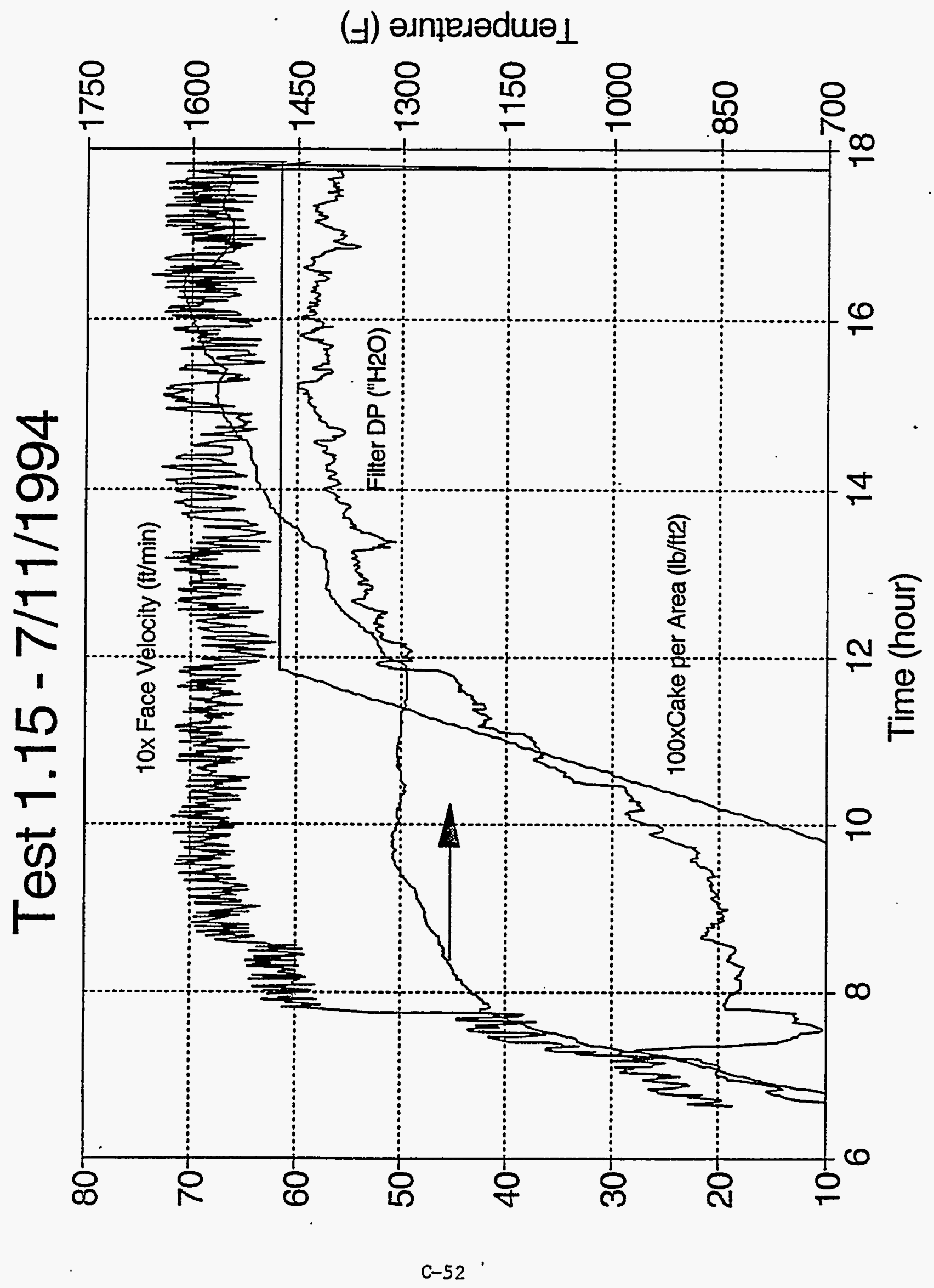




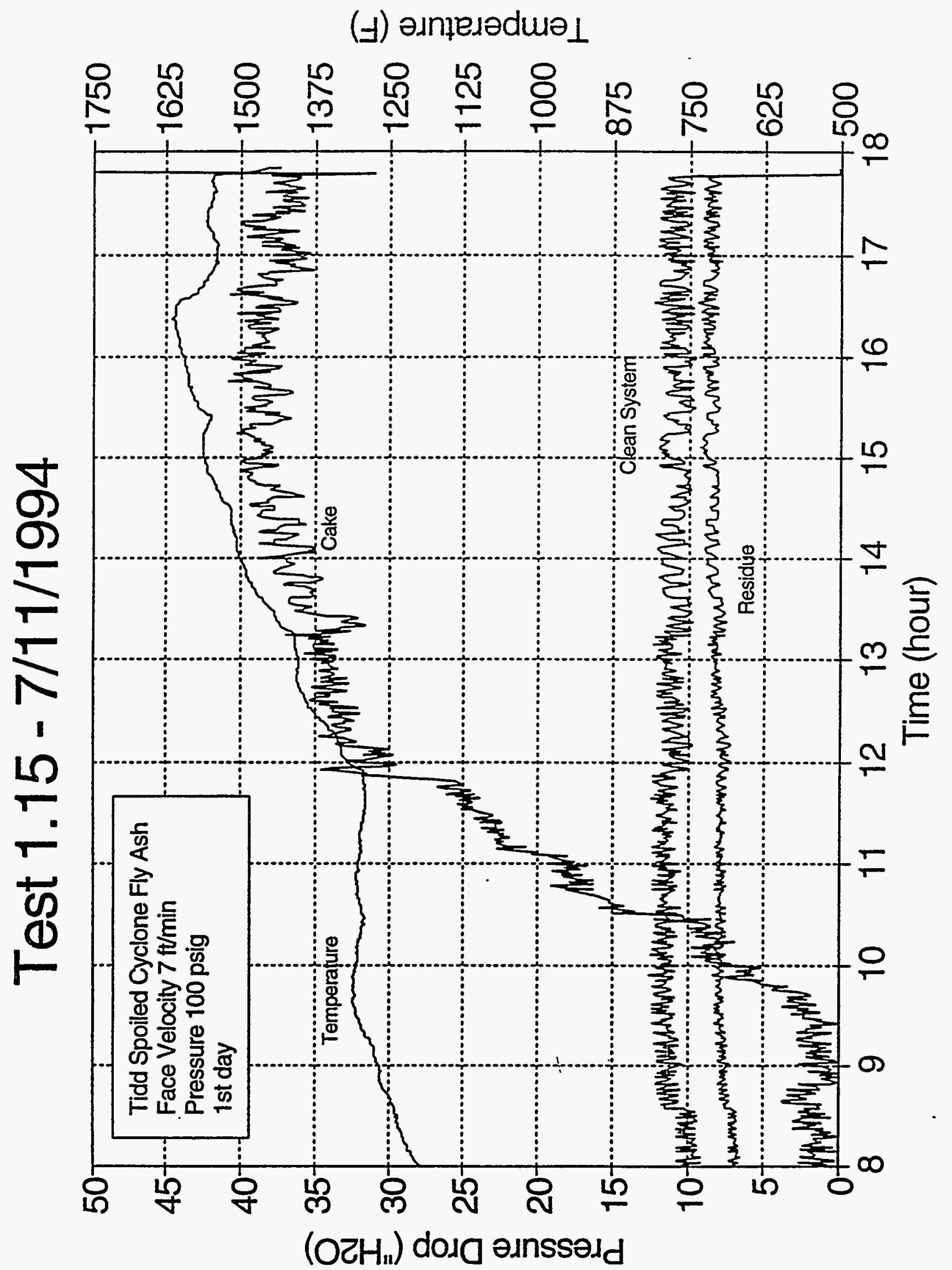




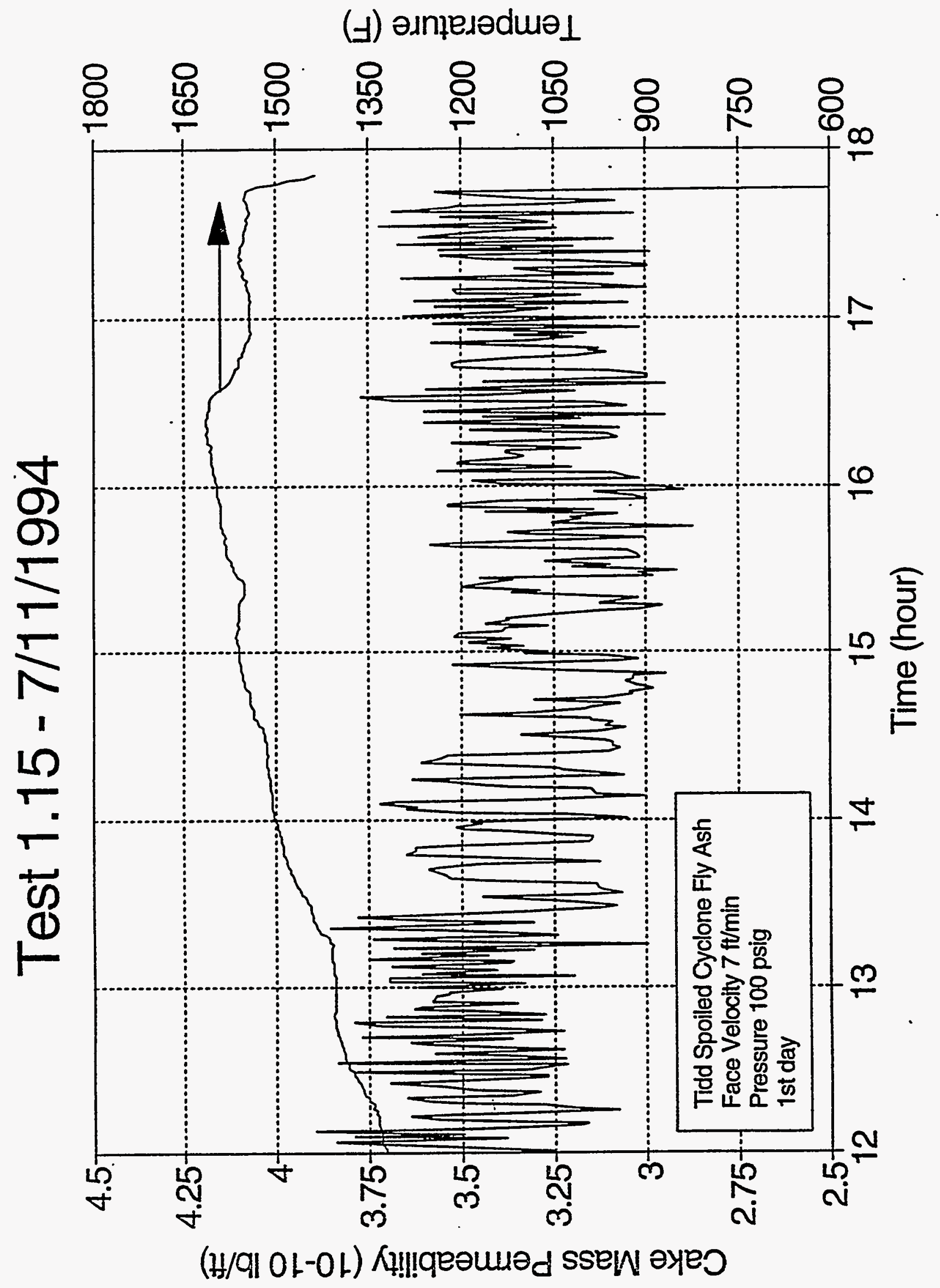

C-54 


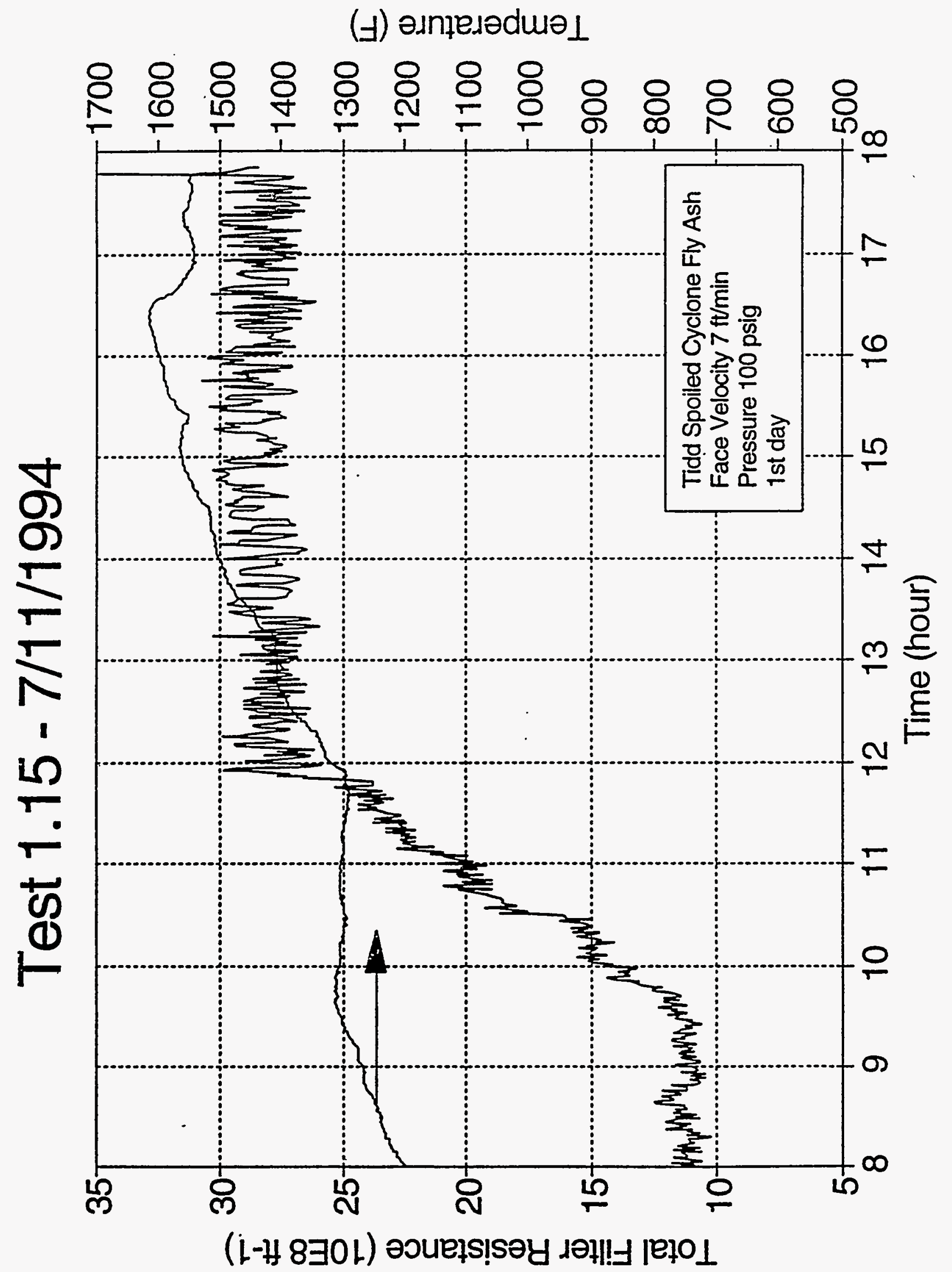




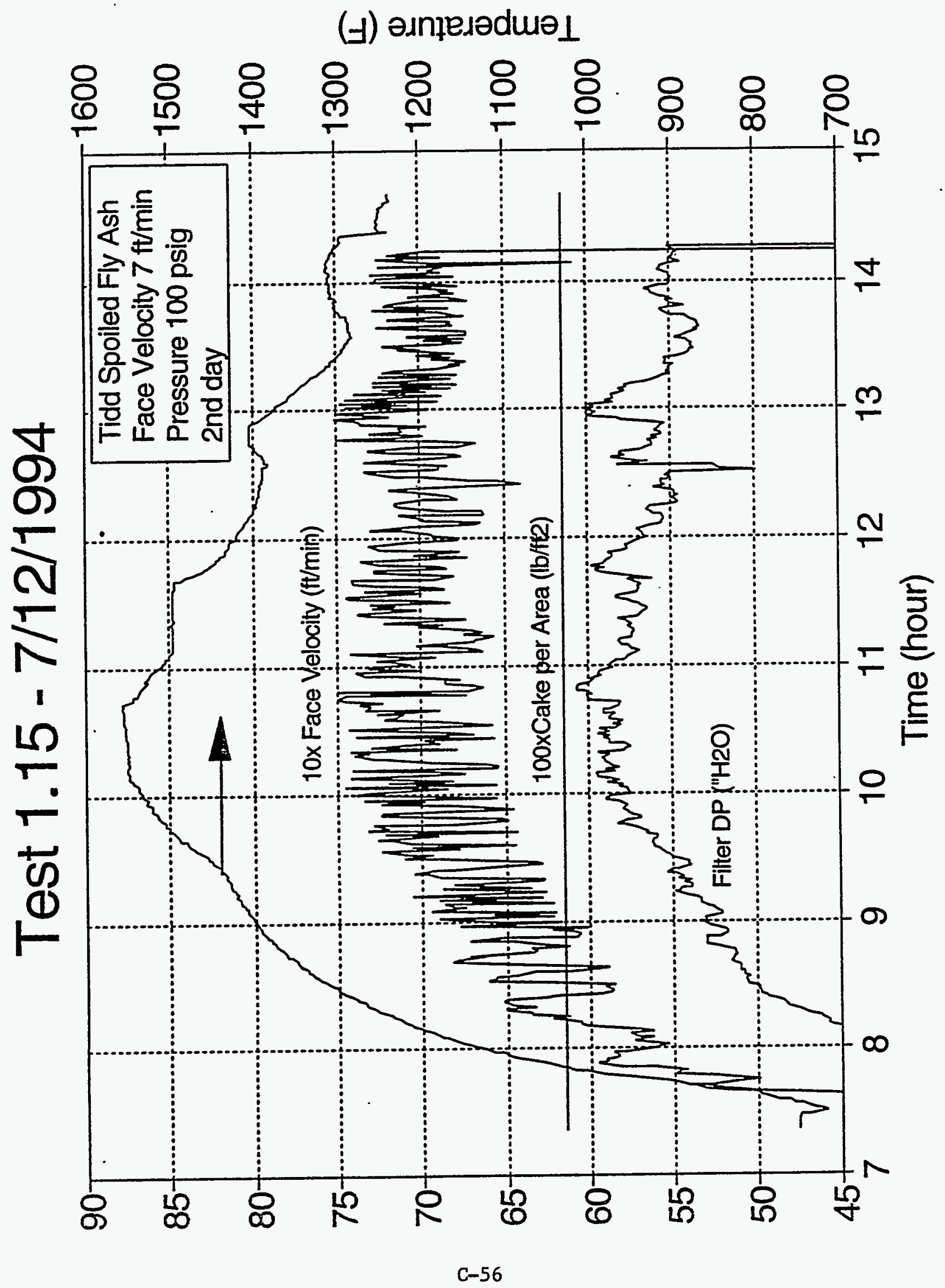




\section{Test $1.15-7 / 12 / 1994$}

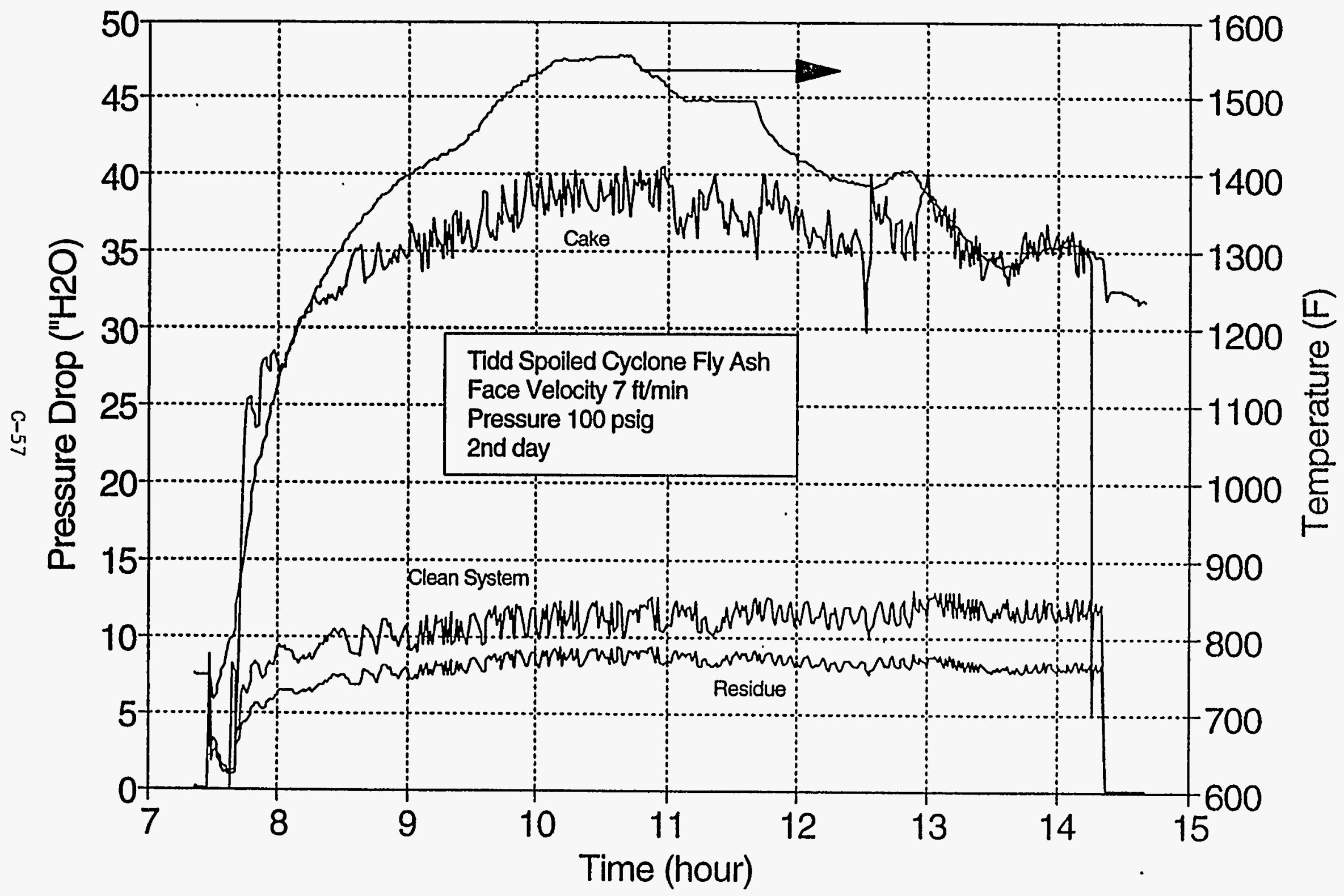




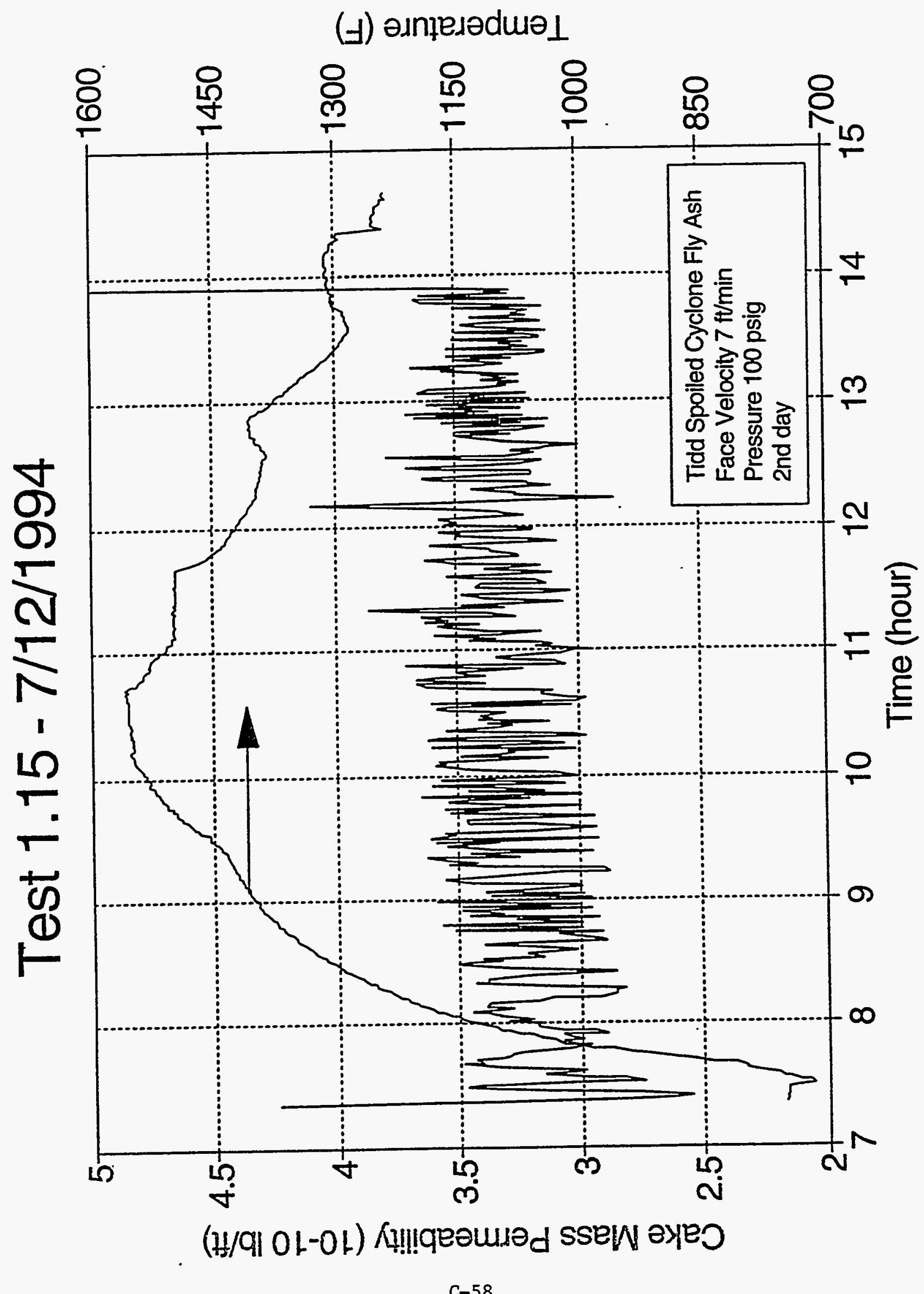




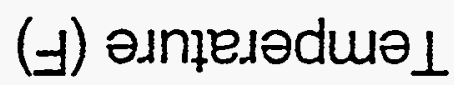

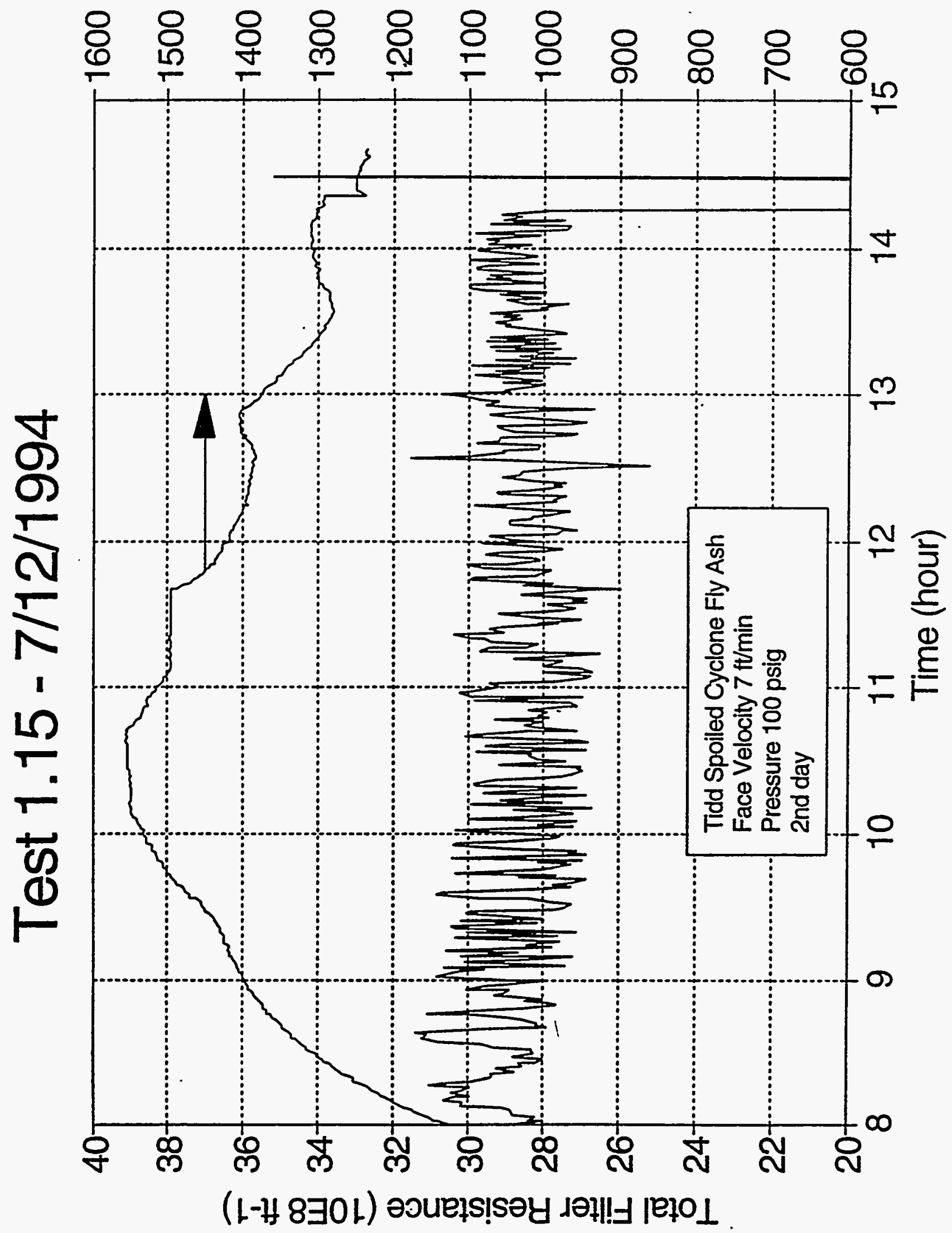




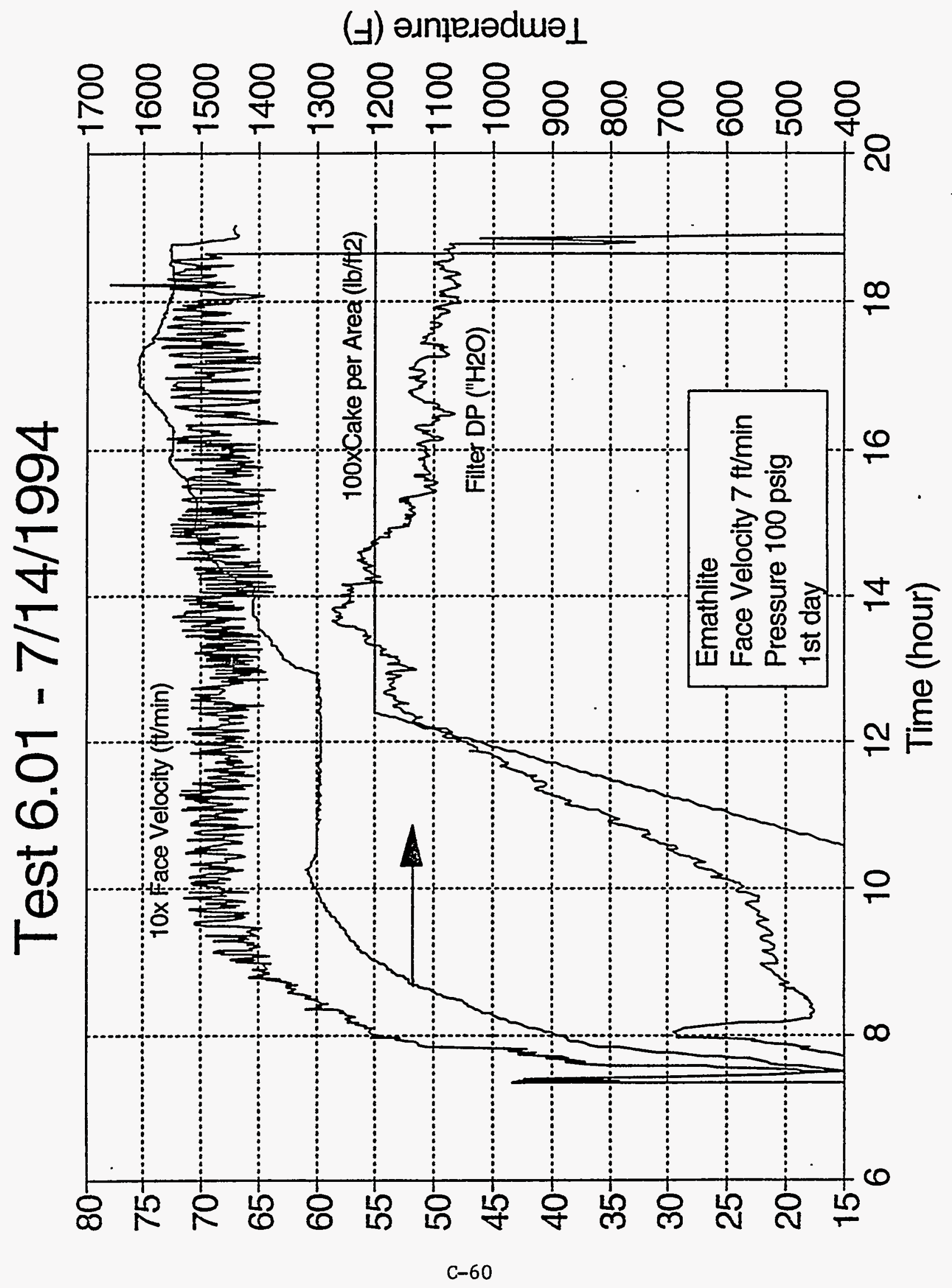




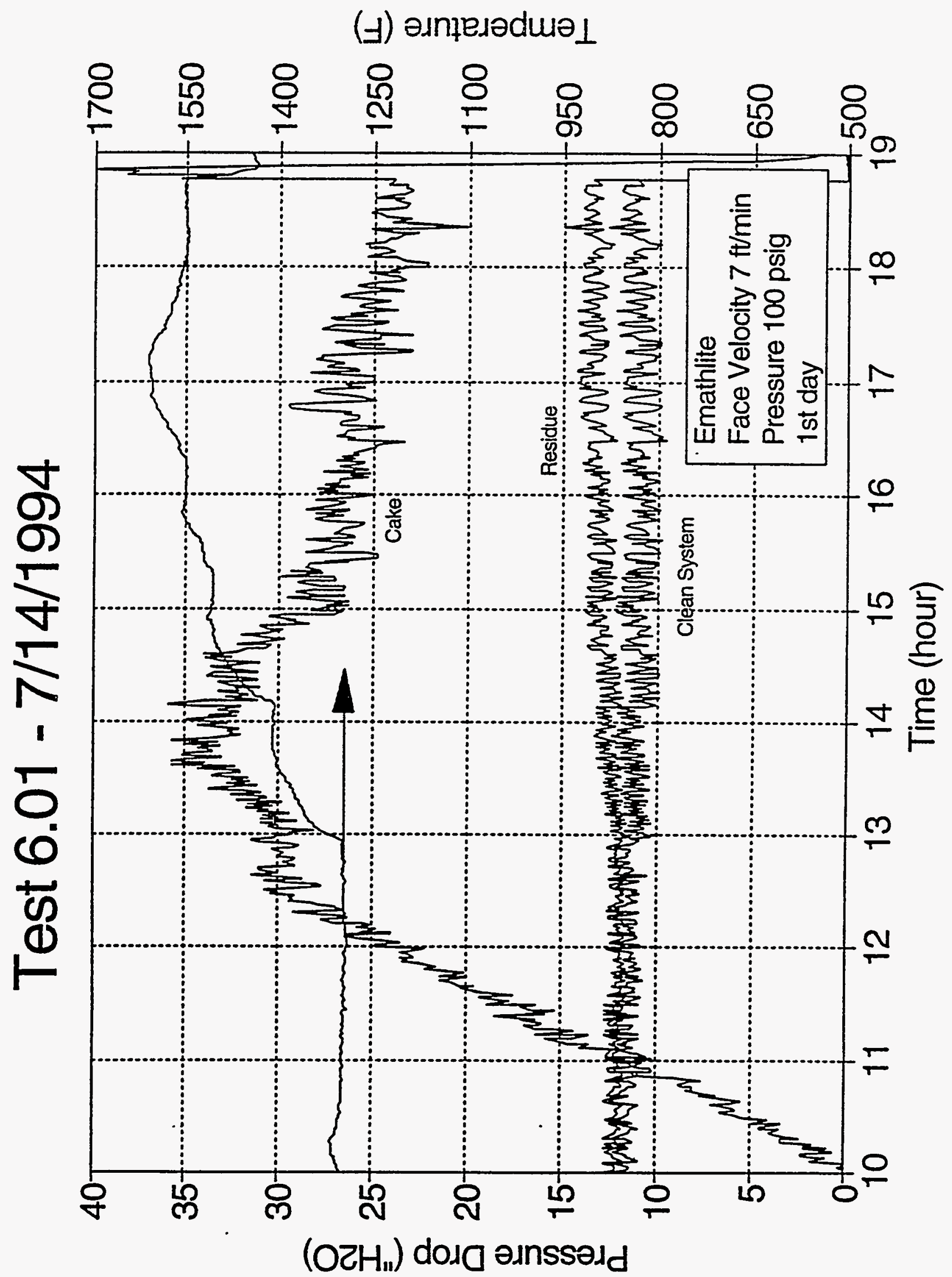




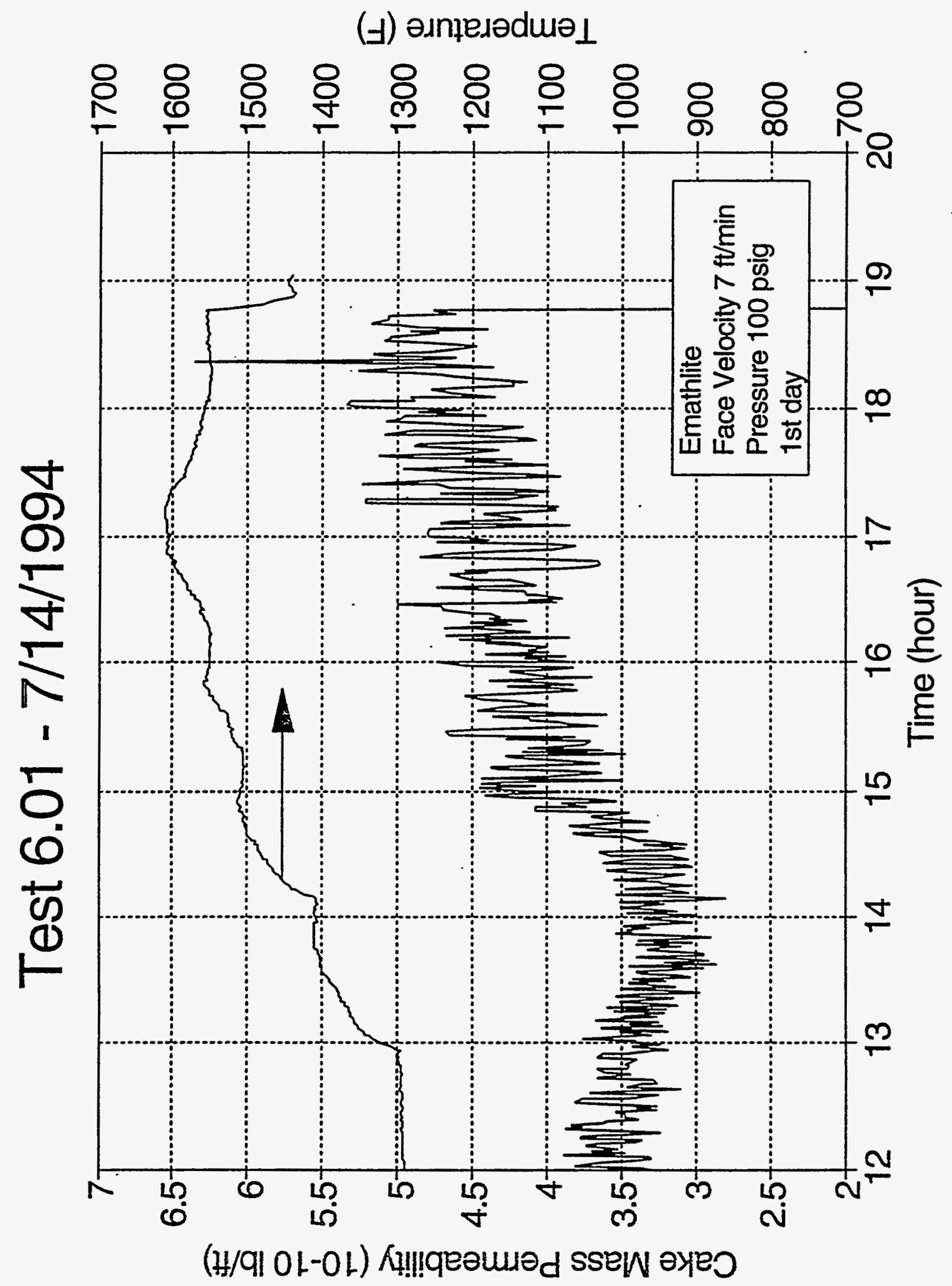




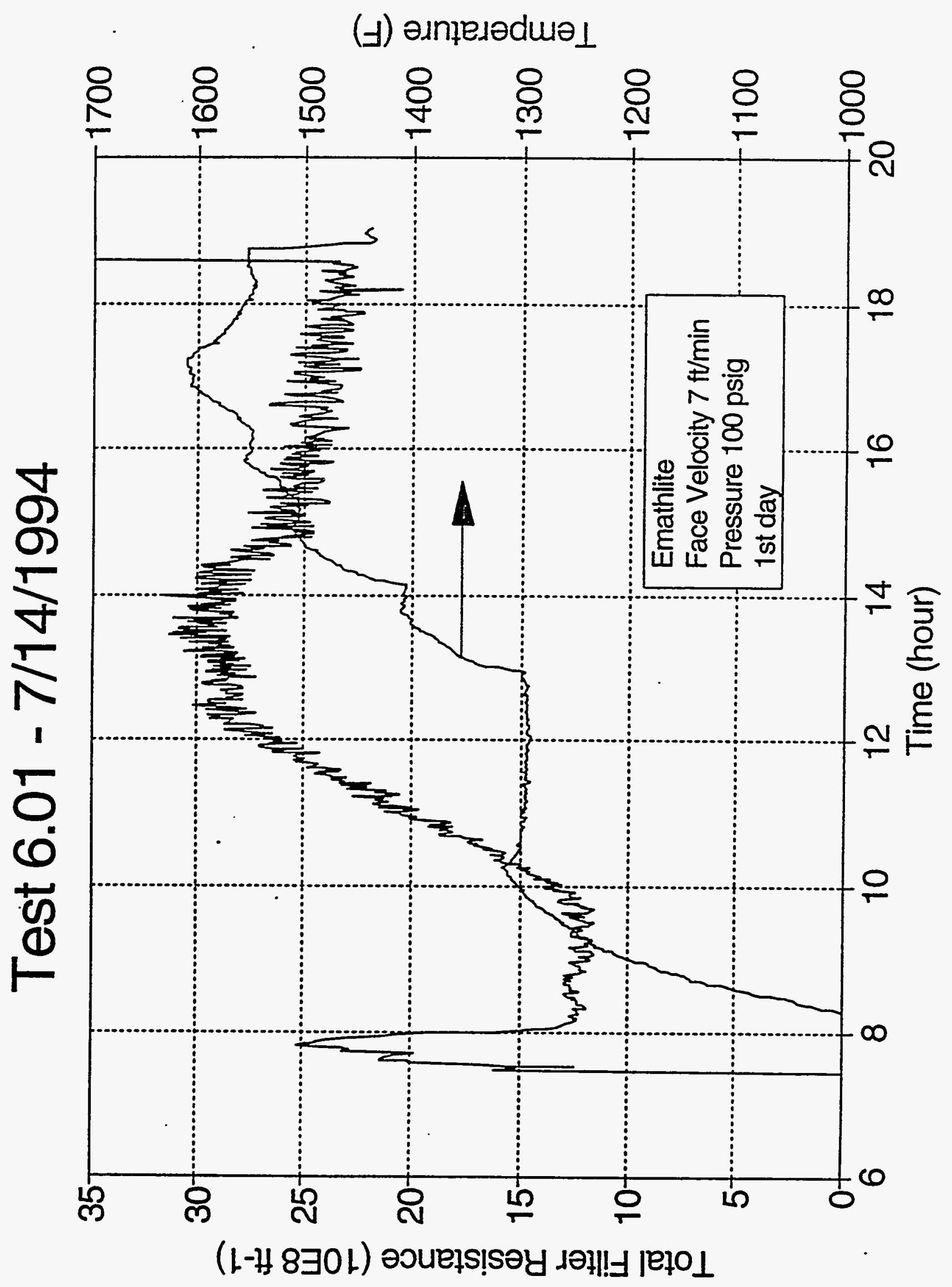




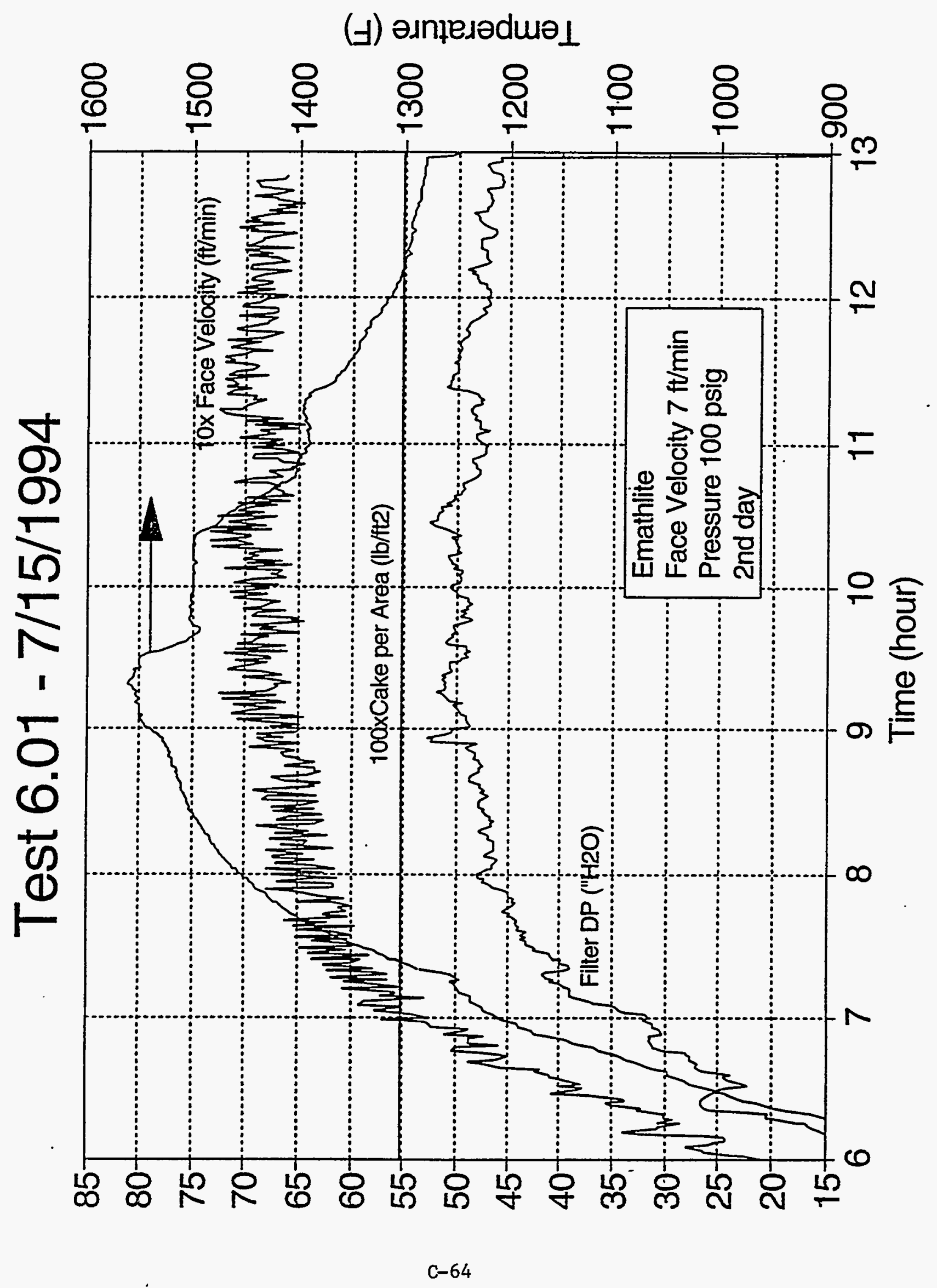




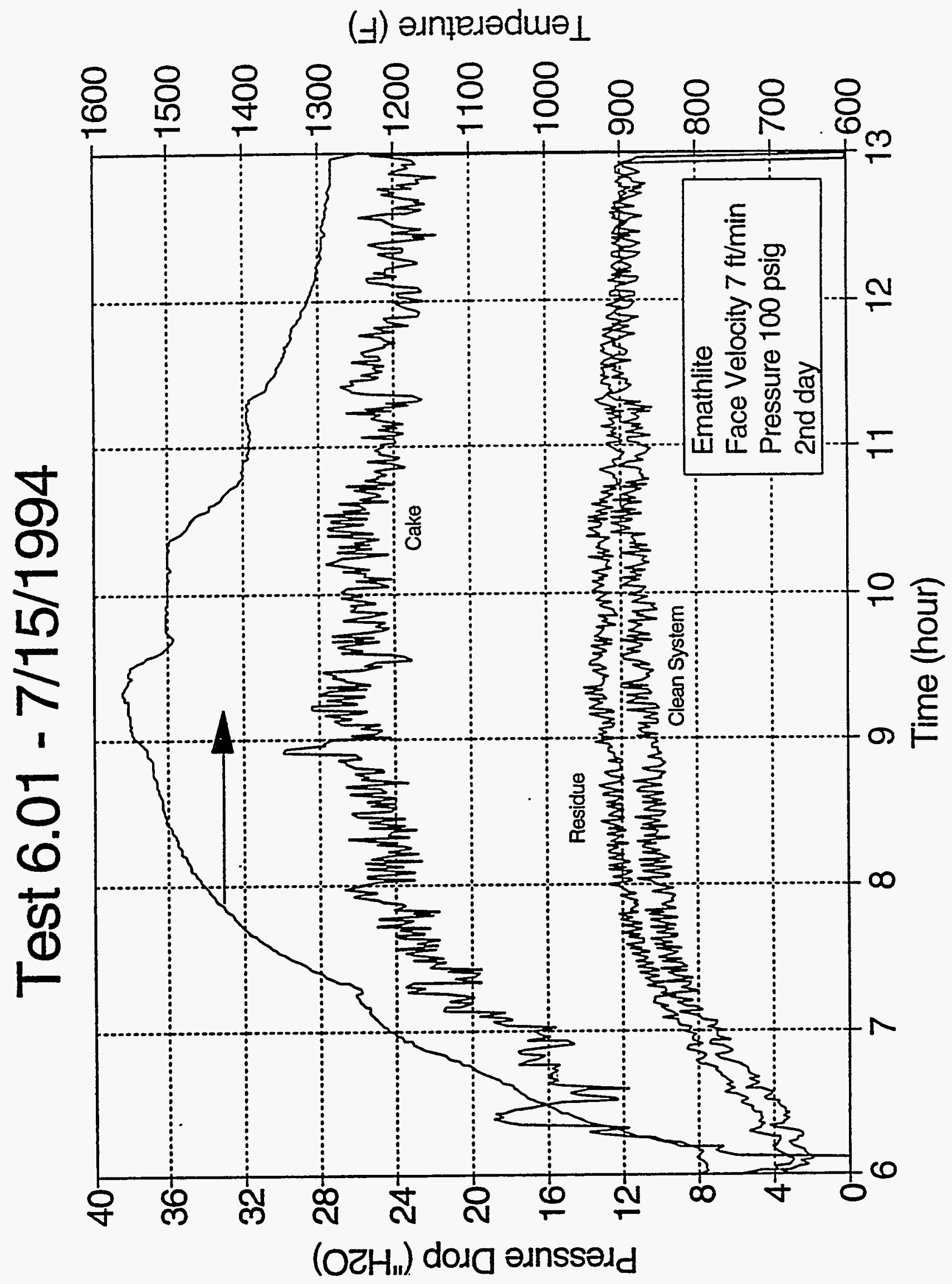




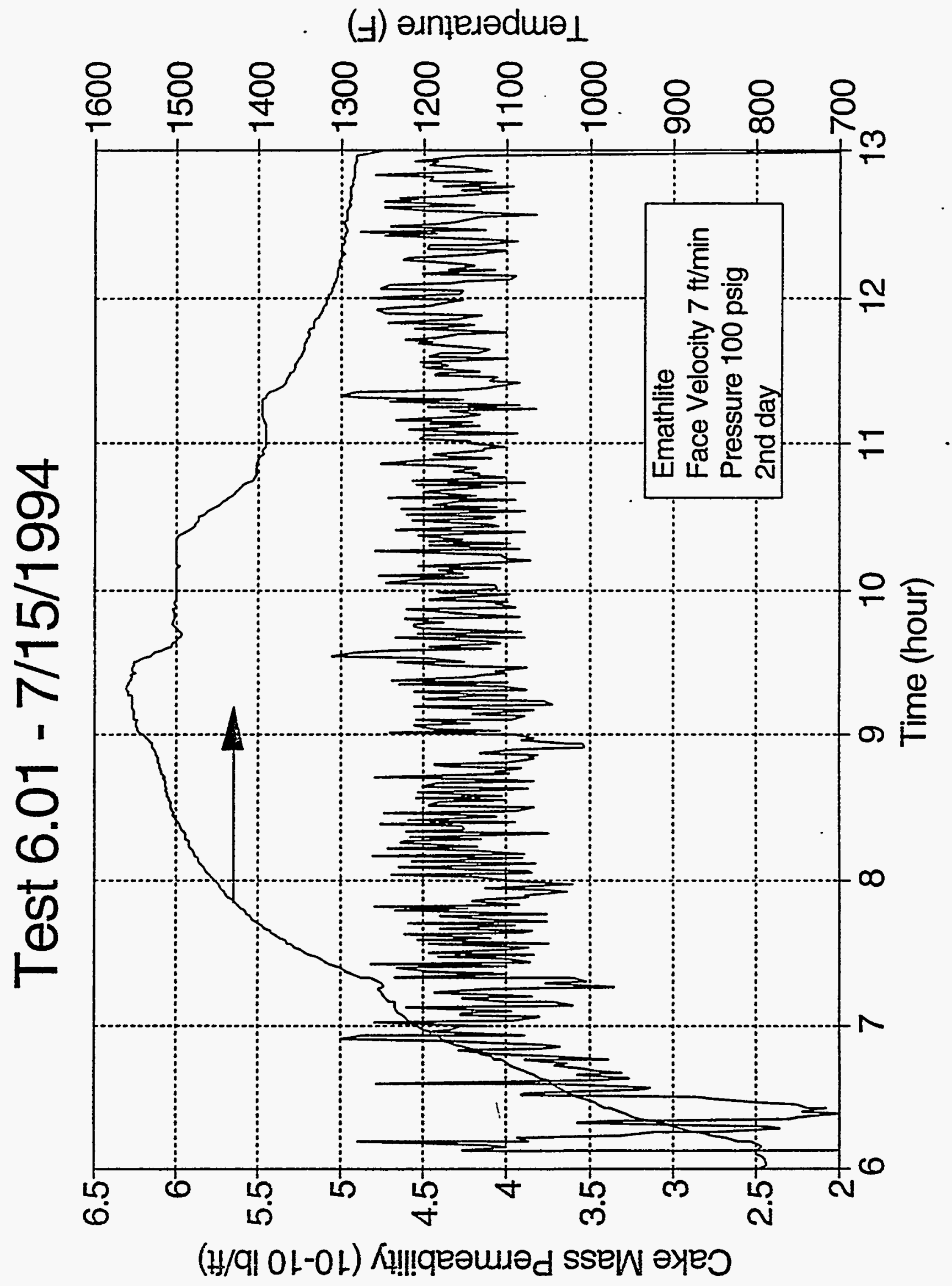




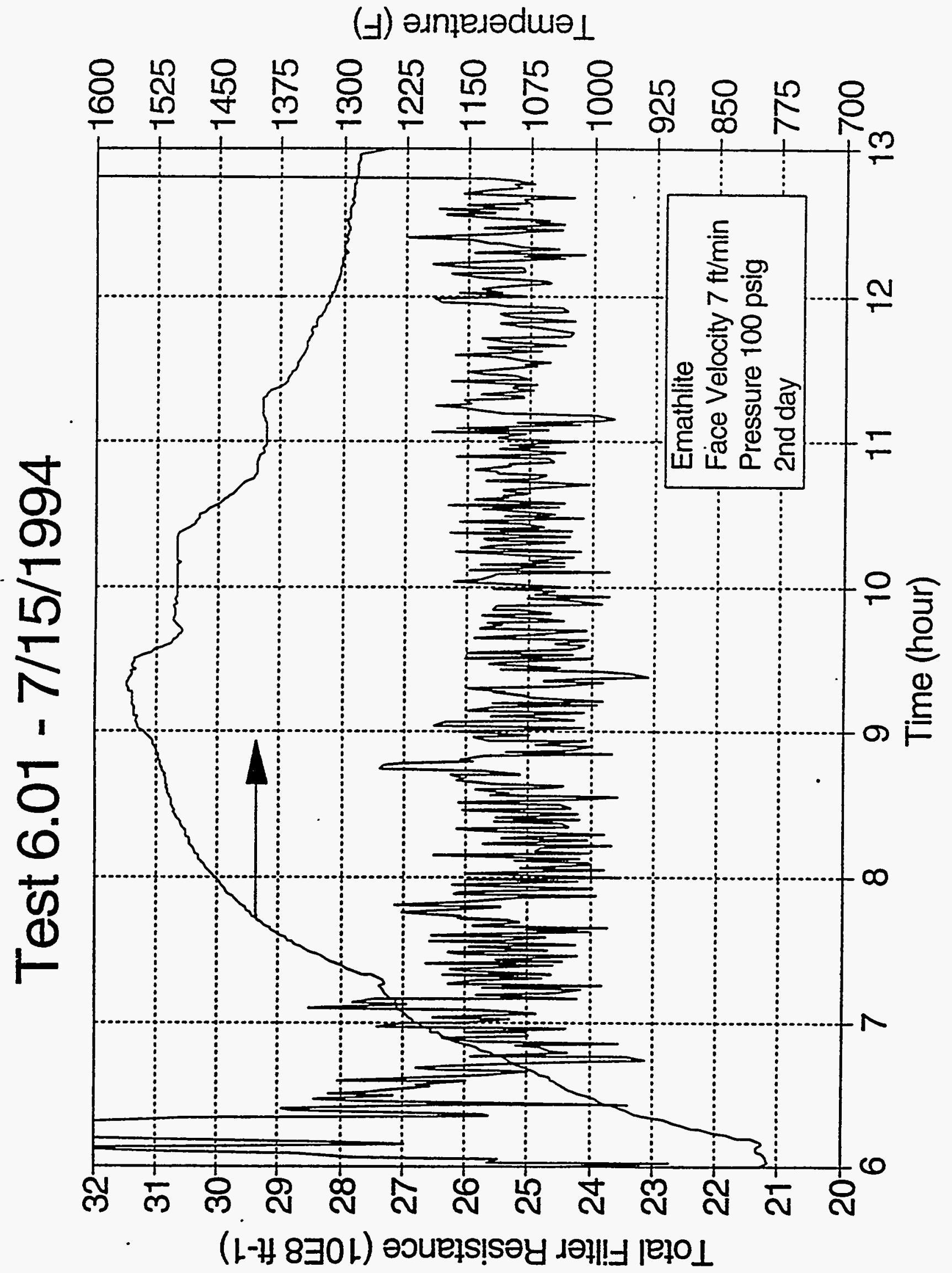




\section{Test 3.01 - 11/24/93}

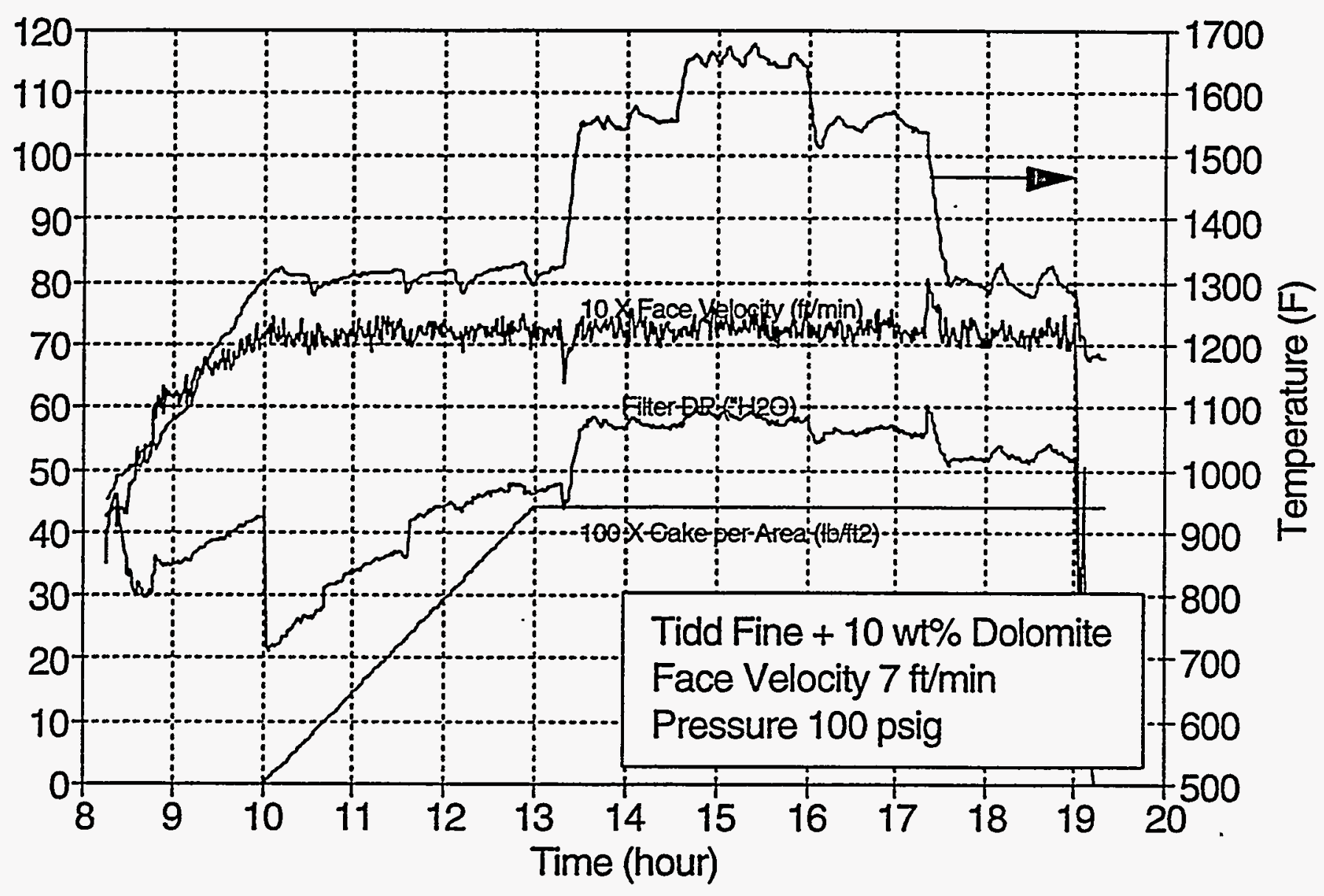




\section{Test 3.01 - 11/24/93}






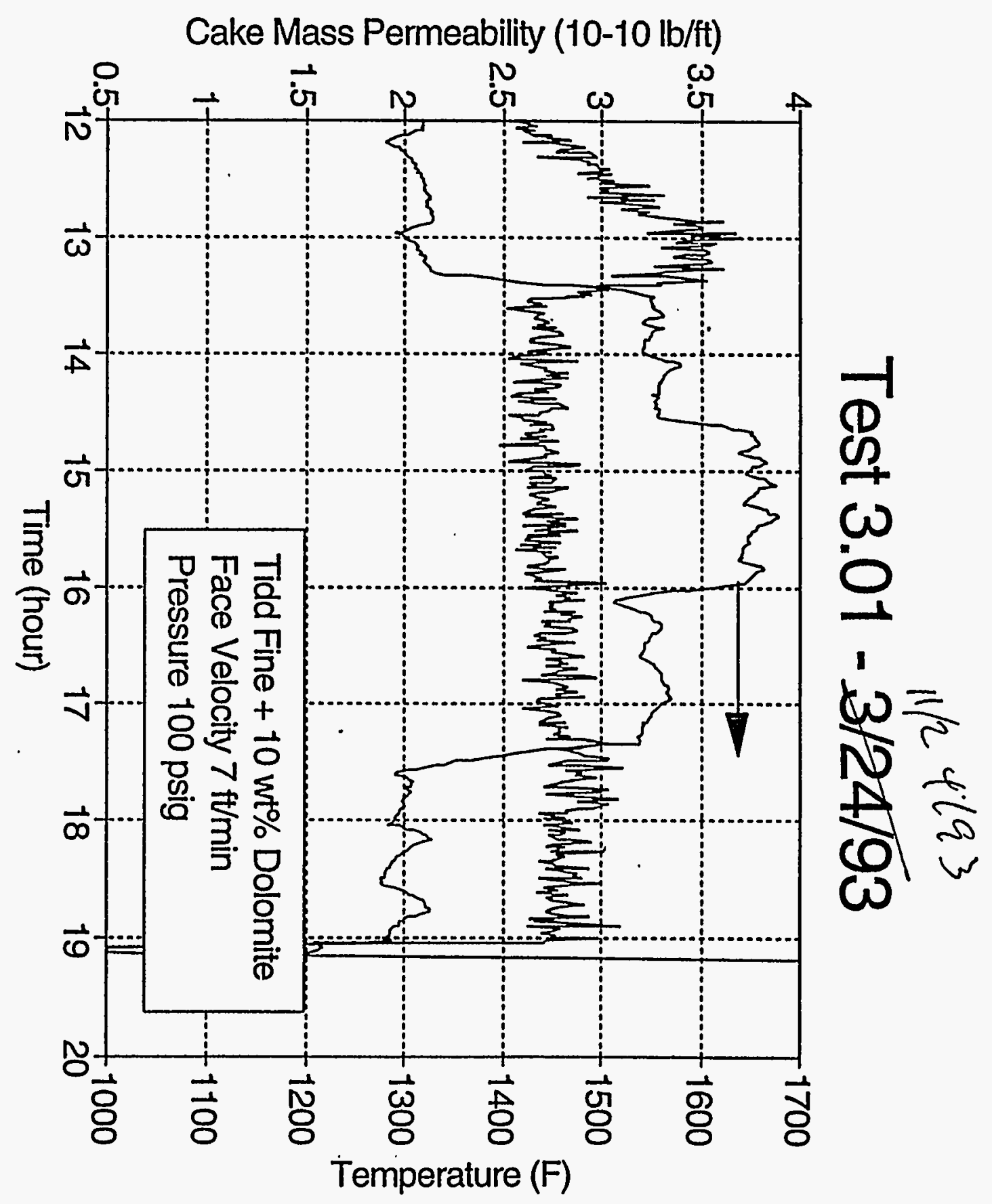




\section{Test 3.020 - 1/24/94}

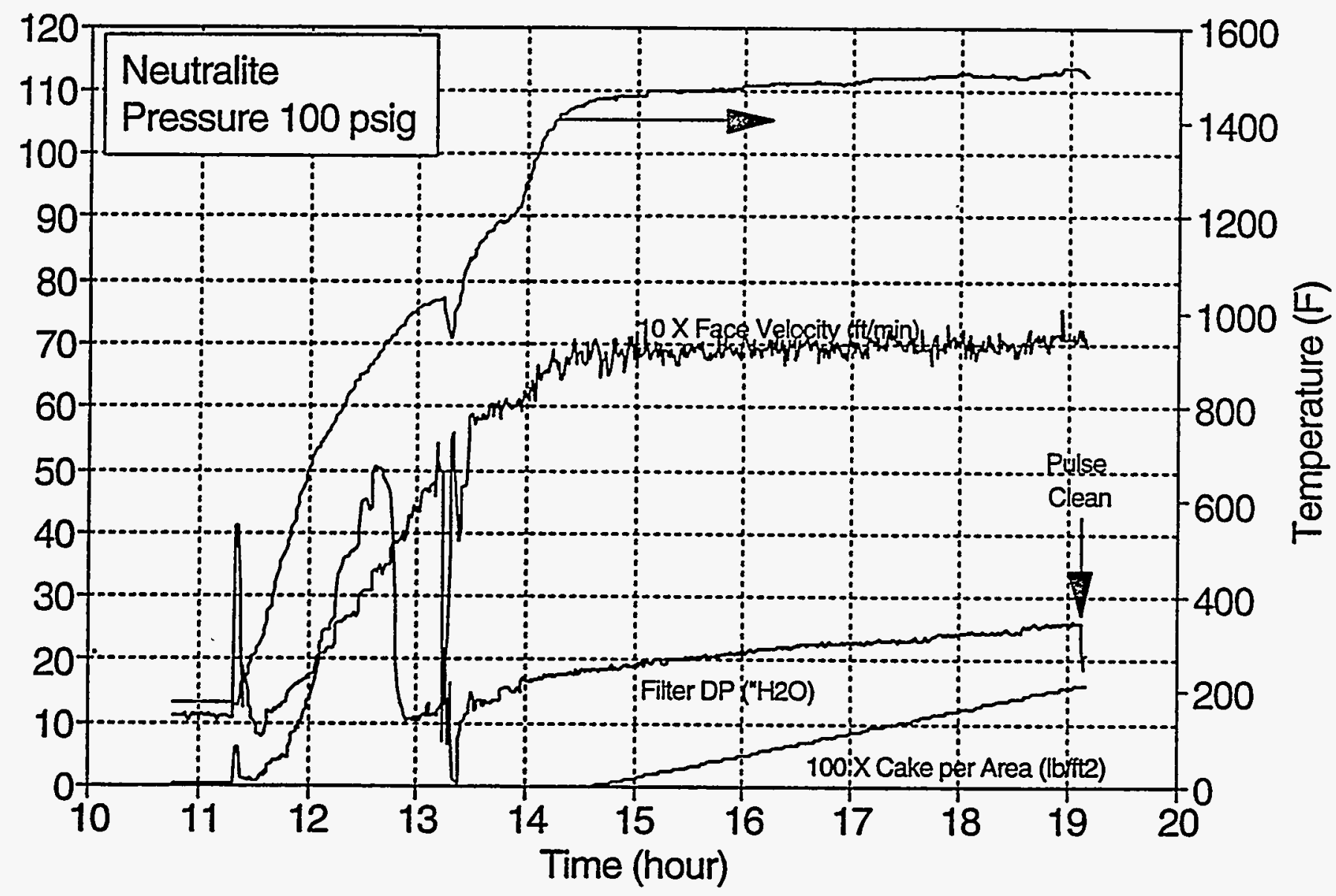




\section{Test 3.021 - 1/25/94}

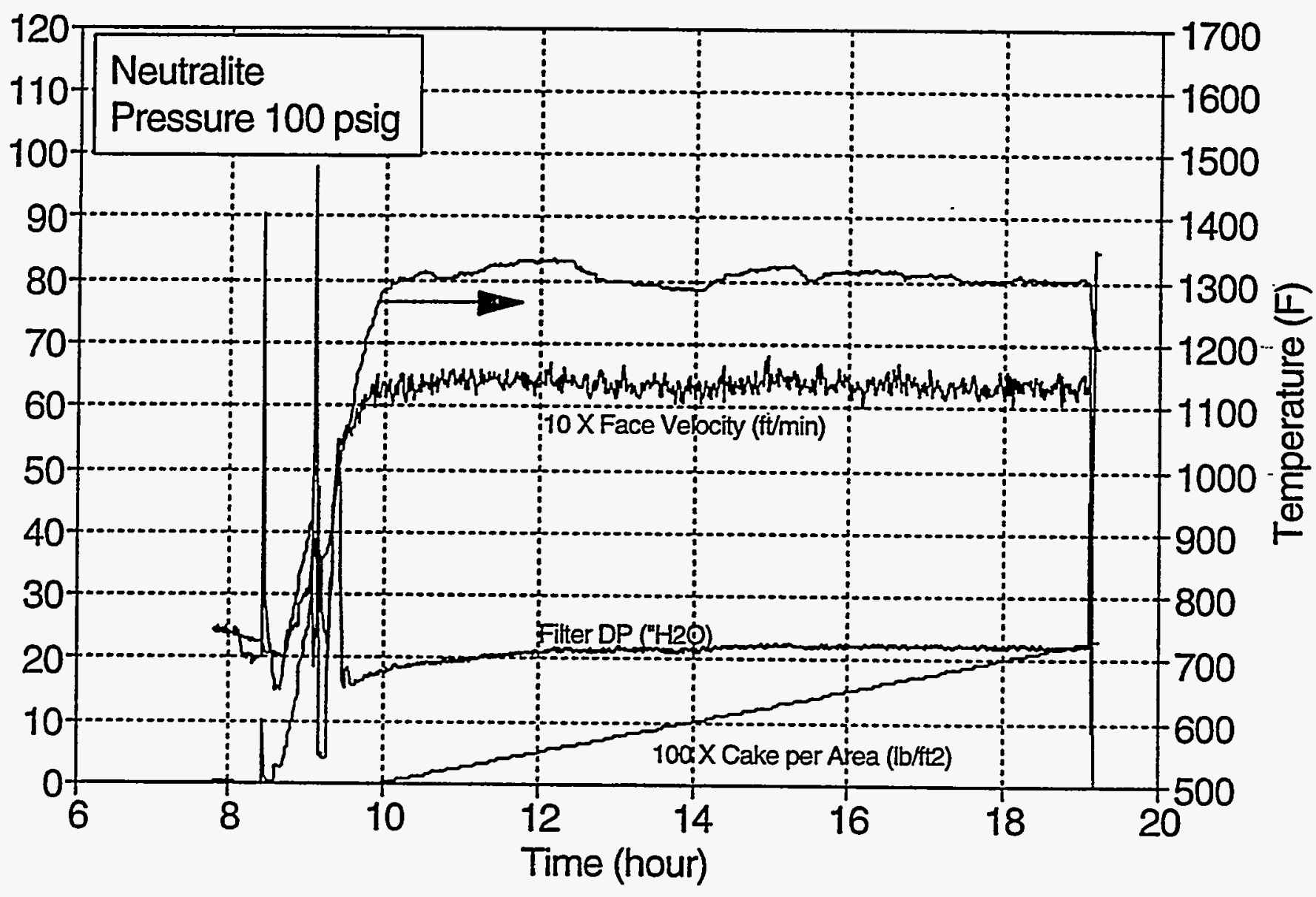




\section{Test 3.022 - 1/26/94}

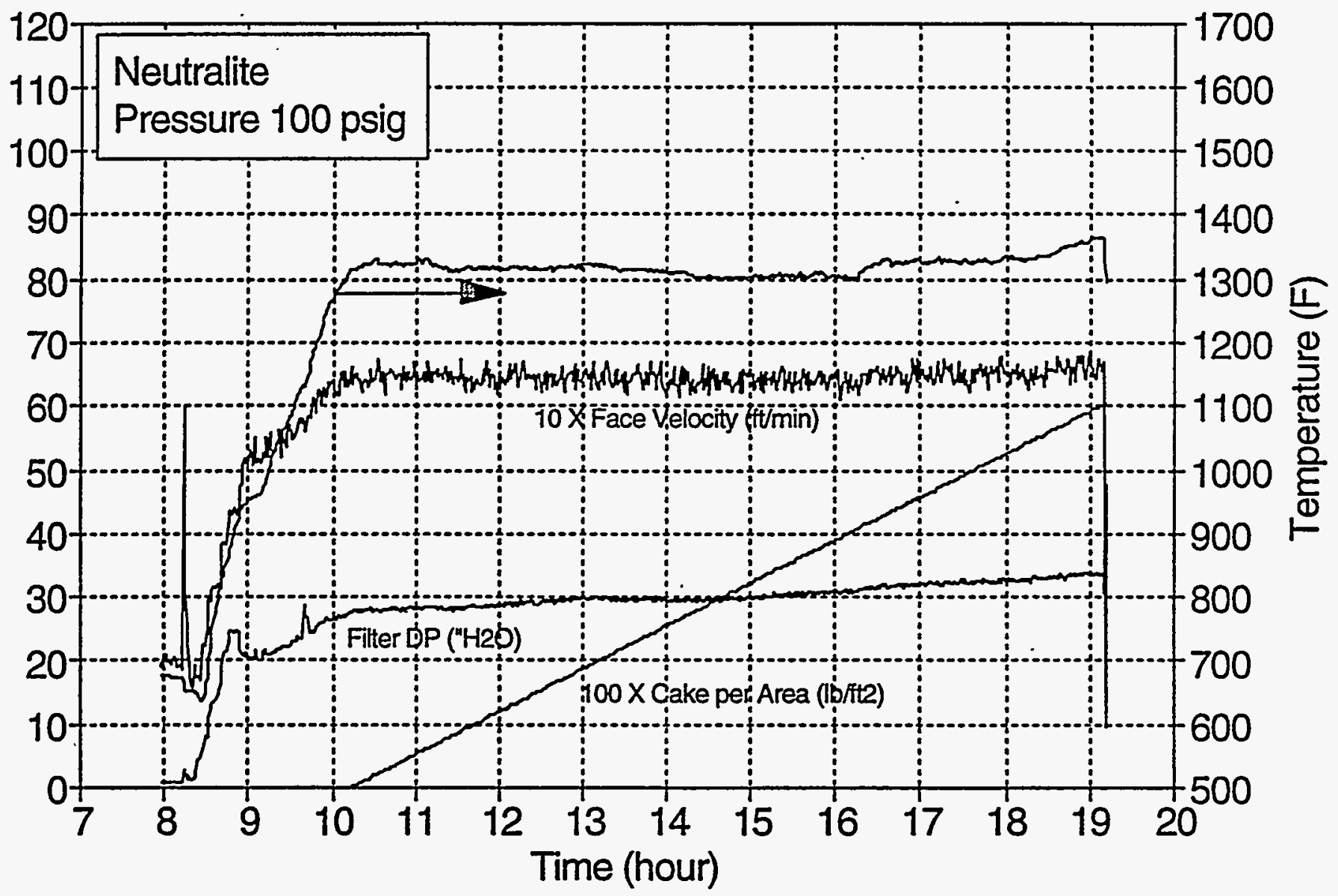




\section{Test 3.023 - 1/27/94}

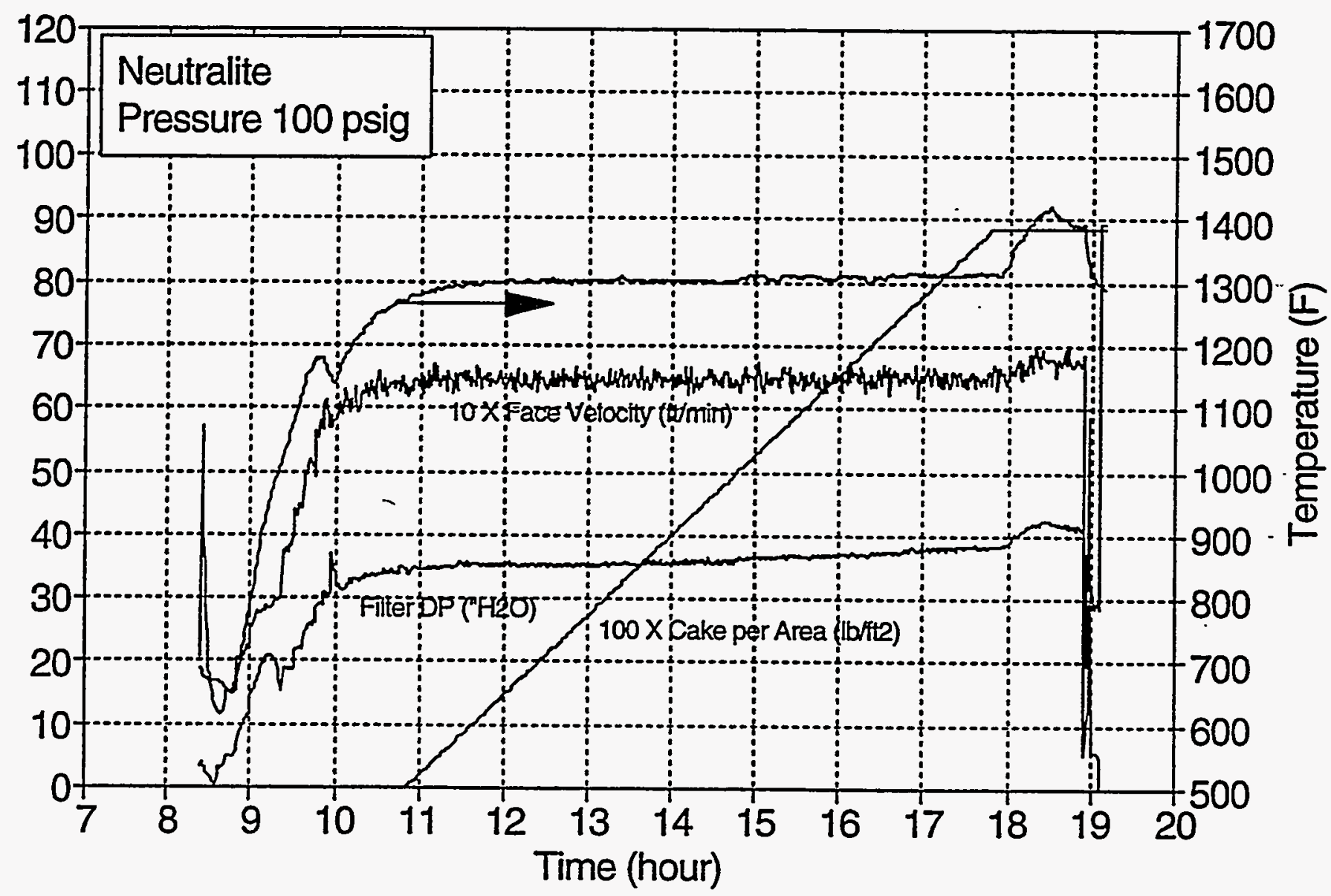




\section{Test 3.024 - 1/28/94}

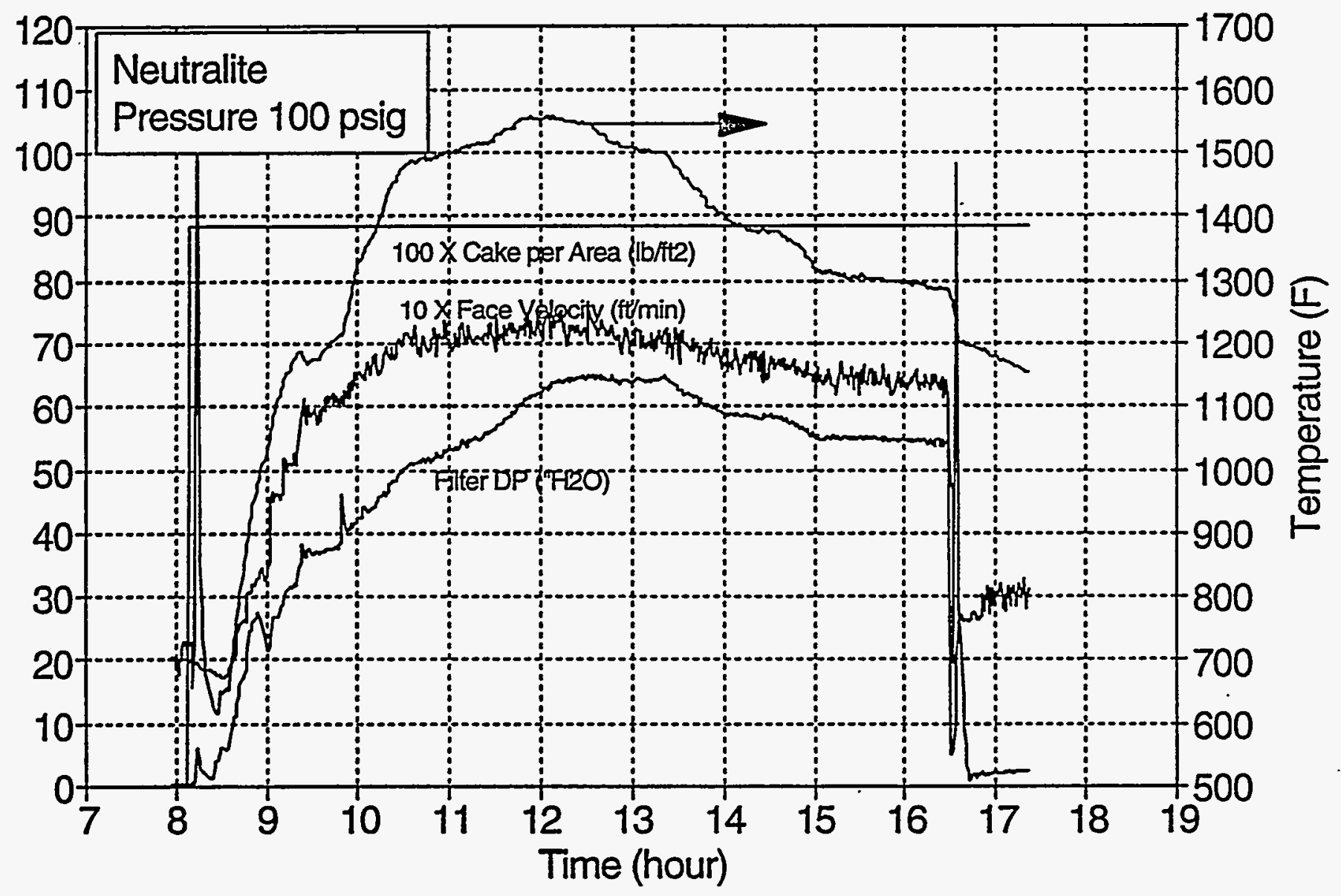


Test 3.024 - 1/28/94

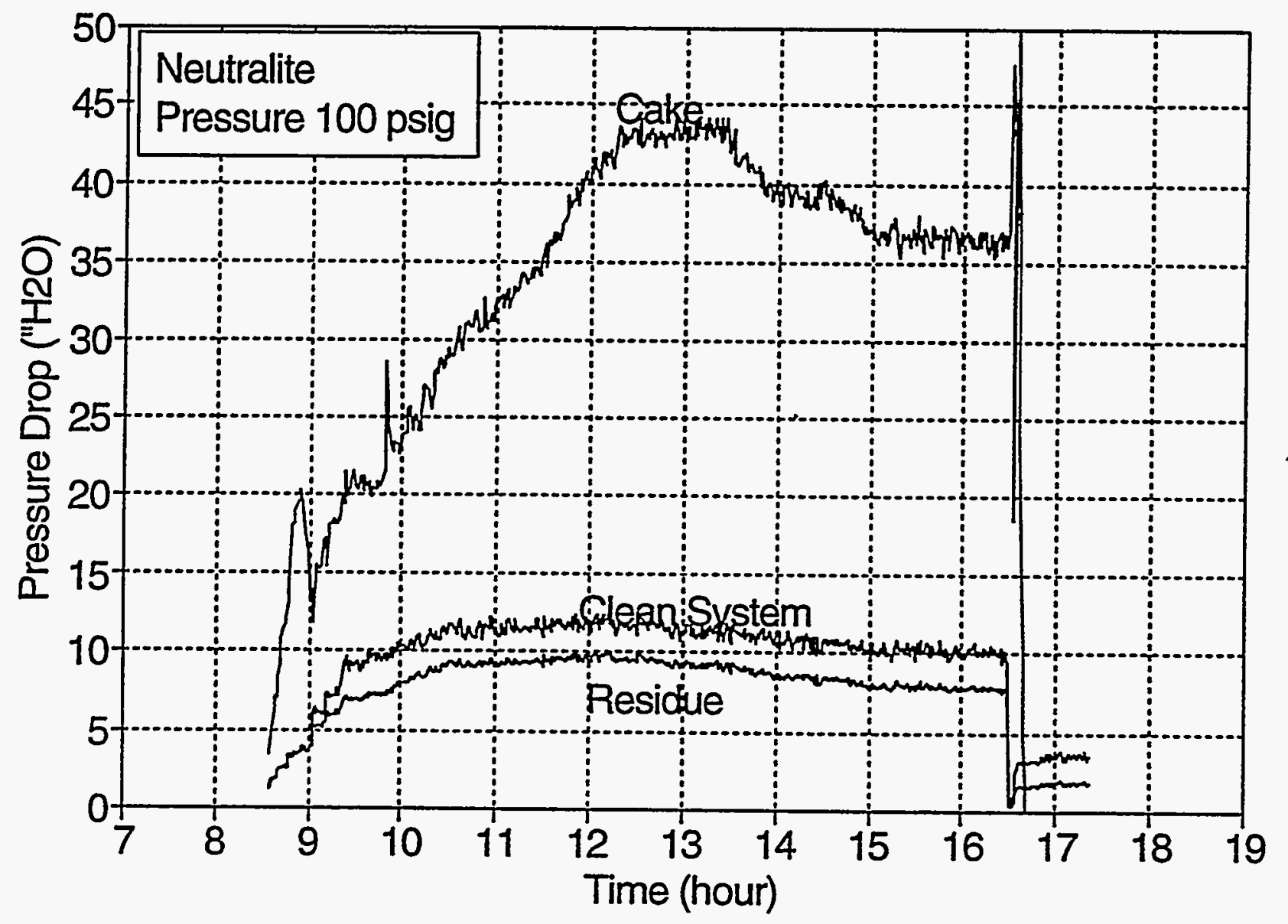




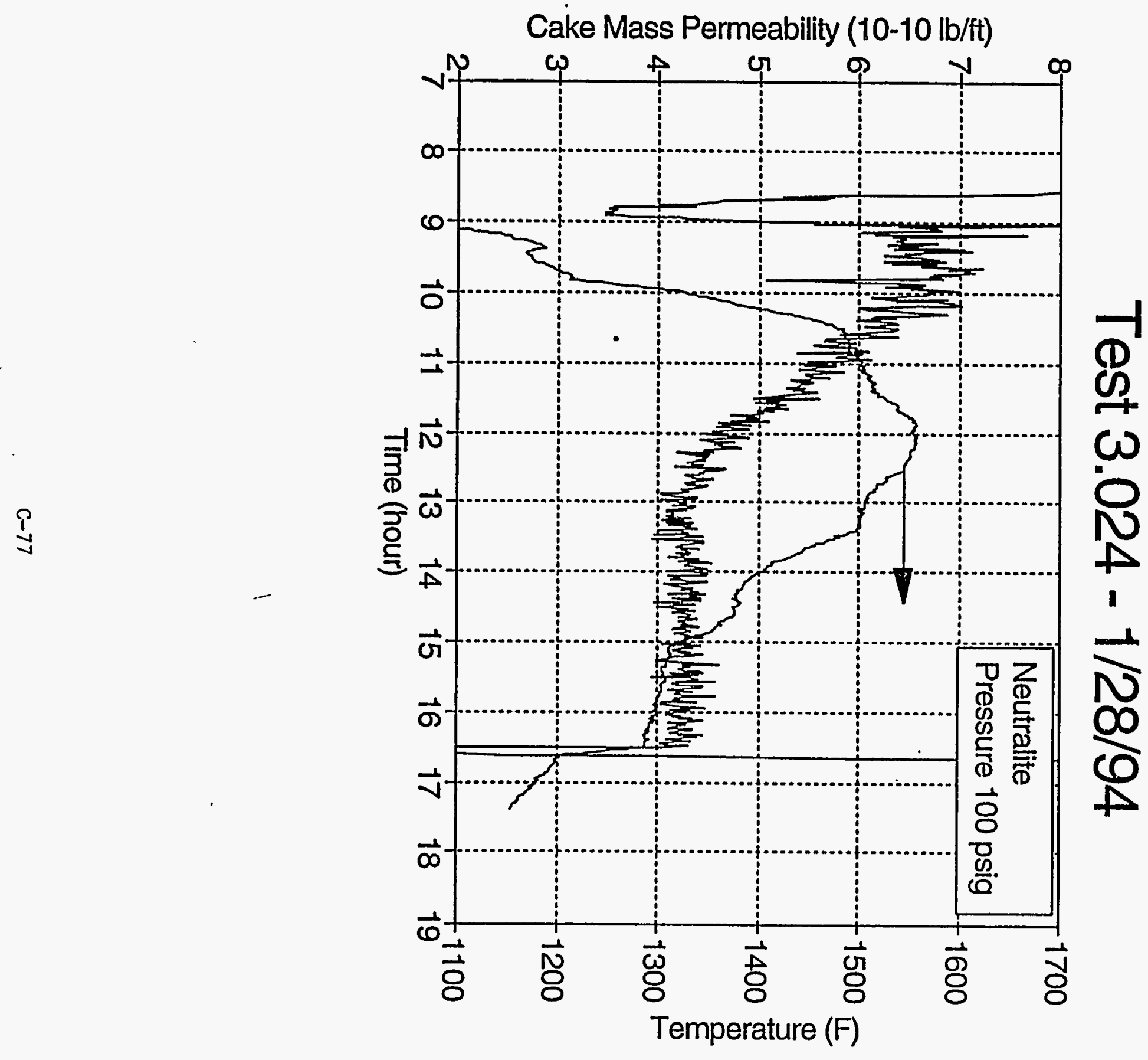




\section{Test 3.025 - 2/02/94}

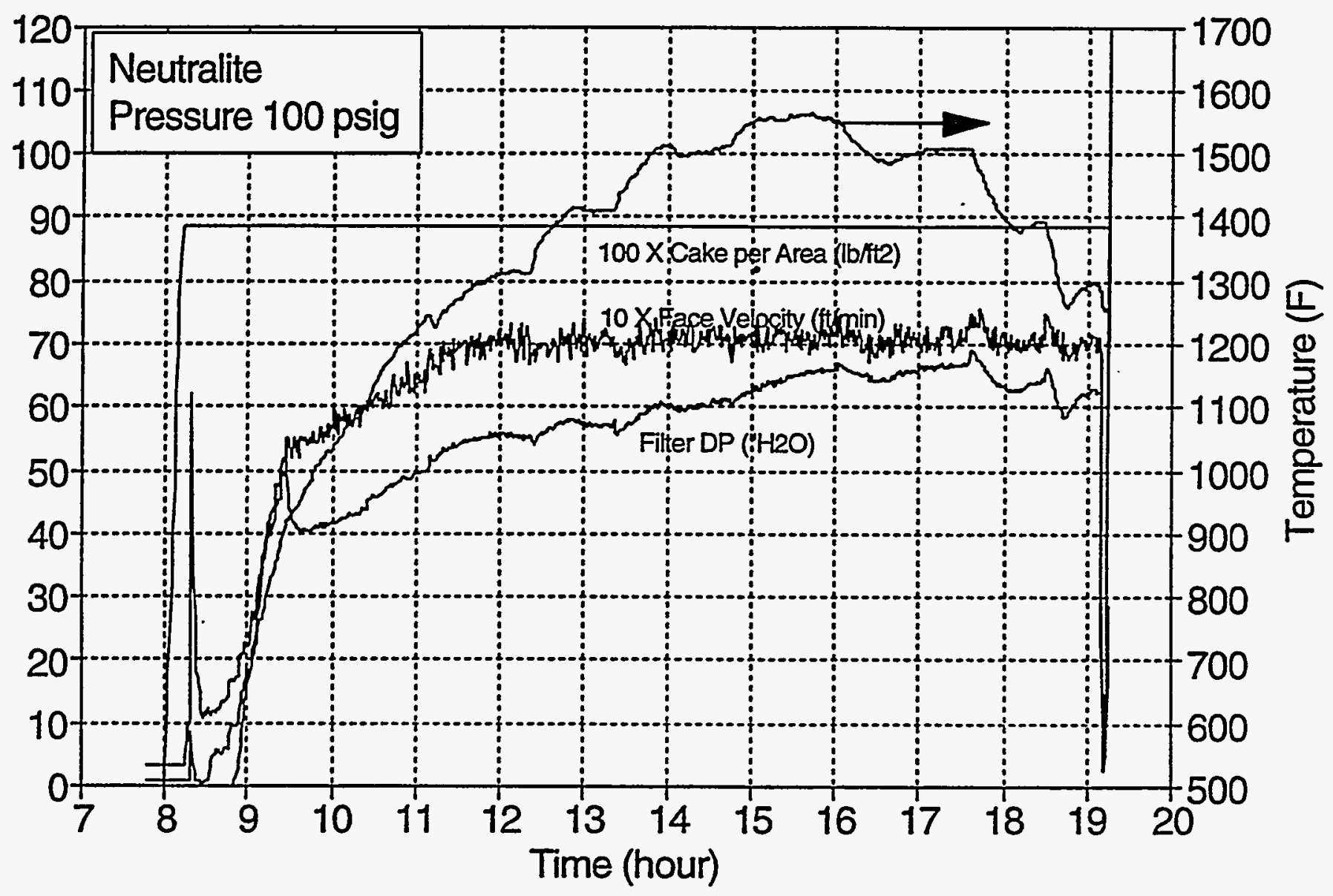




\section{Test 3.025 - 2/02/94}

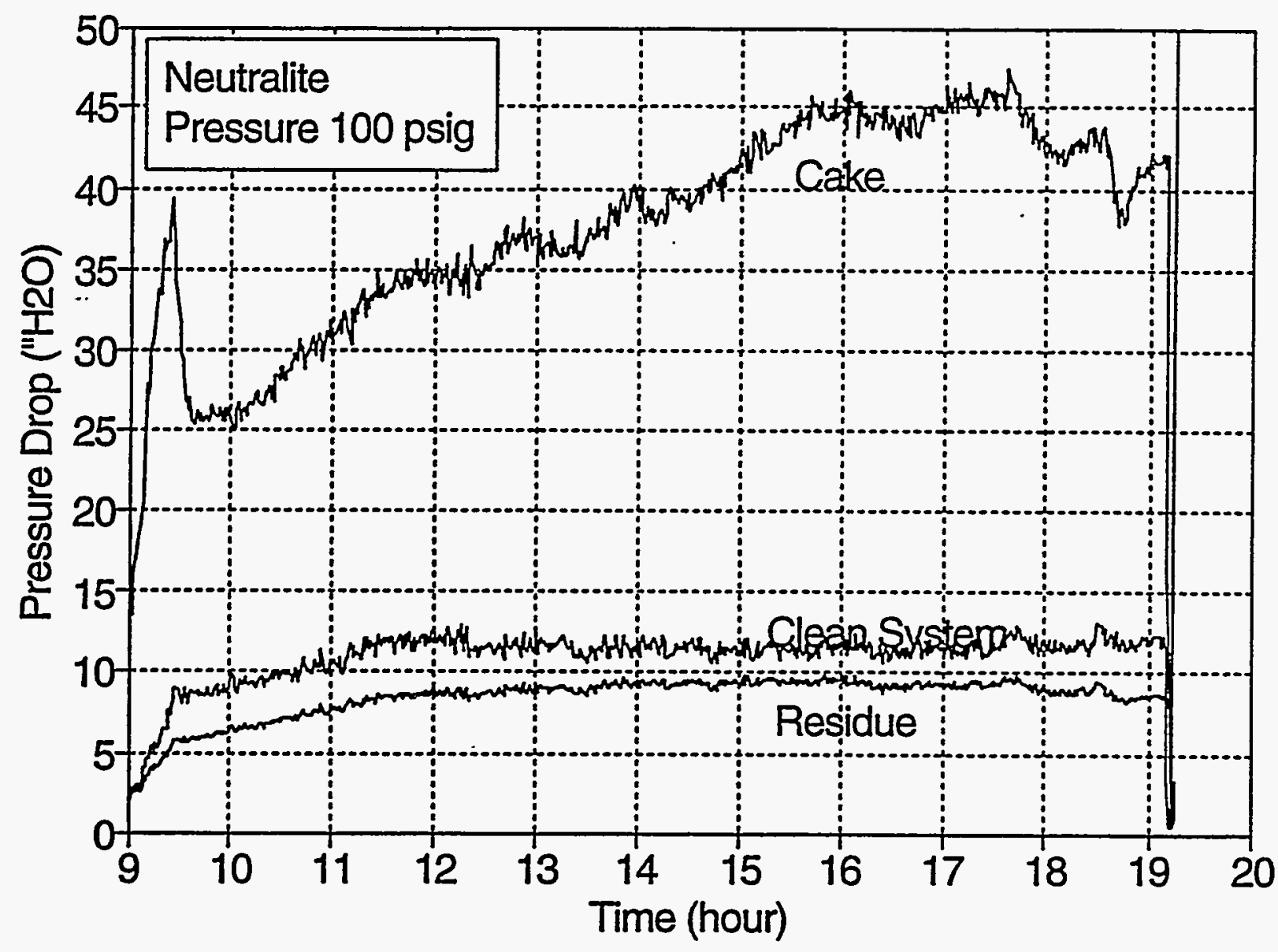




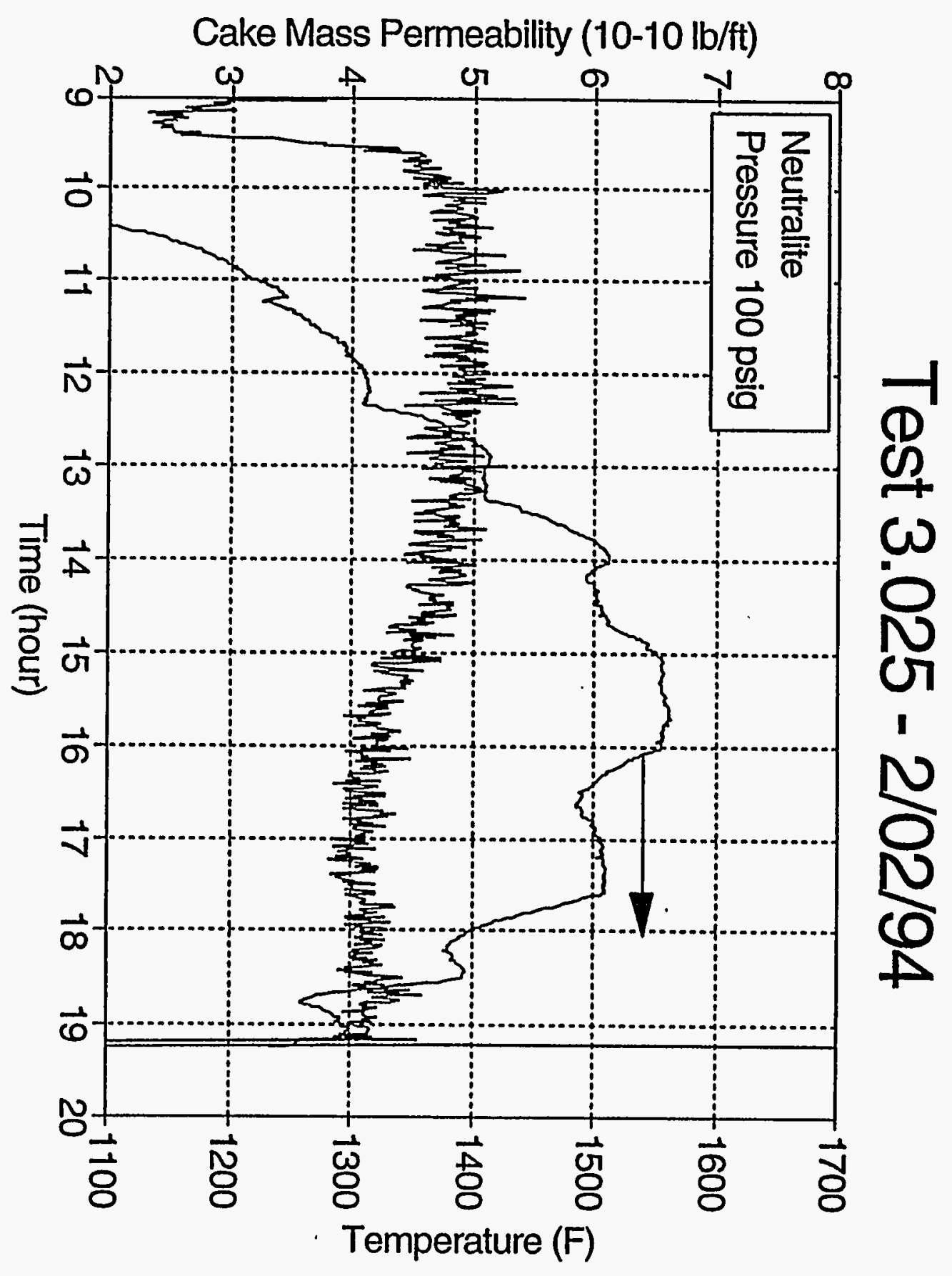




\section{Test 3.03 - 2/03/94}

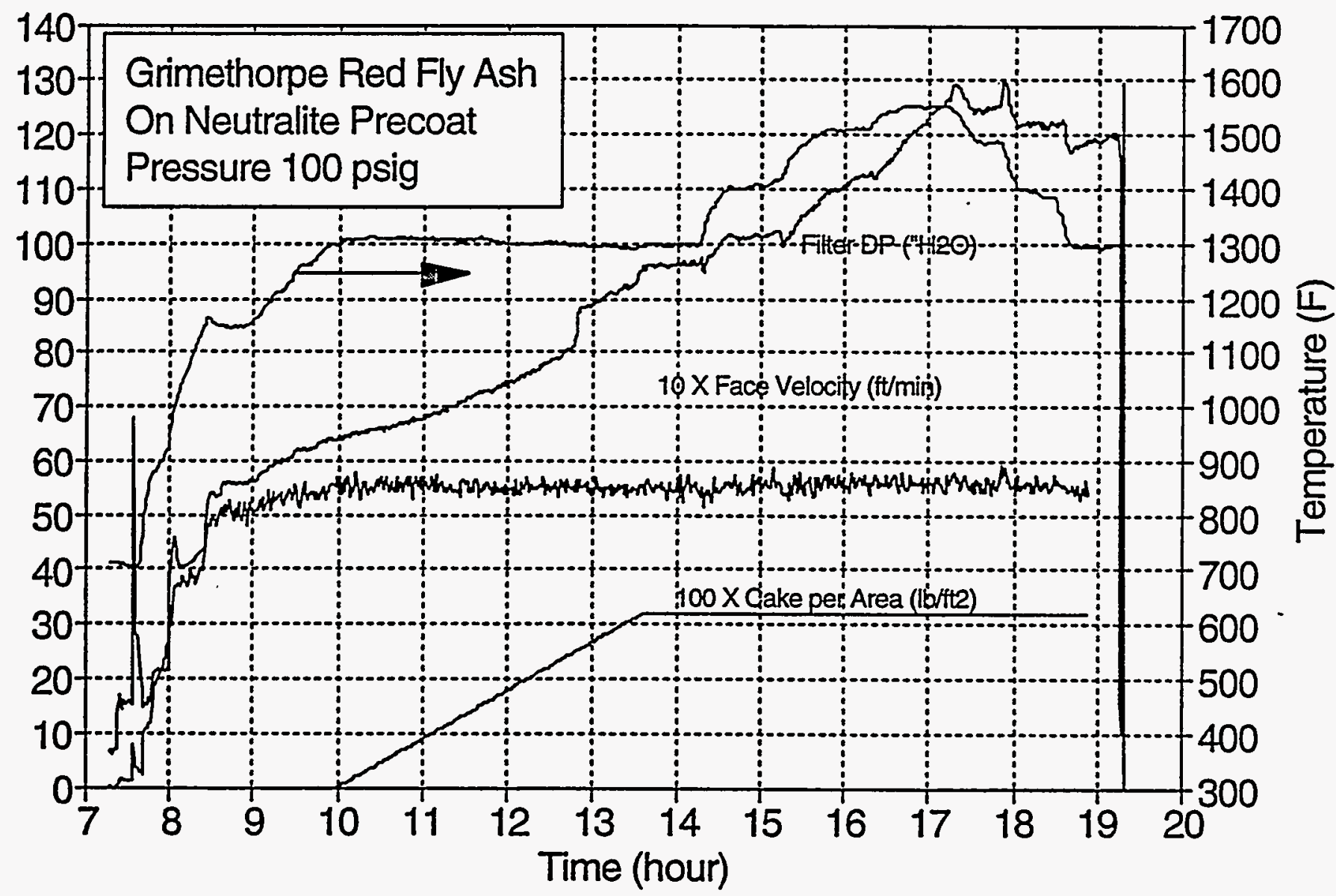




\section{Test 3.03 - 2/03/94}

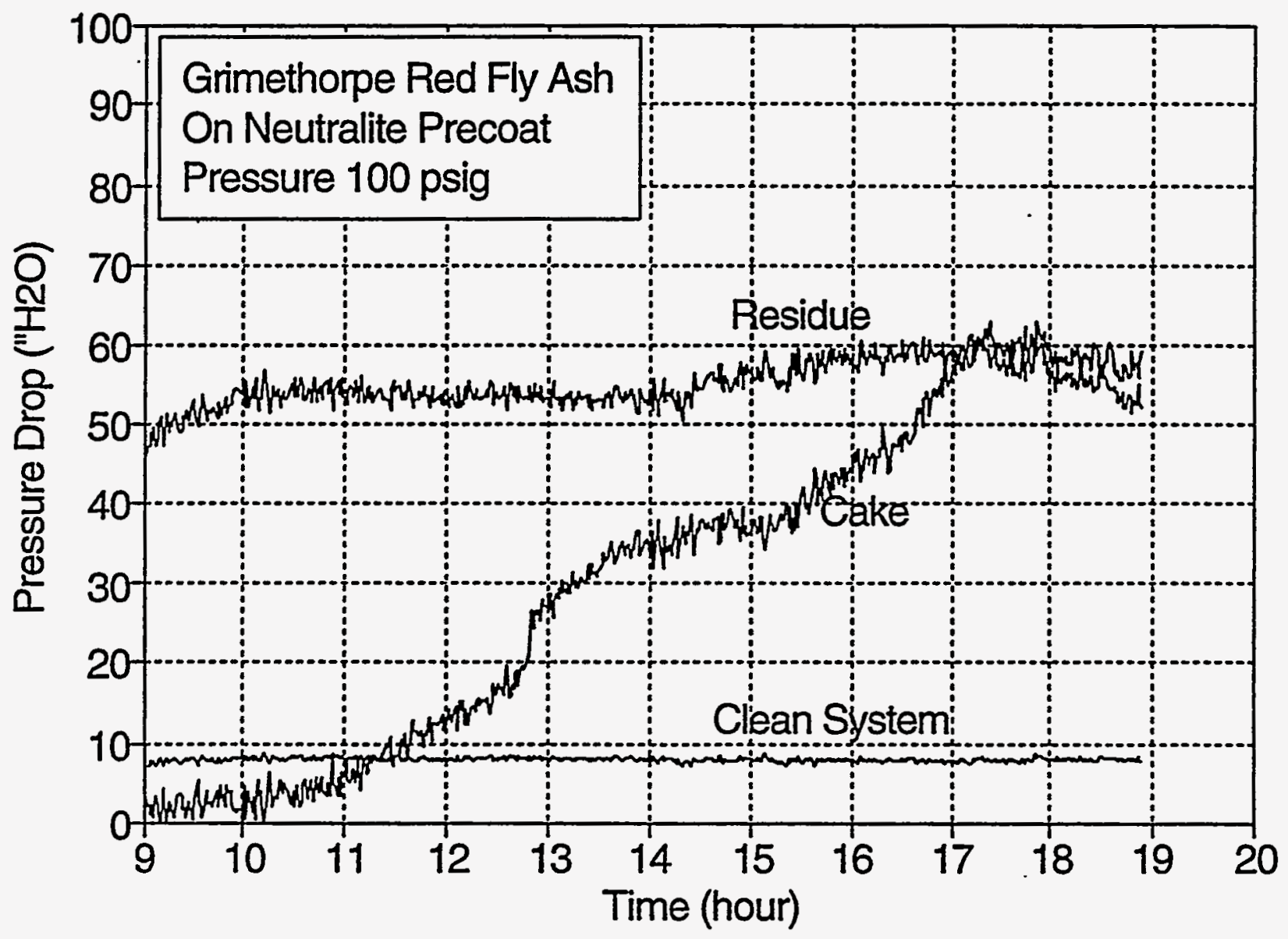


Test 3.03 - 2/03/94

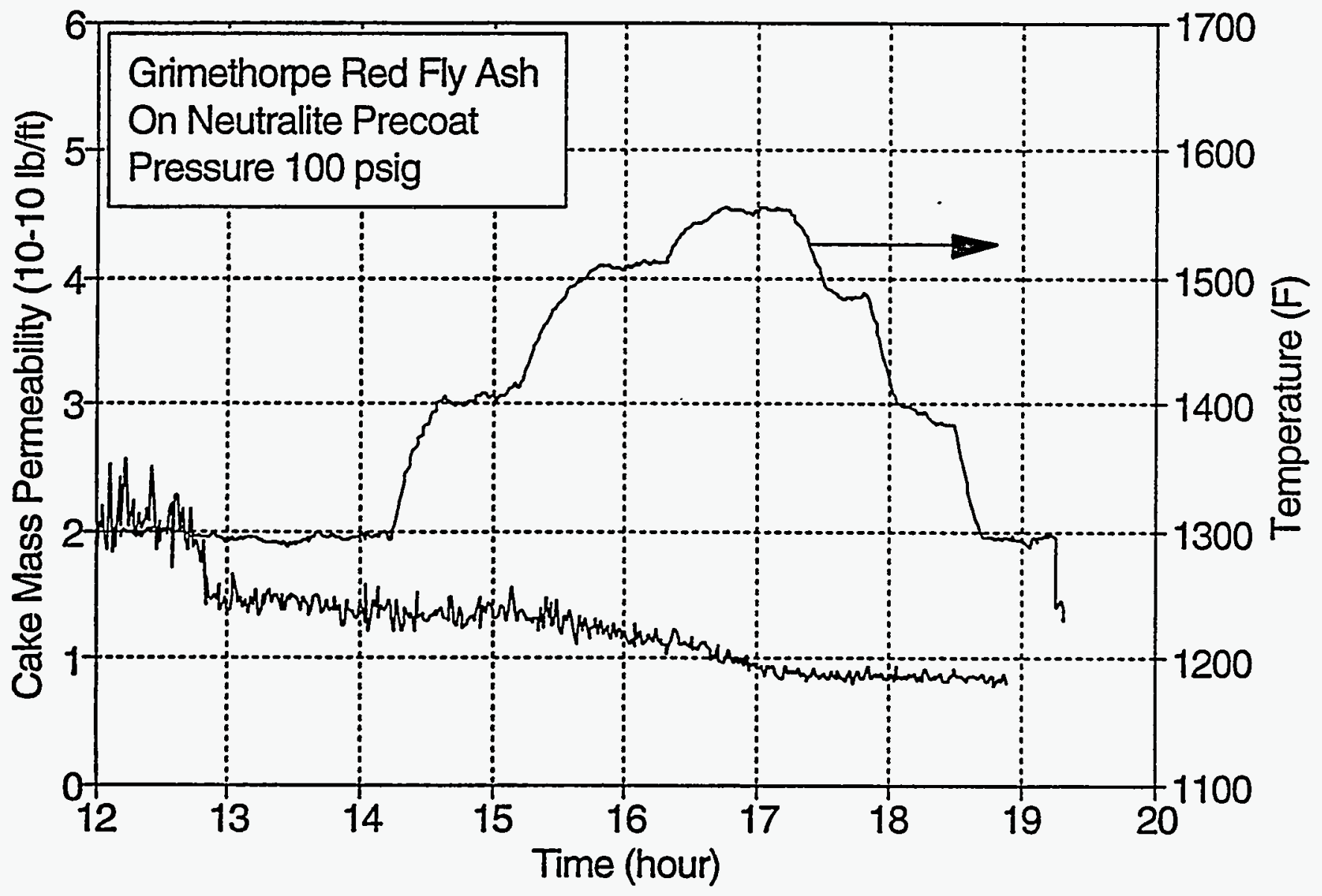


Test 3.041 - 2/04/94

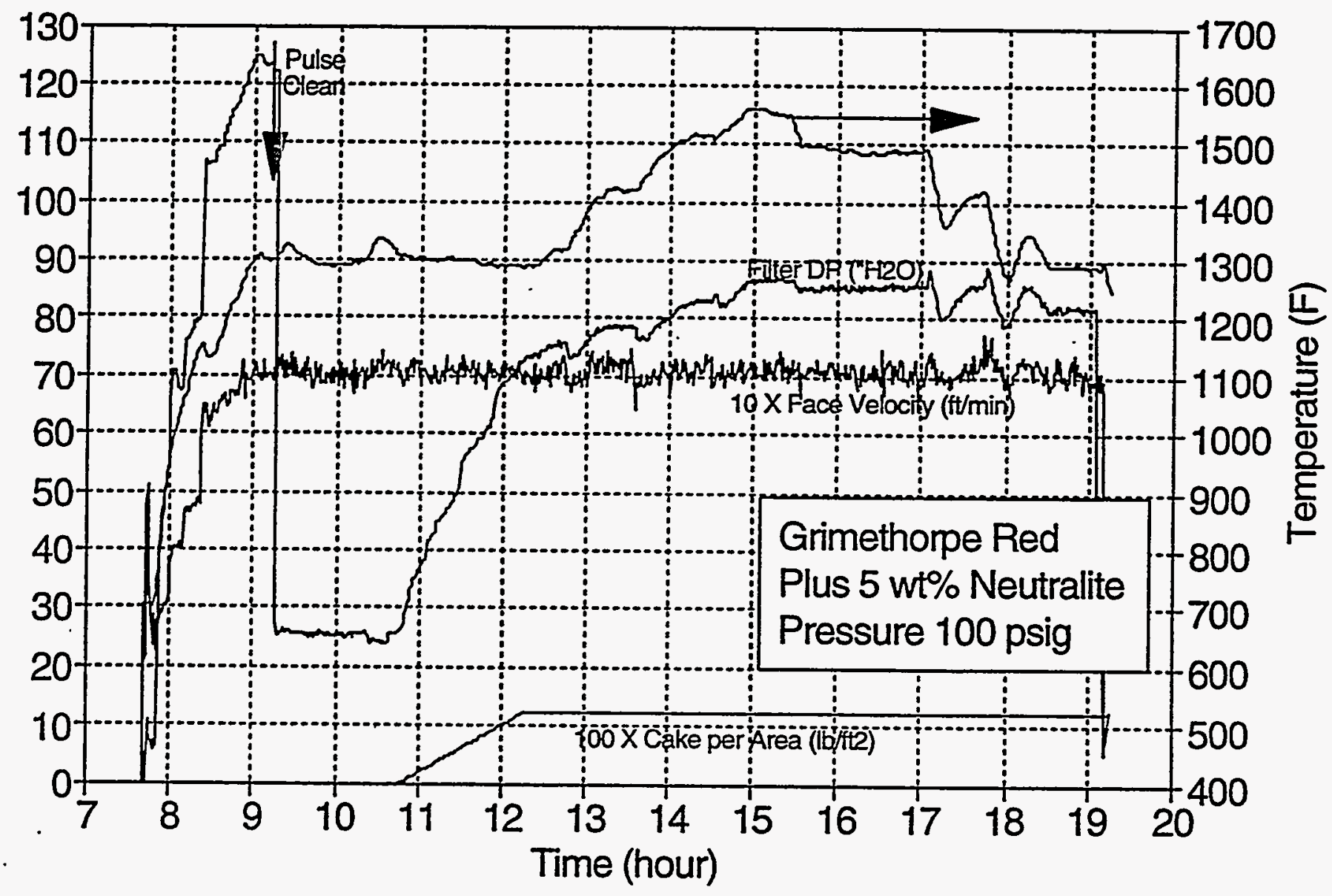




\section{Test 3.041 - 2/04/94}

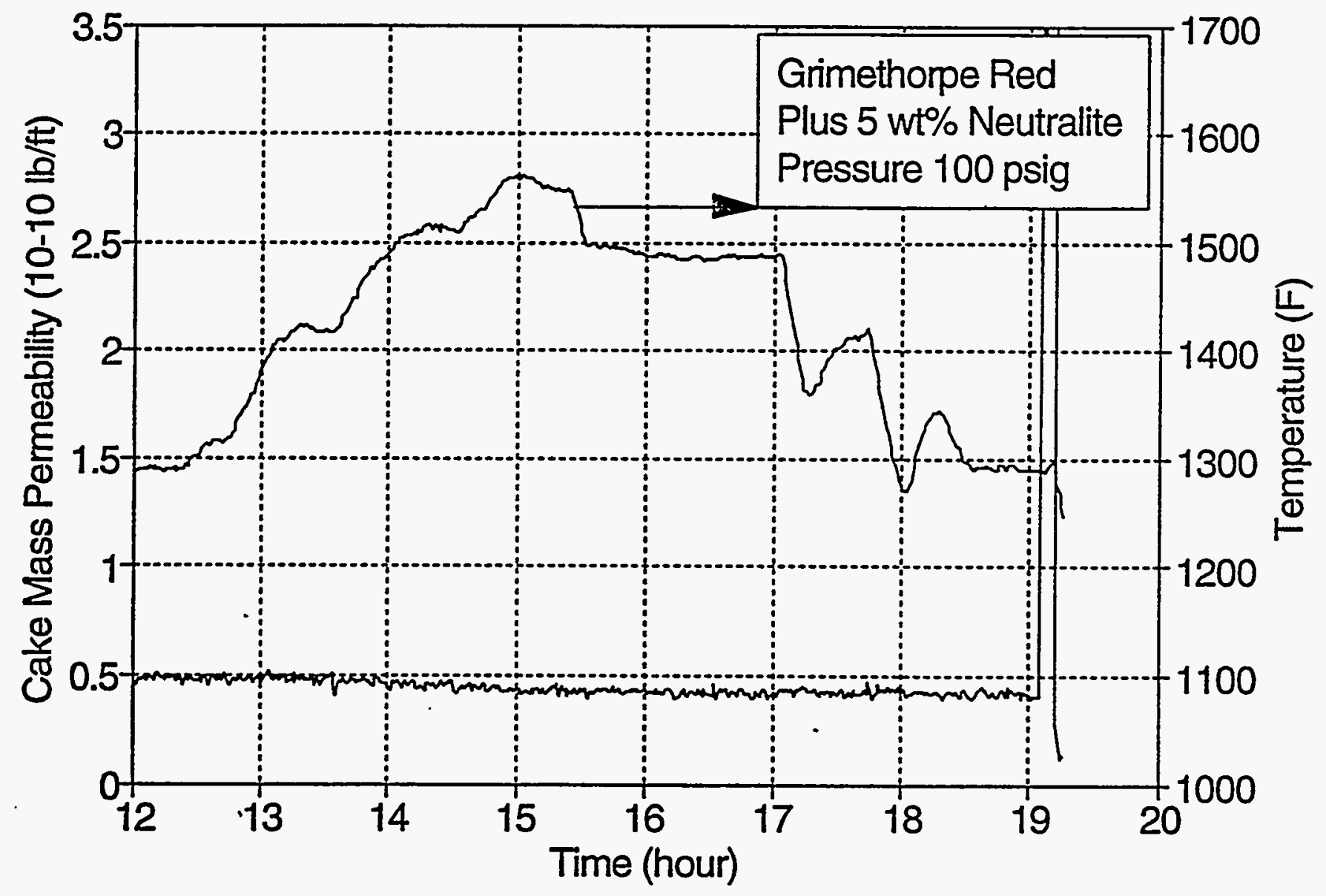




\section{Test 3.042 - 2/07/94}

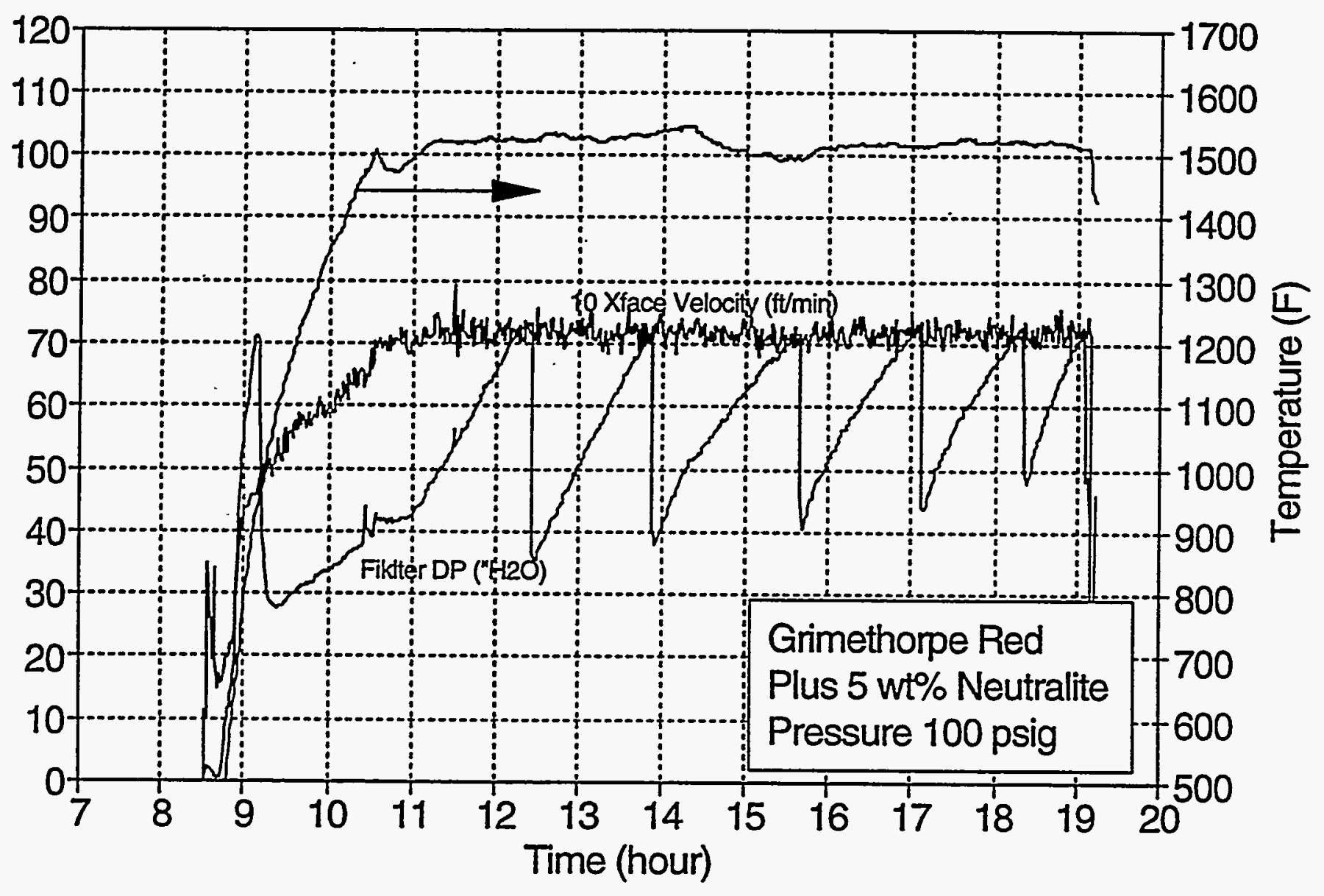


Test 3.05 - 2/16/94

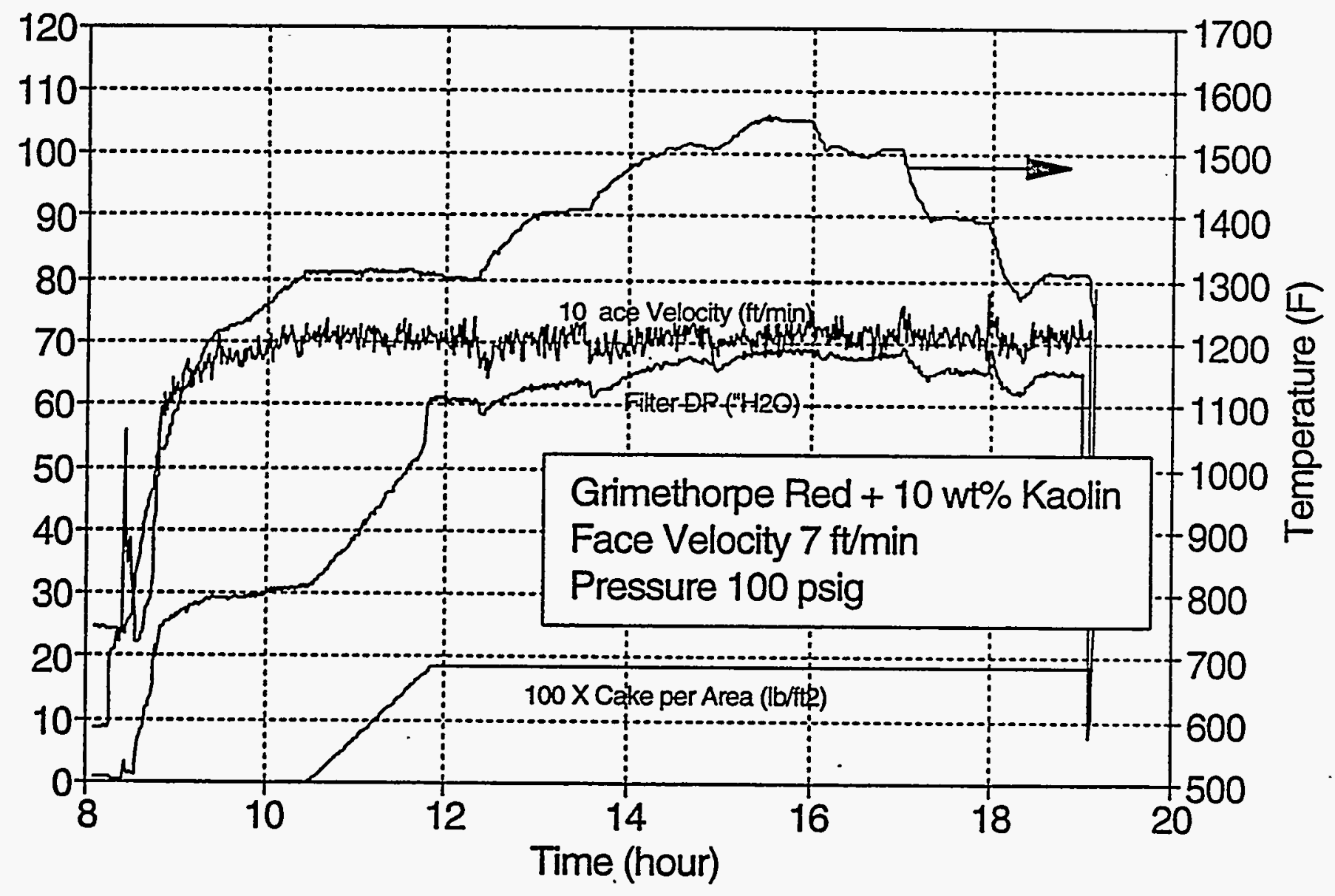




\section{Test 3.05 - 2/16/94}

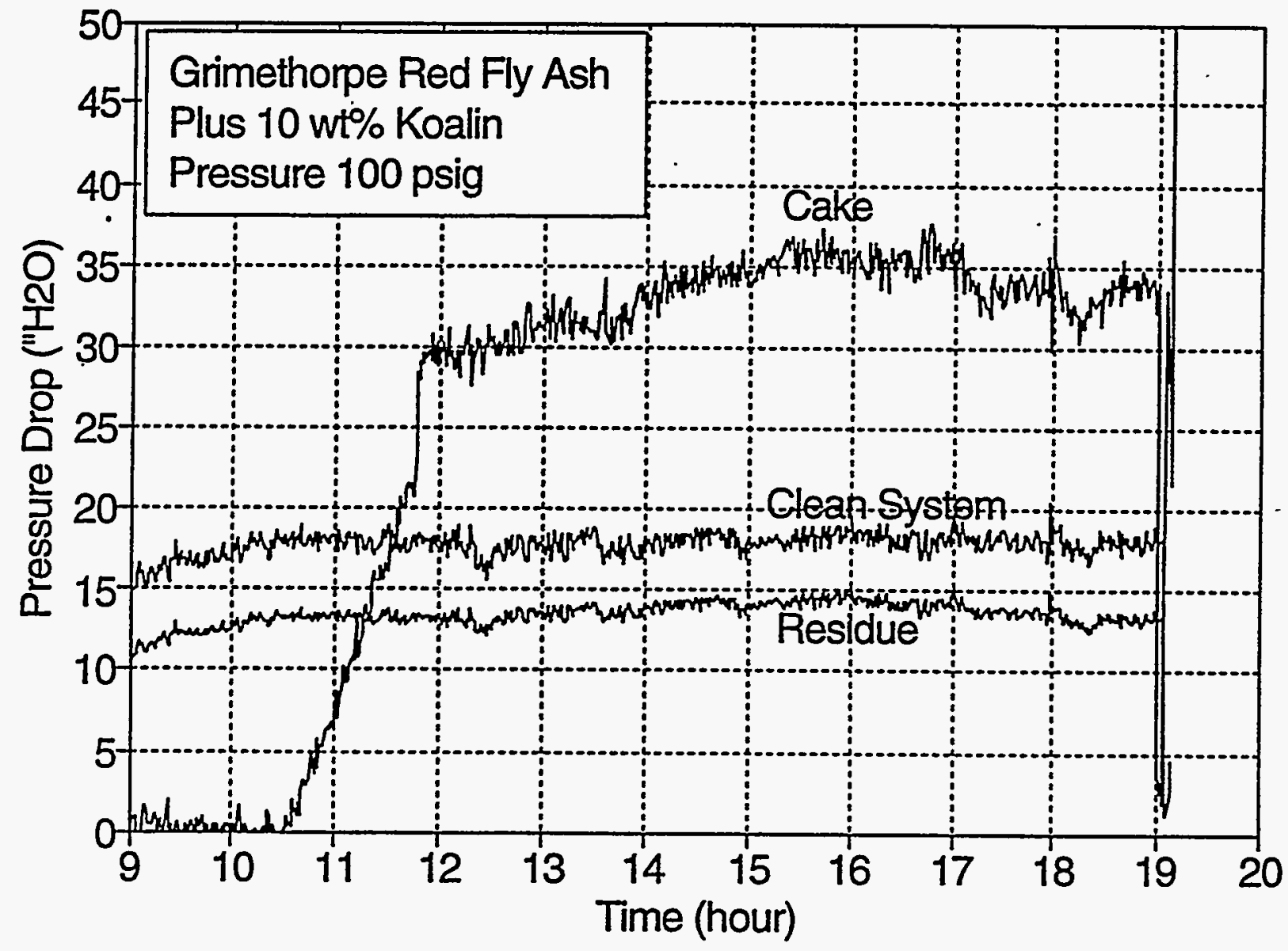


Test 3.05 - 2/16/94

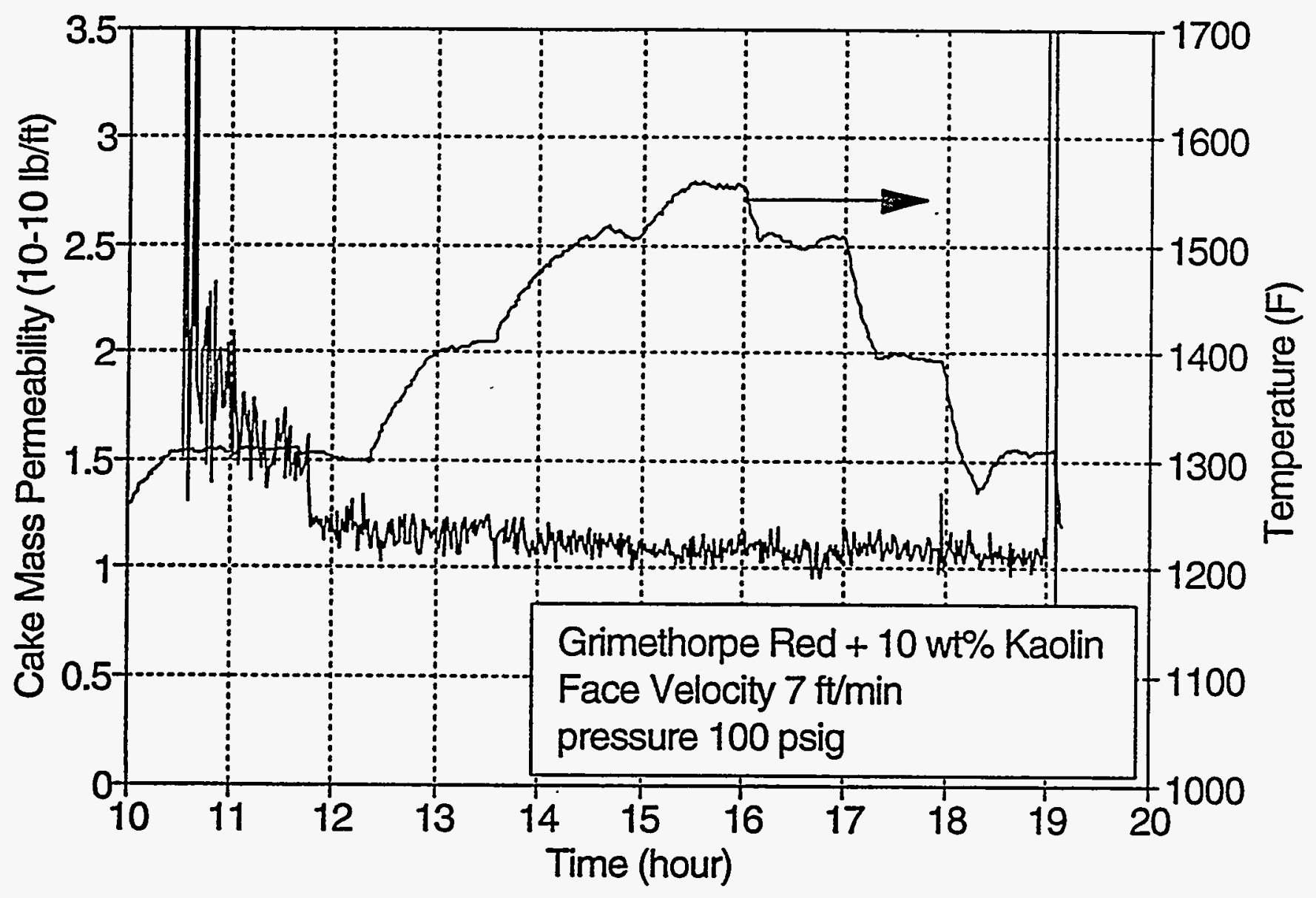




\section{Test $2.01-5 / 23 / 94$}

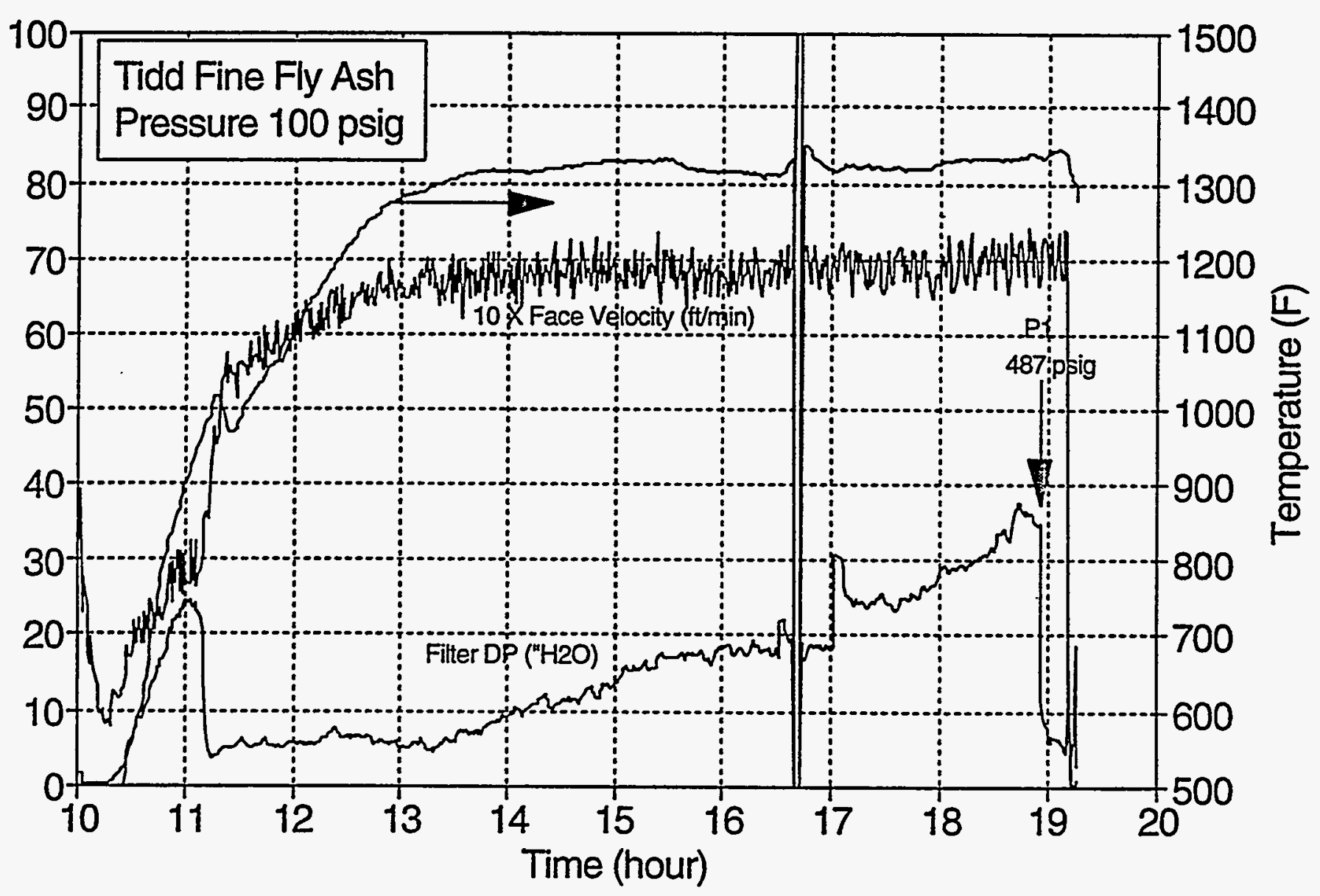




\section{Test 2.01 - 5/24/94}

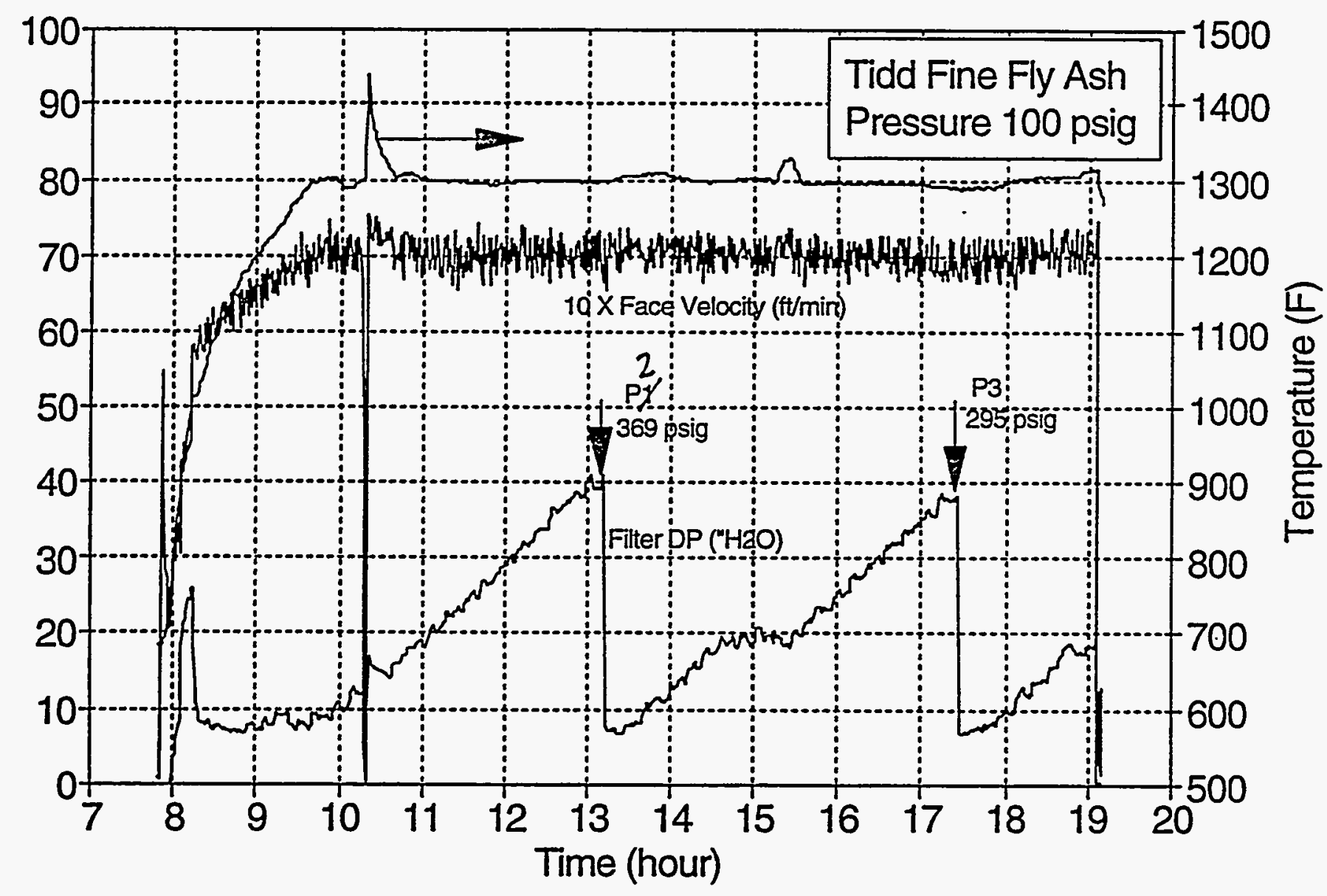




\section{Test $2.01-5 / 25 / 94$}

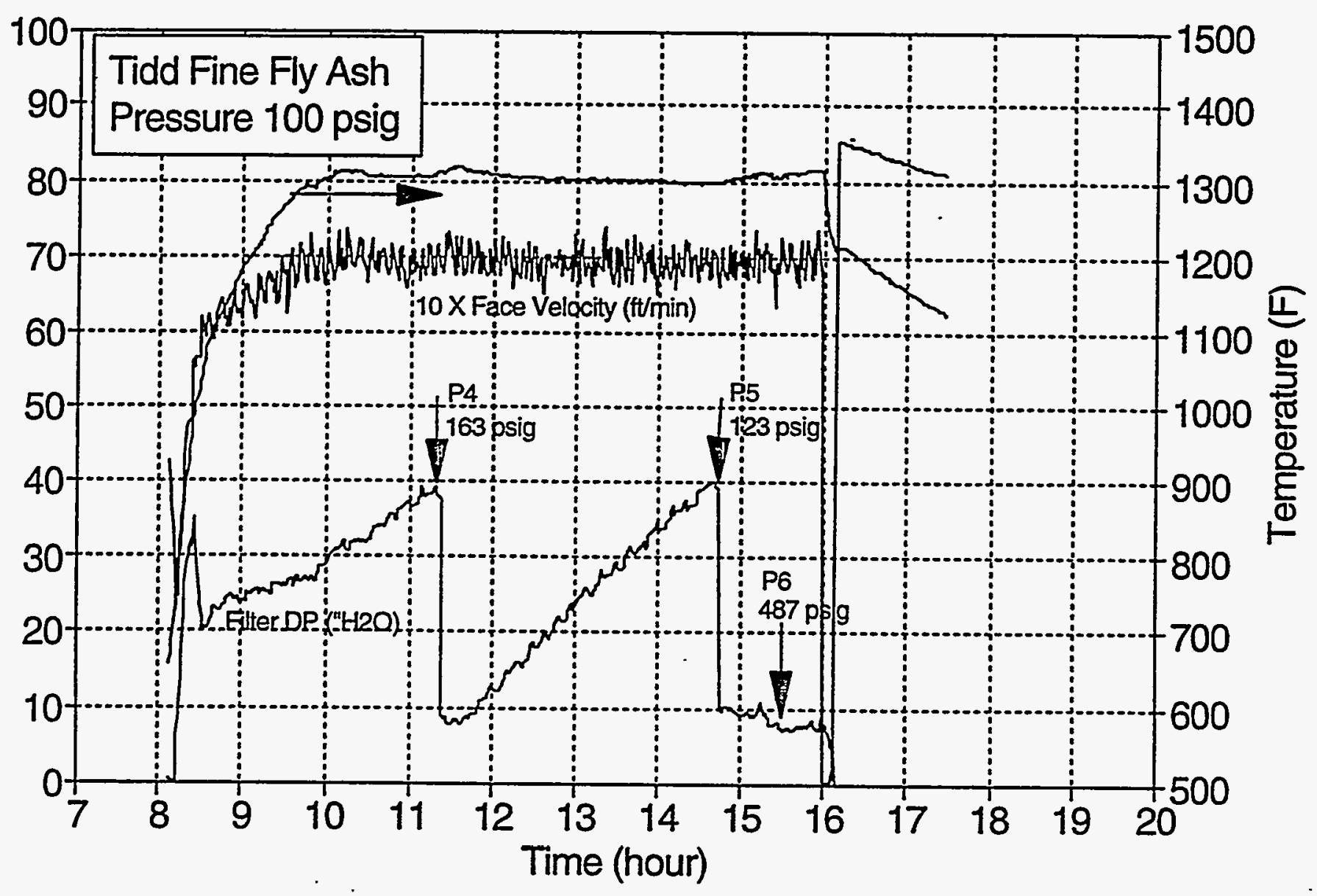




\section{$6 k$ \\ Test 2.02 - 5/27/94}

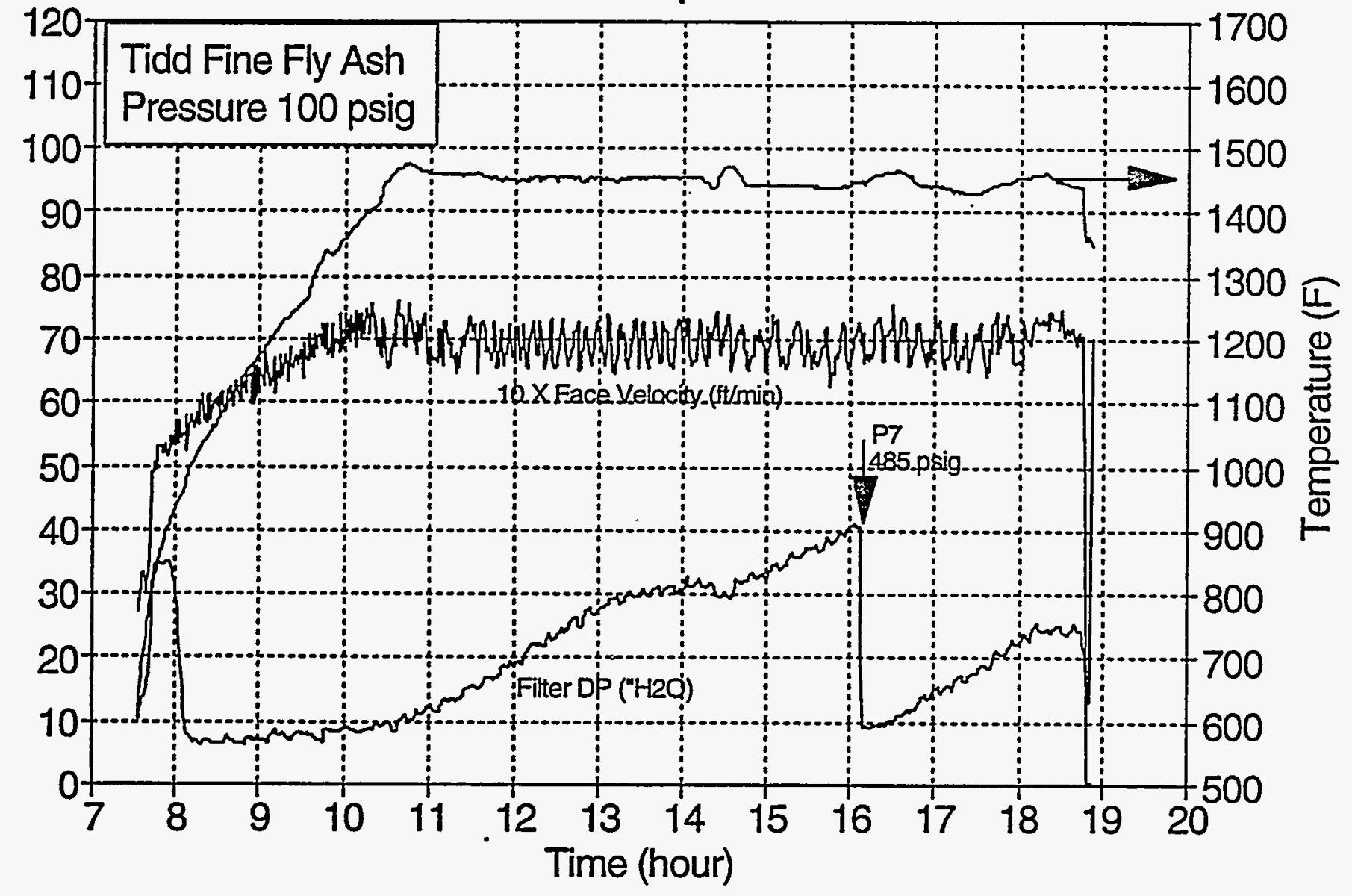


Test 2.02 - 5/31/94

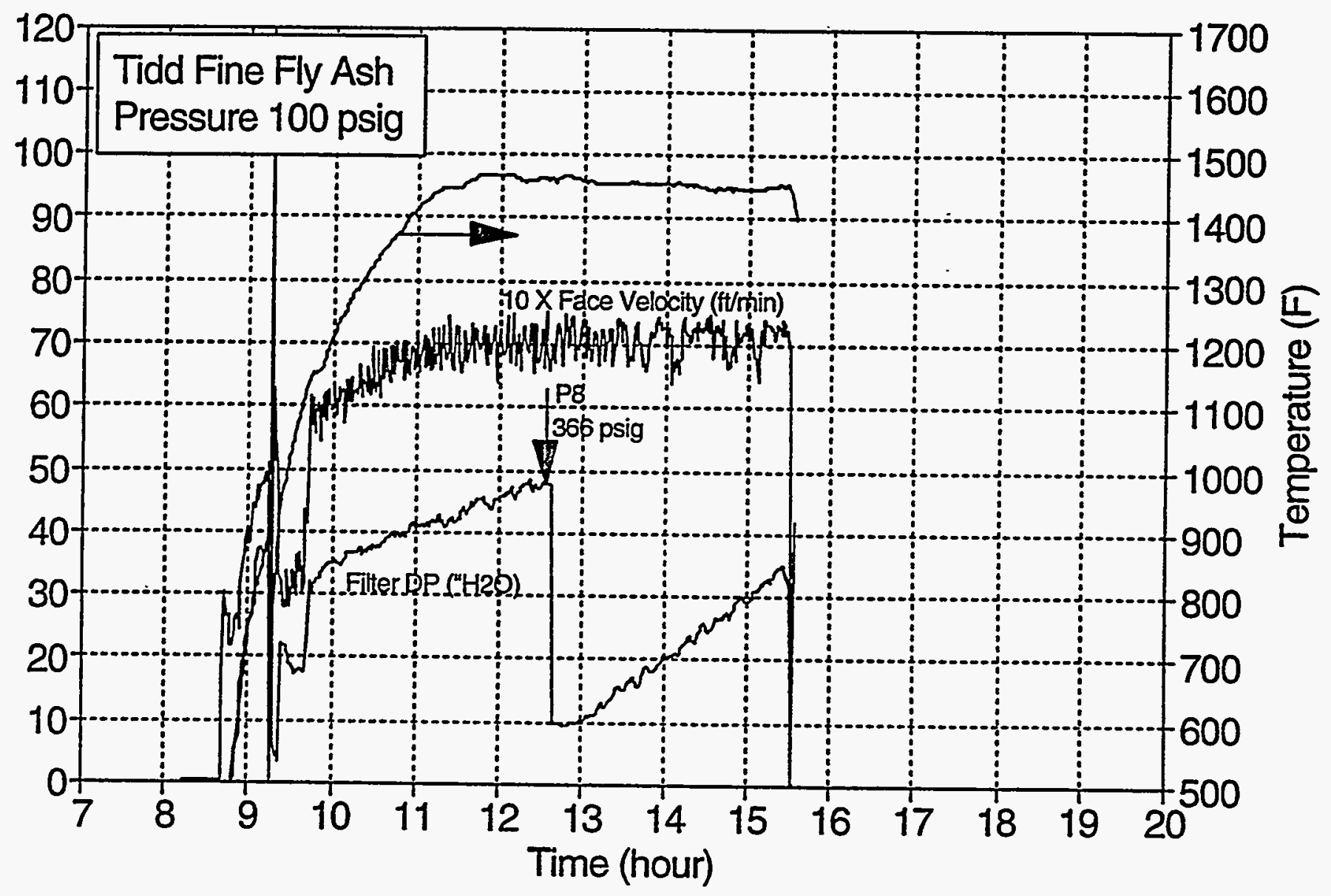




\section{Test 2.02 - 6/01/94}

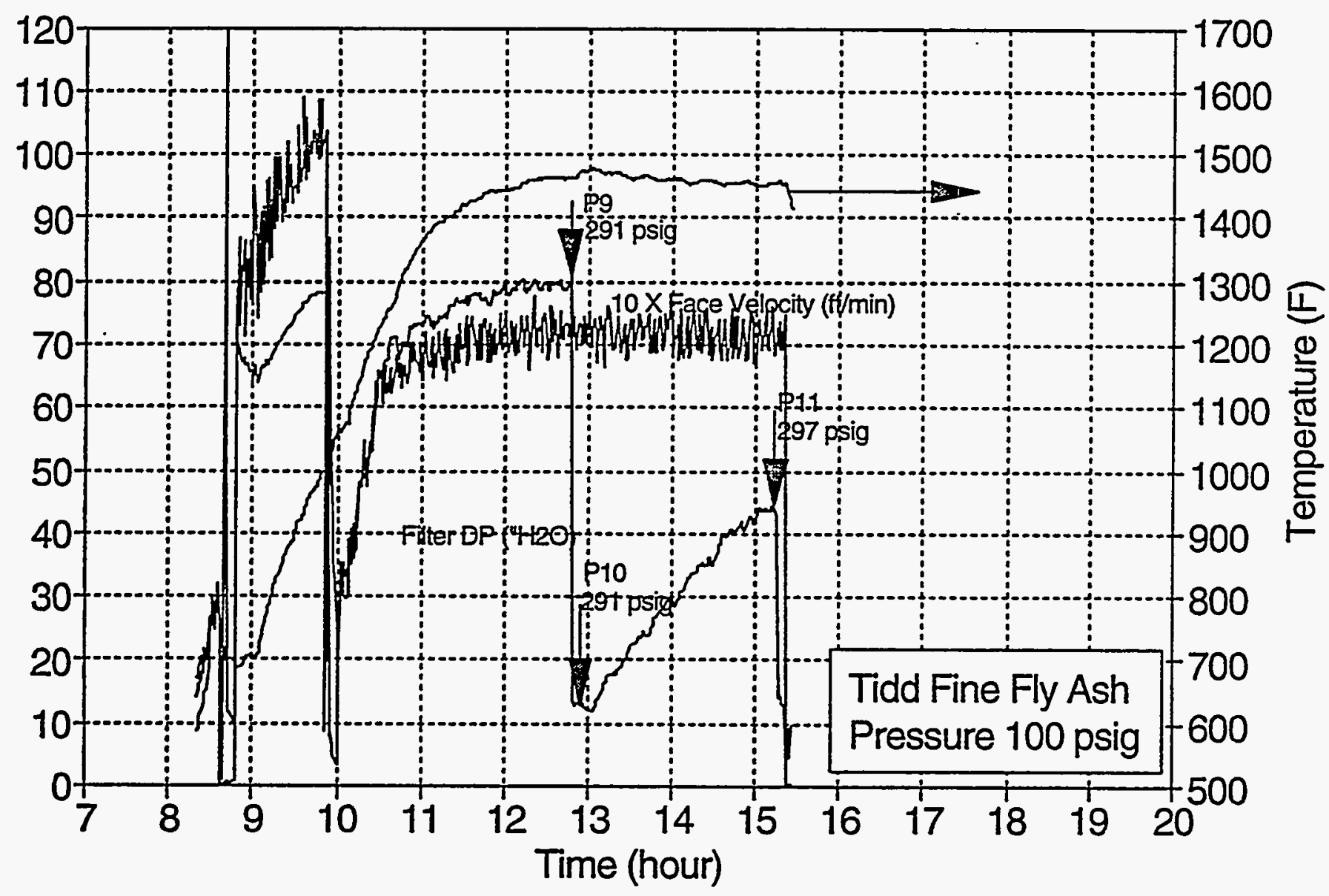




\section{2 \\ Test 2.0 X - 6/02/94}

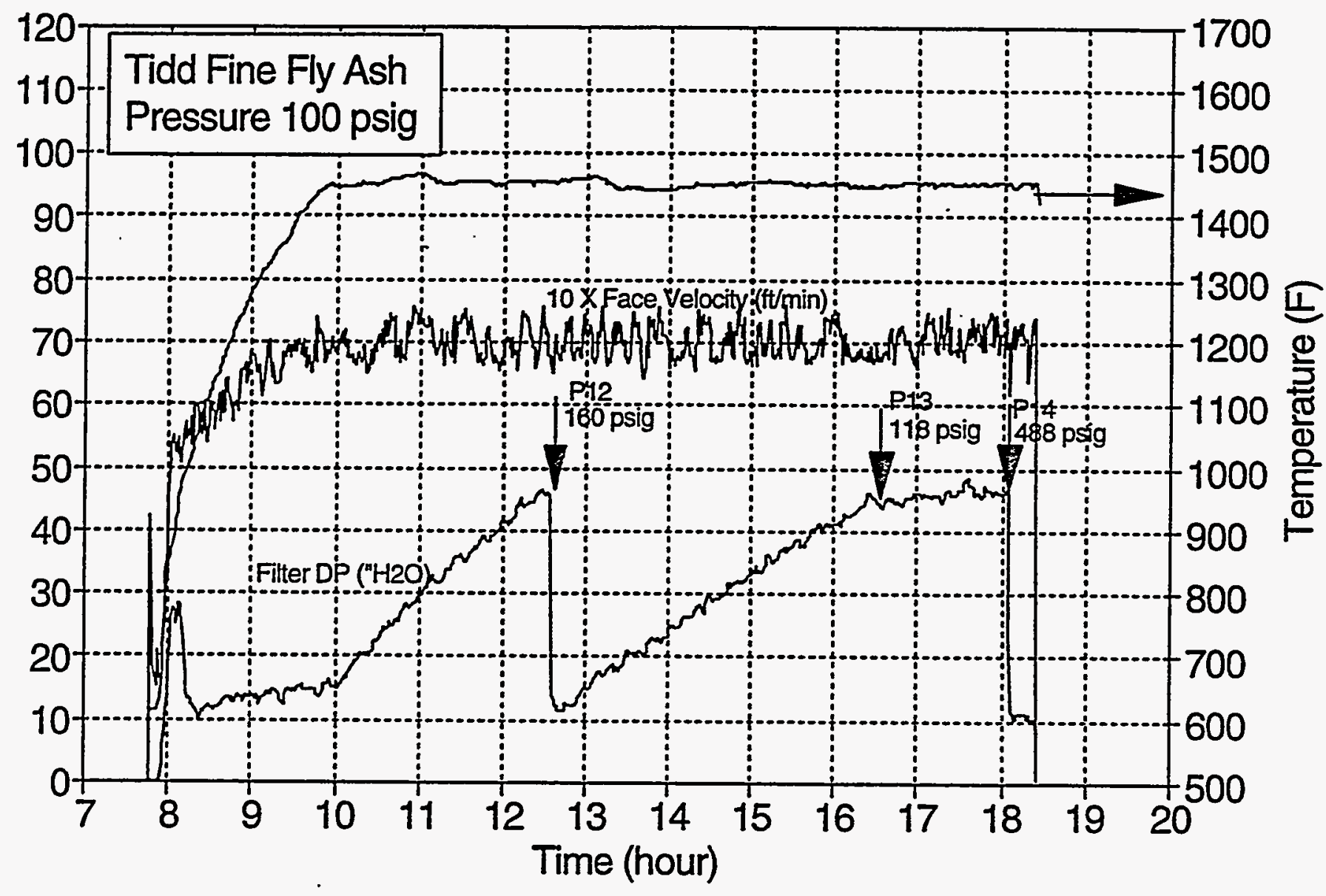




\section{Test 2.03 - 6/08/94}

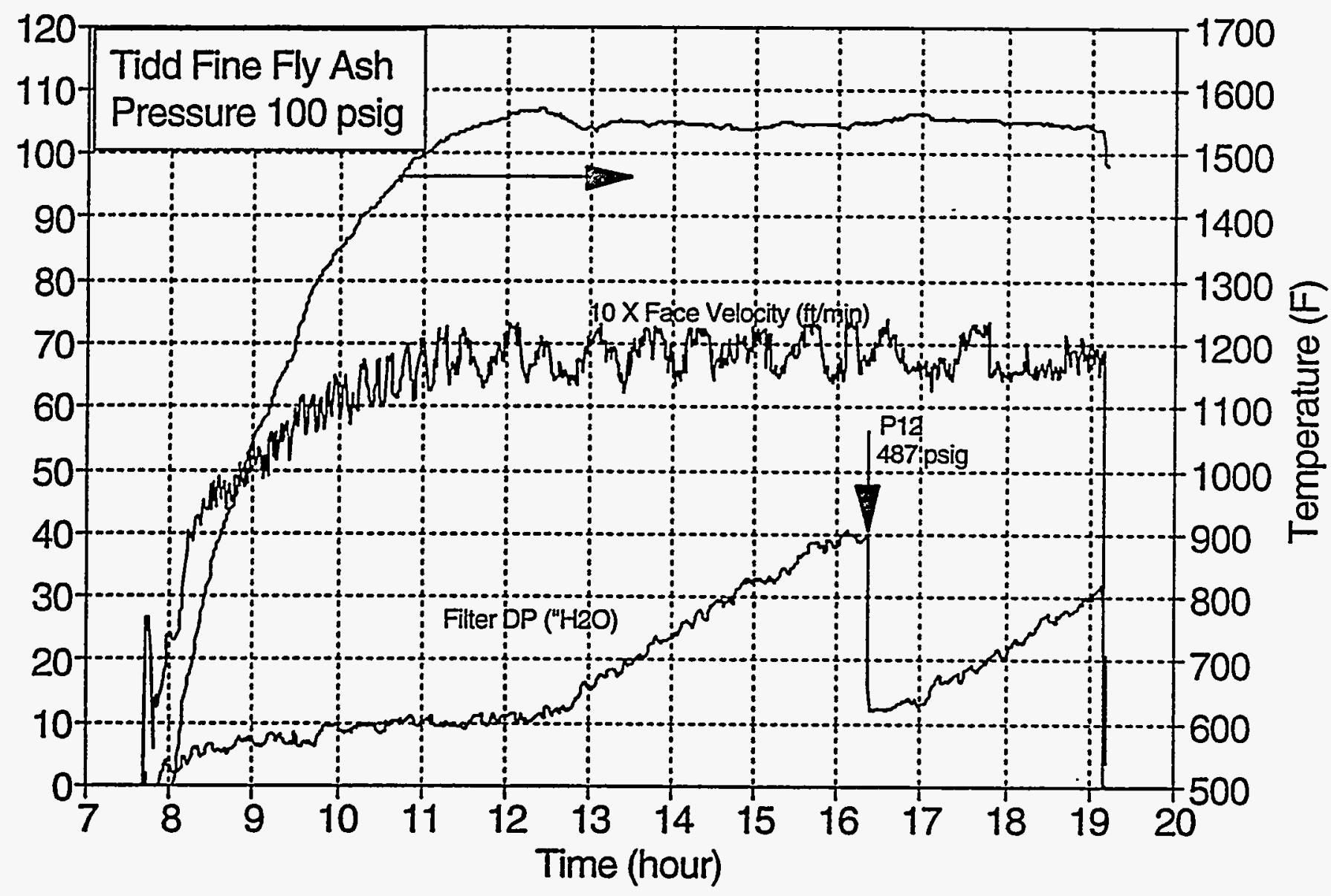




\section{Test 2.03 - 6/09/94}

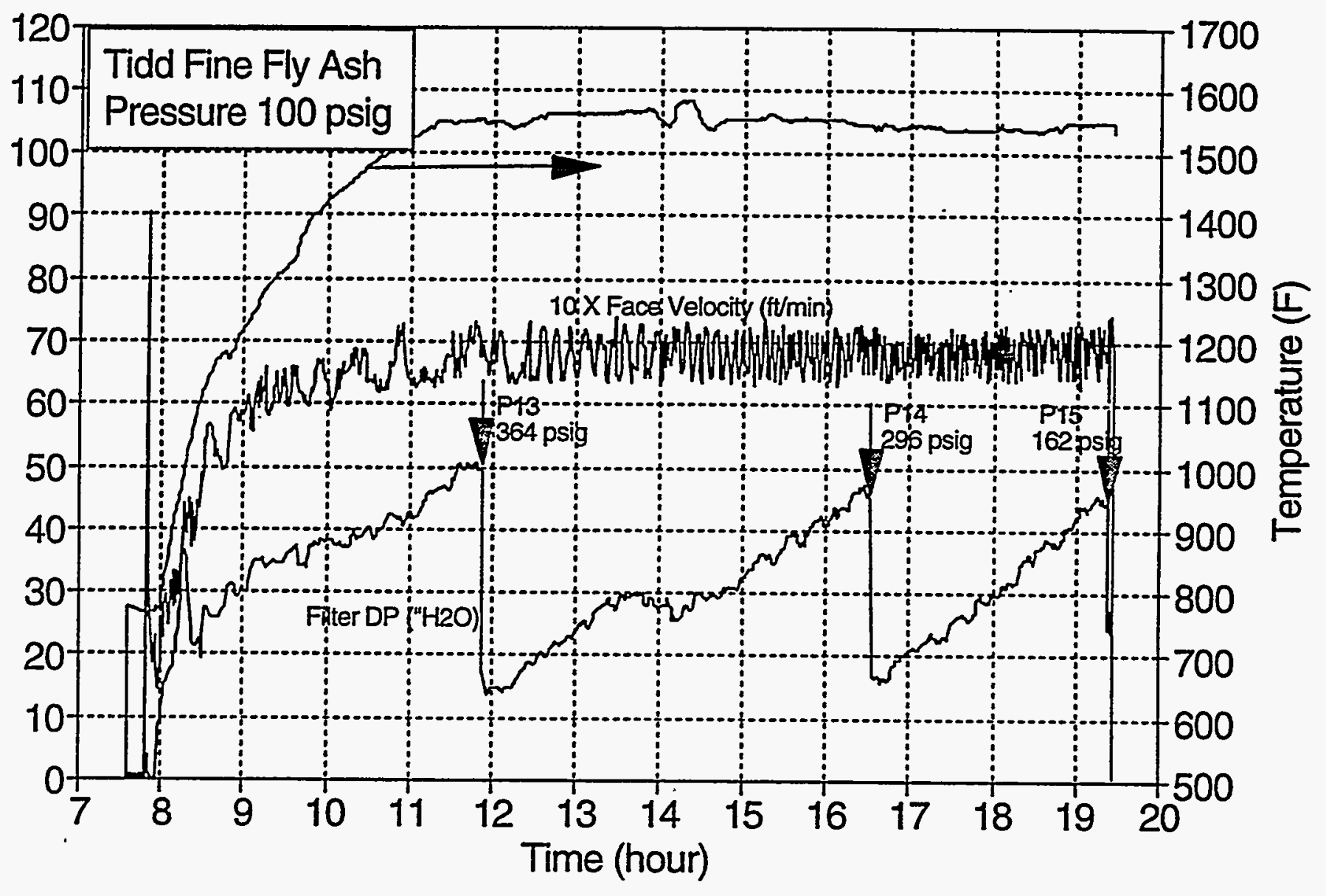




\section{Test 2.03 - 6/10/94}

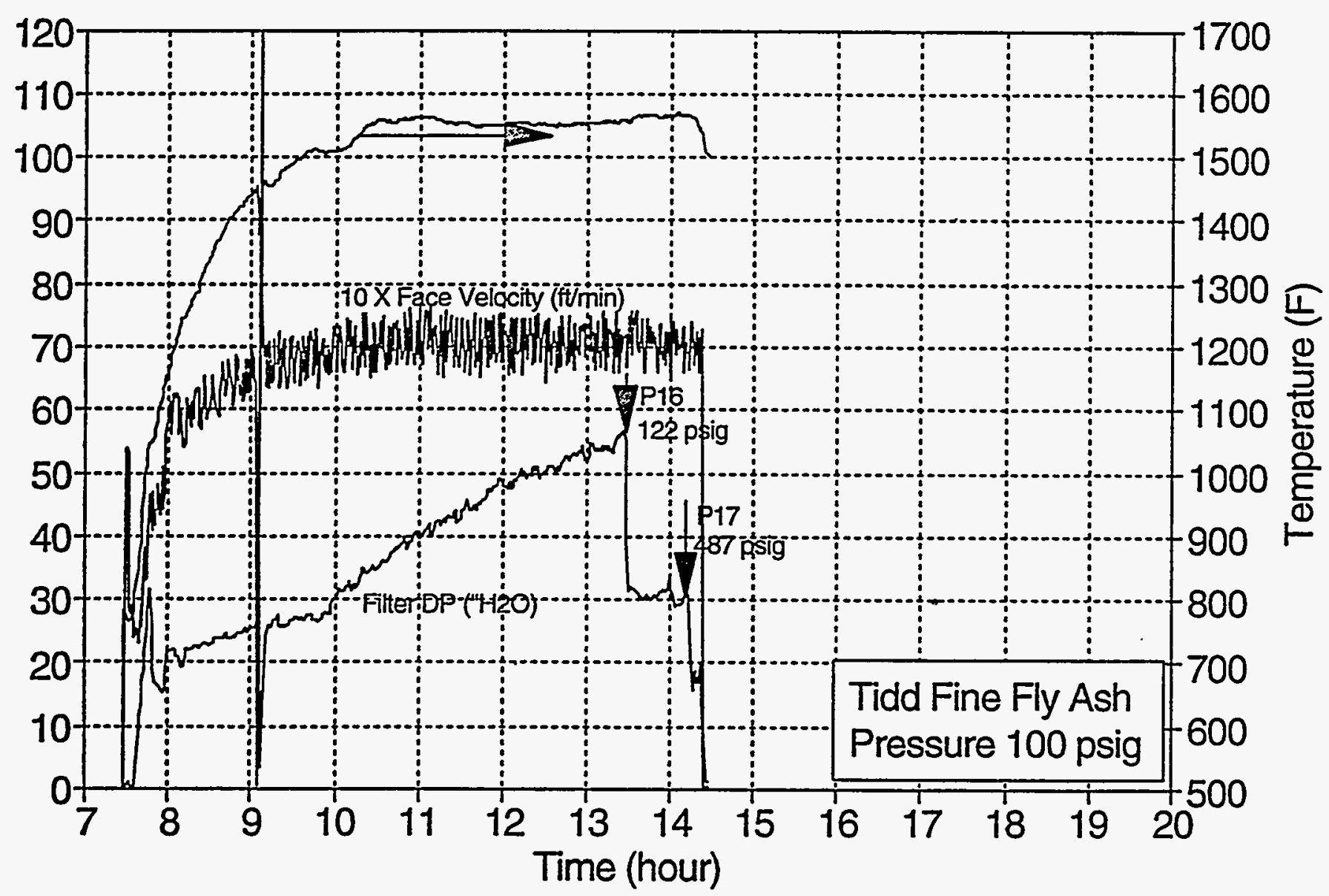

